RUI MACHADO

A REMOÇÃO DO FOLÍCULO DOMINANTE COMO ESTRATÉGIA ANTI-LUTEOLÍTICA EM BOVINOS 
RUI MACHADO

\section{A REMOÇÃO DO FOLÍCULO DOMINANTE COMO ESTRATÉGIA ANTI-LUTEOLÍTICA EM BOVINOS}

Tese apresentada ao Programa de Pós-graduação em Reprodução Animal da Faculdade de Medicina Veterinária e Zootecnia da Universidade de São Paulo para obtenção do Título de Doutor em Medicina Veterinária

\section{Departamento:}

Reprodução Animal

Área de concentração:

Reprodução Animal

Orientador:

Prof. Dr. Mario Binelli 
Autorizo a reprodução parcial ou total desta obra, para fins acadêmicos, desde que citada a fontı

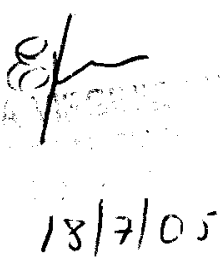

DADOS INTERNACIONAIS DE CATALOGAÇÃO-NA-PUBLICAÇÃO

(Biblioteca da Faculdade de Medicina Veterinária e Zootecnia da Universidade de São Paulo)

T.1551 Machado, Rui

FMVZ A remoção do foliculo dominante como estratégia antiluteolítica em bovinos / Rui Machado. - São Paulo : R. Machado, 2005.

$198 \mathrm{f.}$ : il.

Tese (doutorado) - Universidade de São Paulo. Faculdade de Medicina Veterinária e Zootecnia. Departamento de Reprodução Animal, 2005.

Programa de Pós-graduação: Reprodução Animal.

Área de concentração: Reprodução Animal.

Orientador: Prof. Dr. Mario Binelli.

1. Bovinos. 2. Estro animal. 3. Mortalidade embrionária animal. 4. Estrógenos. 5. Gonadotropinas. 1. Titulo. 


\section{ERRATA}

\section{Folha Linha Onde se lê}

\section{Leia-se}

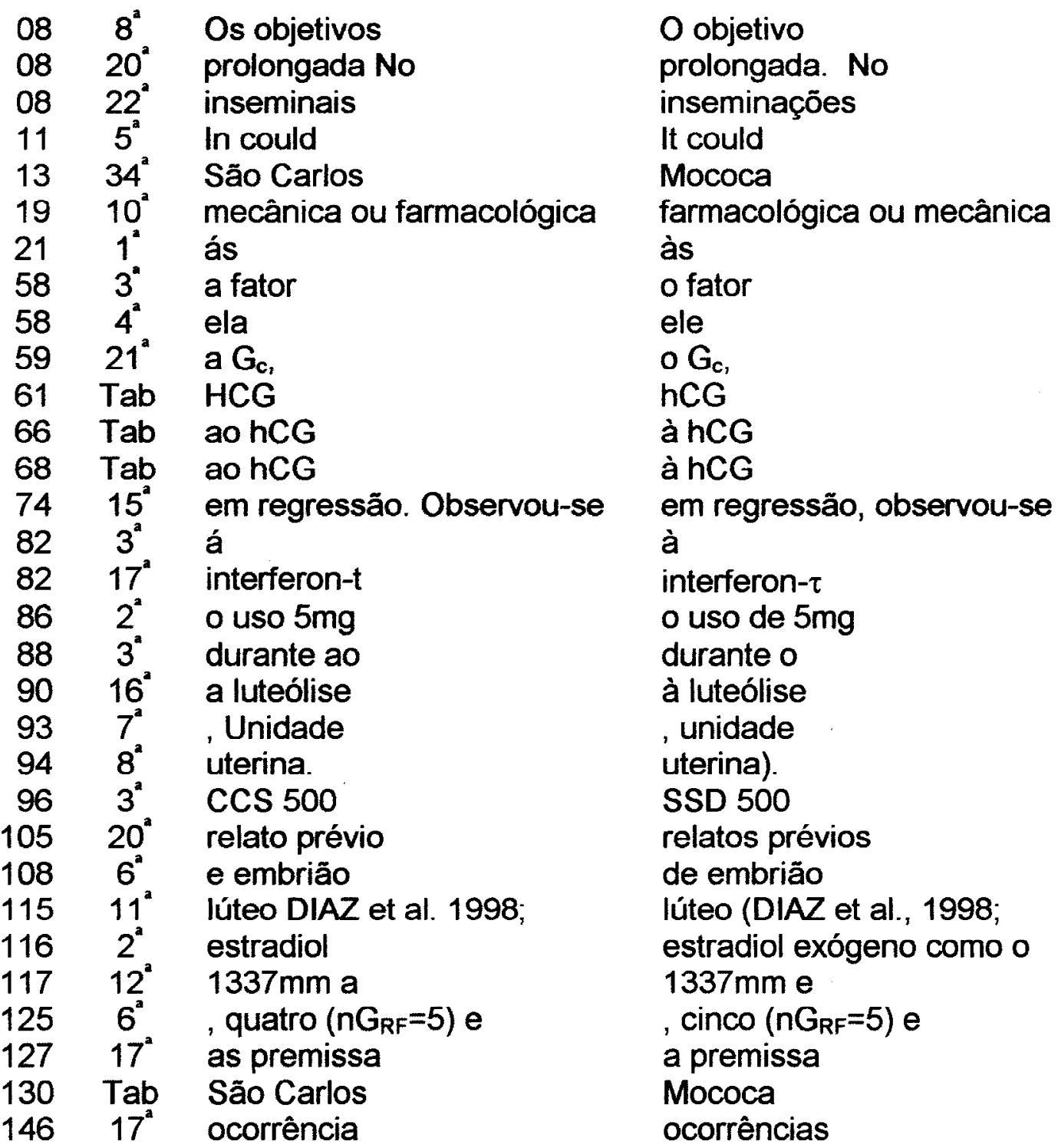




\section{UNIVERSIDADE DE SÃO PAULO \\ Faculdade de Medicina Veterinária e Zootecnia \\ Cidade Universitária "Armando de Salles Oliveira" \\ Comissão Bioética \\ CERTIFICADO}

Certificamos que o Projeto intitulado "Estratégias hormonais para reduzir a mortalidade embrionária em vacas nelore após a inseminação artificial em tempo fixo", protocolo $\mathrm{n}^{\circ} 410 / 2004$, utilizando 200 bovinos, sob a responsabilidade do Prof. Dr: Mario Binelli, está de acordo com os princípios éticos de experimentação animal da Comissão de Bioética da Faculdade de Medicina Veterinária e Zootecnia da Universidade de São Paulo e foi aprovado pela referida Comissão, em sessão de 10 de março de 2004.

(We certify that the Research "Hormonal strategies to reduce embryonic losses in nelore cows after timed artificial insemination" protocol number 410/2004, utilizing 03 bovines, under the responsibility of Prof. Dr. Mario Binelli, agree with Ethical Principles in Animal Research adopted by Bioethic Commission of the Faculty of Veterinary Medicine and Zootechny of University of São Paulo and was approved in 03/10/2004 meeting.

São Paulo, 10 de março de 2004

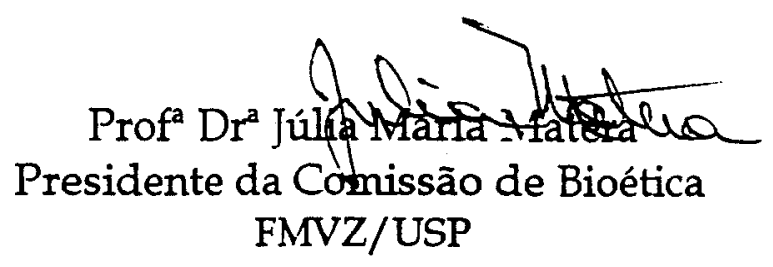

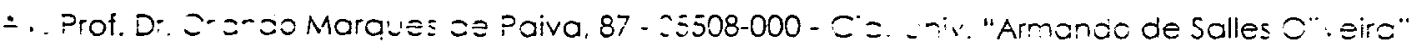

Fones: $: \cdots 3091-7671,3991-7676$ Fax: $\because 3032-2224$ 


\section{FOLHA DE AVALIAÇÃO}

Nome: MACHADO, Rui

Título: A remoção do folículo dominante como estratégia anti-luteolítica em bovinos

Tese apresentada ao Programa de Pós-graduação em Reprodução Animal da Faculdade de Medicina Veterinária e Zootecnia da Universidade de São Paulo para obtenção do Título de Doutor em Medicina Veterinária

Data:

\section{Banca Examinadora}

Prof.Dr. Instituição:

Assinatura: Julgamento:

Prof.Dr. Instituição:

Assinatura: Julgamento:

Prof.Dr. Instituição:

Assinatura: Julgamento:

Prof.Dr. Instituição:

Assinatura: Julgamento:

Prof.Dr. Instituição:

Assinatura: Julgamento: 
À memória dos meus pais Sylvio e Flora, modelos de dedicação, luta, honradez e bravura ao longo de suas vidas e exemplos ímpares de extrema coragem ao lutarem uma batalha desigual contra a doença que os levou. 


\section{AGRADECIMENTOS}

Ao professor Dr. MÁRIO BINELLI, pelo apoio e entusiasmo irrestritos em nos orientar, e pelos seus valiosos ensinamentos e profunda amizade demonstrados ao longo desta jornada.

Ao Prof. Dr. RENATO CAMPANARUT BARNABE, ex-Coordenador do Curso de Pós-Graduação em Reprodução Animal e meu orientador nos primeiros semestres do meu treinamento, pela confiança depositada e pelo apoio e dedicação prestados para o cumprimento de nossa missão como acadêmico da FMVZ da USP. Sua amizade, carinho e compreensão jamais serão esquecidos.

'A EMBRAPA pela oportunidade de treinamento e à EMBRAPA PECUÁRIA SUDESTE pelo apoio técnico, logístico e financeiro ao projeto experimental. Menção especial merecem os senhores chefes: Drs. AIRTON E NÉLSON pelo apoio, compreensão e apreço demonstrados ao longo de nosso treinamento.

À FAZENDA CARDINAL do grupo VPJ e em especial ao seu proprietário, Sr. Valdomiro Polillesi Júnior, ao Médico-Veterinário Dr. Júlio Barbosa, bem como ao Dr. Guga, Sr, Cláudio, Sr. Mineiro, Sr. Ribamar e Bruno que tornaram possível realizar o experimento3.

À INTERVET e ao CENTRO PAULISTA DE DESENVOLVIMENTO FARMACOTÉCNICO pela doação de hormônios, necessários para a consecução dos experimentos.

Aos colegas Dr. MARCO AURÉLIO BERGAMASCHI e Dra. CLÁUDIA BERTAN pelo irrestrito apoio na execução dos trabalhos experimentais.

Aos meus colegas de EMBRAPA, Dr. ROGÉRIO TAVEIRA BARBOSA pelas sugestões ao projeto e pelo ilimitado apoio e ativo empenho para implantação dos experimentos, Dr. MAURícIO MELLO DE ALENCAR pelo inestimável apoio na seleção dos animais, bem como pela viabilização de recursos técnicos, financeiros e logísticos para a execução dos experimentos 1 e 2, Drs. EDISON B. POTT e PEDRO F. BARBOSA pelo apoio na execução dos experimentos, aos Técnicos Sr. NACIR EDSON PARANHOS e Sr. RAFAEL ROZENDO, pelo apoio e pela dedicação e competência e principalmente aos "cow-boys" inseminadores: Srs. ADÃO, ZÉZÃO, CELSO, TIAGO, TADEU, AVARÉ, pela dedicação, competência, carinho e amizade demonstrados, à Srta. VERA pela dedicação, competência emprestados.

Ao Prof. Dr. ED HOFFMANN MADUREIRA pelos ensinamentos, pela inestimável colaboração e pronto apoio ao nosso projeto de pesquisa e principalmente pela amizade, amparo e carinho dedicados à nossa pessoa ao longo das alegrias que o curso me propiciou e infortúnios que a vida me trouxe nesse mesmo período.

Ao Prof. Dr. RUBENS PAES DE ARRUDA pelos ensinamentos, pela inestimável colaboração e apoio ao nosso projeto, e principalmente pela amizade e incentivo. 
Aos professores Dr. PIETRO SAMPAIO BARUSELLI pelas sugestões, conselhos e correções apresentadas na lida dos dados sobre dinâmica folicular e Dr. CLÁUDIO ALVARENGA DE OLIVEIRA pela competência ao conduzir a Coordenação do Curso de Pós-Graduação em Reprodução Animal e pelo auxílio nas dosagens hormonais.

Aos colegas de Pirassununga pela amizade irrestrita e apoios prestados quando necessário. Menção especial merecem Marcelo, Rafael e Zé Rodrigo.

A todos os professores, colegas pós-graduandos e funcionários do Departamento de Reprodução Animal da Faculdade de Medicina Veterinária e Zootecnia da Universidade de São Paulo, pelos ensinamentos, pelo auxílio permanente e pela gentileza e eficiência sempre demonstrados. Menção especial merecem Harumi, Thais, Cláudia, Dayse, Elza (biblioteca) e Profa. Dra."Kiki" e Izabel (Pirassununga).

Ao Prof. Dr. ALÍCIO MARTINS da UNESP de Araçatuba pela pronta colaboração ao início do meu treinamento, sem a qual não se concretizaria este empreendimento.

Àquelas pessoas que deram seu carinho, sua atenção ou sua amizade e que em algum momento de suas vidas proveram apoio aos meus ideais, colaborando assim para o meu treinamento. Especial menção vai para ADÉLIA, ADRIANA, ADRIANA BARBOSA, AMYLCAR, ARIEL, ARCHIMEDES, AURINO, BEATRIZ, BENITO, BERNARDO, BÊ, BRUNELLA, BRUNO GRASSO, BRUNO, CARMEN, CIDA, CRIS, CRISTINA, DADÁIA, DANDA, DERMEVAL, DIÔNES, DORA, GAETANO, EDUARDO, ELISAMA, EUGÊNIO FERRI, "Família" ARAÚJO, "Família" RIBEIRO, "Família" ZANCHIN, HYMERSON, IVANA, JEFFERSON, LETO, LU, LÚCIA, MAIRA, MAUDE, MARELI, MARLI, MARINALVA, MARTA MARIA, MATEUS, NATHALIE, PAINO, PH, RASSINI, REGIANE, RAQUEL, RAQUEL FROSSARD, RITA, SHEIGO, SIBELE, SUZANA, SONINHA, SONISE, SUELI, SUELY GRASSO, TETÊ, "Tio" CÂMARA, "Tia" ÉTNA, "TITICO" VALÉRIA, VALÉRIA ALARCON, VILMINHA, VIVIANE, VITOR, ZÉ ROBERTO, ZILDA, TÂNIA, WILSON.

À inanimada porém fiel e confiável Saveiro.

Aos contribuintes brasileiros que indiretamente proveram fundos para a realização deste empreendimento. 


\section{RESUMO}

MACHADO, R. A remoção do folículo dominante como estratégia anti-luteolítica em bovinos. [The removal of the dominant follicle as antiluteolytic strategy in cattle.] São Paulo, 2005. 198f. Tese (Doutorado em Medicina Veterinária) - Faculdade de Medicina Veterinária e Zootecnia, Universidade de São Paulo, São Paulo, 2005.

O estradiol secretado pelo folículo dominante (DOM) desempenha importante papel na luteólise da vaca. Em adição, o reconhecimento materno da prenhez (MRP) requer um ambiente uterino otimizado, o qual por sua vez depende da função luteínica e de adequadas concentrações de progesterona circulante. Os objetivos do presente estudo foi testar diferentes estratégias para otimizar a função luteínica e prevenir a influência de um DOM durante o período crítico (CP) para o MRP (de $D_{13}$ a $D_{20}$ após 0 estro o estro). Diferentes abordagens foram testadas. No exp.1, 23 vacas Nelore foram tratadas com o protocolo ovsynch para induzir um cio sincronizado $\left(D_{0}\right)$. As vacas receberam: $G_{c}(n=7)$ - nada mais; $T_{h C G}(n=5)-3000 \mathrm{IU}$ de hCG no $D_{5} ; T_{E 2}(n=6)$ - 5 mg de $17 \beta$-estradiol $\left(E_{2}\right)$ no $D_{12} ; T_{h C G / E 2}(n=5)-h C G / D_{5}+$ $E_{2} / D_{12}$. Ultra-sonografias e dosagens de progesterona plasmática durante o ciclo estral permitiram determinar que $\circ \mathrm{E}_{2}$ reprogramou o ciclo ovariano ao prevenir a presença $(P<0,05)$ de um DOM durante quase todo CP $\left(0,6 \pm 0,7\right.$ dias entre $D_{15}$ e $D_{20}$ ), porém o $E_{2}$ induziu a luteólise. As vacas que receberam a $h C G$ desenvolveram corpo lúteo acessório e tiveram $\left[P_{4}\right]$ mais alta até o $D_{13}(P<0,05)$. Portanto, a fase luteínica não foi prolongada No exp.2, os mesmos tratamentos foram impostos a 220 vacas Nelore (55 por grupo) após uma inseminação artificial em tempo fixo (TAI). As taxas de prenhez (PR) à TAl ou às inseminais de repasse durante uma estação com 64 dias de duração foram diminuídas $(P<0,05)$ quando o $E_{2}$ foi usado e a hCG não foi capaz de aumentar aquelas PR. No exp.3, vacas Red Angus no pós-parto 
tiveram seu estro sincronizado $\left(D_{0}\right)$ e receberam: nada mais $\left(G_{C T}, n=5\right)$ ou $200 \mu \mathrm{g}$ de gonadorrelina no $D_{5}$ mais 3000 IU hCG no $D_{13} \quad\left(G_{R F}, n=5\right)$; ou ablação de todos folículos $\geq 7 m m$ através de aspiração folicular em $D_{14}, D_{17}$ e $D_{20}\left(G_{R M}, n=5\right)$. $G_{R F}$ teve luteólise retardada $\left(18,2 \pm 1,0^{\mathrm{b}}\right.$ dias, $23,6 \pm 1,0^{\mathrm{a}}$ dias e $18,7 \pm 1,2^{\mathrm{b}}$ dias para $\mathrm{G}_{\mathrm{CT}}$, $\mathrm{G}_{\mathrm{RF}} \mathrm{e}$ $G_{R M}$, respectivamente) e maior $\left[\mathrm{P}_{4}\right]$ que os outros grupos. Folículos maiores que $7 \mathrm{~mm}$ foram observados quando das aspirações. Foi possível concluir que: a) $E_{2}$ permitiu consistentemente reprogramar o desenvolvimento folicular, porém causou luteólise e o seu uso trouxe efeitos negativos sobre as PR; b) a hCG melhorou a função luteínica mas não aumentou as PR; c) a ablação dos folículos $\geq 7 \mathrm{~mm}$ não preveniu a presença do DOM no $\mathrm{CP}$ para o $\mathrm{MRP}$ e d) a associação $\mathrm{GnRH} / \mathrm{hCG}$ otimizou a função luteínica, retardou a luteólise e prolongou a fase luteínica de modo que todo o CP esteve sob influência da progesterona.

Palavras-chave: Bovinos. Estro animal. Mortalidade embrionária animal. Estrógenos. Gonadotropinas. 


\begin{abstract}
MACHADO, R. The removal of the dominant follicle as antiluteolytic strategy in cattle. [A remoção do folículo dominante como estratégia anti-luteolítica em bovinos.] São Paulo, 2005. 198f. Tese (Doutorado em Medicina Veterinária) Faculdade de Medicina Veterinária e Zootecnia, Universidade de São Paulo, São Paulo, 2005.
\end{abstract}

Estradiol secreted from the dominant follicle (DOM) plays a key role in triggering luteolysis in the cow. In addition, maternal recognition of pregnancy (MRP) requires an optimum uterine environment, which directly depends on luteal function and adequate levels of circulating progesterone. The aim of this study was to test different strategies to optimize luteal function and prevent the influence of a DOM throughout the critical period (CP) for MRP (from $D_{13}$ to $D_{20}$ after estrus). Different approaches were tested. In exp.1, 23 Nelore cows were treated with the ovsync protocol to induce a synchronized estrus $\left(D_{0}\right)$. Cows received: $G_{c}(n=7)$ - nothing else; $T_{\text {hcG }}$ $(n=5)-3000$ IU of hCG five days $\left(D_{5}\right)$ after estrus; $T_{E 2}(n=6)-5 m g$ of $17 \beta$-estradiol $\left(E_{2}\right)$ on $D_{12} ; T_{h C G / E 2}(n=5)-h C G / D_{5}+E_{2} / D_{12}$. Ultrasound evaluation and plasmatic progesterone concentration $\left(\left[\mathrm{P}_{4}\right]\right)$ throughout estrous cycle allowed to conclude: $\mathrm{E}_{2}$ reprogrammed ovarian cycle by preventing the presence $(\mathrm{P}<.05)$ of a DOM during almost all CP (0.6 .7 days within the $D_{15}$ to $D_{20}$ interval) but induced luteolysis; cows receiving hCG developed accessory corpus luteum and had higher $\left[P_{4}\right]$ up to $D_{13}$ $(\mathrm{P}<.05)$. Therefore, luteolysis was not delayed and luteal phase was not prolonged. In exp.2, same treatments were imposed to 220 Nelore cows (55 per group) after a timed artificial insemination (TAI). Pregnancy rates (PR) at TAI or at Als thereafter over a 64-day period were reduced $(P<0.05)$ by using $E_{2}$ and $h C G$ was not capable to improve those PR. In exp.3, postpartum Red Angus cows were estrus synchronized $\left(D_{0}\right)$ and received: nothing else $\left(G_{C T}, n=5\right)$ or $200 \mu \mathrm{g}$ of gonadorrelin on 
$D_{5}$ plus $3000 \mathrm{IU} h C G$ on $D_{13}\left(G_{R F}, n=5\right)$; or ablation of all follicles $\geq 7 \mathrm{~mm}$ through follicular aspiration on $D_{14}, D_{17}$ and $D_{20} \quad\left(G_{R M}, n=5\right)$. $G_{R F}$ had delayed luteolysis $\left(18.2 \pm 1.0^{\mathrm{b}}\right.$ days, $23.6 \pm 1.0^{\mathrm{a}}$ days, $18.7 \pm 1.2^{\mathrm{b}}$ days for $\mathrm{G}_{\mathrm{CT}}, \mathrm{G}_{\mathrm{RF}}, \mathrm{G}_{\mathrm{RM}}$, respectively) and higher $\left[\mathrm{P}_{4}\right]$ than other groups. Follicles larger than $7 \mathrm{~mm}$ were observed in all occasions of aspiration. In could be concluded that: a) $E_{2}$ allowed to consistently reschedule follicular development but caused luteolysis and its use was detrimental to PR; b) hCG improved luteal function but did not increase PR; c) ablation of $7 \mathrm{~mm}$ follicles did not prevent a DOM throughout $\mathrm{CP}$ for MRP and d) $\mathrm{GnRH} / \mathrm{hCG}$ association optimized luteal function, delayed luteolysis and prolonged luteal phase in such a way that all CP was under progesterone influence.

Key words: Cattle. Animal estrus. Animal embryonic mortality. Estrogens. Gonadotropins. 


\section{LISTA DE FIGURAS}

Figura 1.1 - Protocolos de administração dos tratamentos no experimento 1, São Carlos, 2004

Figura 1.2 - Médias dos quadrados mínimos e erros-padrão da média para volume do corpo lúteo $\left(\mathrm{mm}^{3}\right)$ ao longo do ciclo estral para os diferentes grupos experimentais. São Carlos, 2004

Figura 1.3 - Médias dos quadrados mínimos e erros-padrão da média para concentração plasmática de progesterona $(\mathrm{ng} / \mathrm{mL})$ ao longo do ciclo estral para os grupos: sem hCG ("ovsynch") e com hCG ("ovsynch" + 3000 Ul de hCG no $D_{5}$ ) entre $D_{5}$ e $D_{12}$ e para todos grupos experimentais de $D_{13}$ até $D_{21}$.. São Carlos, 2004

Figura 2.1 - Protocolos de administração dos tratamentos no experimento 2, São Carlos, 2004

Figura 2.2 - Curvas de sobrevivência para as taxas de prenhez em função do dia da estação de reprodução. São Carlos, 2004

Figura 3.1 - Protocolos de administração dos tratamentos no experimento 3, Mococa, 2004

Figura 3.2 - Médias dos quadrados mínimos e erros-padrão da média para concentração plasmática de progesterona $(\mathrm{ng} / \mathrm{mL})$ ao final da fase luteínica do ciclo estral para os grupos: controle, remoção farmacológica e remoção mecânica. Mocóca, 2004

Figura 3.3 - Gráficos das vacas dos grupos controle, remoção farmacológica e remoção mecânica representando a concentração plasmática de progesterona em função do dia do ciclo estral. Mococa, 2004 


\section{LISTA DE TABELAS}

Tabela 1.1 - Médias dos quadrados mínimos ( \pm erros-padrão da média) e análise de variância de variáveis relacionadas ao crescimento folicular em resposta à hCG e ao $17_{\beta}$ estradiol. São Carlos, 2004.

Tabela 1.2 - Médias dos quadrados mínimos ( \pm erros-padrão da média) e análise de variância de variáveis relacionadas à dinâmica luteínica em resposta à hCG e ao $17_{\beta}$-estradiol. São Carlos, 2004

Tabela 1.3 - Médias dos quadrados mínimos ( \pm erros-padrão da média) e análise de variância de variáveis relacionadas à concentração plasmática da progesterona em resposta à hCG e ao $17_{\beta}$-estradiol. São Carlos, 2004

Tabela 1.4 - Médias dos quadrados mínimos e erros-padrão da média para os valores máximo, médio (entre $D_{5}$ e a luteólise) e acumulado (entre $D_{5}$ até a luteólise) da concentração de progesterona plasmática $\left(\left[\mathrm{P}_{4}\right]\right)$ considerando-se a administração da hCG. São Carlos, 2004

Tabela 1.5 - Médias dos quadrados mínimos ( \pm erros-padrão da média) e análise de variância de variáveis relacionadas ao estro e à luteólise em resposta à hCG e ao $17_{\beta}$-estradiol. São Carlos, 2004

Tabela 2.1 - Taxas de serviço, concepção e prenhez à inseminação artificial $(I A)$ em tempo fixo, à $1^{a}$ IA de repasse, à $2^{a}$ IA de repasse e taxas de prenhez acumuladas após a $1^{\mathrm{a}}$ IA de repasse e ao final da estação. São Carlos, 2004

Tabela 2.2 - Efeito dos fatores hCG e $E_{2}$ sobre a taxa de prenhez à inseminação artificial em tempo fixo e acumulada ao final da estação de reprodução. São Carlos, 2004

Tabela 3.1 - Níveis de probabilidade pelo teste exato de Fischer, para as comparações das taxas de manifestação do estro até 30 dias depois da ovulação induzida.. Mococa , 2004

Tabela 3.2 - Médias dos quadrados mínimos (erros-padrão da média) para variáveis discretas relativas à função luteínica e à luteólise. São Carlos, 2004

Tabela 3.3 - Resposta das vacas do $G_{R F}$ em relação à formação de corpo lúteo (CL) acessório, produção de progesterona e manifestação do estro. Mococa, 2004 


\section{LISTA DE FIGURAS DO APÊNDICE A}

Figura 1 - Gráficos da dinâmica folicular individual para o diâmetro do folículo dominante em cada onda de crescimento em função do dia do ciclo estral e da ovulação - grupo Controle. São Carlos, 2004 .....

Figura 2- Gráficos da dinâmica folicular individual para o diâmetro do folículo dominante à cada onda de crescimento em função do dia do ciclo estral e da ovulação - grupo hCG. São Carlos, 2004.

Figura 3 - Gráficos da dinâmica folicular individual para o diâmetro do folículo dominante à cada onda de crescimento em função do dia do ciclo estral e da ovulação - grupo $\mathrm{E}_{2}$-São Carlos, 2004

Figura 4 - Gráficos da dinâmica folicular individual para o diâmetro do folículo dominante à cada onda de crescimento, em função do dia do ciclo estral e da ovulação - grupo hCG/E2. São Carlos, 2004

Figura 5 - Gráficos das curvas obtidas das análises de regressão para o diâmetro do folículo dominante das $3^{\mathrm{a}}$ e $4^{\mathrm{a}}$ ondas de crescimento ao longo do ciclo estral. São Carlos, 2004

Figura 6 - Interação entre $\quad$ hCG e $\quad E_{2}$ para o diâmetro máximo do folículo dominante da $3^{3}$ onda de crescimento folicular, o dia em que esse folículo atingiu seu diâmetro máximo e sua taxa de crescimento. São Carlos, 2004.

Figura 7 - Gráfico da interação entre os fatores hCG e $E_{2}$ para o diâmetro do folículo pré-ovulatório. São Carlos, 2004 .

Figura 8 - $\quad$ Gráficos da dinâmica luteínica das vacas do grupo controle representando o diâmetro do corpo lúteo e a concentração plasmática da progesterona, em função do dia do ciclo estral. São Carlos, 2004

Figura 9 - $\quad$ Gráficos da dinâmica luteínica das vacas do grupo hCG representando o diâmetro do corpo lúteo e a concentração plasmática da progesterona, em função do dia do ciclo estral. São Carlos, 2004

Figura 10 - Gráficos da dinâmica luteínica das vacas do grupo $E_{2}$ representando o diâmetro do corpo lúteo e a concentração plasmática da progesterona, em função do dia do ciclo estral. São Carlos, 2004 
Figura 11- Gráficos da dinâmica luteínica das vacas do grupo hCG/E $\mathrm{E}_{2}$ representando o diâmetro do Corpo Lúteo e a concentração plasmática da progesterona, em função do dia do ciclo estral. São Carlos, 2004

Figura 12 - Gráfico e equações das curvas obtidas a partir das análises de regressão para o diâmetro do corpo lúteo em função do dia do ciclo estral para os diferentes grupos experimentais. São Carlos, 2004

Figura 13 - Gráfico e equações das curvas obtidas a partir das análises de regressão para a área do corpo lúteo em função do dia do ciclo estral para os diferentes grupos experimentais. São Carlos, 2004

Figura 14 - Gráfico e equações das curvas obtidas a partir das análises de regressão para o volume do corpo lúteo em função do dia do ciclo estral para os diferentes grupos experimentais. São Carlos, 2004

Figura 15 - Gráfico da interação entre os fatores hCG e $E_{2}$ para a concentração de progesterona plasmática no dia em que o corpo lúteo atingiu seu diâmetro máximo. São Carlos, 2004

Figura 16 - Gráficos das interações entre os fatores hCG e $E_{2}$ para as variáveis diâmetro máximo do corpo lúteo, área máxima do corpo lúteo e volume máximo do corpo lúteo. São Carlos, 2004

Figura 17 - Gráfico da interação entre os fatores hCG e $E_{2}$ para o número de corpos lúteos. São Carlos, 2004

Figura 18 - Gráfico e equações das curvas obtidas a partir das análises de regressão para a concentração plasmática de progesterona em função do dia do ciclo estral para os diferentes grupos experimentais. São Carlos, 2004

Figura 19- Médias pelos quadrados mínimos e epm para concentração plasmática de progesterona ao longo do ciclo estral para os diferentes grupos experimentais. São Carlos, 2004

Figura 20 - Gráfico da interação entre $\mathrm{hCG}$ e $\mathrm{E}_{2}$ para o dia no ciclo estral da luteólise. São Carlos, 2004 


\section{LISTA DE TABELAS DO APÊNDICE A}

Tabela 1 - Equações polinomiais relacionando o diâmetro do folículo dominante de cada onda de crescimento folicular e o dia do ciclo estral para cada grupo experimental. São Carlos, 2004 ....................................

Tabela 2 - Médias dos quadrados mínimos e erros-padrão da média para o diâmetro do corpo lúteo $(\mathrm{mm})$ conforme 0 dia do ciclo estral. São Carlos, 2004

Tabela 3 - Médias dos quadrados mínimos e erros-padrão da média para a área do corpo lúteo $\left(\mathrm{mm}^{2}\right)$ conforme o dia do ciclo estral. São Carlos, 2004

Tabela 4 - Médias dos quadrados mínimos e erros-padrão da média para o volume do corpo lúteo $\left(\mathrm{mm}^{3}\right)$ conforme o dia do ciclo estral. São Carlos, 2004

Tabela 5 - Médias dos quadrados mínimos e erros-padrão da média para a concentração plasmática de progesterona conforme o dia do ciclo estral. São Carlos, 2004

Tabela 6 - Médias dos quadrados mínimos e erros-padrão da média para a concentração plasmática de progesterona conforme o dia do ciclo estral, considerando-se a administração da hCG. São Carlos, 2004 


\section{LISTA DE TABELAS DO APÊNDICE B}

Tabela 1 - Presença de folículos ovarianos com diâmetro $\geq 7 \mathrm{~mm}$ no período crítico do reconhecimento materno da prenhez em vacas Red Angus (Bos taurus taurus).

Mococa, 2004 


\section{SUMÁRIO}

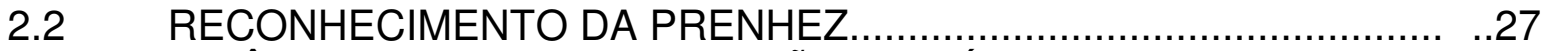

2.3 DINÂMICA FOLICULAR E FUNÇÃO LUTEÍNICA …...........................

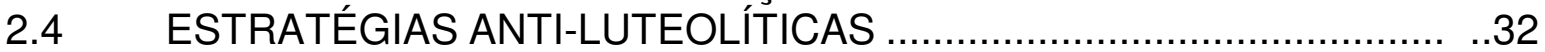

3 EXPERIMENTO 1 - ULTRA-SONOGRAFIA OVARIANA E CONCENTRAÇÃO PLASMÁTICA DE PROGESTERONA EM VACAS NELORE SUBMETIDAS A DIFERENTES DESAFIOS HORMONAIS APÓS A SINCRONIZAÇÃO DA OVULAÇÃO .................. .36

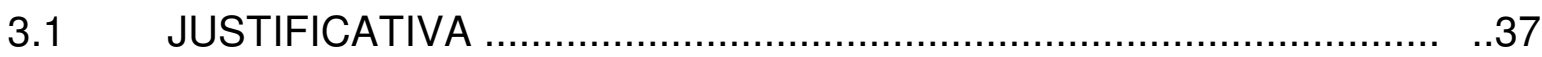

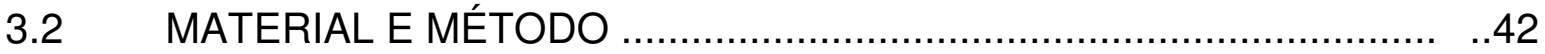

3.2.1 Local do experimento, animais e manejo ….................................... .42

3.2.2 Formação dos grupos ................................................................

3.2.3 Coleta de sangue e dosagem de progesterona plasmática ................. ..45

3.2.4 Exames ultra-sonográficos ….....................................................46

3.2.5 Delineamento experimental e análises estatísticas .............................47

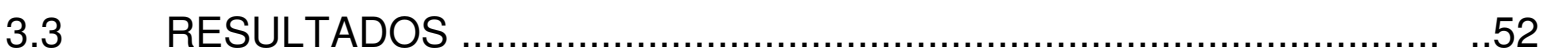

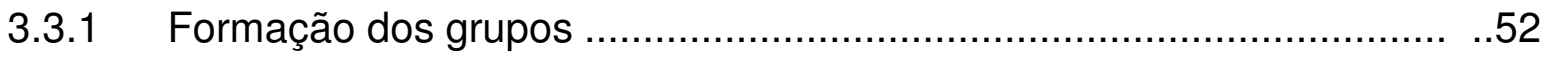

3.3.2 Dinâmica do crescimento folicular ................................................. .53

3.3.3 Número de ondas e ovulação ............................................................

3.3.4 Folículo dominante da $3^{\mathrm{a}}$ onda de crescimento .................................54

3.3.5 Folículo dominante da $4^{\mathrm{a}}$ onda de crescimento ..................................57

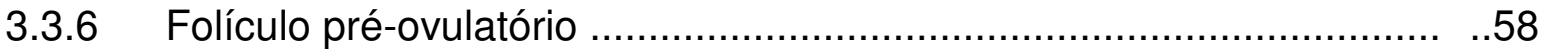

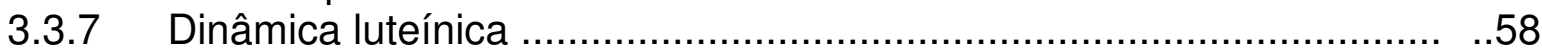

3.3.8 Medidas do corpo lúteo e concentração da progesterona plasmática $\quad .59$

3.3.9 Folículo dominante durante o período crítico ......................................64

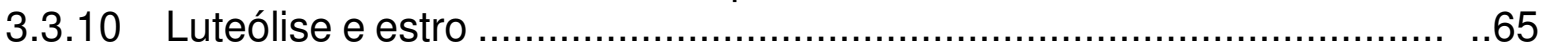

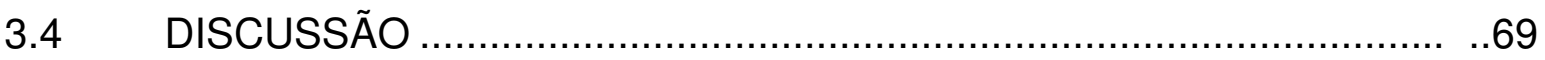

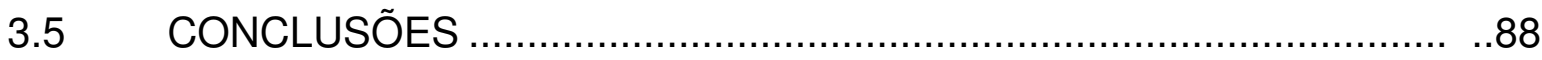

4 EXPERIMENTO 2 - TAXAS DE PRENHEZ DE VACAS NELORE SUBMETIDAS A INSEMINAÇÃO ARTIFICIAL EM TEMPO FIXO E SUPLEMENTADAS COM hCG, 17ß-ESTRADIOL OU A COMBINAÇÃO hCG/17ß-ESTRADIOL 


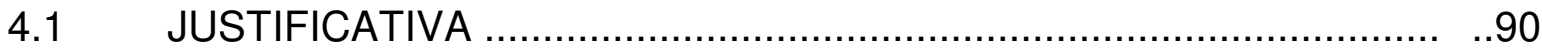

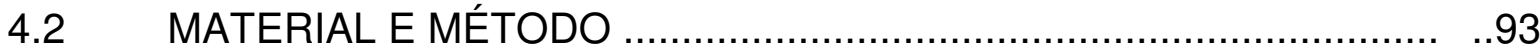

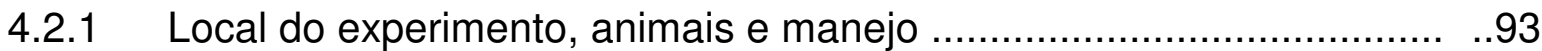

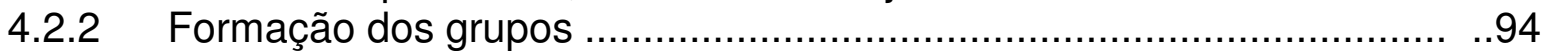

4.2.3 Exames ultra-sonográficos para diagnóstico de prenhez .....................96

4.2.4 Delineamento experimental e análise estatística ..................................96

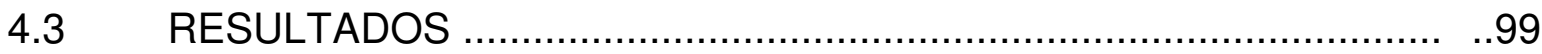

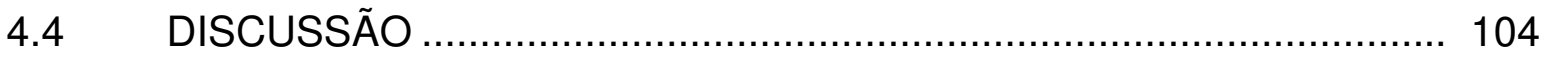

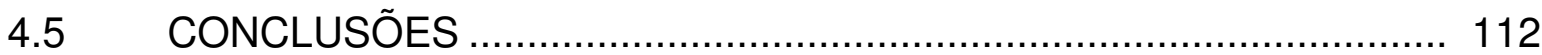

5 EXPERIMENTO 3 - REMOÇÃO MECÂNICA OU FARMACOLÓGICA DO FOLÍCULO DOMINANTE DURANTE O PERÍODO CRÍTICO EM VACAS DE CORTE DA RAÇA REDANGUS (Bos taurus taurus) …................................................ 113

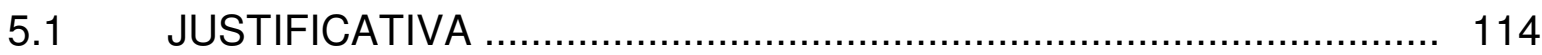

5.2 MATERIAL E MÉTODO …........................................................ 117

5.2.1 Local do experimento, animais e manejo …….............................. 117

5.2.2 Formação dos grupos................................................................. 118

5.2.3 Aspiração folicular .................................................................... 119

5.2.4 Coleta de sangue e dosagem de progesterona plasmática ............... 120

5.2.5 Delineamento experimental e análise estatística .............................. 121

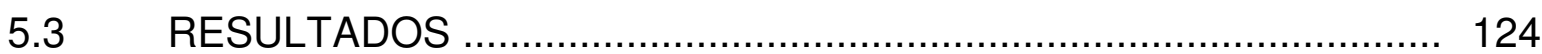

5.3.1 Formação dos grupos ............................................................ 124

5.3.2 Concentração plasmática de progesterona diária ............................... 125

5.3.3 Duração do ciclo estral ............................................................. 125

5.3.4 Imagens ultra-sonográficas dos ovários nas ocasiões de punção ...... 126

5.3.5 Variáveis derivadas das dosagens de progesterona ......................... 126

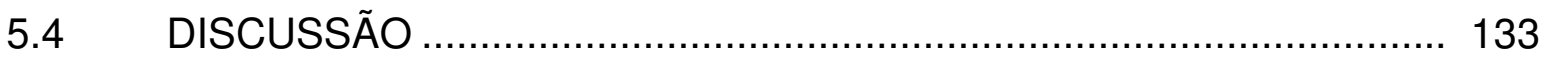

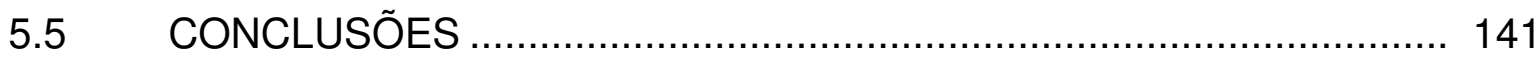

6 DISCUSSÃO GERAL ….......................................................... 142

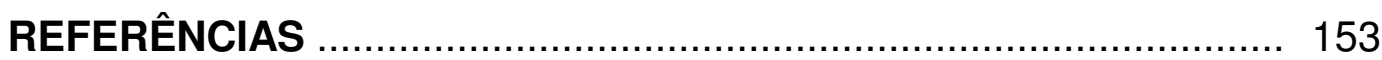

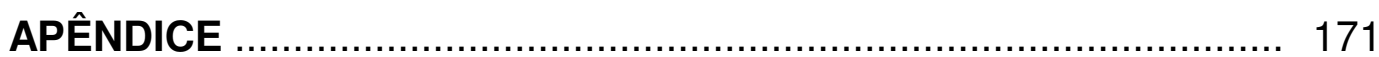


INTRODUÇÃO 


\section{INTRODUÇÃO}

A mortalidade embrionária dos bovinos se refere ás perdas no período compreendido desde a fertilização até que se complete a diferenciação dos tecidos, aproximadamente aos 42 dias de prenhez (DUNNE et al., 2000). Vanroose et al. (2000) em extensa revisão de literatura concluíram que a maioria destas perdas ocorre principalmente nos primeiros dias após a fertilização e durante o processo de implantação podendo atingir de $20 \%$ a $40 \%$. Esses valores assemelham-se aos relatados por Humblot (2001) em rebanhos franceses. Ao progredir a gestação, o impacto das perdas é proporcionalmente menor, como verificado por Starbuck et al. (2004) que reportaram $11,4 \%$ de mortalidade embrionária entre a $5^{a}$ e a $9^{a}$ semana de prenhez. Flint et al. (1990) estimaram prejuízos anuais de 300 milhões de libras esterlinas só no Reino Unido devido às perdas embrionárias. Para Cristhianson (1992) as causas não-infecciosas respondem por mais de $70 \%$ das perdas embrionárias, ilustrando então a importância dos distúrbios do reconhecimento materno e da luteólise na ocorrência da mortalidade embrionária. Neste contexto, pode-se definir um "período crítico" no ciclo reprodutivo da vaca, em que fisiologia da

vaca deve ser ajustada, de não prenhe para o estado de gestante. Esse período crítico situa-se entre os dias 15 e 19 após o estro e nele deve ocorrer o bloqueio da luteólise.

O completo mecanismo da luteólise ainda não é totalmente conhecido. Entretanto, é sabido que o estradiol produzido pelo folículo ovariano tem papel crucial. De fato, a remoção dos folículos ovarianos por cauterização com raios-X retardou a luteólise e prolongou o ciclo estral (VILLA-GODOY et al., 1985). A 
administração exógena de estradiol estimulou a liberação de PGF $_{2 \alpha}$ (KNICKERBOCKER et al., 1986b; THATCHER et al., 1986). Em conclusão, o bloqueio da luteólise durante o período crítico para o reconhecimento materno da prenhez envolve a inibição da produção do estradiol e/ou seus efeitos (BINELLI et al., 2001).

Além disso, para que ocorra a supressão da liberação de $\mathrm{PGF}_{2 \alpha}$ pelo útero gestante é requerida a presença de um concepto bem desenvolvido capaz de sinalizar bioquimicamente sua existência para a unidade materna. O interferon- $\tau$, uma citocina produzida no trofoectoderma, é o principal elemento efetor desta sinalização. A secreção de suficientes quantidades de interferon- $\tau$ para o bem sucedido reconhecimento materno da prenhez é dependente da secreção luteínica de progesterona (MANN; LAMMING, 2001; MANN et al. 1999), hormônio regulador da taxa de desenvolvimento embrionário. Mann e Lamming (1995) haviam relatado maiores concentrações de metabólito da $\mathrm{PGF}_{2 \alpha}$ nas vacas cuja concentração plasmática de progesterona era mais baixa, o que as fazia mais predispostas à perda embrionária. Em adição, Kerbler et al. (1997) verificaram que a síntese de interferon- $\tau$ pelo concepto esteve direta, positiva e significativamente $(r=0,59$; $\mathrm{P}<0,01)$ correlacionada com a concentração plasmática de progesterona materna, sugerindo que a maior progesteronemia pode prover um ambiente uterino mais adequado ao concepto em desenvolvimento.

Para promover aumentos na concentração plasmática de progesterona destaca-se o uso da hCG entre os dias 4 e 7 do ciclo estral (DIAZ et al. 1998; MARQUES, 2002; PRICE; WEBB, 1989; RAJAMAHENDRAN; SIANANGAMA, 1992; SCHMITT et al. 1996a) que induz a formação de um corpo lúteo acessório, com 
conseqüente aumento nas concentrações plasmáticas de progesterona (SANTOS et al., 2001).

Objetivou-se com o presente estudo testar estratégias para otimizar a função luteínica e retardar a luteólise em vacas de corte criadas sob condições tropicais.

O "experimento 1" foi conduzido com vacas da raça Nelore (Bos taurus indicus) e teve por objetivos específicos: $1^{\circ}$ ) quantificar a ação luteotrófica da hCG e seus efeitos sobre as concentrações de progesterona plasmática durante a fase luteínica e $2^{\circ}$ ) quantificar o efeito do $17_{\beta}$-estradiol sobre o crescimento de um folículo dominante durante o período crítico e sobre a luteólise.

O "experimento 2" foi conduzido para comparar a eficácia daquelas estratégias de otimização da função folicular e luteínica propostas no experimento 1 , adotadas em combinação a um protocolo de inseminação artificial em tempo fixo (IA $\left.A_{T F}\right)$. O objetivo específico foi quantificar as taxas de prenhez à $I A_{T F}$ e aos ciclos naturais subsequentes após aplicação dos tratamentos.

No "experimento 3", conduzido com vacas da raça Red Angus (Bos taurus taurus) visou-se comparar a remoção do folículo dominante por meio mecânico ou farmacológico como estratégias para aumentar a duração da fase luteínica e do ciclo estral. Seus objetivos específicos foram: $1^{\circ}$ ) quantificar a possível ação luteotrófica durante a fase luteínica exercida pela associação $\mathrm{GnRH} / \mathrm{hCG} ; 2^{\circ}$ ) verificar se a sincronização das ondas de crescimento folicular exercida pela associação GnRH/hCG foi capaz de impedir o crescimento de um folículo dominante durante o período crítico e $3^{\circ}$ ) quantificar o possível efeito anti-luteolítico da remoção física do folículo dominante por meio da punção folicular. 
REVISÃO DE LITERATURA 


\section{REVISÃO DE LITERATURA}

Práticas de manejo capazes de reduzirem a mortalidade embrionária bovina aumentam a eficiência dos sistemas de produção pecuária. Para tanto, é requerido o desenvolvimento de estratégias específicas que favoreçam o estabelecimento e a manutenção da prenhez. A presente revisão visa estabelecer de que modo a eficiência reprodutiva dos bovinos é afetada pelas perdas embrionárias precoces, bem como relacionar o papel do concepto e de sua relação com a unidade materna para o reconhecimento da prenhez. Além disso, revisou-se brevemente o estado da arte sobre a fisiologia do ciclo estral com ênfase não só nas dinâmicas folicular e luteínica, como também na luteólise. Em seguida foram apresentadas e discutidas estratégias para a redução da mortalidade embrionária precoce.

\subsection{EFICIÊNCIA REPRODUTIVA DE BOVINOS}

As dificuldades para a precisa detecção do estro (BARROS et al., 1998; MIZUTA, 2003; PINHEIRO et al., 1998) e a laboriosa tarefa de separar as fêmeas a serem inseminadas dentro de grandes rebanhos (KOJIMA, 2003) são os principais obstáculos para a adoção da inseminação artificial em bovinos de corte. Como resultado, a eficiência reprodutiva de rebanhos de corte inseminados artificialmente, em geral, é baixa devido a taxas de serviço, usualmente inferires a 50\% (LUCY, 2001). Como agravante, Pinheiro et al. (1998) verificaram que o período de estro das 
fêmeas zebuínas, componente majoritário do rebanho de corte nacional, tem curta duração, sendo de 10,5!0,4 horas para as vacas Nelore.

Além disso, os mesmos autores verificaram que $54 \%$ das vacas Nelore iniciaram o estro no período da noite e que 30\% delas já haviam encerrado o "cio" durante a madrugada, reduzindo ainda mais a eficiência de identificação do estro.

O aumento da taxa de serviço, definida como a razão entre o número de vacas inseminadas pelo número total de vacas disponíveis para a reprodução, pode elevar a eficiência reprodutiva, uma vez que a taxa de prenhez é o produto entre taxa de serviço e taxa de concepção. Neste cenário insere-se a inseminação artificial em tempo fixo $\left(\mathrm{IA}_{\mathrm{TF}}\right)$, a qual aumenta a taxa de serviço para $100 \%$. Entretanto, a despeito de significativos avanços, as manipulações hormonais do ciclo estral que precedem a I $A_{T F}$ ainda produzem resultados variáveis em fertilidade tanto para raças taurinas (MACHADO, 1994) como para as zebuínas (BÓ et al., 2003).

Uma vez obtidas altas taxas de serviço, é importante assegurar a fertilização do ovócito. Em bovinos são relatadas elevadas taxas de fertilização, alcançando valores próximos a 100\% (AYALON, 1978; BREUEL et al., 1993; DISKIN; SREENAN, 1980). De fato, Zavy (1994) e Santos et al. (2004b) inferiram que a maioria das falhas reprodutivas das vacas inseminadas seria devida à mortalidade embrionária.

A perda de prenhez divide-se cronologicamente em: morte embrionária, precoce ou tardia, e morte fetal. A mortalidade precoce se dá até o período de manutenção do corpo lúteo, entre os dias 15 e 17 pós-estro e a tardia se estende até a fase de diferenciação, aos 42 dias de prenhez (SANTOS et al., 2004b). Diskin e Sreenan (1980) verificaram que a mortalidade embrionária, em vacas de corte de raças européias, ocorreu principalmente nos primeiros dias após a fertilização e 
alcançou aproximadamente 30\% entre os dias 8 e 16 após a inseminação artificial. Peters (1996) reportou que as perdas embrionárias em bovinos são de aproximadamente $25 \%$ nas primeiras três semanas de gestação. Para Binelli e Thatcher (1999) a maioria das perdas reprodutivas ocorreu na fase embrionária da gestação e Dunne et al. (2000) verificaram que a maioria das perdas pré-natais em novilhas de corte, ocorreu antes do $14^{\circ}$ dia da gestação. Kunz et al. (2002) encontraram taxas de mortalidade entre $20 \%$ e $40 \%$ até os dias 21 e 22 de prenhez em vacas de corte.

Coletivamente, pode-se concluir que existe uma relação entre a sobrevivência embrionária e a cronologia dos eventos fisiológicos envolvidos no estabelecimento da prenhez, como: a perda da zona pelúcida pelo embrião, a sinalização pelo embrião de sua presença no útero e o bloqueio da luteólise. Este momento situa-se entre 15 e 19 dias após o estro e pode ser então conceituado como o período crítico para o reconhecimento materno da prenhez. Deste modo, o reconhecimento bem sucedido da prenhez é um dos fatores chave para se atingir elevada eficiência reprodutiva, compatível aos modernos sistemas de produção.

\subsection{RECONHECIMENTO DA PRENHEZ}

Binelli e Thatcher (1999) afirmaram que durante o período crítico, as células epiteliais do endométrio seguem uma programação pré-estabelecida para liberar pulsos luteolíticos da $\mathrm{PGF}_{2 \alpha}$, a menos que o concepto envie sinais anti-luteolíticos apropriados para bloquear a produção da $\mathrm{PGF}_{2 \alpha}$. Do contrário, ocorre a luteólise e o 
ciclo ovulatório é mantido culminando com a interrupção da gestação (MANN; LAMMING, 2001; THATCHER et al., 1986; THATCHER et al., 2001).

Há indicações científicas de que o processo da luteólise é acionado antes mesmo do período crítico. Com efeito, o embrião já produz moléculas sinalizadoras da sua presença no útero desde o $10^{\circ}$ dia do seu desenvolvimento (PETERS et al., 1992). Além disso, Banu et al. (2003) estudaram a proteína transportadora de prostaglandinas (PGT), uma enzima envolvida no transporte trans-membranas de prostaglandinas, e verificaram expressão máxima do RNAm para a PGT e da própria PGT já ocorre no dia 13 e também no dia 18 do ciclo estral.

O interferon- $\tau$ é a principal molécula sinalizadora da presença do concepto no útero materno e é secretado pelas células mononucleares do trofectoderma, no estádio precoce de desenvolvimento embrionário (THATCHER et al., 2001). Seu mecanismo de ação para o bloqueio da luteólise envolve a supressão na expressão dos receptores endometriais para a ocitocina (MANN et al., 1999; WATHES et al., 1998) e também a competição pelos sítios de ligação desses mesmos receptores, culminando com a inibição da síntese de PGF $_{2 \alpha}$ (DEMMERS et al., 2001).

O reconhecimento da prenhez e a sobrevivência embrionária estão ainda sujeitos a outros fatores que os afetam. O estresse térmico foi responsabilizado por perdas da prenhez de até 42,7\% (CARTMILL et al., 2001). A influência do estado nutricional da vaca, determinado pela avaliação da condição do escore corporal (ECC) foi estudada por López-Gatius et al. (2002) e também por Silke et al. (2002), os quais verificaram perdas significativas de prenhez quando houve diminuição do ECC. Em vacas leiteiras de alta produção, o desempenho reprodutivo fica comprometido pelo desvio de nutrientes para a síntese láctea (LUCY, 2001; ZERON et al., 2001), o que pode diminuir a concentração de progesterona circulante durante 
o diestro (SANGSRITAVONG et al., 2002), comprometer o desenvolvimento embrionário (MANN; LAMMING, 1999) e reduzir a concepção (WATHES et al., 2003). Além disso, vacas leiteiras de alta produção possuem um maior metabolismo hepático para esteróides (VASCONCELOS et al., 2004).

A fase luteínica que sucede a primeira ovulação pós-parto freqüentemente tem curta duração (INSKEEP, 2002) impedindo a manutenção da prenhez e acarretando baixa fertilidade devido à liberação precoce de $\mathrm{PGF}_{2 \alpha}$ no ciclo subseqüente (SHAHAM-ALBALANCY et al., 2001). Mecanismo similar causou maior incidência de morte embrionária tardia em vacas submetidas à $I A_{T F}$ que estavam em anestro quando foi imposto o tratamento hormonal de indução da ovulação (CARTMILL et al., 2001; SANTOS et al., 2004a).

As doenças caracterizadas por hipertermia e/ou aquelas que se instalam no ambiente uterino reduzem a sobrevivência embrionária e fetal. O momento de grande susceptibilidade aos vários agentes infecciosos coincide com a perda da zona pelúcida pelos embriões, ou seja entre 8 e 9 dias após a fertilização (WRATHALL; SUTMÖLLER, 1998). A infecção uterina por agentes como o herpesvírus (BHV-1) e o vírus da diarréia bovina (BVDV) pode provocar a morte embrionária antes do $14^{\circ}$ dia do ciclo estral (KUNZ et al., 2002). Apesar da importância das doenças infecciosas, Christianson (1992) reputa que $70 \%$ da mortalidade embrionária têm origem não infecciosa.

Vasconcelos et al. (2004) relataram existir diferenças no potencial fecundante do sêmen de touros de raças leiteiras afetando a taxa de concepção, o que corrobora achados prévios de López-Gatius et al. (2002) que reportaram haver touros causadores de maiores perdas de prenhez do que outros. 
Em conclusão, a despeito dos fatores que podem reduzir o reconhecimento da prenhez, o adequado preparo do útero pela progesterona é fundamental para a sobrevivência embrionária. Assim, o crescimento folicular permitindo a formação de um corpo lúteo de alta competência esteroidogênica provê as condições para o desenvolvimento ótimo do concepto. Neste contexto, ressalta-se a importância do conhecimento sobre os fatores que governam a dinâmica do crescimento folicular e a função luteínica.

\subsection{DINÂMICA FOLICULAR E FUNÇÃO LUTEÍNICA}

O ciclo estral dos bovinos tem duração de 17 a 25 dias (SIROIS; FORTUNE, 1988). O desenvolvimento folicular ocorre em ondas de crescimento e cada onda possui três fases: o recrutamento, a seleção e a dominância (GINTHER et al., 1989a), havendo similaridades entre taurinos e zebuínos (BÓ et al., 2003; FIGUEIREDO et al., 1997). Na fase de recrutamento ocorre o crescimento de um grupo de folículos até atingirem o diâmetro aproximado de $5 \mathrm{~mm}$. A seleção se estabelece pela predominância no crescimento de um folículo ("dominante"), o qual destaca-se dos demais com menor diâmetro ("subordinados"). No momento do desvio, o folículo dominante (com aproximadamente $8,5 \mathrm{~mm}$ de diâmetro em taurinos) apresenta crescimento contínuo, em oposição aos subordinados, os quais diminuem ou cessam o crescimento (GINTHER et al., 1996; GINTHER et al., 2001).

Segundo Adams et al. (1992) e Hamilton et al. (1992) o recrutamento é deflagrado pela elevação das concentrações plasmáticas do hormônio folículo 
estimulante (FSH). No desvio, a concentração do FSH declina e ocorre a expressão dos receptores para LH nas células da granulosa do folículo de maior diâmetro, tornando-se dominante (BAO; GARVERICK, 1998; XU et al., 1995). O mecanismo determinante da dominância não esta completamente elucidado. Entretanto, ficou demonstrado que a produção de estrógeno e inibina pelo folículo dominante aumenta e por retroalimentação negativa sobre o eixo hipotalâmico-hipofisário, inibem a secreção de FSH, bloqueando o crescimento dos folículos $\mathrm{FSH}$ dependentes, o que culmina com sua atresia (FORTUNE, 1994; IRELAND et al., 1994).

Ao se desenvolver, o folículo dominante secreta quantidades crescentes de estrógeno, que por retroalimentação positiva sobre o hipotálamo, desencadeia a liberação do GnRH e o conseqüente pico de LH (VOSS; FORTUNE, 1993), promovendo a ovulação. Cumpre lembrar, que a ovulação do folículo dominante só ocorre sob baixa progesteronemia, ou seja após a regressão do corpo lúteo, o que de fato determina se este folículo presente seria ovulatório (GINTHER et al., 1989b; LUCY et al., 1992). Após a ovulação e por ação do LH, as células foliculares se luteinizam, formando o corpo lúteo do ciclo subseqüente (MILVAE et al., 1996).

O corpo lúteo é uma glândula transitória que produz progesterona e ocitocina. A progesterona é essencial para a ciclicidade e para a manutenção da prenhez na vaca. Caso ocorra a fertilização após a ovulação, a progesterona é responsável pelo preparo do endométrio para receber o concepto bem como pela inibição das contrações da parede uterina.

A regressão do corpo lúteo ocorre entre os dias 15 e 19 depois da ovulação no útero não-prenhe. Essa regressão, denominada luteólise é caracterizada por perda funcional e desarranjo da estrutura celular. O seu mecanismo ainda não é 
plenamente conhecido. A prostaglandina $\mathrm{F}_{2 \alpha}\left(\mathrm{PGF}_{2 \alpha}\right)$ produzida no endométrio é o principal agente luteolítico e há evidências de que o estradiol é fundamental na regulação da luteólise pois, tanto o estradiol endógeno (HUGHES et al., 1987; VILLA-GODOY et al., 1985) como o exógeno (KNICKERBOCKER et al., 1986b; THATCHER et al., 1986; SALFEN et al., 1999) desencadeiam a liberação da PGF $_{2 \alpha}$ em quantidades luteolíticas.

Assim, conhecendo-se os eventos que caracterizam e os fatores que regulam o crescimento folicular, a função luteínica e a luteólise é possível criar estratégias anti-luteolíticas que favoreçam o reconhecimento materno da prenhez e diminuam a mortalidade embrionária precoce.

\subsection{ESTRATÉGIAS ANTI-LUTEOLÍTICAS}

O conhecimento dos fenômenos endócrinos e metabólicos que governam o reconhecimento materno da prenhez pode auxiliar o controle da mortalidade embrionária precoce caso levem à elaboração e adoção de estratégias que otimizem a interação mãe-concepto, principalmente durante o período crítico.

Neste contexto, a associação dessas estratégias aos protocolos de $I \mathrm{~A}_{\mathrm{TF}}$ e de manejo das receptoras de embriões deve aumentar as taxas de prenhez, quando comparadas com a adoção dessas biotécnicas isoladamente. A partir desse conceito, Binelli et al. (2001) sugerem: a) aumentar as concentrações circulantes da progesterona na fase luteínica e no período crítico, para estimular o reconhecimento da prenhez e b) reduzir as concentrações circulantes de estradiol durante o período 
crítico, para minimizar o estímulo aos receptores de ocitocina e controlar a liberação de $\mathrm{PGF}_{2 \alpha}$, o que retardaria ou inibiria a luteólise. Para tanto, as estratégias devem objetivar aumentar a capacidade de produção da progesterona pelo corpo lúteo e/ou reduzir os efeitos do folículo dominante no período crítico.

Santos et al. (2004b) enfatizaram o papel essencial da progesterona produzida pelo corpo lúteo no controle do meio uterino e na nutrição do embrião, o que permitiu relacionar elevadas concentrações de progesterona com taxas de concepção maiores (BARUSELLI et al., 2001; FUENTES; DE LA FUENTES, 1997; MARQUES et al., 2003; SANTOS et al., 2000). De fato, diversos autores mostraram que vacas não prenhes após diferentes programas de IA tiveram menores concentrações de progesterona em relação às que emprenharam (LAMMING et al.,1989; LUKASZEWSKA; HANSEL, 1980; MACHADO, 1994; MANN et al., 1995).

Hasler et al. (1980), Payas et al. (1989), Tribulo et al. (1997), Spell et al. (2001) e Nogueira et al. (2002) não detectaram qualquer relação entre progesteronemia no período crítico e taxa de concepção. Por outro lado, Stubbings e Walton (1986) verificaram que a concentração sérica de progesterona no dia da transferência de embrião $\left(D_{7}\right)$ estava significativamente correlacionada com a taxa de prenhez das receptoras. Resultados análogos haviam sido descritos por Remsen e Roussel (1982) e Niemann et al. (1985), os quais indicaram que a concentração ótima de progesterona no dia da inovulação deve estar entre 2,0 e 5,0 ng/mL.

Do ponto de vista molecular, a progesterona diminui a afinidade de ligação entre a ocitocina e seus receptores próprios, favorecendo assim a inibição da luteólise (GRAZZINI et al., 1998). Além disso, Mann e Lamming (1995) reportaram que as vacas portadoras de embriões menos desenvolvidos possuíam concentração de interferon- $\tau$, no lavado uterino, inferior àquela de fêmeas cujos embriões eram 
mais desenvolvidos. Além disso, ficou constatado que a típica elevação na concentração de progesterona do início da fase luteínica ocorreu tardiamente e que as concentrações médias durante toda fase luteínica foram menores.

Mann et al. (1999) enfatizaram a necessidade por concentrações mais altas de progesterona durante o período crítico para a manutenção da prenhez, pois a presença de um concepto bem desenvolvido e capaz de secretar suficientes quantidades de interferon- $\tau$ é dependente da secreção luteínica de progesterona, que por sua vez regula a taxa do desenvolvimento embrionário. Para promover estes efeitos, destaca-se o uso da hCG entre os dias 4 e 7 pós estro (DIAZ et al. 1998; MARQUES, 2002; PRICE; WEBB, 1989; RAJAMAHENDRAN; SIANANGAMA, 1992; SCHMITT et al. 1996a) a qual induz a formação de um corpo lúteo acessório, com conseqüente aumento nas concentrações plasmáticas de progesterona (SANTOS et al., 2001). Em realidade, Schmitt et al. (1996b) após efetuarem a caracterização celular e endócrina dos corpos lúteos, original e acessório, concluíram que a hCG estimulou a secreção de progesterona pelo corpo lúteo original e conseqüente aumento nas taxas de prenhez.

Hariadi et al. (1998) verificaram que vacas tratadas com 3000 UI da hCG no $5^{\circ}$ dia e depois com $\mathrm{PGF}_{2 \alpha}$ no $12^{\underline{0}}$ dia após o estro mostraram luteólise incompleta e ainda sugeriram que as maiores concentrações de progesterona do diestro reduziriam a secreção do LH, suprimindo o crescimento do folículo dominante.

Além disso, o uso da hCG no quinto dia do ciclo estral agiu na dinâmica folicular ao antecipar a ovulação do folículo dominante da $1^{\text {a }}$ onda e a emergência da $2^{\underline{a}}$ onda de crescimento resultando em ciclos de três ondas foliculares (DIAZ et al., 1998). 
Marques (2002) concluiu que o aumento nas concentrações plasmáticas de progesterona pode assumir especial importância em vacas zebuínas, por apresentarem diâmetro do corpo lúteo menor e concentrações plasmáticas de progesterona inferiores àquelas observadas para fêmeas Bos taurus taurus.

Outra biotécnica para estimular o reconhecimento da prenhez usa os estrógenos para sincronizar as ondas de crescimento folicular. A sua ação envolve a indução da ovulação ou a atresia do folículo dominante (BARUSELLI et al., 2004a). Ficou demonstrado que o $17_{\beta}$-estradiol estimula a secreção de PGF $_{2 \alpha}($ THATCHER et al., 1986) podendo potencialmente deflagrar a luteólise em vacas (KNICKERBOCKER et al., 1986b; THATCHER et al., 1986). Por outro lado, a administração exógena de fluído folicular depletado de esteróides retardou a luteólise e Salfen et al. (1999) concluíram que a supressão do crescimento folicular prolonga a fase luteínica do ciclo.

Outra abordagem para prolongar a fase luteínica do ciclo estral e retardar o surgimento de folículos maiores que $9 \mathrm{~mm}$ é o uso estratégico do $\mathrm{GnRH}$, entre os dias 11 e 13 (PETERS, 1996). Ambrose et al. (1998) demonstraram que sem os efeitos de folículos grandes, as concentrações de estradiol mantiveram-se baixas e as de progesterona altas durante o período crítico. Neste caso, o reconhecimento da prenhez foi favorecido e resultou em maior proporção de vacas prenhes. Os autores concluíram que reduzir o tamanho ou eliminar a presença de um folículo dominante deve minimizar o estímulo luteolítico associado ao estradiol.

Em conclusão, a manipulação das funções folicular e luteínica pode se refletir em aumentos na taxa de concepção. A relevância e a mais oportuna aplicação de tais procedimentos vinculam-se à otimização da $I A_{T F}$ ou da inovulação em receptoras de embrião. 
EXPERIMENTO 1

ULTRA-SONOGRAFIA OVARIANA E CONCENTRAÇÃO PLASMÁTICA DE PROGESTERONA EM VACAS NELORE SUBMETIDAS

A DIFERENTES DESAFIOS HORMONAIS APÓS A SINCRONIZAÇÃO DA OVULAÇÃO 
3 EXPERIMENTO 1 - ULTRA-SONOGRAFIA OVARIANA E CONCENTRAÇÃo PLASMÁtica de PROGESTERONA EM VACAS NELORE SUBMETIDAS A DIFERENTES DESAFIOS HORMONAIS APÓS A SINCRONIZAÇÃO DA OVULAÇÃO

\subsection{JUSTIFICATIVA}

O componente mais importante para o estabelecimento da produtividade de um rebanho é a eficiência reprodutiva. Por conseguinte, este é o fator que individualmente mais afeta a lucratividade de uma operação pecuária (NEUMANN; LUSBY, 1986). Além disso, o retorno econômico condiciona-se à obtenção de elevadas taxas de parição. Entretanto, apesar dos bovinos de raças européias alcançarem taxas de fertilização de $96 \%$ a $100 \%$, as taxas de parição após uma única inseminação artificial (IA) situam-se entre 50\% e 55\% para novilhas, entre 52\% e $57 \%$ para vacas leiteiras e por volta de $53 \%$ para vacas de corte (DISKIN; SREENAN, 1980).

Dunne et al. (2000) relataram que a mortalidade embrionária é a maior fonte de prejuízos na bovinocultura, sendo a causa mais freqüente de perdas reprodutivas. A maioria dessas perdas acontece no período embrionário da gestação (KUNZ et al., 2002). Alguns autores (DUNNE et. al., 2000; SANTOS et al., 2004b) afirmaram haver perdas de até $40 \%$ dos conceptos e apontam vários fatores causais. Apesar da etiologia diversa, a maioria das perdas embrionárias acontece de oito a 16 dias depois da inseminação. Christianson (1992) afirmou que as causas 
não-infecciosas tanto de origem materna quanto no próprio embrião respondem por $70 \%$ dos casos de mortalidade embrionária.

Todas essas informações são originárias de estudos realizados com vacas de raças européias criadas em clima temperado no hemisfério norte e destaca-se o impacto das perdas embrionárias sobre a eficiência reprodutiva daqueles rebanhos. No Brasil, onde a eficiência reprodutiva é ainda mais baixa e as taxas de natalidade estão ao redor dos 50\% (ANUALPEC, 2004), não há informações sobre a contribuição das perdas embrionárias para esse baixo desempenho reprodutivo. Para Santos et al. (2004b), o desempenho otimizado dos programas reprodutivos só é alcançado se objetivar um aumento na taxa de concepção, pois a taxa de parição é resultante da multiplicação daquela taxa pela taxa de serviço.

A mortalidade pré-natal em bovinos ocorre de forma mais expressiva num "período crítico" ainda durante a fase embrionária e está relacionada aos eventos fisiológicos do reconhecimento da prenhez (dias 15 a 19 após o estro). Até esse período crítico, a fisiologia uterina é equivalente entre vacas prenhes e não prenhes. Há uma programação preestabelecida de produção da prostaglandina F2-alfa $\left(\mathrm{PGF}_{2 \alpha}\right)$ no endométrio. Portanto, para o reconhecimento da prenhez, o aparato bioquímico enzimático responsável pela liberação de pulsos luteolíticos da $\mathrm{PGF}_{2 \alpha}$ deve ser bloqueado por meio do envio de sinais anti-luteolíticos pelo concepto (BINELLI; THATCHER, 1999). Do contrário, a luteólise irá ocorrer mesmo havendo um concepto no útero (BINELLI et al., 2001). Neste contexto, define-se o reconhecimento materno da prenhez como o processo de sinalização do concepto para a unidade materna, resultando na manutenção de um corpo lúteo funcional.

A sinalização é feita pelo concepto por meio da secreção de macromoléculas. Entre estas, destaca-se o interferon- $\tau$. Esta citocina interage com 0 
endométrio para "re"- programá-lo e impedir a liberação pulsátil da PGF $F_{2 \alpha}$, prevenindo assim a luteólise (BINELLI; THATCHER, 1999).

A magnitude desta ação inibitória provavelmente depende da quantidade total de interferon- $\tau$ secretada e da área do endométrio ocupada pelo concepto. Assim, conceptos maiores teriam maior probabilidade de sobrevivência (BINELLI; THATCHER, 1999). O estresse térmico, assim como outros fatores do meio ambiente podem reduzir a velocidade de desenvolvimento do concepto (GEISERT et al., 1988) e comprometer a sua produção de interferon- $\tau$, o que prejudicaria 0 reconhecimento da prenhez. De fato, esta sinalização, deve ser bem sucedida e ocorrer até os dias 15 a 19 desde a fertilização, antes que se deflagre a cadeia de eventos da luteólise. Thatcher e Hansen (1992) relataram existir variação no tamanho dos conceptos bovinos medidos no $17^{\circ}$ dia da prenhez. Em conclusão, o crescimento ótimo do embrião favorece o bloqueio da luteólise.

A progesterona, produzida pelo corpo lúteo prepara o ambiente uterino para fornecer condições favoráveis para o desenvolvimento embrionário. Ao correlacionarem o desenvolvimento embrionário às concentrações plasmáticas de progesterona, Mann et al. (1996) verificaram que tanto o retardamento na elevação das concentrações, como as baixas concentrações de progesterona durante a fase luteínica estavam associadas aos embriões mal desenvolvidos no $16^{\circ}$ dia após a inseminação. Por sua vez, Geisert et al. (1988) suplementaram a progesterona endógena e constataram um incremento na velocidade do crescimento embrionário e na produção de interferon- $\tau$. Coletivamente, pressupõe-se que animais de função luteínica otimizada podem permitir o melhor desenvolvimento do concepto e aumentam as chances de um efetivo reconhecimento materno da prenhez pelo bloqueio da luteólise. 
Visando a redução na mortalidade embrionária precoce podem ser propostas estratégias de manejo afetando as funções foliculares e luteínicas, de modo a: $1^{\circ}$ ) otimizar os estímulos luteotróficos da unidade materna para prover ao útero um meio apropriado para a máxima expressão de interferon- $\tau$ pelo concepto e $2^{\circ}$ ) extinguir, retardar ou diminuir a capacidade luteolítica no endométrio. Com isso, espera-se o aumento nas taxas de concepção e de parição.

Além da suplementação da progesterona (GEISERT et al., 1988) a otimização da função luteínica pode ser alcançada com a aplicação de substâncias luteotróficas (RAJAMAHENDRAN; SIANANGAMA, 1992). Ambas opções podem ser utilizadas como estratégias de combate à mortalidade embrionária.

A gonadotrofina coriônica humana (hCG) possui atividade semelhante à do hormônio luteinizante (LH) e a sua administração em diferentes fases do ciclo estral bovino promove a ovulação do folículo dominante (DIAZ et al., 1998), a formação de um corpo lúteo acessório e o aumento da concentração plasmática da progesterona (DIAZ et al. 1998; PRICE; WEBB, 1989; SCHMITT et al., 1996a). Estes mesmos efeitos também podem ser obtidos com o hormônio liberador de gonadotrofinas $(\mathrm{GnRH})$. Entretanto, a ocorrência da formação de corpos lúteos acessórios e a magnitude do aumento das concentrações de progesterona são menores (BINELLI et al., 2001).

Por sua vez, o estradiol originado pelos folículos em crescimento, participa do processo que desencadeia a luteólise e a redução das suas concentrações circulantes possivelmente retardaria o processo luteolítico. De fato a irradiação de folículos ovarianos retarda a luteólise e prolonga a fase luteínica (HUGHES et al., 1987). Portanto, manipulações da função folicular para reduzir o estradiol endógeno durante o período crítico potencialmente atrasariam a luteólise, o que aumenta a 
chance para o crescimento do concepto e produção do interferon- $\tau$. Assim, a redução da capacidade endometrial para produzir $\mathrm{PGF}_{2 \alpha}$, pela eliminação dos efeitos do estradiol, durante o período crítico, fundamenta o estabelecimento de estratégias para redução da mortalidade embrionária.

O 17 $\beta_{\beta}$-estradiol, dentre outros estrógenos, aplicado em ocasião estratégica, é capaz de sincronizar a onda de crescimento folicular (BARUSELLI et al., 2004c). Consequentemente, especula-se que o uso de tais drogas pode promover a eliminação farmacológica do folículo dominante da $2^{\underline{a}}$ onda com conseqüente prolongamento da fase luteínica do ciclo.

Deste modo é pertinente o estabelecimento de estratégias para reduzir a mortalidade embrionária baseadas: $1^{\circ}$ ) na otimização da função luteínica; $2^{\circ}$ ) na remoção farmacológica do folículo dominante e $3^{\circ}$ ) na associação das duas estratégias anteriores. Para tanto, este experimento foi conduzido com vacas da raça Nelore (Bos taurus indicus) tendo como objetivos específicos: $1^{\circ}$ ) quantificar a ação luteotrófica da hCG aplicada 5 dias após a ovulação e seus efeitos sobre as concentrações de progesterona plasmática durante a fase luteínica e $2^{\circ}$ ) quantificar o efeito do $17_{\beta}$-estradiol aplicado no $12^{\circ}$ dia após a ovulação sobre o crescimento de um folículo dominante durante o período crítico e sobre a luteólise. 


\subsection{MATERIAL E MÉTODO}

O Material e Método compreendeu o local do experimento, os animais e seu manejo, a formação dos grupos, a coleta de sangue para dosagem da progesterona plasmática, os exames ultra-sonográficos, bem como o delineamento experimental e a análise estatística.

\subsubsection{Local do experimento, animais e manejo}

O experimento foi desenvolvido na Fazenda Canchim, sede da Embrapa Pecuária Sudeste, unidade da Empresa Brasileira de Pesquisa Agropecuária (Embrapa), em São Carlos. A fazenda se localiza na região central do estado de

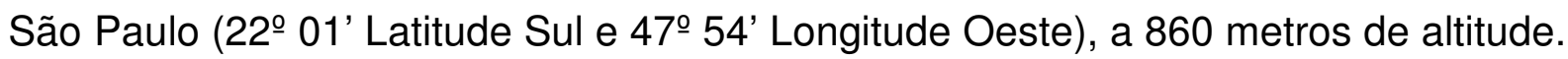
O clima é tropical, do tipo CwA na classificação de Köppen, caracterizado como verão quente e inverno seco. No período de 1970 a 1997, a média da temperatura anual foi de $21,3^{\circ} \mathrm{C}$, da umidade relativa do ar de $77 \%$ e a precipitação pluviométrica média anual foi de 1353 milímetros (mm).

Foram utilizadas 40 vacas da raça Nelore (Bos taurus indicus), com idades entre 5 e 11 anos, tendo pelo menos 240 dias pós-parto e sem bezerro ao pé . As fêmeas foram pesadas e avaliadas quanto ao escore de condição corporal (ECC), com notas de 1 (emaciada) a 9 (obesa), segundo Spitzer (1986), no início do 
experimento. Apenas as vacas com $5 \leq \mathrm{ECC} \leq 7$ foram designadas para a formação dos grupos experimentais.

As fêmeas foram submetidas ao exame ginecológico, no início do experimento, examinando-se os órgãos genitais internos por palpação retal e ultrasonografia transretal para avaliação morfo-funcional dos ovários. As vacas foram classificadas consoante à condição ovariana conforme descrito por Madureira et al. (2004), sendo utilizadas para a composição dos grupos experimentais apenas as vacas classificadas como escore 1 (portadoras de corpo lúteo) ou escore 2 (possuíam ovários com comprimento entre 15 e 30mm e com crescimento folicular associado a turgidez uterina).

Os animais foram manejados em sistema intensivo de rotação de pastagem em piquetes de capim Brachiaria decumbens, Brachiaria brizantha var. Marandu e Panicum maximum var. Tanzânia. Havia nos piquetes livre acesso a sal mineralizado e água.

3.2.2 Formação dos grupos experimentais

O ciclo estral das vacas foi sincronizado pelo método "OvSynch" (PURSLEY et al., 1995) que consiste numa injeção intramuscular de $8 \mu \mathrm{g}$ do Acetato de Buserelina $^{1}$ (agonista do $\mathrm{GnRH}$ ), seguida por uma injeção intramuscular com 0,150mg de d-Cloprostenol ${ }^{2}$ (análogo da $\mathrm{PGF}_{2 \alpha}$ ) sete dias mais tarde e outra aplicação de $\mathrm{GnRH} 48$ horas após esta última. A data da segunda aplicação do

\footnotetext{
${ }^{1}$ Acetato de Buserelina ${ }^{\circledR}$, Centro Paulista de Desenvolvimento Farmacotécnico.
} 
$\mathrm{GnRH}$ foi considerada como o dia (D) zero ( $\left.\mathrm{D}_{\text {zero }}\right)$. A confirmação da ovulação das vacas sincronizadas foi realizada por meio de dois exames ultra-sonográficos. 0 primeiro foi efetuado no momento da $2^{\text {a }}$ aplicação do $\mathrm{GnRH}$ para verificar a presença de um folículo dominante (diâmetro $\mu 7 \mathrm{~mm}$ ) e o segundo, 48 horas depois. A ovulação foi caracterizada como o desaparecimento do folículo ovulatório que estava presente no exame prévio e a subsequente formação de um corpo lúteo. As fêmeas que ovularam foram distribuídas por sorteio aleatório nos seguintes grupos: o grupo Controle (Gc) não recebeu tratamento adicional $(n=7)$. As vacas do grupo hCG $\left(G_{h C G}\right)$ receberam $3000 \mathrm{Ul}$ da $h_{C G}{ }^{3}$ via intramuscular no $D_{5}(n=5)$. As vacas do grupo $17_{\beta}$-estradiol $\left(G_{E 2}\right)$ receberam $5 \mathrm{mg}$ de $17_{\beta}$-estradiol ${ }^{4}$ via intramuscular no $D_{12}$

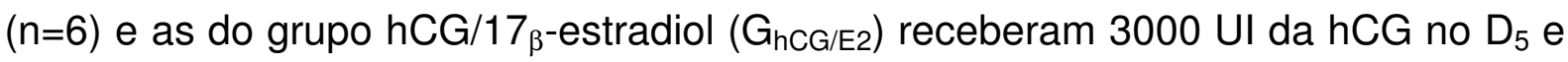
$5 \mathrm{mg}$ do $17_{\beta}$-estradiol no $D_{12}(n=5)$.

Em todos grupos foi procedida a observação do estro, por 30 minutos, duas vezes ao dia (07:00 horas e às $16: 30$ horas) a partir de $D_{12}$ até a manifestação do estro. A observação teve como data limite o $D_{30}$, momento em que o experimento se encerrou. Para auxiliar na detecção dos cios, houve a inclusão de dois rufiões por grupo, equipados com marcador "chin-ball" e mantidos até o final do experimento. Os mesmos eram bovinos cruzados com raça européia, de comprovada libido, os quais foram preparados cirurgicamente por aderência lateral do pênis na parede abdominal associada a caudoepididimectomia. Quando necessário houve substituição dos rufiões.

\footnotetext{
${ }^{2}$ Prolise ${ }^{\circledR}$, Tecnopec.

${ }^{3}$ Vetecor 5000 U.I. ${ }^{\circledR}$, Laboratórios Calier S.A.

4 17beta-Estradiol, Centro Paulista de Desenvolvimento Farmacotécnico.
} 
3.2.3 Coleta de sangue e dosagem de progesterona plasmática

Foram coletadas amostras de sangue para a separação do plasma e dosagem da progesterona, diariamente, desde $D_{5}$ até a manifestação do estro, tendo como data limite $\circ D_{30}$. As amostras foram obtidas por punção da veia jugular. $O$ sangue coletado em tubos de vidro contendo heparina foi acondicionado em gelo, para posterior centrifugação a aproximadamente $700 \times \mathrm{g}$ por 15 minutos. $O$ plasma obtido foi transferido para tubos plásticos e então congelado e estocado em freezer $\left(-20^{\circ} \mathrm{C}\right)$.

As amostras foram dosadas no LDH - Laboratório de Dosagens Hormonais do Departamento de Reprodução Animal da Faculdade de Medicina Veterinária e Zootecnia da Universidade de São Paulo na capital. De cada grupo experimental foram designadas cinco vacas para compor os subgrupos submetidos às dosagens da progesterona. Deste modo, não foram aproveitadas as amostras de duas vacas do $G_{C}$ e uma vaca do $G_{E 2}$, que foram escolhidas por sorteio aleatório antes de serem iniciadas as dosagens.

Para as dosagens foram empregados "kits" comerciais para radioimunoensaio em fase sólida ${ }^{5}$ seguindo as recomendações protocolares do fabricante. A sensibilidade do teste foi de $0,05 \mathrm{ng} / \mathrm{mL}$ e os coeficientes de variação intra e interensaio foram respectivamente de 4,01\% e 7,20\%. Este kit já havia sido usado para trabalhos com plasma bovino (MARQUES, 2002). 


\subsubsection{Exames ultra-sonográficos}

Os exames ultra-sonográficos foram realizados diariamente do $D_{12}$ até a próxima ovulação, tendo como data limite $\circ D_{30}$. Utilizaram-se um aparelho de ultrasom da marca PIE-MEDICAL, modelo Scan200Vet e um aparelho ALOKA, modelo SSD 500, em modo-B, ambos acoplados a seus respectivos transdutores de 7,5 MHz. A Figura 1.1 contém a representação esquemática dos protocolos de administração dos tratamentos.

Foram utilizados os critérios e a metodologia descritos por Rocha (2000) para exame por via retal. As imagens dos ovários foram orientadas da face medial para a face lateral, mostrando imagens em seqüência de modo a expor toda a superfície ovariana. As imagens de cada ovário, a cada exame de cada animal foram congeladas na tela, em maior aumento para a realização das mensurações do corpo lúteo e dos folículos maiores que $4 \mathrm{~mm}$. As anotações foram feitas num "mapa" de cada ovário e a tabulação das medidas dos folículos foi feita em ordem decrescente para facilitar o acompanhamento da sua dinâmica de crescimento (GINTHER et al., 1989a).

\footnotetext{
${ }^{5}$ Coat-aCount $\AA$, DPC - Diagnostic Products Corporation (Los Angeles, EUA).
} 


\subsubsection{Delineamento experimental e análise estatística}

O delineamento experimental adotado foi o inteiramente casualisado em arranjo fatorial $2 \times 2$, tendo como fatores a presença ou ausência da hCG e a presença ou ausência do $17_{\beta}$-estradiol.

Os resultados foram analisados de acordo com a natureza específica de cada variável utilizando-se o programa SAS System for Windows (STATISTICAL ANALYSIS SYSTEM, 1993). Nos casos que os resultados não atendiam as premissas de normalidade dos resíduos e de homogeneidade das variâncias foi procedida a transformação dos dados pelas funções logarítmica ou de raiz quadrada para em seguida serem submetidos às análises apropriadas.

As variáveis contínuas foram analisadas por ANOVA com medidas repetidas no tempo pelos procedimentos GLM e MIXED do SAS. Foram variáveis independentes: $h C G, E_{2}$, vaca $\left(h C G \times E_{2}\right.$ ), dia e as interações. O procedimento $R E G$ do SAS foi usado para estimar a variação das dimensões do corpo lúteo e da concentração de progesterona em função do dia do ciclo estral.

As variáveis de natureza discreta foram submetidas a ANOVA pelo procedimento GLM do SAS, a exceção daquelas tomadas como "taxas", "freqüências" ou "ocorrências", as quais foram expressas como proporções e analisadas aplicando-se o teste do Qui-quadrado $\left(\chi^{2}\right)$ com auxílio do procedimento FREQ do SAS.

Os resultados foram apresentados na forma não-transformada como média dos quadrados mínimos ! erro padrão da média. Os efeitos das fontes de variação foram aceitos para a significância de até $5 \%$ de probabilidade $(P<0,05)$. Conceituou- 
se como tendência, quando os efeitos estiveram situados entre as probabilidades de 5 e $10 \%(0,05<P<0,10)$.

A seguir estão listadas e descritas as variáveis estudadas.

1) Variáveis Contínuas:

- diâmetro do folículo dominante da 3ª onda folicular;

- diâmetro do folículo dominante da 4ª onda folicular;

- concentração plasmática de progesterona diária;

- diâmetro do corpo lúteo (DIACL);

- área do corpo lúteo (AREACL) - obtida pela fórmula: $S=\pi r^{2}$, ou seja: $A R E A C L=$ 3,141592654 * $(\text { DIACL /2) })^{2}$

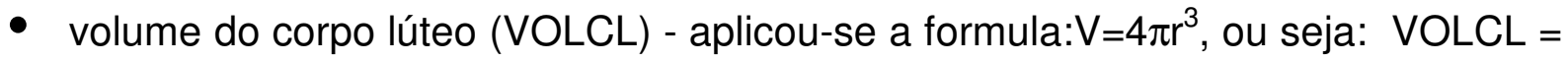
$4^{*} 3,141592654$ * $(\mathrm{DIACL} / 2)^{3}$.

2) Variáveis Discretas:

- diâmetro do folículo ovulatório sincronizado;

- diâmetro máximo do folículo dominante da 3aㅗ onda (FD3);

- dia do ciclo estral em que o FD3 atingiu o máximo diâmetro;

- concentração plasmática de progesterona no dia do diâmetro máximo do FD3;

- taxa de crescimento do FD3 - determinada pela subtração do diâmetro máximo do FD3 pelo do diâmetro $(\varnothing)$ do mesmo, no dia de surgimento desta onda $(\varnothing$ folículou $5 \mathrm{~mm}$ ), dividido pelo número de dias entre o surgimento e a obtenção do diâmetro máximo;

- diâmetro máximo do folículo dominante da 4ª onda (FD4);

- dia do ciclo estral em que o FD4 atingiu seu diâmetro máximo; 
- taxa de crescimento do FD4 - determinada pela subtração do diâmetro máximo do FD4 pelo do diâmetro $(\varnothing)$ do mesmo, no dia de surgimento desta onda $(\varnothing$ folículo $5 \mathrm{~mm}$ ), dividido pelo número de dias entre o surgimento e a obtenção do diâmetro máximo;

- diâmetro do folículo pré-ovulatório - $\varnothing$ do folículo ovulatório no dia anterior à sua ovulação (desaparecimento do folículo dominante à ultra-sonografia);

- intervalo inter-ovulatório - período em dias entre a ovulação sincronizada e a próxima ovulação;

- número de ondas foliculares;

- diâmetro máximo do corpo lúteo;

- área máxima do corpo lúteo;

- volume máximo do corpo lúteo;

- dia do ciclo estral em que ocorreu o diâmetro máximo do corpo lúteo;

- concentração plasmática de progesterona no dia do diâmetro máximo do corpo lúteo;

- diâmetro do corpo lúteo quando a concentração plasmática de progesterona foi máxima;

- área do corpo lúteo quando a concentração plasmática de progesterona foi máxima;

- volume do corpo lúteo quando a concentração plasmática de progesterona foi máxima;

- número de corpos lúteos;

- maior concentração plasmática de progesterona;

- dia do ciclo estral em que ocorreu a maior concentração de progesterona ( $\left.\mathrm{D}_{[\mathrm{P} 4] \mathrm{MAX}}\right)$; 
- concentração plasmática acumulada de progesterona - soma das concentrações plasmáticas de progesterona do dia 5 até a luteólise (definida como sendo: concentração de progesterona $([\mathrm{P} 4])<1 \mathrm{ng} / \mathrm{mL})$;

- concentração plasmática acumulada de progesterona entre a aplicação do $17_{\beta}$ estradiol (ou $D_{12}$ ) e a luteólise;

- taxa de crescimento da concentração plasmática de progesterona até o pico calculada como: $\left[\left([\mathrm{P} 4] \mathrm{D}_{[\mathrm{P} 4] \mathrm{MAX}}-[\mathrm{P} 4] \mathrm{D}_{5}\right) / \mathrm{D}_{[\mathrm{P} 4] \mathrm{MAX}}-5\right]$;

- taxa de crescimento da concentração plasmática de progesterona até a aplicação do $17_{\beta}$-estradiol (ou $\left.D_{12}\right)$ - calculada como: $\left.\left(\left[P_{4}\right]_{D 12}-\left[P_{4}\right]_{D 5}\right) / 7\right]$;

- dia da luteólise - dia do ciclo estral em que a $[\mathrm{P} 4]<1 \mathrm{ng} / \mathrm{mL}$;

- concentração plasmática média de progesterona (P4MEDIA) - é igual a soma das concentrações plasmáticas de progesterona do $D_{5}$ até a luteólise dividida pelo número de dias até a luteólise;

- diâmetro do folículo dominante no dia da luteólise;

- Intervalo entre a luteólise e o estro - número de dias decorridos entre a luteólise e a manifestação do estro;

- dia do estro;

- DOM7/13a19 - número de dias entre $D_{13}$ e $D_{19}$ do ciclo estral nos quais ocorreram folículos dominantes, em crescimento, com $\varnothing>7 \mathrm{~mm}$;

- DOM8/13a19 - número de dias entre $D_{13}$ e $D_{19}$ do ciclo estral nos quais ocorreram folículos dominantes, em crescimento, com $\varnothing>8 \mathrm{~mm}$. 
G-Controle

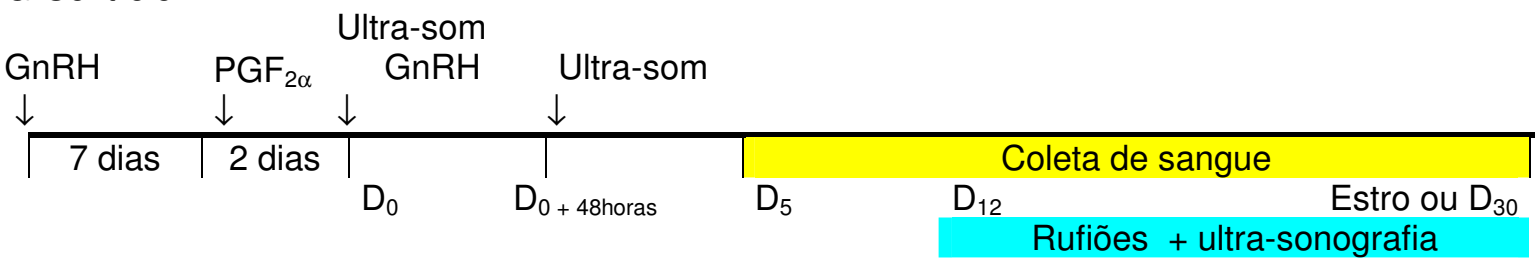

G-hCG

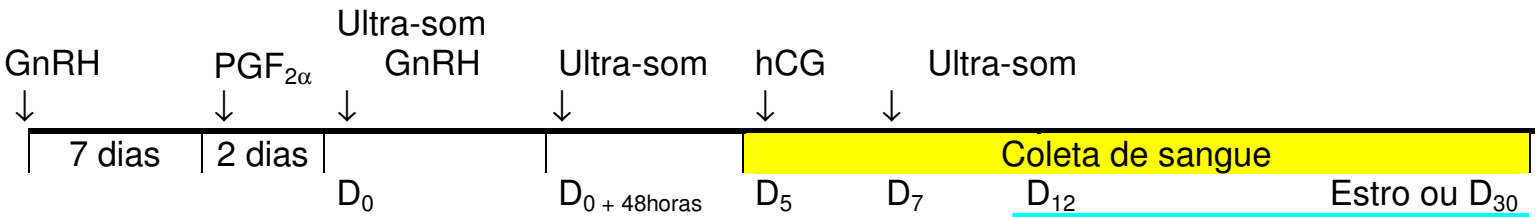
Rufiões + ultra-sonografia

$\mathrm{G}-\mathrm{E}_{2}$

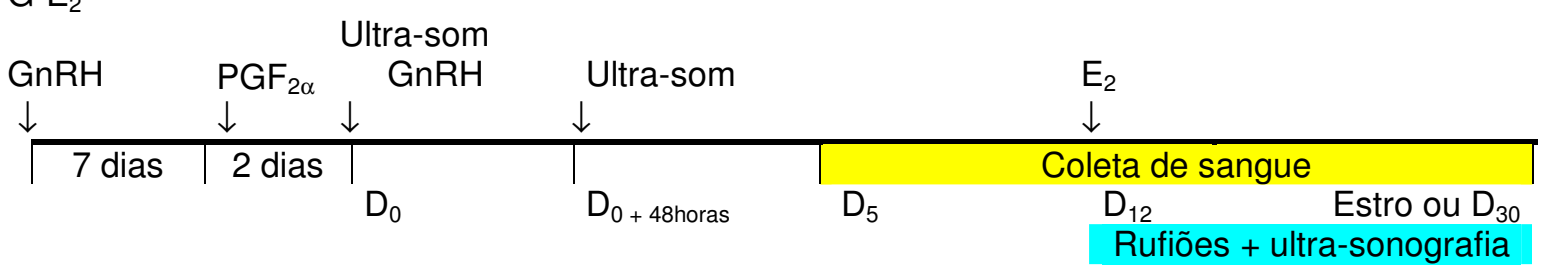

$\mathrm{G}-\mathrm{hCG} / \mathrm{E}_{2}$

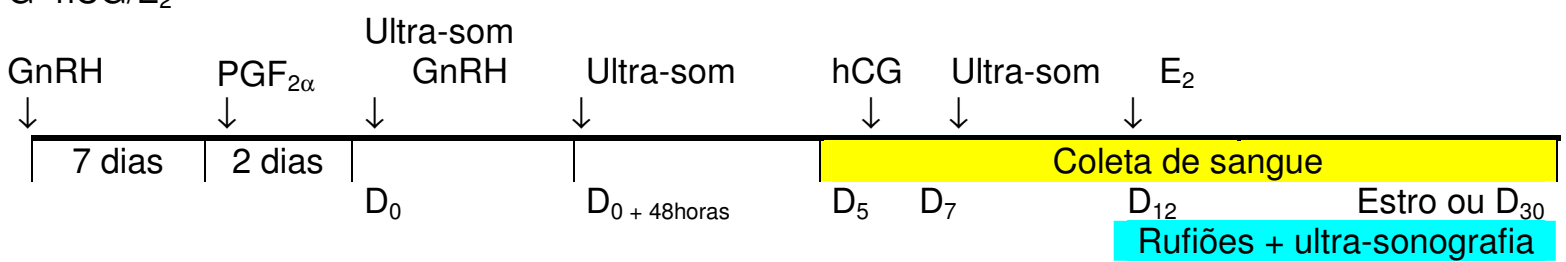

Figura 1.1 - Protocolos de administração dos tratamentos no experimento 1, São Carlos, 2004 


\subsection{RESULTADOS}

Para facilitar a apresentação dos resultados, a sua descrição foi subdivida em variáveis isoladas ou grupos de variáveis.

\subsubsection{Formação dos grupos}

Houve 17 vacas que não foram aproveitadas. Duas vacas não possuíam folículo dominante $(\phi \geq 7 \mathrm{~mm})$ à ultra-sonografia realizada no momento da segunda aplicação do $\mathrm{GnRH}$ e outras 15 delas tiveram prejudicada a emergência da $1^{\underline{a}}$ onda de crescimento folicular pois não apresentavam, ao exame ultra-sonográfico, sinais de dominância folicular no $5^{\circ}$ dia após a segunda injeção do acetato de buserelina. Portanto, o número de animais experimentais ficou totalizado em 23 vacas.

A formação definitiva dos grupos mostrou-se homogênea pois não houve efeito de grupo $(P>0,05)$ para peso vivo $(412,70 \pm 33,90 \mathrm{~kg} ; \mathrm{n}=23)$, ECC ao início do experimento $(5,47 \pm 0,48 ; n=23)$ e diâmetro do folículo pré-ovulatório sincronizado após o tratamento OvSynch $(12,19 \pm 1,20 \mathrm{~mm} ; \mathrm{n}=23)$. 


\subsubsection{Dinâmica do crescimento folicular}

Foram elaborados gráficos com a variação diária nas dimensões do diâmetro do folículo dominante de cada onda de crescimento folicular. Essas informações permitiram elaborar mapas de cada animal, os quais foram organizados por grupo experimental e estão apresentados no apêndice A, em suas figuras 1, 2, 3 e 4 para as vacas dos grupos: controle, $h C G, E_{2}$ e $h C G / E_{2}$, respectivamente. Uma vez que as ultra-sonografias iniciaram no $D_{12}$, as variáveis relativas às $1^{a}$ e $2^{a}$ ondas de crescimento folicular não foram analisadas.

\subsubsection{Número de ondas e ovulação}

Houve vacas de duas e de três ondas de crescimento folicular em todos os grupos, exceto no $G_{n c G}$. Vacas de quatro ondas ocorreram apenas nos grupos que receberam a hCG, havendo variação segundo o tratamento imposto. Entretanto, essa variação não mostrou comportamento de distribuição normal e procedeu-se a aplicação de teste não-paramétrico.

O número médio (média \pm erro padrão da média) de ondas de crescimento folicular foi de: $2,71 \pm 0,49 ; 3,40 \pm 0,89 ; 2,17 \pm 0,41$ e $2,80 \pm 0,84$ respectivamente para as vacas dos grupos controle, $h C G, E_{2}$ e $h C G / E_{2}$. A hCG tendeu $(0,10>P>0,05$,

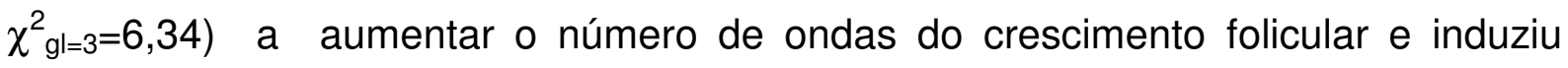
$\left(\mathrm{P}<0,05 ; \chi_{\mathrm{gl}=1}^{2}=4,19\right)$ o crescimento de uma $4^{\mathrm{a}}$ onda de crescimento folicular. 
O intervalo inter-ovulatório não diferiu $(P>0,05)$ entre os grupos e consta na tabela 1.1. Entretanto, a utilização da hCG, independentemente da associação ao $E_{2}$ aumentou $\left(P<0,01 ; \chi_{g l=1}^{2}=8,24\right)$ a proporção de vacas com intervalo entre ovulações maior que 22 dias.

3.3.4 Folículo dominante da $3^{a}$ onda de crescimento

Nenhum dos efeitos incluídos no modelo para a análise do diâmetro do folículo dominante da $3^{\mathrm{a}}$ onda mostrou ser significativo $(P>0,05)$. Em redundância, as interações também não foram significativas.

A relação entre o diâmetro do folículo dominante da $3^{\mathrm{a}}$ onda e o dia do ciclo estral gerou equações polinomiais de graus distintos, conforme o tratamento imposto. Essas equações constam na tabela 1 do apêndice $A$ e suas representações gráficas estão mostradas na figura 5 do apêndice $A$. As análises foram feitas em separado para as vacas que ovularam, ditas de "três ondas", e para aquelas as quais esse folículo dominante sofreu atresia.

A análise estatística, bem como as médias dos quadrados mínimos e errospadrão da média para as variáveis do crescimento folicular relativos à $3^{a}$ onda estão mostradas na tabela 1.1 . 
Tabela 1.1 -

Médias dos quadrados mínimos ( \pm erros-padrão da média) e análise de variância de variáveis relacionadas ao crescimento folicular em resposta ao hCG e ao $17_{\beta}$-estradiol. São Carlos, 2004

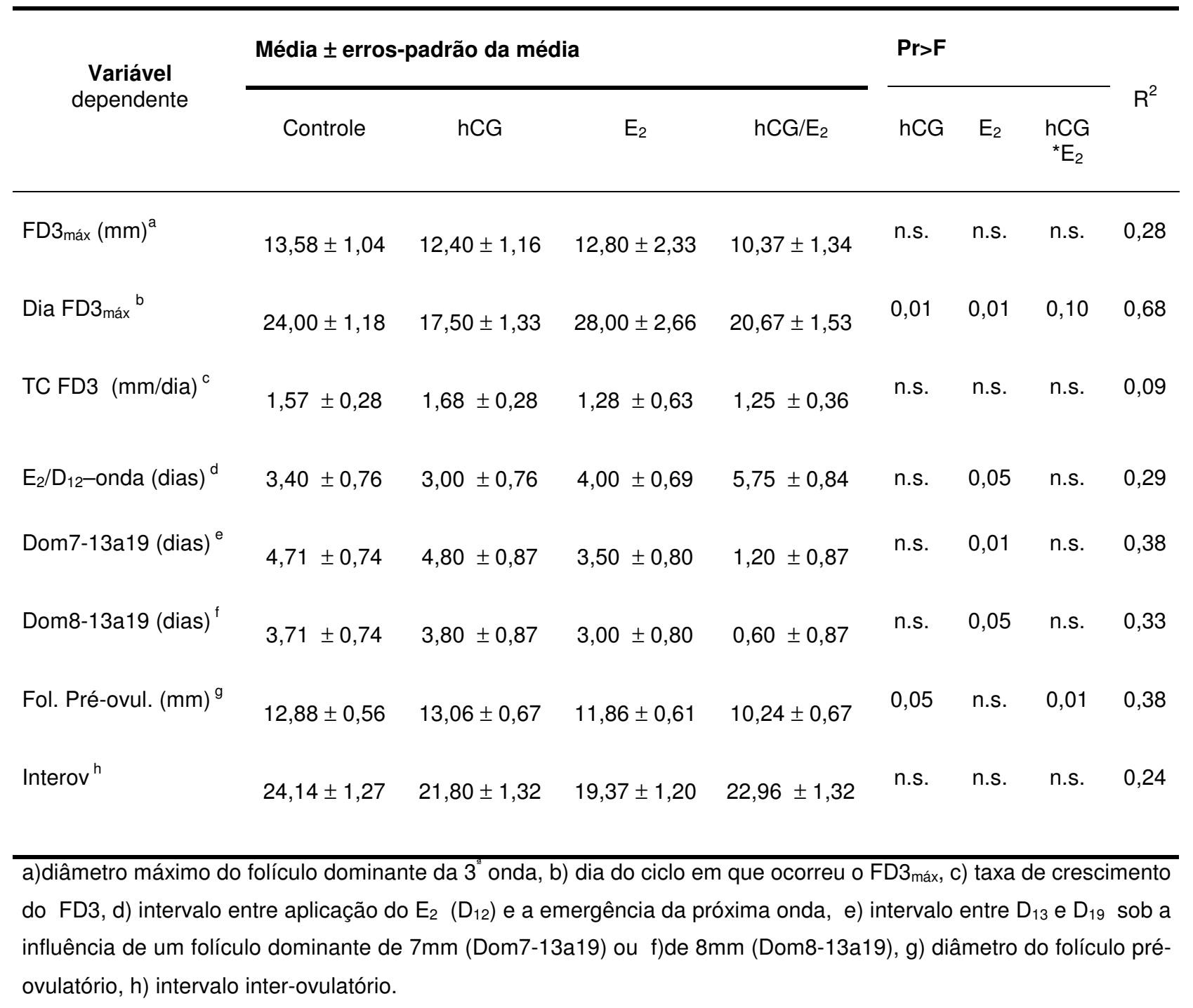


O intervalo entre $D_{12}$ e a emergência de uma nova onda de crescimento folicular consta na tabela 1.1 e a aplicação do $17_{\beta}$-Estradiol afetou esse valor

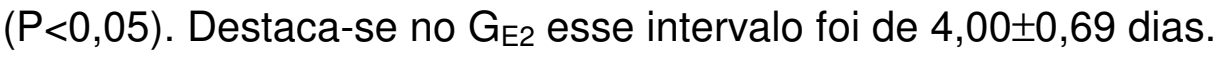

A figura 6 do apêndice A contém os gráficos da interação das médias dos fatores "hCG" e "E $E_{2}$ para as variáveis diâmetro máximo do folículo dominante da $3^{\text {a }}$ onda, dia da sua ocorrência e taxa de crescimento desse folículo.

A hCG antecipou $(\mathrm{P}<0,01)$ e o $17_{\beta}$-estradiol retardou $(\mathrm{P}<0,01) \circ$ atingimento do diâmetro máximo pelo folículo dominante dessa onda, embora as taxas de crescimento não diferiram $(P>0,05)$ entre grupos.

A totalidade das vacas dos $G_{C}$ e $G_{E 2}$, bem como a maioria das fêmeas do $\mathrm{G}_{\mathrm{hCG} / \mathrm{E} 2}$ ovulou até a $3^{\underline{a}}$ onda de crescimento folicular. Portanto a medida da concentração de progesterona plasmática no dia em que o folículo dominante da $3^{\text {a }}$ onda atingiu seu diâmetro máximo foi obtida apenas para três vacas do $\mathrm{G}_{\mathrm{hcG}}$ e uma

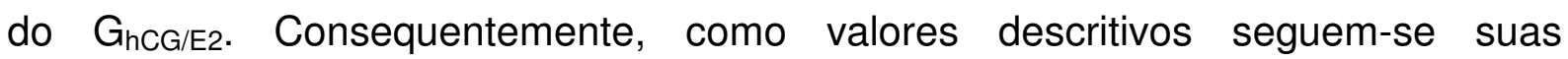

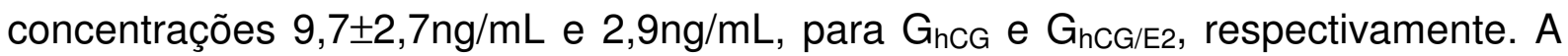
relação entre o máximo diâmetro alcançado pelo folículo dominante da $3^{\underline{a}}$ onda de crescimento ( $\phi F 3$ máx) do $\mathrm{G}_{\mathrm{hcG}}$ e a concentração de progesterona plasmática no dia

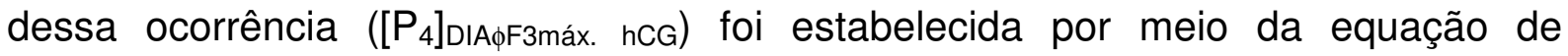
regressão a seguir.

$$
\phi F 3 \text { máx }=26,79-1,56\left[\mathrm{P}_{4}\right]_{\mathrm{DI} \text { A } \phi \text { F3máx. hCG }} \quad \mathrm{R}^{2}=0,69
$$


3.3.5 Folículo dominante da $4^{a}$ onda de crescimento

Nenhum dos efeitos incluídos no modelo para a análise do diâmetro do folículo dominante da $4^{a}$ onda mostrou ser significativo $(P>0,05)$. Em redundância, as interações também não foram significativas.

A relação entre o diâmetro do folículo dominante da $4^{a}$ onda e o dia do ciclo estral gerou equações polinomiais de $1^{0}$ grau. Essas equações e suas representações gráficas estão mostradas respectivamente na tabela 1 e na figura 5 do apêndice A. Foram usados os dados de apenas três vacas para gerar a equação

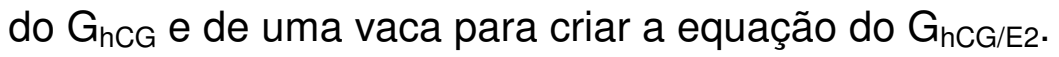

Os valores para o diâmetro máximo do folículo dominante da $4^{\mathrm{a}}$ onda foram

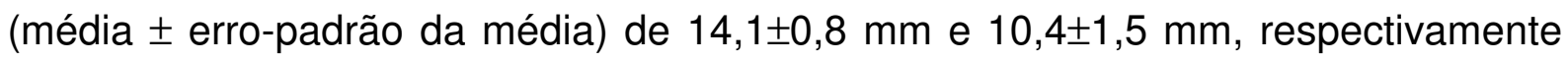
para $G_{h C G}$ e $G_{h C G / E 2}(P>0,05)$. As taxas de crescimento desse folículo não diferiram estatisticamente $(P>0,05)$ e foram de $1,35 \pm 0,30 \mathrm{~mm} /$ dia para $\circ \mathrm{G}_{\mathrm{hCG}}$ e $1,80 \pm 0,50$ $\mathrm{mm} /$ dia para o $\mathrm{G}_{\mathrm{hCG} / \mathrm{E} 2 \text {. }}$

O dia do ciclo estral no qual foi alcançado o diâmetro máximo do folículo dominante da $4^{\sharp}$ onda não apresentou distribuição normal, mesmo após transformação dos seus valores absolutos pelas funções logarítmica ou de raiz quadrada. Os seus valores (média \pm erro-padrão da média) foram de: $20,3 \pm 0,7$ ( $n=3$ ) e $29,0(n=1)$, respectivamente para $G_{h C G}$ e $G_{n C G / E 2}$. Não houve vacas de quatro ondas no $G_{C}$ e no $G_{E 2}$, não havendo então gráficos dessas variáveis. 


\subsubsection{Folículo pré-ovulatório}

A análise de variância e as médias estimadas dos quadrados mínimos e os erros-padrão da média para o diâmetro do folículo pré-ovulatório consta da tabela 1.1. Isoladamente, a fator $\mathrm{hCG}$ aumentou $(\mathrm{P}<0,05)$ o diâmetro do folículo préovulatório e em associação ao $17_{\beta}$-estradiol ela diminuiu $(P<0,01)$ essa mediada. No apêndice $A$ encontra-se, em sua figura 7, o gráfico da interação $(P<0,05)$ das médias dos fatores "hCG" e "E" para o diâmetro do folículo pré-ovulatório.

\subsubsection{Dinâmica luteínica}

A dinâmica luteínica para $\circ \mathrm{G}_{c}$ esta mostrada na figura 8 do apêndice $A$. Analogamente, a dinâmica das vacas do $G_{h C G}, G_{E 2}$ e $G_{h C G / E 2}$ esta apresentada respectivamente nas Figuras 9, 10 e 11 do apêndice A. Nessas figuras estão mostrados apenas os dados relativos às cinco vacas de cada grupo que também haviam sido submetidas à dosagem da progesterona plasmática.

Nenhuma das vacas do $\mathrm{G}_{\mathrm{c}}$ apresentou corpo lúteo acessório. Por outro lado,

todos animais tratados com hCG ( $G_{h C G}$ e $\left.G_{h C G / E 2}\right)$ e duas fêmeas do $G_{E 2}$ desenvolveram corpo lúteo acessório. 
3.3.8 Medidas do corpo lúteo e concentração da progesterona plasmática

As médias diárias para o diâmetro, para a área e para o volume do corpo lúteo em cada grupo estão respectivamente nas tabelas 2,3 e 4 do apêndice $A$. Além disso, as médias diárias para o volume do corpo lúteo em cada grupo foram plotadas no gráfico da figura 1.2.

$O$ fator $E_{2}$ e a interação $h C^{*}$ dia afetaram significativamente $(P<0,05)$ os valores do volume do corpo lúteo. Analogamente, o efeito da interação $E_{2}^{*}$ dia foi altamente significativo $(\mathrm{P}<0,01)$.

A relação entre o diâmetro, a área ou o volume do corpo lúteo e o dia do ciclo estral (D) gerou equações polinomiais de graus distintos. Essas equações e suas representações gráficas constam no apêndice A, nas figuras 12, 13 e 14, respectivamente.

A análise estatística e as médias dos quadrados mínimos e os erros-padrão da média para as variáveis discretas relativas às dimensões do corpo lúteo estão mostradas na tabela 1.2. A hCG aumentou $(P<0,05)$ todas dimensões do corpo lúteo.

A variável número de corpos lúteos não atendeu as premissas de normalidade, mesmo após transformações pelas funções logarítmica e de raiz quadrada. Assim, as médias e erros-padrão da média para o número de corpos

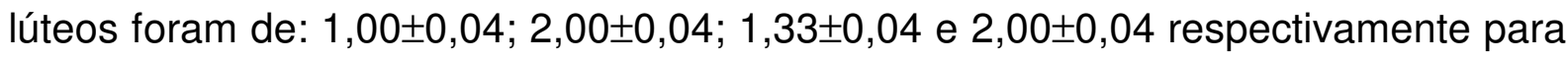
a $G_{C}, G_{h C G}, G_{E 2}$ e $G_{h C G / E 2}$. 


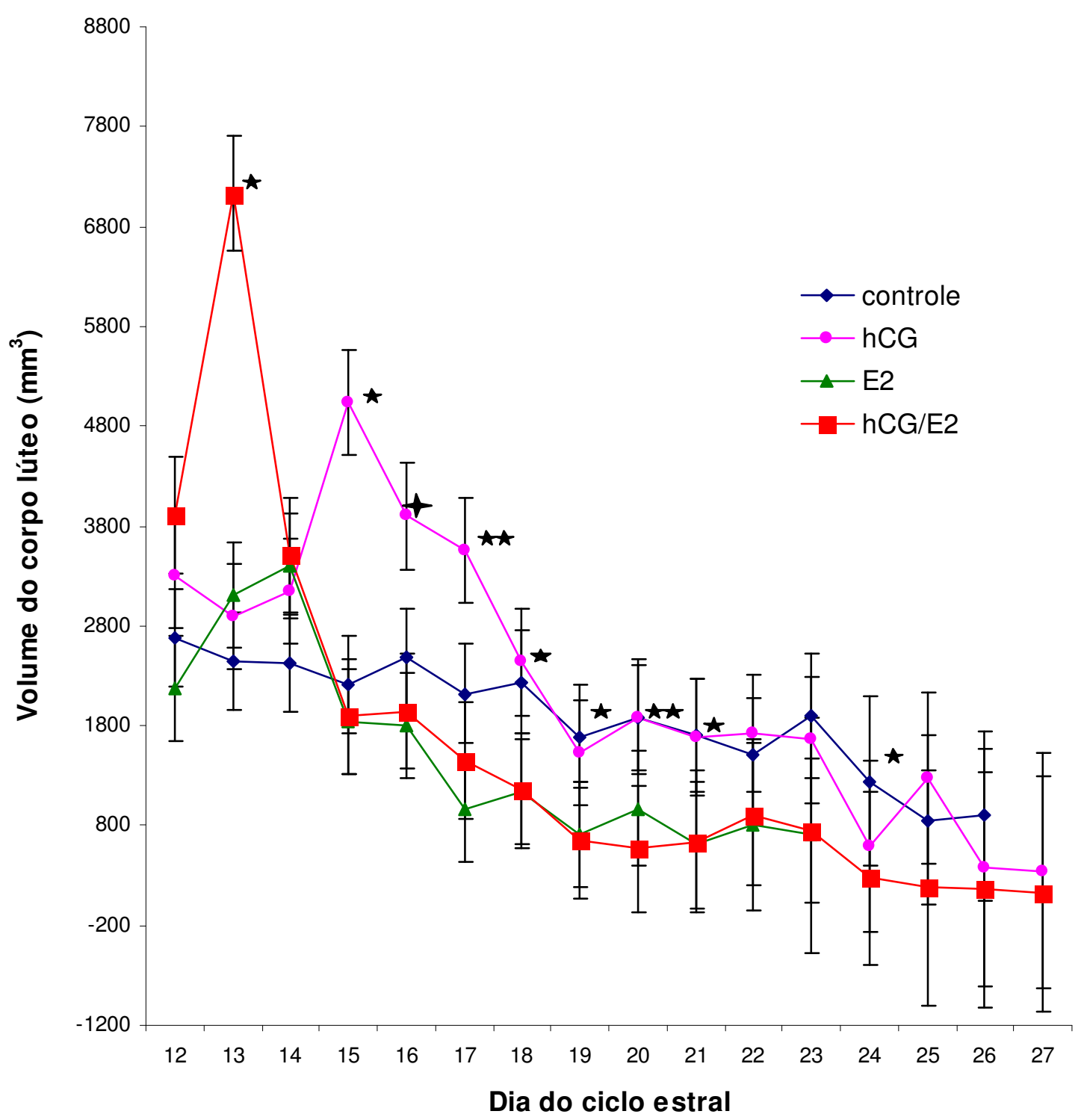

Figura 1.2 - Médias dos quadrados mínimos e erros-padrão da média para volume do corpo lúteo $\left(\mathrm{mm}^{3}\right)$ ao longo do ciclo estral para os diferentes grupos experimentais. Médias em mesmo dia diferem estatisticamente se: $t(0,10<\mathrm{P}<0,05) ; ;^{\star}(\mathrm{P}<0,05) \mathrm{e}^{\star \star}(\mathrm{P}<0,01)$. São Carlos, 2004 
Tabela 1.2 - Médias dos quadrados mínimos ( \pm erros-padrão da média) e análise de variância de variáveis

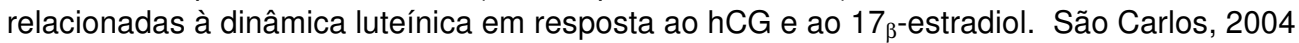

\begin{tabular}{|c|c|c|c|c|c|c|c|c|}
\hline \multirow{2}{*}{$\begin{array}{c}\text { Variável } \\
\text { dependente }\end{array}$} & \multicolumn{4}{|c|}{ Média \pm erros-padrão da média } & \multicolumn{3}{|l|}{$\operatorname{Pr}>F$} & \multirow{2}{*}{$\mathrm{R}^{2}$} \\
\hline & Controle & hCG & $\mathrm{E}_{2}$ & $\mathrm{hCG} / \mathrm{E}_{2}$ & $\mathrm{HCG}$ & $E_{2}$ & $\begin{array}{c}\mathrm{hCG} \\
{ }^{*} \mathrm{E}_{2} \\
\end{array}$ & \\
\hline 2 MáxCL (mm) ${ }^{a}$ & $18,21 \pm 1,11$ & $21,80 \pm 1,32$ & $19,37 \pm 1,20$ & $22,96 \pm 1,32$ & 0,01 & n.s. & n.s. & 0,33 \\
\hline ÁreaMáxCL $\left(\mathrm{mm}^{2}\right)^{\mathrm{b}}$ & $262 \pm 37$ & $375 \pm 44$ & $296 \pm 40$ & $439 \pm 44$ & 0,01 & n.s. & n.s. & 0,37 \\
\hline VolMáxCL $\left(\mathrm{mm}^{3}\right)^{\mathrm{c}}$ & $3226 \pm 879$ & $5535 \pm 1040$ & $3878 \pm 950$ & $7299 \pm 1040$ & 0,01 & n.s. & n.s. & 0,35 \\
\hline Dia ao 2 MáxCL $^{d}$ & $14,42 \pm 0,64$ & $13,80 \pm 0,76$ & $13,67 \pm 0,69$ & $13,40 \pm 0,76$ & 0,05 & 0,10 & n.s. & 0,55 \\
\hline 2CL[P $\left.\mathrm{P}_{4}\right] \operatorname{máx}(\mathrm{mm})^{\mathrm{e}}$ & $15,48 \pm 1,38$ & $18,76 \pm 1,38$ & $15,86 \pm 1,38$ & $19,00 \pm 1,38$ & 0,05 & n.s. & n.s. & 0,25 \\
\hline S CL[P $\left.\mathrm{P}_{4}\right]$ máx $\left(\mathrm{mm}^{2}\right)^{\mathrm{f}}$ & $191 \pm 141$ & $750 \pm 141$ & $273 \pm 141$ & $594 \pm 141$ & 0,01 & n.s. & n.s. & 0,39 \\
\hline V CL[P $\left[\mathrm{P}_{4}\right]$ máx $\left(\mathrm{mm}^{3}\right)^{\mathrm{g}}$ & $2020 \pm 4310$ & $16493 \pm 4310$ & $3760 \pm 4310$ & $13075 \pm 4310$ & 0,01 & n.s. & n.s. & 0,33 \\
\hline
\end{tabular}

a) diâmetro (2 MáxCL), b) área (ÁreaMáxCL), c) volume (VolMáxCL) máximos do corpo lúteo (CL), d) dia do ciclo estral em que o CL atingiu seu diâmetro máximo (Dia ao 2 MáxCL), e) diâmetro do $\mathrm{CL}($ (2CL[P 4 ]máx), f) área do $C L$ (S CL[ $\left.\mathrm{P}_{4}\right]$ máx) e g) volume do $C L$ quando $\left[\mathrm{P}_{4}\right]$ foi máxima (V CL[ $\left.\mathrm{P}_{4}\right]$ máx). 
A figura 15 do apêndice A contém a representação gráfica da interação $(P>0,05)$ entre as médias para concentração da progesterona no dia em o corpo lúteo atingiu suas medidas máximas. No apêndice A encontram-se os gráficos das médias dos fatores "hCG" e " $E_{2}$ " para as variáveis diâmetro máximo do corpo lúteo, área máxima do corpo lúteo e volume máximo do corpo lúteo (Figura 16 do apêndice A), número de corpos lúteos (Figura 17 do apêndice A). A interação entre os fatores não foi significativa $(P>0,05)$ para essas variáveis.

O estudo das variações da concentração de progesterona plasmática ao longo do ciclo estral necessitou uma avaliação em dois momentos distintos, pois entre $D_{5}$ e $D_{12}$ havia apenas o efeito de um dos fatores (hCG). A partir do $D_{12}$ podese analisar os efeitos do fator $E_{2}$. A figura 1.3 contém os valores médios (quadrados mínimos) e os erros padrão da média para os grupos experimentais plotados num gráfico.

Analogamente, foram determinadas as equações polinomiais para estimativa da concentração de progesterona plasmática em função do dia do ciclo estral para cada grupo experimental. As equações de regressão e sua representação gráfica constam da figura18 do apêndice A. Em adição foi elaborado um gráfico com valores médios (quadrados mínimos) e os erros padrão da média para os quatro grupos experimentais, desconsiderando que os efeitos do $E_{2}$ iniciaram após $D_{12}$. Esse gráfico está apresentado na Figura 19 do apêndice A. As médias diárias (quadrados mínimos) e os erros-padrão da média para a concentração plasmática de progesterona estão na tabela 5 do Apêndice $A$. Uma vez que o fator " $E_{2}$ " foi administrado apenas no $D_{12}$, foram tomadas médias em separado para os efeitos da hCG e os valores encontrados estão na tabela 6 do apêndice A. 


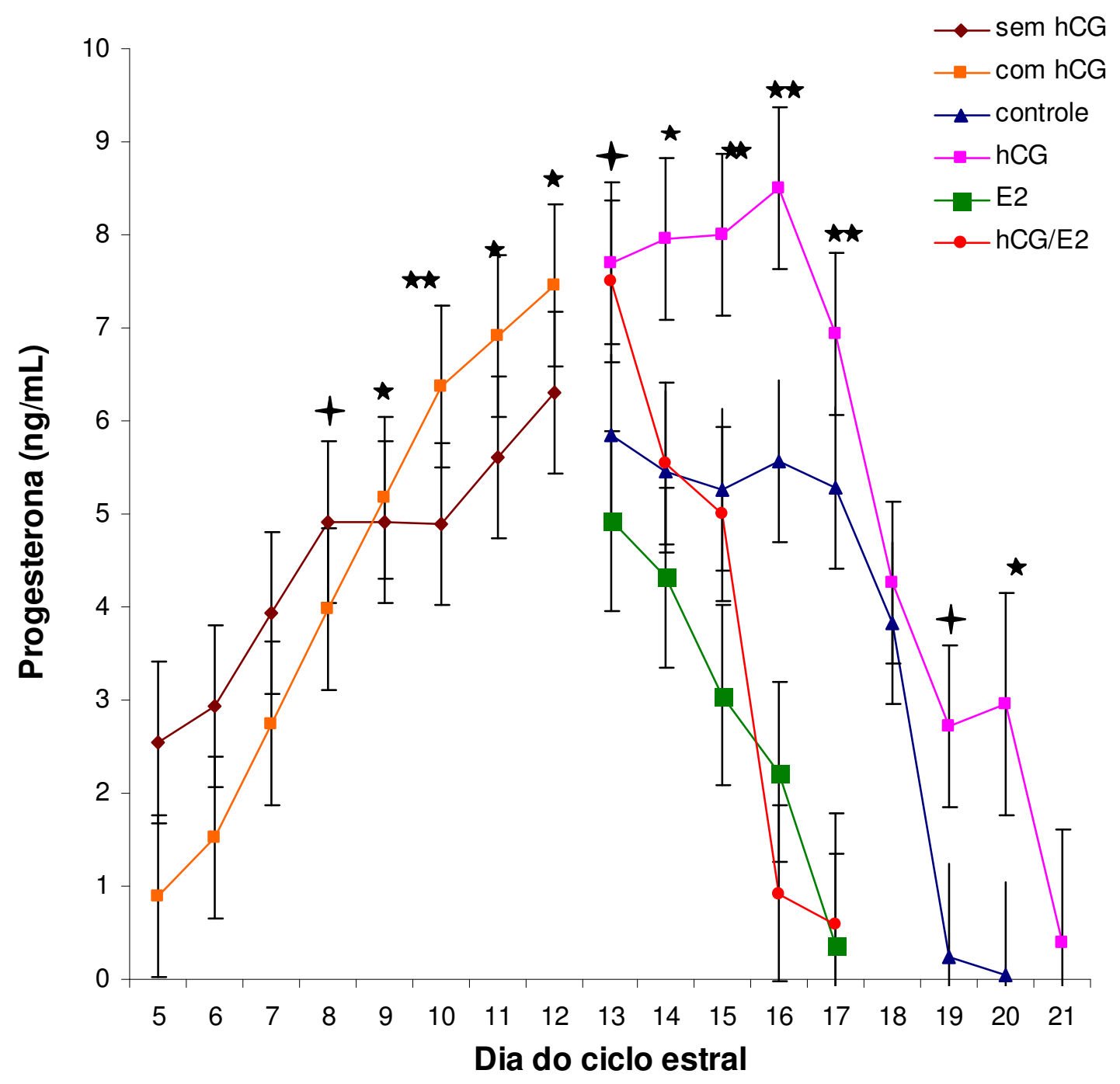

Figura 1.3 - Médias dos quadrados mínimos e erros-padrão da média para concentração plasmática de progesterona $(\mathrm{ng} / \mathrm{mL})$ ao longo do ciclo estral para os grupos: sem hCG ("ovsynch") e com hCG ("ovsynch" + 3000 Ul de hCG no $D_{5}$ ) entre $D_{5}$ e $D_{12}$ e para todos grupos experimentais de $D_{13}$ até $D_{21}$. Médias em mesmo dia diferem estatisticamente se: $\rightarrow(0,10<P<0,05) ; \star \quad(P<0,05)$ e $\star \star(P<0,01)$. São Carlos, 2004 
As variáveis discretas relacionadas à concentração da progesterona plasmática estão mostradas na tabela 1.3.

A hCG induziu às maiores taxas de crescimento da concentração plasmática de progesterona, tanto entre $D_{5}$ e $D_{12}(P<0,01)$, como entre $D_{5}$ e o dia da maior

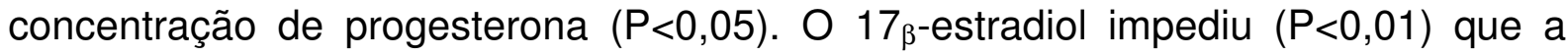
concentração máxima da progesterona fosse alcançada além do $D_{12}$ (Tabela 1.3) e portanto a concentração plasmática da progesterona acumulada também foi menor $(P<0,01)$ para $G_{E 2}$ e $G_{n C G / E 2}$.

Como o fator " $E_{2}$ " foi administrado apenas no $D_{12}$, também foram tomadas médias para os efeitos da hCG e a taxa de crescimento da concentração plasmática da progesterona foi significativamente $(P<0,05)$ mais alta $(1,04 \pm 0,11 \mathrm{ng} / \mathrm{mL} / \mathrm{dia})$ para as vacas que receberam hCG do que para aquelas que não a receberam $(0,63 \pm 0,11$ ng/mL/dia). Na tabela 1.4 estão os valores para as concentrações plasmáticas de progesterona: máxima, média e acumulada (entre $\mathrm{D}_{5}$ e a luteólise).

\subsubsection{Folículo dominante durante o período crítico}

Na análise feita sobre o número de dias no período crítico sob influência de um folículo dominante foram consideradas as seguintes situações: o dominante possuir diâmetro maior ou igual a $7 \mathrm{~mm}$ ou possuir diâmetro maior ou igual a $8 \mathrm{~mm}$. Além disso, considerou-se como período crítico para o reconhecimento da prenhez o limite temporal do ciclo estral compreendido entre $D_{13}$ e $D_{19}$. A análise estatística e os seus valores (média dos quadrados mínimos e erros-padrão da média) constam 
na tabela 1.1. Para as duas dimensões, o efeito do $17_{\beta}$-estradiol foi significativo em reduzir o número de dias sob influência do dominante. A maior redução ocorreu

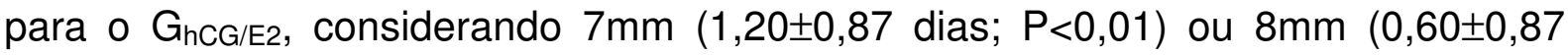
dias; $\mathrm{P}<0,05)$ como medidas mínimas do dominante.

\subsubsection{Luteólise e estro}

A análise estatística e os valores (média dos quadrados mínimos e errospadrão da média) para o dia da ocorrência do estro e da luteólise, o intervalo entre a luteólise e a manifestação do estro, bem como para o diâmetro do folículo dominante à luteólise constam na tabela 1.5. $\mathrm{O} 17_{\beta}$-estradiol antecipou $(\mathrm{P}<0,01)$ a luteólise e esse efeito foi amplificado pelo tratamento prévio com $h C G$ ( $\left.G_{h C G / E 2}\right)$, pois a interação foi significativa $(P<0,05)$ como mostrado na figura 20 do apêndice $A$. 
Tabela 1.3 - Médias dos quadrados mínimos ( \pm erros-padrão da média) e análise de variância de variáveis relacionadas à concentração plasmática da progesterona em resposta ao hCG e ao $17_{\beta}$-estradiol. São Carlos, 2004

\begin{tabular}{|c|c|c|c|c|c|c|c|c|}
\hline \multirow{2}{*}{$\begin{array}{c}\text { Variável } \\
\text { dependente }\end{array}$} & \multicolumn{4}{|c|}{ Médias \pm erros-padrão da média } & \multicolumn{3}{|l|}{$\operatorname{Pr}>F$} & \multirow{2}{*}{$\mathrm{R}^{2}$} \\
\hline & Controle & hCG & $E_{2}$ & $\mathrm{hCG} / \mathrm{E}_{2}$ & hCG & $E_{2}$ & $\begin{array}{l}\mathrm{hCG} \\
{ }^{*} \mathrm{E}_{2} \\
\end{array}$ & \\
\hline Dia $\left[\mathrm{P}_{4}\right]$ máxima $^{\mathrm{a}}$ & $13,40 \pm 0,58$ & $15,20 \pm 0,58$ & $12,00 \pm 0,58$ & $11,20 \pm 0,58$ & n.s. & 0,01 & 0,05 & 0,63 \\
\hline $\begin{array}{c}\mathrm{TC}\left[\mathrm{P}_{4}\right] \mathrm{D}_{5}-\mathrm{D}_{12} \\
(\mathrm{ng} / \mathrm{mL} / \mathrm{dia})^{\mathrm{b}}\end{array}$ & $0,54 \pm 0,14$ & $0,94 \pm 0,14$ & $0,59 \pm 0,14$ & $1,00 \pm 0,14$ & 0,01 & n.s. & n.s. & 0,36 \\
\hline $\begin{array}{c}\mathrm{TC}\left[\mathrm{P}_{4}\right] \mathrm{D}_{5}-\left[\mathrm{P}_{4}\right]_{\mathrm{máx}} \\
(\mathrm{ng} / \mathrm{mL} / \mathrm{dia})^{\mathrm{c}}\end{array}$ & $0,59 \pm 0,16$ & $0,86 \pm 0,16$ & $0,66 \pm 0,16$ & $1,22 \pm 0,16$ & 0,05 & n.s. & n.s. & 0,37 \\
\hline $\begin{array}{l}\otimes\left[P_{4}\right] E_{2}-l i s e \\
(n g / m L)^{d}\end{array}$ & $34,86 \pm 6,71$ & $54,56 \pm 6,71$ & $24,18 \pm 6,71$ & $24,78 \pm 6,71$ & n.s. & 0,01 & n.s. & 0,45 \\
\hline $\begin{array}{l}\text { a) dia do ciclo estral } \\
{\left[P_{4}\right] \text { entre } D_{5} \text { e } D_{12} \text {, }} \\
\text { das }\left[P_{4}\right] \text { s entre } D_{12}\end{array}$ & $\begin{array}{l}\text { ue a concentr } \\
\text { taxa de cresc }\end{array}$ & $\begin{array}{l}\text { ão plasmática } \\
\text { ento da }\left[\mathrm{P}_{4}\right] \mathrm{e} \\
\mathrm{E}_{2} \text {-lise). }\end{array}$ & $\begin{array}{l}\text { progesterol } \\
\text { e entre } D_{5} \mathrm{e}\end{array}$ & $\begin{array}{l}\left.\left(\mathrm{P}_{4}\right]\right) \text { foi máx } \\
\text { náxima }\left[\mathrm{P}_{4}\right]\end{array}$ & $\begin{array}{l}\mathrm{a}, \mathrm{b}) \mathrm{t} \\
\mathrm{C}\left[\mathrm{P}_{4}\right]\end{array}$ & $\begin{array}{l}\mathrm{a} \mathrm{de} \mathrm{Cr} \\
-\left[\mathrm{P}_{4}\right] \mathrm{n}\end{array}$ & $\begin{array}{l}\overline{\text { escim }} \\
\text { áx), c }\end{array}$ & $\begin{array}{l}\overline{\text { nto da }} \\
\text { Soma }\end{array}$ \\
\hline
\end{tabular}


Tabela 1.4 - Médias dos quadrados mínimos e erros-padrão da média para os valores máximo, médio (entre $D_{5}$ e a luteólise) e acumulado (entre $D_{5}$ até a luteólise) da concentração de progesterona plasmática $\left(\left[\mathrm{P}_{4}\right]\right)$ considerando-se a administração da hCG. São Carlos, 2004

\begin{tabular}{ccc}
\hline & \multicolumn{2}{c}{ Grupo $^{1}$} \\
\cline { 2 - 3 } & Sem HcG & Com hCG \\
& & \\
& & \\
Máxima $\left[\mathrm{P}_{4}\right]$ & & $9,54 \pm 2,65$ \\
$(\mathrm{ng} / \mathrm{mL})$ & & \\
Média $\left[\mathrm{P}_{4}\right]$ & & \\
$(\mathrm{ng} / \mathrm{mL})$ & $4,35 \pm 1,72$ & \\
& & \\
Acumulada $\left[\mathrm{P}_{4}\right]$ & $55,78 \pm 13 \pm 1,32$ \\
$(\mathrm{ng} / \mathrm{mL})$ & & $75,58 \pm 18,78$
\end{tabular}

1. Sem hCG = vacas Nelore sincronizadas pelo método "ovsynch"; Com hCG = vacas Nelore sincronizadas pelo método "ovsynch", recebendo $3000 \mathrm{UI}$ da hCG no $\mathrm{D}_{5}$. 
Tabela 1.5 - Médias dos quadrados mínimos ( \pm erros-padrão da média) e análise de variância de variáveis relacionadas ao estro e à luteólise em resposta ao hCG e ao $17_{\beta}$-estradiol. São Carlos, 2004

\begin{tabular}{|c|c|c|c|c|c|c|c|c|}
\hline \multirow{2}{*}{$\begin{array}{c}\text { Variável } \\
\text { dependente }\end{array}$} & \multicolumn{4}{|c|}{ Médias e erros-padrão da média para } & \multicolumn{3}{|c|}{$\operatorname{Pr}>\mathrm{F}$} & \multirow{2}{*}{$\mathrm{R}^{2}$} \\
\hline & Controle & hCG & $\mathrm{E}_{2}$ & $\mathrm{hCG} / \mathrm{E}_{2}$ & hCG & $E_{2}$ & $\begin{array}{l}\mathrm{hCG} \\
{ }^{*} \mathrm{E}_{2} \\
\end{array}$ & \\
\hline Dia da luteólise ${ }^{a}$ & $18,20 \pm 0,57$ & $19,80 \pm 0,57$ & $17,00 \pm 0,57$ & $16,00 \pm 0,57$ & n.s & 0,01 & 0,05 & 0,61 \\
\hline Inter Lise-Cio (dias) ${ }^{\mathrm{b}}$ & $3,67 \pm 1,32$ & $3,25 \pm 1,14$ & $3,50 \pm 1,61$ & $5,00 \pm 1,32$ & n.s & n.s. & n.s. & 0,12 \\
\hline Dom na lise $(\mathrm{mm})^{c}$ & $9,60 \pm 1,75$ & $8,64 \pm 1,75$ & $7,86 \pm 1,75$ & $5,50 \pm 1,75$ & n.s & 0,10 & n.s. & 0,24 \\
\hline Dia do estro ${ }^{d}$ & $23,40 \pm 1,38$ & $23,25 \pm 1,54$ & $19,33 \pm 1,78$ & $21,67 \pm 1,78$ & n.s & n.s. & n.s. & 0,26 \\
\hline
\end{tabular}

a)Dia do ciclo estral que ocorreu a luteólise $\left(\left[\mathrm{P}_{4}\right]<1 \mathrm{ng} / \mathrm{mL}\right)$, b) Intervalo entre a luteólise e a manifestação do estro, c) diâmetro do folículo dominante à luteólise, d) dia da ocorrência do estro. 


\subsection{DISCUSSÃO}

O protocolo OvSynch tem por base fisiológica a capacidade do $\mathrm{GnRH}$ induzir a ovulação ou a luteinização do folículo dominante e a emergência de uma nova onda de crescimento, dois dias depois. A $\mathrm{PGF}_{2 \alpha}$ deve promover a luteólise sete dias depois e uma segunda aplicação de $\mathrm{GnRH}$ induz uma nova liberação de LH e a sincronização da ovulação do novo folículo dominante (BÓ et al., 2002).

O aproveitamento inicial dos animais eqüivale à taxa de ovulação sincronizada, a qual foi de $62,5 \%$ neste experimento. Este percentual esteve abaixo dos valores recentemente reportados (entre $70,0 \%$ e 76,0\%) para vacas Nelore após sincronização da ovulação com progestágenos (MARQUES et al., 2003; SÁ FILHO et al. 2004) com ou sem adição de gonadotrofina coriônica eqüina ao protocolo (BERGAMASCHI, 2005). Após revisão, Baruselli et al. (2004a) implicaram falhas na ovulação após a $1^{a}$ aplicação de GnRH como causadoras do insucesso do protocolo para vacas de corte. Castilho et al. (1997) já haviam apontado esta limitação e Kastelic e Mapletoft (1998) concluíram que podem ocorrer falhas na ovulação com o protocolo OvSynch dependendo do estádio de desenvolvimento do folículo dominante no momento da aplicação do GnRH.

Além disso, a sincronização da ovulação após a $2^{\mathrm{a}}$ dose do $\mathrm{GnRH}$ depende da efetiva ocorrência da luteólise após a aplicação da $\mathrm{PGF}_{2 \alpha}$. Para Pinheiro et al. (1998) pode ocorrer luteólise parcial ou incompleta em vacas Nelore que recebem $\mathrm{PGF}_{2 \alpha}$ exógena. Tal fenômeno havia sido relatado para fêmeas zebuínas de outras raças por Edvquist et al. (1975) e Voh et al. (1987). Mais recentemente, Youngs et al. (2004) verificaram a baixa eficiência em manifestação do estro após o uso de 
diferentes formulações da $\mathrm{PGF}_{2 \alpha}$ aplicadas pela via intramuscular ou pela via intravulvar. Fernandes et al. (1997) relataram taxas de concepção tão baixas quanto 25\% para vacas Nelore sincronizadas pelo OvSynch, mesmo após a confirmação da presença de um corpo lúteo em $89 \%$ das fêmeas no momento da injeção de $\mathrm{PGF}_{2 \alpha}$.

Para Mann (2001) um fator adicional que pode induzir falhas na ovulação é o estresse proporcionado aos animais pelas movimentações e manipulações experimentais, bem como pelo re-arranjo hierárquico imposto quando da formação de novos grupos de animais. Além disso, os procedimentos cotidianos como contenção em brete podem elicitar importante aumento no Cortisol circulante por toda a duração da tarefa (THUN et al., 1998), indicando que as vacas são susceptíveis aos agentes estressores. A ocorrência de ovulações tardias em conseqüência de um atraso no pico pré-ovulatório do LH é o quadro típico de fêmeas submetidas a fatores estressores moderados (DOBSON; SMITH, 1998) e pode ter diminuído a taxa de ovulações síncronas $(62,5 \%)$ verificada neste experimento.

A maioria dos ciclos de vacas zebuínas possui duas ou três ondas de crescimento folicular. Para vacas de raça Nelore, Barros et al. (1995) e Figueiredo et al. (1997) encontraram respectivamente, 90,0\% e 83,3\% de ciclos com duas ondas. Opostamente, Bergamaschi (2005) contabilizou 71,8\% de ciclos com três ondas para vacas Nelore após sincronização da ovulação com progestágenos.

A ocorrência de duas ou três ondas pode regular a fertilidade após a inseminação artificial. Baseados em taxas de concepção, Ahmad et al. (1997) haviam lançado a hipótese que nas vacas de três ondas o mecanismo antí-luteolítico é mais favorecido. Com efeito, Diaz et al. (1998) relataram que novilhas com duas ondas tiveram um folículo potencialmente estrogênico (diâmetro $\geq 10 \mathrm{~mm}$ ) já no dia 
13,5 do ciclo estral e que naquelas de três ondas esta ocorrência se deu quase quatro dias depois. Para Mihm et al. (1999) e para Towson et al. (2002) as taxas de concepção mais altas verificadas nas vacas de três ondas decorrem de um menor intervalo para desenvolvimento do folículo ovulatório. Por sua vez, Ginther et al. (1989a, 1989b) responsabilizaram a regressão tardia do corpo lúteo. Ambos mecanismos provêm maior oportunidade para o reconhecimento materno da prenhez.

No presente experimento, a hCG tendeu a aumentar o número médio de ondas de crescimento folicular por ciclo. Resultado análogo havia sido obtido por Sianangama e Rajamahendran (1996). Em estudos anteriores, a duração do ciclo estral não diferiu entre vacas de duas ou de três ondas (DIAZ et al., 1998; FIGUEIREDO et al., 1997; NOGUEIRA et al., 2004; SANTOS et al., 1998; SIANANGAMA; RAJAMAHENDRAN, 1996; VIANA et al., 1998; VIANA et al., 2000; ZEITOUN et al., 1996). Analogamente, o intervalo inter-ovulatório também não foi diferente para vacas de duas ou de três ondas (SIANANGAMA; RAJAMAHENDRAN, 1996; ZEITOUN et al., 1996). Em oposição, Ginther et al. (1989b), Rhodes et al. (1995) e Figueiredo et al. (1997) verificaram estreita correlação entre número de ondas e duração do intervalo inter-ovulatório.

Portanto, a cronologia dos eventos da luteólise deve ocorrer de maneira similar entre vacas de duas ou de três ondas (DIAZ et al., 1998; SIANANGAMA; RAJAMAHENDRAN, 1996; ZEITOUN et al., 1996).

No presente experimento, a ocorrência de ciclos com quatro ondas de crescimento folicular foi induzida $(P<0,05)$ pela $h C G$. Tal fenômeno, considerado raro em vacas Nelore (BÓ et al., 2002) é expontâneo em vacas de outras raças zebuínas e atingiu freqüências de 6,8\% para novilhas Brahman (RHODES et al., 
1995), 9,0\% para vacas Brahman (ZEITOUN et al., 1996), 26,7\% para vacas Gir (VIANA et al., 1998; VIANA et al., 2000) e 12,5\% (1/8) para vacas Guzerá (NOGUEIRA et al., 2004). O mecanismo para a indução de uma onda de crescimento folicular adicional pode estar relacionado não só à ovulação do folículo dominante da $1^{\underline{a}}$ onda, mas também pode ter sido o resultado de alteração das influências endócrinas sobre o eixo hipotálamo-hipófise-ovários. A elevação contínua nas concentrações plasmáticas de progesterona das vacas que receberam hCG pode ter diminuído a liberação do $\mathrm{GnRH}$ por retroalimentação negativa ao hipotálamo, levando a menor liberação de LH e FSH. Assim, ocorreria a atresia precoce do folículo dominante, possibilitando um recrutamento adicional e um ciclo de quatro ondas.

A ocorrência de uma $4^{a}$ onda de crescimento folicular têm resultado em maior duração do ciclo estral (SALFEN et al., 1999; ZEITOUN et al., 1997) embora no presente experimento este achado não se repetiu, uma vez que apenas quatro vacas tratadas com hCG tiveram quatro ondas. Barros et al. (1995) e Figueiredo et al. (1997) haviam relatado freqüência maior de vacas Nelore com ciclos de duas ondas do que de três ondas. Nesse caso, cumpre lembrar que tanto o intervalo inter-ovulatório como a duração do ciclo estral não difere entre vacas de duas e de três ondas.

O intervalo inter-ovulatório observado neste experimento não foi afetado $(P>0,05)$ pelos fármacos aplicados, embora a aplicação da hCG promoveu uma tendência $(P<0,10)$ para aumentar o número de vacas com intervalos superiores aos 22 dias. Em verdade, muitos autores (BERGAMASCHI, 2005; FIGUEIREDO et al., 1997; RANDEL et al., 1984; RHODES et al., 1995) relataram intervalos menores que 22 dias para fêmeas zebuínas. 
Havia a expectativa de que os grupos tratados apresentariam intervalos interovulatórios maiores que o do controle. Entretanto, apesar de todas as dez fêmeas que receberam a hCG terem ovulado o folículo dominante da $1^{\text {a }}$ onda com a formação de um corpo lúteo acessório, apenas quatro delas mostraram uma $4^{\underline{a}}$ onda de crescimento, insuficiente para modificar as médias para intervalo inter-ovulatório. Por sua vez, era esperado que a aplicação do $17_{\beta}$-estradiol no $12^{\circ}$ dia do ciclo estral poderia reprogramar a função ovariana ao causar a atresia do folículo dominante. Como conseqüência haveria o aumento no número de ondas de crescimento folicular por ciclo, o que não ocorreu. Contudo, apesar do $17_{\beta}$-estradiol reprogramar a função ovariana ele também induziu a luteólise nas vacas tratadas e não houve ampliação do intervalo inter-ovulatório.

A ação do $17_{\beta}$-estradiol como indutor da atresia envolve a redução da produção de gonadotrofinas, pois $o 17_{\beta}$-estradiol em ambiente predominantemente progesterônico suprime o efeito de retroalimentação ao eixo hipotálamo-hipófise. Deste modo as ações FSH e LH dependentes não ocorrem. O FSH atua nas células da granulosa estimulando sua mitose e aumentando o número de receptores para LH. Além disso, a atividade esteroidogênica folicular também é dependente da ação do FSH e LH sobre as células da granulosa e tecais, respectivamente. O $17_{\beta}$ estradiol ainda potencializa o efeito mitótico do FSH. Por essas razões, o diâmetro folicular no momento da luteólise também foi mais reduzido no grupo hCG/E $\mathrm{E}_{2}$ que no controle (Tabela 1.5). Esse resultado por si só, era desejável pois buscava-se com a administração do $17 \beta_{\beta}$-estradiol a redução e/ou remoção dos efeitos de um folículo dominante, em atividade esteroidogênica durante o período crítico, como sugerido por Binelli et al. (2001). Entretanto, a luteólise também foi induzida após o uso do 
$17_{\beta}$-estradiol. Esses resultados e conclusões são análogos aos de Bergamaschi (2005).

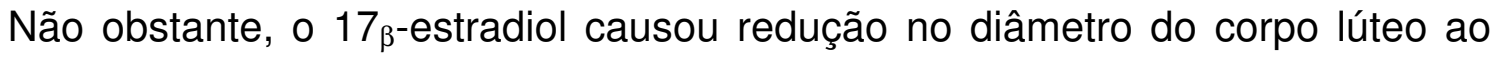
final da fase luteínica, marcadamente a partir do $D_{15}(P<0,05$; Figura 1.2). Depreende-se que o $17_{\beta}$-estradiol afetou negativamente a estrutura do corpo lúteo, o que é um indicativo de luteólise (ACOSTA; MYIAMOTO, 2004).

Esse efeito luteolítico se ilustrou na ocorrência de interação $(P<0,01)$ entre $E_{2} e$ dia do ciclo estral (Figura 1.2) para o volume do corpo lúteo. Bergamaschi (2005) encontrou resultados análogos para o volume do corpo lúteo de vacas Nelore sincronizadas e tratadas com $17_{\beta}$-estradiol no $12^{\circ}$ dia do ciclo estral. Nesse mesmo trabalho, o efeito luteotrófico da eCG não impediu a regressão do corpo lúteo, a qual se iniciou entre $D_{13}$ e $D_{14}$.

A interação entre hCG e dia do ciclo estral foi significativa $(P<0,05)$ para 0 volume do corpo lúteo. Em verdade, enquanto o corpo lúteo das vacas dos grupos controle, $\mathrm{E}_{2}$ e $\mathrm{hCG} / \mathrm{E}_{2}$ já estava em regressão. Observou-se o crescimento das dimensões luteínicas do grupo hCG até o $D_{15}$ (Figura 1.2). Cumpre lembrar, que Shirasuna et al. (2004) atestaram redução gradual do volume luteínico apenas a partir de $D_{15}$ e $D_{16}$

Salfen et al. (1999) lograram controlar a função luteínica pela administração de fluído folicular bovino tratado com carvão ativado para remoção dos esteróides. Esses autores concluíram que a aplicação exógena do estrógenos num momento adequado influencia a regressão luteínica. No presente experimento, $0 \quad 17_{\beta}$ estradiol foi dado quando a predominância da progesterona era de oito ou nove dias $\left(D_{12}\right)$. Neste momento, os receptores para a progesterona estariam sob regulação repressora o suficiente para que o $17_{\beta}$-estradiol pudesse estimular a síntese de 
ocitocina e de $\mathrm{PGF}_{2 \alpha}$. Cumpre lembrar, que o efeito luteolítico observado tanto em Bergamaschi (2005) como no presente experimento não havia sido reportado quando $5 \mathrm{mg}$ do $17_{\beta}$-estradiol foram aplicados no $D_{1}$ ou $D_{3}$ ou $D_{6}$ ou $D_{9}$ do ciclo estral (BÓ et al., 1994).

Para Mann e Lamming (1995) o momento da repressão dos receptores para a progesterona e da atividade da prostaglandina $\mathrm{H}$ sintase podem determinar se $\mathrm{o}$ estrógeno do folículo dominante da $2^{\underline{a}}$ onda será efetivo em desencadear a cascata de eventos luteolíticos. De fato, Binelli et al. (2004a) concluíram que o estradiol estimulou a liberação da $\mathrm{PGF}_{2 \alpha}$ independentemente da ação da progesterona no dia 17 do ciclo estral. Essa inferência suporta o fato de que o grupo $h C G / E_{2}$, o qual havia mostrado o maior volume do corpo lúteo em $D_{12}$ (Figura 1.2) também sofreu luteólise após a aplicação do $17_{\beta}$-estradiol e mostrou a queda mais abrupta nas dimensões do corpo lúteo se comparadas à redução dos demais grupos.

Por outro lado, Portella et al. (2004) verificaram que o papel do Benzoato de estradiol na indução da luteólise não envolve a síntese da $\mathrm{PGF}_{2 \alpha}$, uma vez que aquele estrógeno aplicado no $D_{13}$ ou no $D_{17}$ não afetou a transcrição da COX-2, enzima reguladora da síntese da prostaglandina.

Com base na declividade (ou no grau de descenso) das curvas apresentadas na figura 1.2 pode-se especular que a regressão do corpo lúteo se procedeu mais rapidamente nos grupos que receberam o $17_{\beta}$-estradiol . Não obstante, a magnitude da regressão luteínica, ou seja o valor absoluto no $21^{\circ}$ dia do ciclo estral, também foi mais acentuada nos grupos que receberam o $17_{\beta}$-estradiol. Em adição, já em $D_{16}$ as curvas para $E_{2}$ e para $h C G / E_{2}$ se eqüivaleram em declividade e expressam valores absolutos muito próximos entre si. Portanto, a hCG aplicada no $\mathrm{D}_{5}$ proveu as maiores dimensões luteínicas em $D_{12}$ mas não impediu a ação do $17_{\beta}$-estradiol 
sobre a estrutura do corpo lúteo, uma vez que depois de três ou quatro dias $\left(D_{15}\right.$ e $\left.D_{16}\right)$ após a aplicação do estrógeno o comportamento de regressão do corpo lúteo entre as vacas do grupo $\mathrm{E}_{2}$ e do $\mathrm{hCG} / \mathrm{E}_{2}$ foi análogo.

A aplicação do $17_{\beta}$-estradiol provocou os mesmos efeitos sobre as dimensões do corpo lúteo, expressas por curvas de regressão apresentadas em Bergamaschi (2005). De fato, esse autor observou que o $17_{\beta}$-estradiol acelerou a regressão do corpo lúteo, medida como a diminuição de volume do tecido luteínico, tanto para vacas suplementadas com eCG à sincronização da ovulação como para vacas não suplementadas. Similarmente ao presente experimento, Bergamaschi (2005) constatou, ao verificar a declividade das curvas de regressão, que os efeitos benéficos da eCG sobre a função luteínica se dissiparam já em $D_{14}$, ou seja, dois dias após a aplicação do $17_{\beta}$-estradiol.

Os fatores hCG e $E_{2}$ afetaram $(P<0,01)$ a dinâmica de crescimento folicular de modo que, o dia do ciclo estral em que o folículo dominante da $3^{a}$ onda atingiu seu máximo diâmetro diferiu entre os grupos (Tabela 1.1). Nas vacas que receberam hCG houve uma antecipação dessa ocorrência, provavelmente devido ao fato dessa droga promover a ovulação do folículo dominante da $1^{\text {a }}$ onda.

Em trabalho recente, Bergamaschi (2005) reportou redução significativa no diâmetro máximo do folículo dominante da $3^{\underline{a}}$ onda de crescimento após a aplicação do $17_{\beta}$-estradiol no $12^{\circ}$ dia do ciclo estral . No presente experimento, a ANOVA não detectou esse efeito (Tabela 1.1). Os valores observados no presente experimento (Tabela 1.1) aproximaram-se dos relatados por Randel (1984) para fêmeas Bos indicus e por Viana et al. (1998) e Viana et al. (2000) para vacas Gir de três ondas, embora situem-se abaixo das dimensões relatadas por Bergamaschi (2005) para 
vacas Nelore com bezerro ao pé após sincronização da ovulação por progestágenos.

As taxas de crescimento ora relatadas para o folículo dominante da $3^{\underline{a}}$ onda (Tabela 1.1) não diferiram entre os grupos experimentais e foram similares àquelas obtidas por Bergamaschi (2005) e superiores àquela $(1,06 \mathrm{~mm} / \mathrm{dia})$ reportada por Figueiredo et al. (1997) para vacas Nelore ou por Viana et al. (1998) para vacas Gir $(1,08 \mathrm{~mm} / \mathrm{dia})$. Ressalta-se que, no presente trabalho e no de Bergamaschi (2005) os ciclos estrais estudados estiveram sob influências hormonais exógenas como a aplicação de gonadotrofinas "pré" ou "pós" ovulação, bem como a aplicação de $17_{\beta^{-}}$ estradiol no terço final da fase luteínica.

Uma vez que houve uma $4^{a}$ onda de crescimento folicular apenas para vacas que receberam hCG, não puderam ser detectados efeitos dos fatores ou da interação entre eles sobre a dinâmica do folículo dominante dessa onda.

Os valores médios observados neste experimento para o diâmetro do folículo pré-ovulatório (Tabela 1.1) das vacas do $G_{C}, G_{n C G}$ e $G_{E 2}$ foram similares aos relatados por Barros et al. (1995), Figueiredo et al. (1997) e Bergamaschi (2005) para vacas Nelore. $O$ diâmetro para $\circ \mathrm{G}_{\mathrm{hCG} / \mathrm{E} 2}$ encontra-se abaixo ou nos limites inferiores da maioria dos valores reportados para vacas zebuínas (BARROS et al., 1995; BERGAMASCHI, 2005; FIGUEIREDO et al.,1997; RHODES et al., 1995).

Para Binelli et al. (2001) as dimensões do folículo ovulatório se relacionam diretamente ao tamanho do corpo lúteo gerado após a ovulação. Neste contexto, a ovulação de folículos maiores deve gerar a formação de corpos lúteos também maiores (BINELLI et al., 2001; VASCONCELOS et al., 2004) o que pode influenciar positivamente a função luteínica da vaca por meio da produção otimizada de progesterona. Com efeito, corpos lúteos de maior dimensão estiveram associados às 
maiores concentrações circulantes de progesterona no período crítico (BERGAMASCHI, 2005). Deste modo, o 17 $\beta_{\beta}$-estradiol além de causar a luteólise (Tabela 1.4) e prejudicar a função luteínica no ciclo estral em curso, ainda induziu a ovulação de um folículo de menor diâmetro. Tal evento resulta na gênese de um corpo lúteo de menores dimensões, o que potencialmente terá influencia negativa sobre a função luteínica no ciclo estral subseqüente.

A relação entre as dimensões do corpo lúteo e a concentração de progesterona circulante está discutida adiante.

O volume do corpo lúteo (Figura 1.2), bem como as demais dimensões obtidas no presente estudo, ao longo da fase luteínica foram, em geral, menores daquelas reportadas em Bergamaschi (2005) para vacas Nelore com bezerro ao pé. Especulase algum efeito do método de sincronização sobre o desenvolvimento luteínico após a ovulação, pois os diâmetros dos folículos pré-ovulatórios sincronizados foram similares para ambos trabalhos. Bergamaschi (2005) relatou diâmetros médios entre 12,7mm e 13,4mm, comparáveis aos diâmetros médios ora obtidos de $11,4 \mathrm{~mm}$ a $13,9 \mathrm{~mm}$.

Como esperado, o 17 ${ }_{\beta}$-estradiol causou $(\mathrm{P}<0,05)$ a reprogramação ovariana de crescimento folicular (Tabela 1.1) pois uma nova onda foi recrutada $4,0 \pm 0,69$ dias após sua aplicação, intervalo similar ao relatado por Bó et al. (1995) de 4,2 dias. Além disso, o $17_{\beta}$-estradiol reduziu o lapso de tempo dentro do período crítico $\left(D_{13}\right.$ a $\left.D_{19}\right)$ do reconhecimento da prenhez (Tabela 1.1) sob a influência de folículos dominantes (com $7 \mathrm{~mm}$ ou $8 \mathrm{~mm}$ ) em crescimento. Este efeito foi mais pronunciado quando a programação induzida pelo $17_{\beta}$-estradiol sucedeu a ovulação do folículo dominante da $1^{\underline{a}}$ onda causada pela hCG e, neste caso, a presença de um folículo dominante no período crítico foi, em média, inferior a um dia (Tabela 1.1). 
No presente experimento, a efetiva regressão do corpo lúteo para o grupo hCG iniciou-se a partir de $D_{15}$ e mostrou perfil menos abrupto que aquele descrito por Bergamaschi (2005). Assim, sugere-se que a ação luteotrófica da hCG após a ovulação seja mais efetiva do que a provida pela eCG no momento da sincronização da ovulação.

A hCG administrada entre $D_{4}$ e $D_{7}$ provoca a ovulação do folículo dominante da $1^{\text {a }}$ onda de crescimento, induzindo a neo-formação de um corpo lúteo acessório (DIAZ et al., 1998; FRICKE et al., 1993) bem como atua diretamente sobre o corpo lúteo original. Neste caso, o efeito luteotrófico se dá por meio do aumento no tamanho das pequenas e grandes células luteínicas (SCHMITT et al., 1996b), longa meia-vida da hCG e lenta degradação do complexo hCG-rceptor para LH nas células da granulosa (FRICKE et al., 1993; SCHMITT et al., 1996a), aumento na proporção das pequenas células luteínicas do corpo lúteo original (BENNETT et al., 1989) e aumento no peso do corpo lúteo (BREUEL et al., 1989). A resultante desses efeitos é o aumento nas dimensões do corpo lúteo e na produção de progesterona. Diaz et al. (1998) não demonstraram aumento no tamanho do corpo lúteo original após a aplicação da hCG.

Sob o ponto de vista aplicado, têm sido relatado (BARUSELLI et al., 2000; BÓ et al., 2002) que o tamanho do corpo lúteo à inovulação está direta e positivamente relacionado à taxa de concepção de receptoras de embrião. Com efeito, Baruselli et al. (2000) verificaram que receptoras cujas áreas luteínicas eram maiores que $200 \mathrm{~mm}^{2}$ apresentaram concentrações circulantes de progesterona de $2,44 \mathrm{ng} / \mathrm{mL}$ no $D_{6}$ e obtiveram taxas de concepção de 58,4\%, valores superiores aos, respectivamente $0,96 \mathrm{ng} / \mathrm{mL}$ e $31,8 \%$ obtidos para vacas com área menor que $150 \mathrm{~mm}^{2}$. No presente estudo, não foram tomadas medidas do corpo lúteo nas datas 
indicadas para a inovulação. Entretanto, as vacas que receberam a hCG apresentaram ao final da fase luteínica, em geral as maiores dimensões de corpo lúteo (Figura 1.2) e as maiores concentrações plasmáticas de progesterona (Tabela 1.3 e Figura 1.3).

A regressão do corpo lúteo foi gradual para os grupos controle e hCG, tendo início, respectivamente em $D_{16}$ e $D_{15}$ (Figura 1.2), cronologia análoga à descrita por Shirasuna et al. (2004). Entretanto, a regressão foi abrupta nos grupos que receberam o $17_{\beta}$-estradiol, ficando antecipada para $D_{14}$ no $E_{2}$ e para $D_{13}$ no $h C G / E_{2}$. Comportamento similar após a aplicação do $17_{\beta}$-estradiol foi reportado por Bergamaschi (2005).

A ANOVA para algumas variáveis discretas relativas à função luteínica (Tabela 1.2) permitiu revelar que o efeito luteotrófico da hCG caracterizou-se pelo aumento $(\mathrm{P}<0,05)$ nas dimensões máximas alcançadas pelo corpo lúteo. Os diâmetros médios máximos de $21,8 \mathrm{~mm}$ e $22,9 \mathrm{~mm}$ para os grupos $\mathrm{hCG}$ e $\mathrm{hCG} / \mathrm{E}_{2}$ respectivamente são maiores que os valores de 11,0 a 17,0mm citados por Barros et al. (1995) e daqueles de 15,9 a 17,7mm mencionados por Figueiredo et al. (1997) para vacas Nelore. Mais recentemente, Bergamaschi (2005) relatou diâmetros de até $23,4 \mathrm{~mm}$ para vacas Nelore sincronizadas com progestágenos associados à eCG, a qual segundo conclusão do autor propiciou efeito luteotrófico sobre o volume do corpo lúteo.

No presente experimento, o diâmetro dos folículos ovulatórios sincronizados não diferiu $(P>0,05)$ entre os grupos. No entanto, as maiores dimensões luteínicas foram observadas nas vacas que receberam a hCG cinco dias após a ovulação desse folículo. Portanto, o efeito luteotrófico da hCG ocorreu independentemente do diâmetro do folículo ovulado. A concentração plasmática de progesterona, dosada 
no dia em que o corpo lúteo tinha seu máximo tamanho (Tabela 1.3), também foi maior $(\mathrm{P}<0,05)$ para vacas tratadas com hCG.

Na verdade, a ação luteotrófica da hCG já havia sido estabelecida ao se analisar a figura 1.2 pois os grupos que receberam hCG possuíam os maiores volumes do corpo lúteo, exceção ao grupo $\mathrm{hCG} / \mathrm{E}_{2}$ a partir do momento que o efeito luteolítico do $17_{\beta}$-estradiol se manifestou $\left(D_{13}\right)$. Importante mencionar que a interação $h C G^{*} E_{2}$ não foi significativa $(P>0,05)$ sobre as dimensões do corpo lúteo, pois no momento em que o efeito luteolítico do $17_{\beta}$-estradiol se estabeleceu, a ação luteotrófica da hCG já havia se manifestado, tanto sobre o tamanho do corpo lúteo (Figura 1.2) como sobre a concentração plasmática de progesterona (Figura 1.3).

A ocorrência expontânea de corpos lúteos acessórios relaciona-se à dupla ovulação, a qual pode ser reflexo inclusive de estresse ambiental moderado sofrido pelas vacas, o que acarretaria uma fraca dominância do folículo ovulatório sobre seu subordinado (VASCONCELOS et al., 2004). No grupo $\mathrm{E}_{2}$ duas vacas tiveram corpo lúteo acessório. Por sua vez, em todas as vacas que receberam hCG foi induzida a presença de um corpo lúteo acessório. Esta resposta é mais consistente quando são usadas doses mais altas, de até 3000 Ul (BENNETTTT et al., 1989; DOBSON; FITZPATRICK, 1975; WALTON et al., 1990) e a aplicação realizada entre $D_{4}$ e $D_{7}$ (PRICE; WEBB, 1989), provavelmente devido à existência de maior número de receptores para LH nas células da granulosa nesse intervalo.

Assim, a ação luteotrófica da hCG é fruto da combinação dos efeitos sobre o corpo lúteo original (preexistente em $D_{5}$ ), bem como pela neo-formação de tecido luteínico, representado pelo corpo lúteo acessório. De fato, na figura 1.3 nota-se que a velocidade de crescimento da concentração plasmática da progesterona, observada pela declividade das curvas foi maior $(P<0,05)$ no grupo hCG 
$(1,04 \mathrm{ng} / \mathrm{mL} / \mathrm{dia})$ quando comparado às vacas do grupo que não recebeu $\mathrm{hCG}$ $(0,63 \mathrm{ng} / \mathrm{mL} / \mathrm{dia})$. Assim, depreende-se que a $\mathrm{hCG}$ iniciou sua atuação logo após $D_{5}$ sobre uma estrutura pronta para responder á algum estímulo esteroidogênico. Nesse momento ainda não havia tecido luteínico acessório. Este achado concorda com Fricke et al. (1993) que concluíram que o aumento inicial na concentração circulante de progesterona se deve a ação da hCG sobre o corpo lúteo original.

$\mathrm{Na}$ figura 1.3 verifica-se que o crescimento da concentração de progesterona foi contínuo até $D_{16}$ para o grupo hCG. No mesmo período, a concentração de progesterona se manteve estabilizada para o grupo controle. Pode se especular que esse efeito luteotrófico prolongado foi advindo do suporte em produção de progesterona provido pelo corpo lúteo acessório.

Em diversos estudos anteriores (BENNETTT et al., 1989; BREUEL et al., 1989; DIAZ et al., 1998; FRICKE et al., 1993; KERBLER et al., 1997; SCHMITT et al., 1996a; SCHMITT et al., 1996b; WALTON et al., 1990) os resultados obtidos foram análogos. Este efeito é um dos requisitos para a criação e manutenção de um ambiente uterino favorável ao desenvolvimento inicial do concepto (GEISERT et al., 1988; WATHES et al., 2003), condição essencial para que este produza interferon-t em quantidades adequadas (KERBLER et al., 1997) para se assegurar o êxito do reconhecimento materno da prenhez (THATCHER et al., 2001).

Ainda persistem divergências sobre a natureza do principal efeito luteotrófico gerado pela hCG. Em alguns estudos o efeito preponderante é pela formação de um corpo lúteo acessório com conseqüente aumento na progesteronemia (DIAZ et al., 1998; SCHMITT et al., 1996b). Porém, outros autores concluíram que a ação primordial afeta ao corpo lúteo original (BREUEL et al., 1989; FRICKE et al., 1993; KERBLER et al., 1997). Para Schmitt et al. (1996b) a maior produção de 
progesterona verificada entre $D_{6}$ e $D_{13}$ seria o efeito da hCG através do tecido lúteo néo-formado e os valores aumentados da progesterona ao final da fase luteínica $\left(D_{14}\right.$ a $\left.D_{17}\right)$ seriam oriundos do corpo lúteo original.

Rajamahendran e Sianangama (1992) creditam o incremento na concentração de progesterona circulante não só ao corpo lúteo acessório mas também à hipertrofia das células luteínicas do corpo lúteo original, o que já havia sido constatado por Schmitt et al. (1996b) para vacas da raça Holandesa entre $D_{14}$ e $D_{17}$. Cumpre lembrar que, a despeito de um corpo lúteo acessório atingir aproximadamente o mesmo tamanho do original de mesma idade (SCHMITT et al., 1996a; SIANANGAMA; RAJAMAHENDRAN, 1996), sua capacidade secretória é menor do que a do corpo lúteo original (SIANANGAMA; RAJAMAHENDRAN, 1996), possivelmente por sua neogênese ocorrer num período $\left(D_{4}-D_{7}\right)$ sobre predominância progesterônica. No presente experimento, foi constatada uma significativa hipertrofia do corpo lúteo (Figura 1.2 e Tabela 1.2).

A regressão luteínica ocorre simultaneamente para o corpo lúteo original e o acessório. Embora tenha sido demonstrada a existência de uma proporção maior de grandes células luteínicas no corpo lúteo acessório e que estas teriam receptores com maior afinidade pela PGF $_{2 \alpha}$ do as pequenas células (NIASARI-NASLAJI et al., 1996; SIANANGAMA; RAJAMAHENDRAN, 1996). Portanto a lise das células do corpo lúteo acessório dar-se-ia mais fácil e rapidamente do que do original (NIASARI-NASLAJI et al., 1996). Em oposição à esta assertiva estão os achados de Bennett et al. (1991) que não constataram efeitos da aplicação da hCG sobre a sensibilidade do corpo lúteo à ação lítica da $\mathrm{PGF}_{2 \alpha}$.

Ainda ao apreciar-se a figura 1.3 verifica-se o marcado efeito do $17_{\beta}$-estradiol sobre a concentração plasmática de progesterona. Em adição, a concentração 
plasmática de progesterona cumulativa a partir de $D_{12}$ sofreu efeito altamente significativo $(P<0,01)$ do $17_{\beta}$-estradiol (Tabela 1.3) tendo valores menores do que aqueles verificados para os grupos que não receberam esse estrógeno. Esse efeito confirma os achados relativos à estrutura do corpo lúteo (Figura 1.2). Assim, o declínio das concentrações plasmáticas de progesterona antecedeu a constatação ultra-sonográfica da regressão luteínica, expressa como a redução no volume $(\mathrm{P}<0,05)$ do corpo lúteo. Resultado análogo foi descrito por Acosta e Myiamoto (2004). Embora para Shirasuna et al. (2004) o descenso da concentração de progesterona circulante ocorreu de forma abrupta entre $D_{17}$ e $D_{18}$, sendo dois dias depois do início da redução do volume luteínico, o qual foi gradativo.

A relação entre as dimensões do corpo lúteo, a progesteronemia e os efeitos da hCG sobre esses indicativos da atividade luteínica se ilustram no fato de que essa gonadotrofina afetou as medidas (Tabela 1.2) do diâmetro $(P<0,05)$, da área e do volume $(\mathrm{P}<0,01)$ do corpo lúteo no dia do ciclo estral em que foi observada a maior concentração circulante de progesterona (Tabela 1.3). Bergamaschi (2005) obteve resultados similares, o que reforça a proposição de um efeito direto das gonadotrofinas sobre o corpo lúteo original. Reforça essa assertiva o fato de que houve incremento nas taxas diárias do crescimento da concentração plasmática de progesterona, tanto entre $D_{5}$ e $D_{12}$ como entre $D_{5}$ e a máxima concentração obtida $(P<0,01$ e $P<0,05$, respectivamente) pela ação luteotrófica da hCG (Tabela 1.3).

Por outro lado, da tabela 1.5 verificou-se que a luteólise $\left(\left[\mathrm{P}_{4}\right]<1,0 \mathrm{ng} / \mathrm{mL}\right)$ completou-se mais precocemente $(P>0,05)$ para as vacas que receberam $017_{\beta}$ estradiol, sozinho (dia 17,0 $\pm 0,0$ do ciclo estral) ou combinado à hCG (dia 16,0 $\pm 0,5$ do ciclo estral), do que para as vacas do grupo controle (dia $18,2 \pm 0,7$ do ciclo estral) ou do grupo hCG (dia 19,2£0,5 do ciclo estral). Neste caso, pelos efeitos não só do 
$17_{\beta}$-estradiol $(P<0,01)$ mas também pela interação $(P<0,05)$ entre a hCG e $017_{\beta}$ estradiol. Confirmou-se então o poder do $17_{\beta}$-estradiol em deflagrar a luteólise, como sugerido anteriormente (KNICKERBOCKER et al., 1986b; THATCHER et al., 1986) e determinou-se o poder potencializador da $h C G$ aplicada no $D_{5}$ sobre esses efeitos. A hCG dada previamente ao $17_{\beta}$-estradiol amplificou seus efeitos luteolíticos. Como citado anteriormente, a hCG aumenta a afinidade entre a $\mathrm{PGF}_{2 \alpha} \mathrm{e}$ os seus receptores situados nas células luteínicas (NIASARI-NASLAJI et al., 1996), o que pode ter acelerado os fenômenos luteolíticos nas vacas do grupo $\mathrm{hCG} / \mathrm{E}_{2}$.

Rhodes et al. (1995) relataram uma persistência do corpo lúteo situada entre 18,1 e 20 dias para novilhas Brahman. Sianangama e Rajamahendran (1996) verificaram que a regressão do corpo lúteo ocorreu entre os dias 18,8 e 19,3 do ciclo estral e que a hCG não afetou essa ocorrência. Para Diaz et al. (1998) a luteólise se completou no dia 21 do ciclo estral, tanto para vacas controle como para vacas tratadas com $3000 \mathrm{UI}$ de hCG no $D_{5}$. Bergamaschi (2005) concluiu que o uso de $17_{\beta}$-estradiol no $12^{\circ}$ dia do ciclo estral reduziu significativamente a fase luteínica de vacas Nelore e esta redução variou de 1,4 a 2,0 dias.

No presente estudo, a hCG quando ministrada sozinha deslocou $(P>0,05)$ a obtenção da máxima concentração plasmática de progesterona para o dia 15,2 do ciclo estral, provavelmente devido ao fato que sob influência progesterônica, a afinidade de ligação da ocitocina por seus receptores é diminuída, o que inibe o desencadear da luteólise (GRAZZINI et al., 1998).

Como antecipado, o $17_{\beta}$-estradiol causou a atresia do folículo dominante e proporcionou um período maior $(P<0,05)$ sem a observação de folículos em crescimento maiores que $7 \mathrm{~mm}$ ou $8 \mathrm{~mm}$ (Tabela 1.1) durante o período crítico. Possivelmente, o 17 $\beta$-estradiol aumentou a retroalimentação negativa ao hipotálamo 
reduzindo então o aporte de gonadotrofinas aos ovários e consequentemente ao folículo dominante. Bó et al. (1994) e Bó et al. (1995) concluíram que o uso $5 \mathrm{mg}$ de $17_{\beta}$-estradiol aplicados em novilhas diminuiu a concentração do $\mathrm{FSH}$ durante 6 horas, o que pode causar a atresia dos folículos FSH-dependentes. Além disso, o $177_{\beta}$-estradiol causa logo após sua administração, um declínio nas concentrações plasmáticas do $\mathrm{LH}$, a qual persiste durante toda a meia vida do $17_{\beta}$-estradiol, estimada em 30 horas (BÓ et al., 1994). Esse período de supressão do LH é suficiente para ocorrer a atresia dos folículos LH-dependentes (MARTINEZ et al., 2004).

O efeito supressor do $17_{\beta}$-estradiol ainda é potencializado pela combinação com a progesterona, pois esta promove uma redução na freqüência dos pulsos de LH, similar aos perfis da fase luteínica do ciclo estral. Assim, o crescimento do folículo dominante fica comprometido e decorre a regressão folicular e a emergência de uma nova onda de crescimento (ADAMS et al., 1992; RAJAMAHENDRAN; MANIKKAM, 1994).

Ao observar a tabela 1.1 e a figura 1.3, pode-se especular que para o grupo $\mathrm{hCG} / \mathrm{E}_{2}$ do presente experimento a alta progesteronemia da fase luteínica diminuiu a freqüência dos pulsos de LH e que o $17_{\beta}$-estradiol reduziu a amplitude dos pulsos de LH. Esta ação sinérgica culminou com a redução nas concentrações circulantes do LH e com a conseqüente atresia do folículo dominante e bloqueio da emergência de nova onda de crescimento (MARTINEZ et al., 2004).

O $177_{\beta}$-estradiol antecipou $(p<0,05)$ a data da luteólise (Tabela 1.5) e como resultante, o diâmetro do folículo dominante (ou do maior folículo presente) à luteólise (Tabela 1.1) naquele momento tendeu $(P<0,10)$ a ser menor. $A$ antecipação da manifestação do estro (Tabela 1.5) e o intervalo entre a luteólise e o estro não 
foram afetados pela aplicação do $17_{\beta}$-estradiol. Isto se refletiu em: a) lapso de tempo maior desde a luteólise até a ovulação e b) folículos ovulatórios também menores (Tabela 1.1), ocorrências que para Wolfenson et al. (2000) podem acarretar maturação anormal do ovócito a ser ovulado e causar falhas na fertilização ou morte embrionária precoce.

Uma vez mais, o $17_{\beta}$-estradiol teve seu efeito potencializado pela administração prévia da hCG. Para Bennett et al. (1989) a hCG alterou o número e a função das células da granulosa, reduzindo a função aromatase, o que diminui a resposta em estro após a luteólise. 


\subsection{CONCLUSÕES}

A hCG teve efeito luteotrófico mas não retardou a luteólise.

O $177_{\beta}$-estradiol removeu o folículo dominante durante ao período crítico, porém causou a luteólise e induziu a ovulação de folículo com menor diâmetro, o que prejudicou a função luteínica do ciclo estral em curso e potencialmente a função luteínica do ciclo estral subseqüente.

As manipulações das funções foliculares e luteínicas baseadas no uso do $17_{\beta}$ estradiol devem ser feitas com cautela pois o mesmo teve ação luteolítica.

A despeito das ações famacólogicas da hCG e do $17_{\beta}$-estradiol terem comportamento como antecipado, os seus efeitos permitem concluir que as estratégias idealizadas não asseguram a redução da mortalidade embrionária. 
EXPERIMENTO 2

TAXAS DE PRENHEZ DE VACAS NELORE SUBMETIDAS À INSEMINAÇÃO ARTIFICIAL EM TEMPO FIXO E SUPLEMENTADAS COM hCG, 17ß-ESTRADIOL OU A COMBINAÇÃO hCG/17ß- ESTRADIOL 
4 EXPERIMENTO 2 - TAXAS DE PRENHEZ DE VACAS NELORE SUBMETIDAS À INSEMINAÇÃO ARTIFICIAL EM TEMPO FIXO E SUPLEMENTADAS COM hCG, 17ß-ESTRADIOL OU A COMBINAÇÃO hCG/17 $\beta$ - ESTRADIOL

\subsection{JUSTIFICATIVA}

A atual situação da economia mundial exige práticas eficientes de manejo para a obtenção de alta rentabilidade das operações pecuárias (BO et al., 2003). No caso da pecuária de corte nacional, a taxa de desfrute situada próxima aos $21 \%$ (ANUALPEC, 2004) está muito aquém do potencial real para a atividade e a baixa fertilidade dos rebanhos brasileiros é apontada como um dos fatores para este desempenho insatisfatório. Dentre os principais fatores causais de fertilidade baixa em bovinos, de corte ou de leite, destacam-se as perdas embrionárias que podem atingir taxas superiores aos 40\% (HUMBLOT, 2001; SANTOS et al., 2004b; VANROOSE et al., 2000).

A maioria das perdas embrionárias toma lugar no início da gestação e é devida aos distúrbios relativos á luteólise a ao reconhecimento da prenhez propriamente. Neste contexto, define-se um "período crítico", situado entre 15 e 19 dias desde a fertilização, momento no qual o mecanismo pré-programado para a ocorrência da luteólise deve ser bloqueado.

Diversos estudos revisados por Binelli et al. (2001) implicaram o estradiol nos fenômenos que desencadeiam a luteólise. Os mesmos autores concluíram que o 
sucesso da manutenção da prenhez depende de mecanismos que inibam a produção e/ou ação desse esteróide. De fato, as vacas prenhes apresentam uma redução nas concentrações de estradiol circulante (PRITCHARD et al., 1994), provavelmente devido à redução na produção de estradiol por folículo (THATCHER et al., 1991).

O bloqueio do sistema preestabelecido para a luteólise depende da competência do concepto em enviar sinais bioquímicos anti-luteolíticos para a unidade materna. Para tanto, o ambiente uterino já na fase antecedente ao período crítico deve permitir um desenvolvimento otimizado ao concepto. O preparo do útero para fornecer as condições de melhor desenvolvimento ao concepto é mediado pela ação da progesterona materna circulante. Mann et al. (1996) e Mann et al. (1998) concluíram que tanto o atraso na elevação das concentrações após a ovulação como as baixas concentrações plasmáticas de progesterona na fase luteínica estavam relacionadas à presença de embriões menos desenvolvidos no útero. Assim, Binelli et al. (2001) sugeriram que animais de função luteínica otimizada e com condições de manter altas concentrações de progesterona no período crítico favorecerão um melhor desenvolvimento do concepto com maior capacidade de bloquear a luteólise. De fato, Geisert et al. (1988) já haviam demonstrado que a suplementação com progesterona aumentou a taxa de crescimento embrionário e também sua capacidade em produzir interferon- $\tau$.

Para promover aumentos na concentração plasmática de progesterona destaca-se o uso da hCG entre os dias 4 e 7 do ciclo estral (DIAZ et al. 1998; MARQUES, 2002; PRICE; WEBB, 1989; RAJAMAHENDRAN; SIANANGAMA, 1992; SCHMITT et al. 1996a) que induz a formação de um corpo lúteo acessório, com 
conseqüente aumento nas concentrações plasmáticas de progesterona (SANTOS et al., 2001).

Em diversos estudos com vacas cíclicas ficou demonstrado que fêmeas com concentração plasmática de progesterona mais baixa após a inseminação artificial apresentaram taxas de concepção menores (LAMMING et al., 1989; LUKASEWSKA; HANSEL, 1980; MANN, 2002; MANN; LAMMING, 1999; MANN et al., 1999;). Entretanto há outros relatos que discordam desses resultados. Com efeito, Mann e Lamming (1999) revisaram 17 estudos individuais e encontraram que, em geral, vacas suplementadas com progesterona após a inseminação artificial obtiveram taxas de concepção aproximadamente $5 \%$ mais altas do que vacas não suplementadas.

Neste experimento visou-se comparar a eficácia das diferentes abordagens de manipulação luteínica e folicular apresentadas no experimento 1 aplicadas no sentido de reduzir a mortalidade embrionária após uma inseminação artificial (IA) em tempo fixo (IA $\left.\mathrm{A}_{\mathrm{TF}}\right)$. As estratégias para redução da mortalidade embrionária foram: $1^{\circ}$ ) otimização da função luteínica pela administração da hCG no $5^{\circ}$ dia após a IA alteração da função folicular pela remoção farmacológica do folículo dominante ao final da fase luteínica por meio da aplicação do $17_{\beta}$-estradiol no $12^{0}$ dia após a IA $A_{T F}$, e $\left.3^{\circ}\right)$ combinação das duas abordagens anteriores. Para tanto, foram comparadas entre os grupos, as taxas de prenhez à $I A_{T F}$ e às inseminações feitas nos ciclos naturais subsequentes dentro de uma estação reprodutiva de 64 dias. 


\subsection{MATERIAL E MÉTODO}

O Material e Método compreendeu o local do experimento, os animais e seu manejo, a formação dos grupos, os exames ultra-sonográficos para o diagnóstico da prenhez, bem como o delineamento experimental e a análise estatística.

\subsubsection{Local do experimento, animais e manejo}

O experimento foi desenvolvido na Fazenda Canchim, sede da Embrapa Pecuária Sudeste, Unidade da Empresa Brasileira de Pesquisa Agropecuária (Embrapa), em São Carlos. A fazenda se localiza na região central do estado de São Paulo (22 $01^{\prime}$ Latitude Sul e $47^{\circ} 54^{\prime}$ Longitude Oeste), a 860 metros de altitude. $\mathrm{O}$ clima é tropical, do tipo CwA na classificação de Köppen, caracterizado como verão quente e inverno seco. No período de 1970 a 1997, a média da temperatura anual foi de $21,3^{\circ} \mathrm{C}$ e a umidade relativa do ar foi de $77 \%$. A precipitação pluvial média anual foi de 1353 milímetros ( $\mathrm{mm}$ ).

Foram utilizadas 220 vacas da raça Nelore (Bos taurus indicus), com idades entre 5 e 16 anos, ordens de parto entre $2^{\mathrm{a}}$ e $9^{\mathrm{a}}$, tendo pelo menos 240 dias pósparto e sem bezerro ao pé . As fêmeas foram pesadas e avaliadas quanto ao ECC (SPITZER, 1986), no início e ao final do experimento. Todas as vacas usadas no experimento tinham $5 \leq \mathrm{ECC} \leq 7$. 
As fêmeas foram submetidas ao exame ginecológico, no início do experimento, examinando-se os órgãos genitais internos por palpação retal e ultrasonografia transretal para avaliação morfo-funcional dos ovários. As vacas foram classificadas consoante à condição ovariana conforme descrito por Madureira et al. (2004), sendo utilizadas para a composição dos grupos experimentais apenas as vacas classificadas como escore 1 (portadoras de corpo lúteo) ou escore 2 (possuíam ovários com comprimento entre 15 e 30mm e com crescimento folicular associado a turgidez uterina.

Os animais foram manejadas em sistema intensivo de rotação de pastagem em piquetes de capim Brachiaria decumbens, Brachiaria brizantha var. Marandu e Panicum maximum var. Tanzânia. Havia nos piquetes livre acesso a sal mineralizado e água.

\subsubsection{Formação dos grupos}

As vacas tiveram o ciclo estral sincronizado pelo método "OvSynch" (PURSLEY et al., 1995) e receberam uma injeção intramuscular de $8 \mu \mathrm{g}$ do Acetato de Buserelina $^{6}$, seguida por uma injeção intramuscular com 0,150mg de dCloprostenol ${ }^{7}$ (análogo da $\mathrm{PGF}_{2 \alpha}$ ) sete dias mais tarde e outra aplicação de $\mathrm{GnRH}$ 48h após esta última. A I $\mathrm{A}_{\mathrm{TF}}$ ocorreu em média 16 horas depois da segunda aplicação de $\mathrm{GnRH}$. A data da $\mathrm{IA}_{\mathrm{TF}}$ foi considerada como o dia $\mathrm{D}_{\text {zero. Foram }}$ designados, em rodízio, seis inseminadores experientes, os quais aplicaram o

\footnotetext{
${ }^{6}$ Acetato de buserelina ${ }^{\circledR}$, Centro Paulista de Desenvolvimento Farmacotécnico;
} 
sêmen de touros distintos que haviam sido determinados previamente por sorteio aleatório.

O grupo Controle (Gc) não recebeu tratamento adicional. As vacas do grupo hCG $\left(G_{h C G}\right)$ receberam 3000 Ul da $\mathrm{hCG}^{8}$ via intramuscular no $D_{5}$. As vacas do grupo $17_{\beta}$-estradiol $\left(\mathrm{G}_{\mathrm{E} 2}\right.$ ) receberam $5 \mathrm{mg}$ de $17_{\beta}$-estradiol ${ }^{9}$ via intramuscular no $D_{12}$ e as do grupo hCG/17 $\beta_{\text {-estradiol (G }}$ hCG/E2) receberam $3000 \mathrm{Ul}$ da hCG no $\mathrm{D}_{5}$ e $5 \mathrm{mg}$ do $17_{\beta}$-estradiol no $D_{12}$. Cada grupo tinha 55 vacas.

Em todos grupos foi procedida a observação do estro, por 30 minutos, duas vezes ao dia (07:00 horas e às 16:30 horas) a partir de $D_{5}$ e até o fim da estação de reprodução $\left(D_{64}\right)$. Para auxiliar na detecção dos cios, houve a inclusão de dois rufiões por grupo (proporção aproximada de 1:25), equipados com marcador "chinball" e mantidos até o final da estação reprodutiva, incluindo as IAs de repasse. Os rufiões eram bovinos adultos cruzados $1 / 2$ sangue europeu $1 / 2$ sangue zebu, de comprovada libido, os quais foram preparados cirurgicamente por aderência lateral do pênis na parede abdominal associada a caudoepididimectomia. Quando necessário houve substituição dos rufiões. O esquema experimental contendo os protocolos de aplicação dos tratamentos consta na figura 2.1.

\footnotetext{
${ }^{7}$ Prolise ${ }^{\circledR}$, Tecnopec.

${ }^{8}$ Vetecor 5000 U.I. ${ }^{\circledR}$, Laboratórios Calier S.A.;

9 17beta-Estradiol, Centro Paulista de Desenvolvimento Farmacotécnico.
} 
4.2.3 Exames ultra-sonográficos para diagnóstico de prenhez

O diagnóstico de prenhez foi realizado no $D_{31}$ e após o final da estação reprodutiva $\left(\mathrm{D}_{99}\right)$. Foi utilizado um aparelho de ultra-som da marca ALOKA, modelo CCS 500, em Modo-B, com transdutor de 7,5 MHz, por via retal e a metodologia do exame e os critérios utilizados estão descritos por Pierson e Ginther (1988).

\subsubsection{Delineamento experimental e análise estatística}

As fêmeas foram estratificadas segundo a ordem de parto, o peso vivo e o ECC para distribuição por sorteio aleatório em quatro grupos experimentais com 55 vacas cada. Deste modo, o delineamento experimental adotado foi o de blocos casualizados generalizados. As variáveis analisadas foram: taxa de prenhez à IA $A_{T F}$, taxa de prenhez à $1^{\text {a }}$ IA de repasse, taxa de prenhez à $2^{\underline{a}}$ IA de repasse, taxas de prenhez cumulativas à cada IA de repasse, taxa de prenhez ao final da estação de reprodução. Neste contexto, a taxa de prenhez foi definida como a razão, tomada em porcentagem, entre o número de vacas prenhes e 0 número de vacas disponíveis (não-prenhes) àquela IA. Além das taxas de prenhez, foram analisadas as taxas de serviço, definidas como a razão entre o número de vacas inseminadas pelo número total de vacas disponíveis à cada inseminação e as taxas de concepção, definidas como a razão entre as vacas diagnosticadas prenhes à ultrasonografia e o número de vacas inseminadas em cada IA. 
As taxas foram tomadas como proporções e então analisadas por dispersão das freqüências aplicando-se o teste do Qui-quadrado $\left(\chi^{2}\right)$ com o auxílio do procedimento FREQ do programa SAS System for Windows (STATISTICAL ANALYSIS SYSTEM, 1993). Os efeitos dos grupos foram aceitos para a significância de até $5 \%$ de probabilidade $(P<0,05)$. Conceituou-se como tendência, quando os efeitos estiveram situados entre as probabilidades de 5 e $10 \%(0,05<\mathrm{P}<0,10)$. 
G-controle

\begin{tabular}{|c|c|c|c|c|c|c|}
\hline $\begin{array}{l}\text { GnRH } \\
\downarrow\end{array}$ & $\begin{array}{l}\mathrm{PGF}_{2 \alpha} \\
\downarrow\end{array}$ & $\begin{array}{l}\text { GnRH } \\
\downarrow\end{array}$ & $\begin{array}{l}\mathrm{IA}_{\mathrm{TF}} \\
\downarrow\end{array}$ & $\begin{array}{l}\text { Diagnóstico } \\
\text { de prenhez } \\
\text { à } \mathrm{A}_{\mathrm{TF}} \\
\downarrow\end{array}$ & $\begin{array}{r}\text { Fim da } \\
\text { estação } \\
\text { reprodutiva } \\
\downarrow\end{array}$ & $\begin{array}{r}\text { Diagnóstico de } \\
\text { prenhez final } \\
\downarrow\end{array}$ \\
\hline 7 dias & 2 dias & 16 horas & & $\begin{array}{l}\text { Rufiões + IA } \\
D_{35}\end{array}$ & asse & $\mathrm{D}_{99}$ \\
\hline
\end{tabular}

G-hCG

\begin{tabular}{|c|c|c|c|c|c|c|c|}
\hline $\begin{array}{c}\text { GnRH } \\
\downarrow\end{array}$ & $\begin{array}{l}\mathrm{PGF}_{2 \alpha} \\
\downarrow\end{array}$ & $\begin{array}{l}\text { GnRH } \\
\downarrow\end{array}$ & $\begin{array}{l}\mathrm{IA}_{\mathrm{TF}} \\
\downarrow\end{array}$ & $\begin{array}{l}\text { hCG } \\
\downarrow\end{array}$ & $\begin{array}{l}\text { Diagnóstico } \\
\text { de prenhez } \\
\text { à IA } A_{T F} \\
\downarrow\end{array}$ & $\begin{array}{r}\text { Fim da } \\
\text { estação } \\
\text { reprodutiva } \\
\downarrow\end{array}$ & $\begin{array}{r}\text { Diagnóstico de } \\
\text { prenhez final } \\
\downarrow\end{array}$ \\
\hline 7 dias & 2 dias & 16 horas & $\mathrm{D}_{0}$ & $D_{5}$ & $\overline{s+I A}$ & asse & $D_{99}$ \\
\hline
\end{tabular}

$\mathrm{G}-\mathrm{E}_{2}$

\begin{tabular}{|c|c|c|c|c|c|c|c|}
\hline $\mathrm{RH}$ & $\begin{array}{l}\mathrm{PGF}_{2 \alpha} \\
\downarrow\end{array}$ & $\begin{array}{l}\text { GnRH } \\
\downarrow\end{array}$ & $\begin{array}{l}\mathrm{IA}_{\mathrm{TF}} \\
\downarrow\end{array}$ & $\begin{array}{l}\mathrm{E}_{2} \\
\downarrow\end{array}$ & $\begin{array}{l}\text { Diagnóstico } \\
\text { de prenhez } \\
\text { à IA } A_{T F} \\
\downarrow\end{array}$ & $\begin{array}{r}\text { Fim da } \\
\text { Estação } \\
\text { reprodutiva } \\
\downarrow\end{array}$ & $\begin{array}{l}\text { Diagnóstico de } \\
\text { prenhez final }\end{array}$ \\
\hline $7 \mathrm{dia}$ & 2 dias & $16 \mathrm{~h}$ & & ח & es + IA de & $\mathrm{se}$ & \\
\hline
\end{tabular}

$\mathrm{G}-\mathrm{hCG} / \mathrm{E}_{2}$

\begin{tabular}{|c|c|c|c|c|c|c|c|c|}
\hline $\begin{array}{c}\text { GnRH } \\
\downarrow\end{array}$ & $\begin{array}{l}\mathrm{PGF}_{2 \alpha} \\
\downarrow\end{array}$ & $\begin{array}{l}\text { GnRH } \\
\downarrow\end{array}$ & $\begin{array}{l}\mathrm{I}_{\mathrm{TF}} \\
\downarrow\end{array}$ & $\begin{array}{l}\text { hCG } \\
\downarrow\end{array}$ & $\begin{array}{l}\mathrm{E}_{2} \\
\downarrow\end{array}$ & $\begin{array}{l}\text { Diagnóstico } \\
\text { de prenhez } \\
\text { à } \mid A_{T F} \\
\downarrow\end{array}$ & $\begin{array}{r}\text { Fim da } \\
\text { Estação } \\
\text { reprodutiva } \\
\downarrow\end{array}$ & $\begin{array}{r}\text { Diagnóstico } \\
\text { de prenhez } \\
\text { fina } \\
\downarrow\end{array}$ \\
\hline 70 & \begin{tabular}{l|l}
$s$ & 2 dia
\end{tabular} & 16 horas & $\mathrm{D}_{0}$ & $\mathrm{D}_{5}$ & $D_{12}$ & $D_{35}$ & sse & \\
\hline
\end{tabular}

Figura 2.1 - Protocolos de administração dos tratamentos no experimento 2, São Carlos, 2004 


\subsection{RESULTADOS}

Na tabela 2.1 estão apresentadas as taxas de serviço, concepção e prenhez observadas ao longo da estação de reprodução com 64 dias de duração, tendo sido o dia da IA $A_{T F}$ considerado como dia "1" da estação.

Neste caso, foi possível elaborar as "curvas de sobrevivência“, baseadas na evolução temporal das taxas de prenhez ao longo da estação de reprodução para cada grupo experimental. A representação gráfica das curvas de sobrevivência está na figura 2.2. Na realidade, tais curvas expressam o resíduo de fêmeas não-prenhes dia-a-dia ao longo da estação de reprodução.

Outra análise foi realizada considerando "grupos" de vacas que receberam ou não a hCG e que receberam ou não o $17_{\beta}$-estradiol. Esses resultados estão mostrados na tabela 2.2. 
Tabela 2.1 - Taxas de serviço (TS), concepção (TC) e prenhez $(T P)^{1}$ à inseminação artificial (IA) em tempo fixo (IATF), à $1^{\text {at }}$ IA de

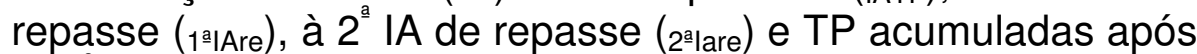
a $1^{a} \quad A_{r e}\left(T_{|A T F+1| A \mid A r e}\right)$ e ao final da estação (TP acum). São Carlos, 2004

\begin{tabular}{ccccc}
\hline & \multicolumn{4}{c}{ Grupo } \\
\cline { 2 - 5 } Taxas & Controle & $\mathrm{hCG}$ & $\mathrm{E}_{2}$ & $\mathrm{hCG} / \mathrm{E}_{2}$
\end{tabular}$\chi^{2} \mathrm{GL}=3$

Prenhez

\begin{tabular}{|c|c|c|}
\hline TP IATF & $\begin{array}{c}34,5 \%{ }^{\mathrm{ab}} \\
(19 / 55)\end{array}$ & $\begin{array}{l}36,4 \%^{\mathrm{a}} \\
(20 / 55)\end{array}$ \\
\hline $\mathrm{TP}_{\text {1/ARe }}$ & $\begin{array}{l}55,5 \% \\
(20 / 36)\end{array}$ & $\begin{array}{c}42,8 \% \\
(15 / 35)\end{array}$ \\
\hline $\mathrm{TP}_{2^{21} \text { Are }}$ & $\begin{array}{l}37,5 \% \\
(6 / 16)\end{array}$ & $\begin{array}{c}45 \% \\
(9 / 20)\end{array}$ \\
\hline
\end{tabular}

\section{$5,4 \%^{\mathrm{c}}$}

$(3 / 55)$

$40,4 \%$

$(21 / 52)$

$38,7 \%$

$(12 / 31)$

$100,0 \%{ }^{\mathrm{A}}$

$100,0 \%{ }^{\mathrm{A}}$

$55,7 \%{ }^{\mathrm{B}}$

(29/52)

$65,7 \%^{\mathrm{B}}$

(23/35)

$74,2 \%{ }^{\mathrm{B}}$

(23/31)

(13/20)

$(8 / 16)$

Concepção

\begin{tabular}{|c|c|c|}
\hline $\mathrm{TC}_{\text {IATF }}$ & $34,5 \%{ }^{a b, ~ B ~}$ & $36,4 \%{ }^{a,}$ \\
\hline $\mathrm{TC}_{\text {1IIAre }}$ & $\begin{array}{l}76,9 \%{ }^{A} \\
(20 / 26)\end{array}$ & $\begin{array}{l}65,2 \%^{A} \\
(15 / 23)\end{array}$ \\
\hline $\mathrm{TC}_{2^{\mathrm{a} \mid} \text { Are }}$ & $\begin{array}{c}75,0 \%{ }^{A} \\
(6 / 8)\end{array}$ & $\begin{array}{c}69,2 \%^{A} \\
(9 / 13)\end{array}$ \\
\hline
\end{tabular}

(6/8)

$(9 / 13)$

$63,3 \%^{\mathrm{a}}$

$(35 / 55)$

$\mathrm{TP}_{\text {acum }}$

(39/55)

$81,8 \%$

(45/55)
$80,0 \%$
$(44 / 55)$
$5,4 \%{ }^{c, B}$

$72,4 \%{ }^{\mathrm{A}}$

(21/29)

$52,2 \%{ }^{A}$

(12/23)

$43,6 \%$ ab

(25/55)

$67,3 \%$

(37/55)
$18,2 \%{ }^{b}$

$(10 / 55)$

$33,3 \%$

(15/45)

$30,0 \%$

$(9 / 30)$

$22,40^{* *}$

$4,14^{\text {ns }}$

$1,12^{\text {ns }}$

$100,0 \%{ }^{\mathrm{A}}$

ns

$57,8 \%{ }^{\mathrm{B}}$

(26/45)

$63,3 \%^{\mathrm{B}}$

$(19 / 30)$

$2,50^{\mathrm{ns}}$

$2,59^{\text {ns }}$

$18,2 \%^{\text {b, B }} \quad 22,40^{* *}$

$57,7 \%{ }^{\mathrm{A}}$

(15/26)

$2,28^{\mathrm{ns}}$

$47,4 \%{ }^{\mathrm{A}}$

(9/19)

$2,72^{\text {ns }}$

$38,2 \%{ }^{b}$

$(21 / 55)$

$65,4 \%$

$(36 / 55)$

1. ${ }^{*}=0,10>\mathrm{P}>0,05 ;{ }^{* *}=\mathrm{P}<0,05 ; \mathrm{ns}=$ não-significativo $(\mathrm{P} \geq 0,10)$; letras minúsculas superscritas distintas na mesma linha indicam diferença entre grupos $\left(P<0,05 ; G L \chi^{2}=1\right)$; letras maiúsculas superscritas distintas na mesma coluna indicam diferença dentro de grupo para aquela taxa comparada $\left(P<0,05 ; G L \chi^{2}=1\right)$. 


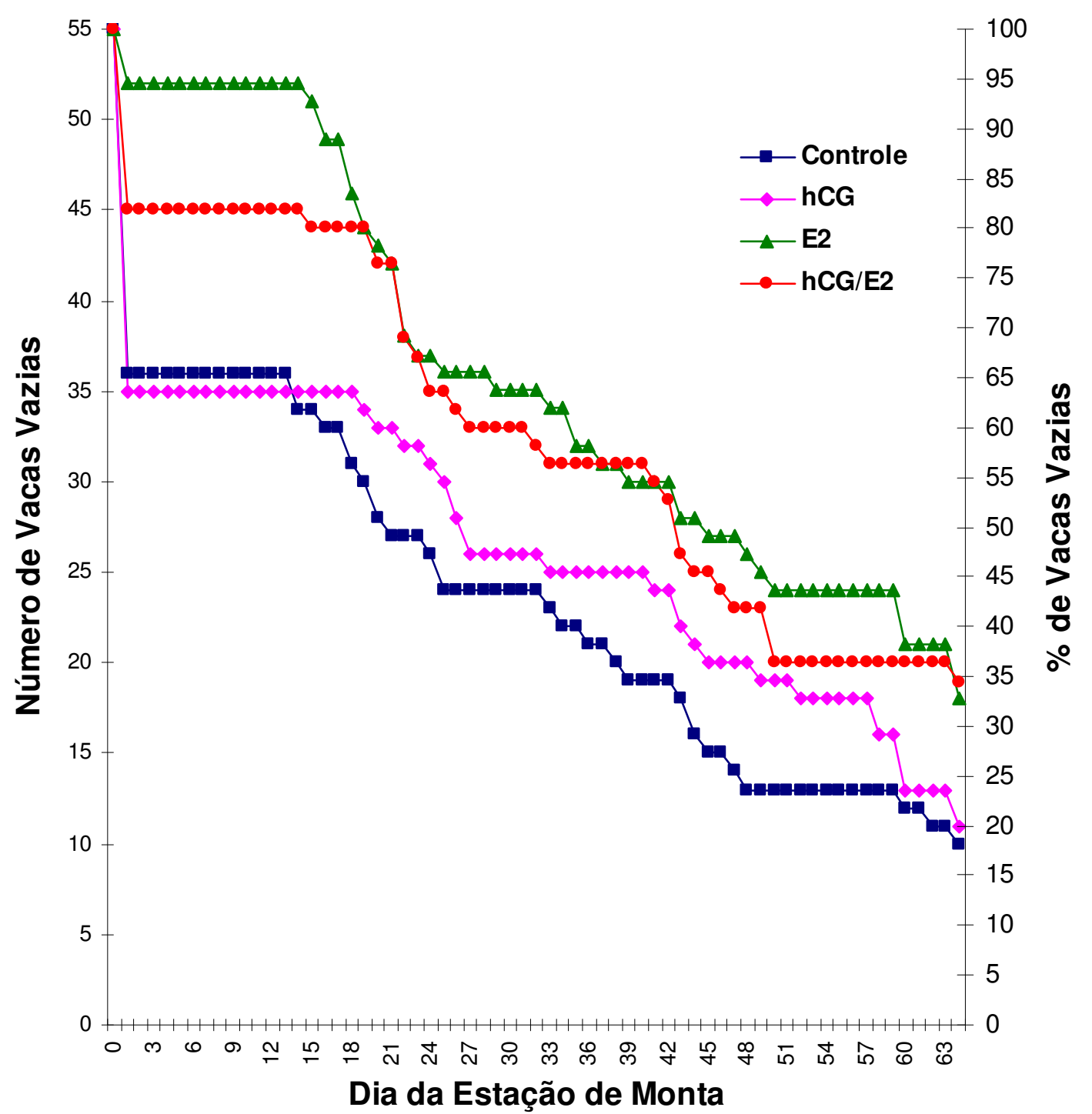

Figura 2.2 - Curvas de sobrevivência para as taxas de prenhez em função do dia da estação de reprodução. São Carlos, 2004 
Tabela 2.2 - Efeito" dos fatores "hCG" e "E${ }_{2}$ " sobre a taxa de prenhez à inseminação artificial em tempo fixo (TP IATF) e taxa de prenhez acumulada ao final da estação de reprodução ( $\left(\mathrm{PP}_{\text {acum }}\right)$. São Carlos, 2004

\begin{tabular}{|c|c|c|c|c|c|}
\hline \multirow{2}{*}{$\begin{array}{l}\text { Variável } \\
\text { Resposta }\end{array}$} & \multicolumn{4}{|c|}{ Fatores $^{2}$} & \multirow{2}{*}{$\chi^{2}$} \\
\hline & Sem hCG & com hCG & sem $E_{2}$ & $\operatorname{com} \mathrm{E}_{2}$ & \\
\hline TP $_{\text {IATF }}$ & $\begin{array}{c}20,0 \% \\
(22 / 110)\end{array}$ & $\begin{array}{c}27,3 \% \\
(30 / 110)\end{array}$ & - & - & $1,61^{\mathrm{ns}}$ \\
\hline TP IATF & - & - & $\begin{array}{c}35,4 \% \\
(39 / 110)\end{array}$ & $\begin{array}{c}11,8 \% \\
(13 / 110)\end{array}$ & $15,2^{*}$ \\
\hline $\mathrm{TP}_{\mathrm{acum}}$ & $\begin{array}{c}74,5 \% \\
(82 / 110)\end{array}$ & $\begin{array}{c}72,7 \% \\
(80 / 110)\end{array}$ & - & - & $0,07^{\mathrm{ns}}$ \\
\hline $\mathrm{TP}_{\text {acum }}$ & - & - & $\begin{array}{c}80,9 \% \\
(89 / 110)\end{array}$ & $\begin{array}{c}66,4 \% \\
(73 / 110)\end{array}$ & $4,65^{\star}$ \\
\hline
\end{tabular}

$1 .{ }^{*}=\mathrm{P}<0,05$ com Graus de Liberdade $=1 ; \mathrm{ns}=$ não-significativo $(\mathrm{P} \geq 0,10)$;

2. O grupo "sem hCG" ficou composto por fêmeas dos grupos "Controle" e "E$E_{2}$ e o grupo "com hCG" teve fêmeas dos grupos "hCG e hCG/E". O grupo "sem E2" foi composto por vacas dos grupos "Controle e hCG" e o grupo "com $E_{2}$ " teve vacas dos grupos " $E_{2}$ " e "hCG/ $\mathrm{E}_{2}$ ". 
As taxas de serviço para a $1^{\mathrm{a}}$ e $2^{\mathrm{a}}$ IA de repasse não diferiram $(P>0,05)$ entre os grupos (Tabela 2.1). Em adição, não houve diferença $(P>0,05)$ entre as taxas de serviço observadas à $1^{\mathrm{a}}$ ou à $2^{\mathrm{a}}$ IA de repasse "dentro" de grupo. No entanto, a taxa de serviço à $\operatorname{IA} A_{T F}(100,0 \%)$ foi maior $(P<0,05)$ do que as taxas de serviço em qualquer das duas inseminações de repasse (comparação dentro de grupo).

As taxas de concepção para a $1^{\mathrm{a}}$ e $2^{\mathrm{a}} \mathrm{IA}$ de repasse não diferiram $(P>0,05)$ entre os grupos (Tabela 2.1) e não houve diferença $(P>0,05)$ entre as taxas de concepção observadas à $1^{\text {a }}$ ou à $2^{\mathrm{a}}$ IA de repasse "dentro" de grupo. No entanto, as taxas de concepção à $I A_{T F}$ foram menores $(P<0,05)$ do que as taxas de concepção em qualquer das duas inseminações de repasse (comparação dentro de grupo).

Houve diferenças $(\mathrm{P}<0,05)$ nas taxas de prenhez à $\mathrm{I}_{\mathrm{TF}}$ entre grupos (Tabela 2.1) e além disso, a taxa e prenhez do grupo controle tendeu $\left(\chi^{2}=3,79_{\mathrm{GL}=1}\right.$; $0,10>P>0,05)$ ser maior $(34,5 \%)$ que a do grupo $h C G / E_{2}(18,2 \%)$. Analogamente houve tendências $(0,10>P>0,05)$ das taxas de prenhez acumuladas diferirem entre os grupos controle e $\mathrm{E}_{2}\left(\chi^{2}=3,06_{\mathrm{GL}=1} ; 81,8 \%\right.$ e $67,3 \%$, respectivamente), controle e $\mathrm{hCG} / \mathrm{E}_{2}\left(\chi^{2}=3,79_{\mathrm{GL}=1} ; 81,8 \%\right.$ e $65,4 \%$, respectivamente), bem como entre os grupos $\mathrm{hCG}$ e hCG/E $\mathrm{E}_{2}\left(\chi^{2}=2,93_{\mathrm{GL}=1} ; 80,0 \%\right.$ e $65,4 \%$, respectivamente). 


\subsection{DISCUSSÃO}

A taxa de prenhez à $I A_{T F}$ variou $(P<0,05)$ entre os grupos (Tabela 2.1), sendo que a baixa taxa de prenhez na $I A_{T F}$ dos grupos que receberam o $17_{\beta}$-estradiol aparentemente se refletiu também na taxa de prenhez acumulada até a $1^{\underline{a}}$ IA de repasse $(P<0,05)$. Similarmente, esses mesmos grupos tenderam $(P<0,10)$ à menor taxa de prenhez acumulada ao final da estação reprodutiva.

As taxas de prenhez à IA TF após o protocolo OvSynch têm sido variáveis. Em vacas leiteiras, Kastelic (2004) relatou valores entre $22 \%$ e $48 \%$; Rajamahendran et al. (2004) relatam 31\%; Gabor et al. (2004) relataram média de $28,6 \%$ com variação de $25,7 \%$ a $47 \%$ dependendo da fazenda; Vasconcelos et al. (2004) reportaram 33,3\%. Em bovinos de corte, Fernandes et al. (1997) encontraram taxas de parição entre $25 \%$ e $47,7 \%$ para vacas Nelore em função da raça do touro; Baruselli et al. (2004a) relataram 15\% em vacas Nelore no Brasil; Cavalieri (2004) reportou 38,1\% para rebanhos de corte na Austrália; Vilela et al. (2004), reportaram 19,5\% a $24,6 \%$ para vacas Nelore e obtiveram os melhores resultados quando o OvSynch foi associado à retirada do bezerro.

As principais causas de variação na resposta a esse protocolo são: a) falta de sincronização dos ciclos ovarianos entre as vacas tratadas, fruto da ocorrência de diferentes estádios de desenvolvimento folicular no momento da aplicação dos tratamentos (BÓ et al., 1995); b) resposta pobre ou variável em ovulação/luteinização após a 1ª injeção de GnRH (BÓ et al., 2002); c) resposta pobre ou variável das vacas Nelore à ação luteolítica da PGF $_{2 \alpha}$ exógena (PINHEIRO 
et al., 1998); d) Ocorrência de luteólise expontânea entre a $1^{\text {a }}$ e $2^{\text {a }}$ doses de $G n R H$ (MARTINEZ et al., 2004), e e) função ovariana anormal causada por balanço energético negativo (RHODES et al., 1996; SANTOS et al., 1998). Por sua vez, Cavalieri (2004) enfatizou a importância dos fatores relativos à indução da ovulação pelo $\mathrm{GnRH}$, de modo que sub-dosagens ou baixa potência de seus análogos poderiam causar falhas na resposta devidas a: incapacidade do $\mathrm{GnRH}$ induzir um pico de LH com magnitude suficiente para causar a ovulação; incapacidade do folículo em responder com ovulação à esse pico de LH; indução precoce da ovulação com a liberação de um ovócito ainda imaturo e formação de um corpo lúteo com função esteroidogênica sub-normal.

As taxas de prenhez à IA $A_{T F}$ observadas neste experimento (Tabela 2.1) para os grupos controle (OvSynch) e hCG (OvSynch + hCG) estiveram dentro das faixas reportadas para bovinos leiteiros e nos limites superiores dos intervalos mais freqüentemente reportados para bovinos de corte. Entretanto, Baruselli et al. (2004b) reportaram taxas de prenhez superiores aos $60 \%$ após IA $A_{T F}$ com o uso de protocolos de indução da ovulação baseados em progestágenos e levantaram dúvidas sobre a aplicabilidade do OvSynch para bovinos de corte em regiões tropicais, uma vez que as taxas de concepção são baixas após o seu uso, especialmente em rebanhos com alta proporção de vacas em anestro ou de novilhas, o que corroborou relato prévio (DISKIN et al., 2002; FERNANDES et al., 2001).

Ainda na tabela 2.1 observa-se que ao final da estação reprodutiva de 64 dias as taxas de prenhez dos grupos controle e hCG se eqüivalem àquela $(79,8 \%)$ reportada por Cavalieri (2004) para vacas de corte na Austrália após uma estação reprodutiva com 56 dias de duração e são superiores aos 59,7\% encontrados por 
Vilela et al. (2004) para vacas Nelore após uma estação de monta com 60 dias. Estes últimos investigadores lograram aumentar a taxa de prenhez para $80,1 \%$ por meio da remoção do bezerro quando da $\mathrm{I}_{\mathrm{TF}}$ que abriu a estação de monta.

Outra limitação potencial do protocolo OvSynch é a ocorrência subsequente de ciclos estrais de curta duração. Córdoba e Fricke (2002), Shephard (2002) e McMillan et al. (2003) concluíram que função luteínica sub-normal após a indução da ovulação pelo OvSynch causou alta percentagem de ciclos estrais de curta duração (menores de 18 dias), acarretando alto percentual (31,8\% a 51\%) de inseminações de repasse antes dos 18 dias após a IA TF.

No presente experimento, houve $10,7 \%$ de ciclos curtos pois apenas nove das 84 inseminações de repasse ocorreram antes do $D_{18}$. Este fato permite concluir que tanto a dose como a potência do análogo do $\mathrm{GnRH}(8 \mu \mathrm{g}$ do acetato de buserelina) adotadas foram adequados.

Em adição, ao ser analisada a figura 2.2 nota-se que a sincronização inicial da ovulação, auxiliou a concentrar as manifestações de estro e inseminações que se seguiram na estação de reprodução. De fato, houve nitidamente "picos" de inseminações artificiais entre os dias 15 e 25, bem como entre os dias 35 e 48 da estação de reprodução.

O efeito da hCG sobre as taxas de prenhez à IA $A_{T F}$ e acumulada (Tabela 2.2) não foi significativo $(P>0,05)$. Resultados análogos foram relatados por Kerbler et al. (1997) usando 1500 Ul da hCG no $D_{5}$ em novilhas de corte de raça européia. Ramakrishmappa et al. (2004) também não encontraram aumentos na taxa de prenhez após a suplementação com, respectivamente 1500 UI de hCG no $D_{5}$ e 2000 Ul de hCG no $D_{7}$ em vacas leiterias. Breuel et al. (1990) e Walton et al. (1990) não demonstraram efeito da hCG após a IA sobre as taxas de prenhez. Em gado leiteiro, 
Schmitt et al. (1996a) não encontraram qualquer efeito da hCG sobre as taxas de prenhez de novilhas férteis ou de vacas sob estresse térmico. No presente experimento, as taxas de concepção e de prenhez acumulada para os grupos que receberam hCG não foram influenciadas $(P>0,10)$ pela administração dessa gonadotrofina, como mostrado na tabela 2.1 e na figura 2.2. Estes achados confirmam os resultados de estudo anterior de Diaz et al. (1998), que demonstraram não existir efeitos residuais da hCG sobre a duração do ciclo estral ou concentração de progesterona circulante.

Por outro lado, Rajamahendran e Sianangama (1992) trabalhando com um número reduzido de animais verificaram que a taxa de prenhez de vacas tratadas com $1500 \mathrm{UI}$ de hCG no $D_{7}$ após a IA foi mais alta que as do grupo controle. No mesmo estudo, havia a presença de um corpo lúteo acessório por mais de 20 dias nas vacas que a IA não foi fértil e os investigadores concluíram que o efeito benéfico da hCG advém da permanência dessa estrutura luteínica acessória. Kastelic (2004) relatou importante aumento na taxa de prenhez em vacas suplementadas com hCG após indução da ovulação com OvSynch e IA $A_{T F}$. Com efeito, a hCG consistentemente induz a formação de corpo lúteo acessório (RAJAMAHENDRAN; SIANANGAMA, 1992; SCHMITT et al., 1996b) e aumenta a concentração de progesterona circulante (BREUEL et al., 1990; WALTON et al., 1990).

Breuel et al. (1990) e Walton et al. (1990) concluíram então que a hCG deve ser usada como uma ferramenta clínica em animais "repeat breeder", quando se antecipa a ocorrência de baixas concentrações de progesterona circulante no diestro que sucede o serviço. Schmitt et al. (1996a) haviam concluído que a concentração de progesterona circulante não seria fator limitante no estabelecimento da prenhez e os possíveis danos advindos do estresse térmico ao concepto ocorreriam entre a 
fertilização e $D_{7}$, de modo que a elevação da progesterona estimulada pela $h C G$ ocorre num momento em que os danos ao embrião já tenham sido causados e o seu desenvolvimento já esteja comprometido. Pode-se também concluir que as taxas de prenhez à $I A_{T F}$ não foram limitadas por baixas concentrações de progesterona no período crítico, contrastando com os achados de Marques (2002) para receptoras e embrião.

Da tabela 2.2 depreende-se que o $17_{\beta}$-estradiol reduziu a taxa de prenhez à IATF e esse dano não foi revertido ao longo da estação reprodutiva, pois o efeito do $17_{\beta}$-estradiol sobre a taxa de prenhez acumulada também foi significativo $(P<0,05)$. Peters (1996) havia demonstrado que a produção do $17_{\beta}$-estradiol folicular ainda na fase luteínica do ciclo estral teria influência negativa sobre o reconhecimento materno da prenhez. No presente experimento, a aplicação de $17_{\beta}$-estradiol exógeno no $D_{12}$ pode ter tido efeito análogo. No experimento 1 deste estudo e em Bergamaschi (2005) o 17 $\beta_{\beta}$-estradiol induziu um efeito luteolítico quando aplicado no $D_{12}$. Essa mesma ocorrência levaria à mortalidade embrionária precoce nas vacas deste experimento. Fenômeno similar de perda embrionária foi descrito por Colazzo

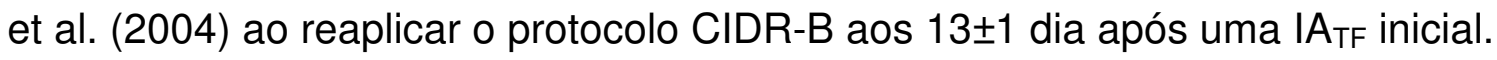

Reforçando as inferências de Peters (1996) e Colazzo et al. (2004) verificouse ainda (Tabela 2.1) que a taxa de prenhez à $I_{T F}$ para o grupo $E_{2}$ foi mais baixa $(P<0,05)$ do que a de qualquer outro grupo experimental. Esse efeito detrimental do $17_{\beta}$-estradiol sobre as taxas de prenhez se deve á ocorrência de luteólise induzida, como demonstrado em Bergamaschi (2005) e também no experimento 1 deste estudo.

A taxa de prenhez acumulada (Tabela 2.1) do grupo $\mathrm{hCG} / \mathrm{E}_{2}$ tendeu $(0,10>P>0,05)$ ser mais baixa $(65,4 \%)$ que a do controle $(81,8 \%)$ e do hCG $(80,0 \%)$ 
embora equivalente $(P>0,10)$ à do grupo $E_{2}(67,3 \%)$. Em oposição ao esperado a partir dos resultados do experimento 1 deste estudo, o grupo $\mathrm{hCG} / \mathrm{E}_{2}$ obteve taxa de prenhez à $I A_{T F}(18,2 \%)$ superior $(P<0,05)$ à do grupo $E_{2}(5,4 \%)$. Nesse caso, especula-se o eventual efeito luteotrófico da hCG, o que pode ter "resgatado" a função luteínica de algumas vacas com potencial progesteronemia mais baixa. Tal hipótese ganha força, uma vez que a dose de $5 \mathrm{mg}$ de $17_{\beta}$-estradiol não teve eficiência de $100 \%$ na indução da luteólise, pois três vacas do grupo $E_{2}(5,4 \%)$ foram refratárias ao tratamento e mantiveram a prenhez. Salienta-se que, embora Wiltbank et al. (1961) tivessem reportado o efeito do estradiol em causar a regressão luteínica, outros relatos foram consistentes ao verificar que nem sempre as vacas Bos indicus com presença de corpo lúteo respondem com luteólise aos desafios impostos por agentes luteolíticos exógenos. Isto está bem documentado para a prostaglandina $F_{2 \alpha}$ e seus análogos (ALONSO et al., 1995; GALINA; ARTUR 1990; MORENO et al., 1986; PINHEIRO et al., 1998).

Da tabela 2.1 especula-se que a taxa de ciclicidade das vacas não tenha alcançado $100 \%$ ao longo da estação de reprodução, pois as taxas de serviço foram mais baixas $(P<0,05)$ para as inseminações de repasse do que para a $I_{T F}$. Com efeito, 13 das 220 vacas usadas não tornaram-se prenhes, nem retornaram ao estro depois da $I_{\mathrm{TF}}$. $\mathrm{O}$ sistema para a detecção do estro aplicado nesse experimento, rufiões equipados com "chin-ball", foi sugerido por Marques et al. (2004) devido à alta freqüência de apresentação de "cios" curtos durante a noite e a madrugada. Por outro lado, a despeito de não ter sido constatada diferença $(P>0,05)$, as taxas de serviço à $1^{a} \mathrm{I} A$ de repasse para os grupos $\mathrm{E}_{2}$ e $\mathrm{hCG} / \mathrm{E}_{2}$ tiveram valores percentuais mais baixos. A resultante é que ao final da estação reprodutiva a taxa de prenhez acumulada para as vacas que receberam o $17_{\beta}$-estradiol no $D_{12}$ (Tabela 2.2 - grupos 
$\left.E_{2}+h C G / E_{2}\right)$ foi menor $(66,4 \% ; P<0,05)$ que das vacas que não receberam (grupos controle + hCG) esse estrógeno $(80,9 \%)$.

As taxas de concepção às $I A_{s}$ de repasse foram mais altas $(P<0,05)$ do que à IA $A_{T F}$. No caso de uma estação reprodutiva relativamente curta (64 dias), o impacto da baixa concepção inicial reflete-se em limitação para se atingir uma taxa de prenhez otimizada ao final da estação. Neste contexto, ressalta-se que além dos fatores ligados ao protocolo de indução da ovulação previamente discutidos, especula-se a influência negativa de fatores estressores sobre a concepção.

Numa revisão feita por Bó et al. (2003) estão descritos alguns dos efeitos de agentes climáticos (altas temperaturas e umidade, ventanias, etc.) e de manejo (movimentação, contenção) sobre o comportamento de monta dos animais e outras atividades relativas ao estro e ovulação. Nessa revisão, os autores afirmaram que agentes estressores alteram a freqüência e a amplitude dos pulsos de $\mathrm{LH}$ e de liberação de $\mathrm{GnRH}$ retardando o pico pré-ovulatório do $\mathrm{LH}$ com subsequente redução na expressão do comportamento estral e da ovulação. Para Galina et al. (1996) este mecanismo explica as baixas taxas de serviço e de fertilidade dos programas de IA aplicados ao bovinos Bos indicus.

Bergamaschi (2005) sugeriu que o manejo intensivo aplicado às vacas Nelore envolvendo a rotação de pastagens e o arraçoamento em cocho pode resultar em taxas de prenhez mais baixas para vacas inseminadas artificialmente do que para aquelas servidas por touros. Suspeita similar pode ser levantada sobre os resultados do presente experimento, pois várias situações de estresse foram aplicadas. De fato, intensa movimentação e contenção das fêmeas foi procedida para a avaliação ginecológica, seleção, indução da ovulação (OvSynch requer três operações) e IA $A_{T F}$. Além disso, após a $I_{T F}$ o rebanho foi submetido a um re-arranjo 
para a formação de quatro lotes, correspondentes aos quatro grupos experimentais. Consequentemente, a estrutura social hierárquica foi modificada. Dobson e Smith (1998) relataram períodos de serviço mais longos para as fêmeas "rebaixadas" socialmente dentro de um rebanho.

No caso da continuidade da estação de reprodução, o rebanho foi submetido diariamente ao acompanhamento do estro pelos inseminadores seguido por movimentação de cada do lote para a apartação da fêmeas a serem inseminadas e sofreram ainda movimentação menos freqüente a para mudança de piquete. Neste caso, Mann (2001) verificou que vacas leiteiras sob estresse das situações exigidas para a experimentação científica tiveram ovulação tardia e as taxas de prenhez foram reduzidas significativamente. A ovulação tardia resulta em falhas da fertilização pela liberação de um ovócito envelhecido, produzindo um embrião de menor viabilidade (HUNTER, 1982). Numa outra situação dentro do mesmo estudo, as vacas foram "ambientadas" previamente e a fertilidade foi restabelecida, atingindo taxas de prenhez de $89,7 \%$. 


\subsection{CONCLUSÕES}

A suplementação luteotrófica provida pela hCG para rebanhos de vacas Nelore sem bezerro ao pé, em bom ECC e alta taxa de ciclicidade é dispensável pois não aumentou as taxas de concepção ou prenhez.

A reprogramação ovariana mediada pela aplicação exógena do $17_{\beta}$-estradiol após uma IA $A_{T F}$ exige cautela pois sua aplicação está relacionada à obtenção das menores taxas de prenhez.

A hCG minimiza os efeitos deletérios da aplicação exógena do $17_{\beta}$-estradiol.

Há a necessidade do desenvolvimento de estratégias para a redução da mortalidade embrionária em bovinos. 
EXPERIMENTO 3

REMOÇÃO FARMACOLÓGICA OU MECÂNICA DO FOLÍCULO DOMINANTE DURANTE O PERÍODO CRÍTICO EM VACAS DE CORTE DA RAÇA RED ANGUS 
5 EXPERIMENTO 3 - REMOÇÃO FARMACOLÓGICA OU MECÂNICA DO FOLÍCULO DOMINANTE DURANTE O PERÍODO CRÍTICO EM VACAS DE CORTE DA RAÇA RED-ANGUS (Bos taurus taurus)

\section{$5.1 \quad$ JUSTIFICATIVA}

Após diversos estudos (DISKIN; SREENAN, 1980; DUNNE et al., 2000) e algumas revisões de literatura sobre mortalidade embrionária em bovinos (KUNZ et al., 2002; VANROOSE et al., 2000) ficou estabelecido o efeito desse tipo de perda na eficiência produtiva e reprodutiva de rebanhos tanto de corte como de leite. As percentagens de perda embrionária se situam em geral entre $20 \%$ e $40 \%$ (DISKIN; SREENAN, 1980; DUNNE, 2000; HUMBLOT, 2001) e elas ocorrem preponderantemente até $016^{\circ}$ dia da gestação.

Com a adoção de modernas biotécnicas da reprodução como a $I A_{T F}$ e principalmente a transferência de embriões (TE) os investimentos nas explorações pecuárias exigem lucratividade mais robusta e rápida. No caso do Brasil, durante o ano de 2002 foram transferidos mais de 110.000 embriões bovinos e portanto, fatores que otimizem a eficiência da técnica devem ser prioritários (MARQUES et al., 2004). Broadbent et al. (1991) enfatizaram o importante papel da seleção das receptoras de embriões para o retorno econômico da TE e Spell et al. (2001) concluíram que a retenção bem sucedida da prenhez após a inovulação depende de fatores relacionados ao embrião, à receptora e à interação entre ambos. 
No caso da TE o reconhecimento da prenhez pela receptora esta condicionado à habilidade do embrião inovulado em sinalizar sua presença no útero por meio da secreção do interferon- $\tau$ (MANN et al., 1998). Ocorre que o desenvolvimento embrionário e a sua capacidade de secretar interferon- $\tau$ são relacionados à concentração de progesterona circulante materna (GEISERT et al., 1988). Portanto, com o objetivo de aumentar a taxa de prenhez das receptoras, têm sido desenvolvidos tratamentos não só para aumentar essa concentração de progesterona (BÓ et al., 2002) mas também para retardar ou bloquear a luteólise (BINELLI et al., 2001) nas receptoras após a inovulação. O uso da hCG ou do GnRH entre os dias 4 e 7 após o estro induziu a formação de um corpo lúteo acessório e agiu como um estímulo gonadotrófico ao corpo lúteo DIAZ et al. 1998; MARQUES, 2002; PRICE; WEBB, 1989; RAJAMAHENDRAN; SIANANGAMA, 1992; SCHMITT et al. 1996a), com conseqüente aumento nas concentrações plasmáticas de progesterona (SANTOS et al., 2001).

O papel do estradiol endógeno na luteólise ficou evidenciado após os estudos de Hughes et al. (1987) que submeteram os folículos ovarianos à irradiação e verificaram que houve a eliminação reversível da produção de estradiol folicular, retardamento da luteólise e prolongamento do ciclo estral. Além disso ficou demonstrado que a remoção física dos foliculos ovarianos (VILLA-GODOY et al., 1985) aumentou a duração do ciclo estral. Corroborando esses achados, porém com outra abordagem, Moser et al. (1989) e Turzillo e Fortune (1990) demonstraram que a aplicação exógena de fluído folicular bovino (previamente tratado com carvão para torná-lo isento de esteróides) houve atraso no desenvolvimento do folículo dominante e os eventos que precedem a luteólise foram retardados. O papel da inibina também foi destacado pelos autores. Pritchard et al. (1994) demonstraram 
que a produção de estradiol é reduzida durante a prenhez. Coletivamente, esses achados permitem concluir que tanto o estradiol produzido intra-folicularmente induziram a luteólise. Neste contexto, o desenvolvimento de estratégias que promovam a redução na produção e/ou nos efeitos do estradiol durante o período crítico do reconhecimento da prenhez deve diminuir as taxas de mortalidade embrionária.

No presente experimento, conduzido com vacas da raça Red Angus (Bos taurus taurus) foram comparadas a remoção do folículo dominante por meio mecânico ou farmacológico como estratégias para aumentar a duração da fase luteínica e do ciclo estral. Além disso e mediante dosagens da progesterona, visouse: quantificar a ação luteotrófica da remoção folicular ao final da fase luteínica, bem como determinar o dia da luteólise e a duração da fase luteínica. 


\subsection{MATERIAL E MÉTODO}

O Material e Método compreendeu o local do experimento, os animais e seu manejo, a formação dos grupos, a aspiração folicular, a coleta de sangue para dosagem da progesterona plasmática, bem como o delineamento experimental e a análise estatística.

\subsubsection{Local do experimento, animais e manejo}

O experimento foi desenvolvido na fazenda Cardinal, sede do grupo VPJ, em Mococa, região central do estado de São Paulo (21ํ $28^{\prime}$ Latitude Sul e 47우 $01^{\prime}$ Longitude Oeste), a 665 metros de altitude. O clima é tropical, do tipo CwA na classificação de Köppen, caracterizado como verão quente e inverno seco. As temperaturas média anuais são de $22,4^{\circ} \mathrm{C}$ a $23,9^{\circ} \mathrm{C}$. Nos últimos cinco anos, a precipitação pluvial média anual variou entre $1337 \mathrm{~mm}$ a $1916 \mathrm{~mm}$, sendo o trimestre de menor precipitação de junho a agosto.

Foram utilizadas 30 vacas da raça Red-Angus (Bos taurus taurus), entre 31 e 58 meses de idade, ordens de parto entre $1^{a}$ e $3^{a}$, tendo entre 108 e 213 dias pósparto e com bezerro ao pé. Ao inicio e ao final do experimento as fêmeas foram pesadas e avaliadas quanto ao ECC (SPITZER, 1986). Apenas as vacas com $4 \leq$ ECC $\leq 6$ foram designadas para a formação dos grupos experimentais. 
No início do experimento, as fêmeas foram submetidas ao exame ginecológico por palpação retal, avaliando-se os ovários por ultra-sonografia transretal. As vacas foram classificadas consoante à condição ovariana conforme descrito por Madureira et al. (2004), sendo utilizadas para a composição dos grupos experimentais apenas as vacas classificadas como escore 1 (corpo lúteo presente) ou aquelas que possuíam ovários com comprimento entre 15 e $30 \mathrm{~mm}$ e com crescimento folicular associado a turgidez uterina (escore 2).

Os animais foram manejados em piquetes de grama Estrela (Cynodon plectostachyum Pilger) e suplementados com feno de aveia (Avena sativa L.) e $3 \mathrm{~kg} / \mathrm{dia}$ de rolão de Milho (Zea maiz L.). Havia nos piquetes livre acesso a sal mineralizado e água.

\subsubsection{Formação dos grupos}

O ciclo estral das vacas foi sincronizado pela inserção subcutânea de um implante comercial $^{9} \mathrm{com} 3 \mathrm{mg}$ de norgestomet (análogo sintético da progesterona) na face convexa da orelha, associado a uma injeção intramuscular da combinação de $3 \mathrm{mg}$ do norgestomet e $5 \mathrm{mg}$ do valerato de estradiol. O implante foi removido nove dias depois, concomitantemente à aplicação de uma injeção intramuscular com $300 \mathrm{UI}$ da gonadotrofina da égua prenhe $\left(\mathrm{eCG}^{11}\right)$.

A confirmação da ovulação das vacas sincronizadas foi realizada por meio de dois exames ultra-sonográficos dos ovários. O primeiro foi efetuado 48 horas após a

\footnotetext{
${ }^{10}$ Crestar $^{\circledR}$, INTERVET.

${ }^{11}$ Folligon $^{\circledR}$, INTERVET.
} 
remoção do implante auricular para verificar a presença de um folículo dominante (diâmetro $\geq 7 \mathrm{~mm}$ ) e o segundo 30 horas depois do primeiro. A ovulação foi caracterizada como o desaparecimento do folículo ovulatório que estava presente no exame prévio e a subsequente formação de um corpo lúteo. As fêmeas que ovularam foram distribuídas por sorteio aleatório nos seguintes grupos: Controle $\left(\mathrm{G}_{\mathrm{CT}}\right)$ que não recebeu tratamento adicional $(n=5)$; Remoção Farmacológica $\left(\mathrm{G}_{\mathrm{RF}}\right)$ que recebeu 200 $\mu$ g de gonadorrelina ${ }^{12}$ (análogo do $\mathrm{GnRH}$ ) via intramuscular no $\mathrm{D}_{5} \mathrm{e}$ 3000 UI da hCG ${ }^{13}$ no $D_{13}(n=6)$ e Remoção Mecânica $\left(G_{R M} ; n=6\right)$ que foi submetido à punção folicular nos dias $14\left(D_{14}\right) ; 17\left(D_{17}\right)$ e $20\left(D_{20}\right)$. Considerou-se como $D_{1}$ o dia da ovulação.

Em todos os grupos procedeu-se a observação do estro, por 60 minutos, duas vezes ao dia (as 07:00 e 17:00 horas) a partir do $D_{15}$ até a manifestação do estro. A observação teve como data limite $\circ \mathrm{D}_{30}$, momento em que o experimento se encerrou. Para auxiliar na deteç̧ão dos cios, houve a inclusão de um rufião por grupo (proporção aproximada de um para cada cinco vacas), o qual foi mantido até o final do experimento.

\subsubsection{Aspiração folicular}

Realizaram-se três punções ovarianas em que se removeram todos os folículos com diâmetro $\geq 7 \mathrm{~mm}$ das vacas do $G_{R M}$. As punções seguiram o procedimento descrito por Rodrigues e Garcia (1997) utilizando uma sonda

\footnotetext{
${ }^{12}$ Fertagyl $^{\circledR}$, INTERVET.
} 
idealizada por Hill (Maple Hill Embryos Inc. - Woodstock, Ontario, Canada) com o apoio de um aparelho de ultra-som (ALOKA-SSD 500, em modo-B com transdutor retal de 5,0 MHz). Após obter imagens ultra-sonográficas de cada ovário, o operador localizava manualmente os folículos com diâmetros $\geq 7 \mathrm{~mm}$ para introduzir em seguida a sonda de Hill até o fornix vaginal. Procedia-se então a perfuração da parede vaginal e posterior punção do folículo, com auxílio de palpação transretal. Em seguida, era tomada nova imagem ultra-sonográfica para confirmação da ruptura folicular. Esta operação era repetida até a punção de todos os folículos desejados.

Cumpre lembrar que aproveitaram-se as ocasiões de punção do $G_{R M}\left(D_{14}, D_{17}\right.$ e $D_{20}$ ), para tomarem-se imagens ultra-sonográficas dos ovários visando verificar (nas vacas de todos os grupos) a presença de corpos lúteos acessórios e de folículos com diâmetro $\geq 7 \mathrm{~mm}$.

5.2.4 Coleta de sangue e dosagem de progesterona plasmática

Foram coletadas diariamente amostras de sangue para a separação do plasma e posterior dosagem de progesterona, desde $D_{15}$ até a apresentação do estro, tendo como data limite $\circ D_{30}$. As amostras foram obtidas por punção da veia jugular. O sangue coletado, em tubos de vidro $(15 \mathrm{~mL})$ contendo $350 \mu \mathrm{L}$ de uma solução a $30 \%$ de citrato de sódio, foi acondicionado em gelo para posterior centrifugação a aproximadamente $700 \times \mathrm{g}$ por 15 minutos. O plasma obtido foi transferido para tubos plásticos e então congelado e estocado em freezer $\left(-20^{\circ} \mathrm{C}\right)$.

${ }^{13}$ Chorulon $5000^{\circledR}$, INTERVET. 
Os protocolos de administração dos tratamentos estão apresentados na figura 3.1 .

A dosagem de progesterona foi realizada segundo procedimento descrito em Knickerbocker et al. (1986a) e validado pelo LFEM - Laboratório de Fisiologia e Endocrinologia Molecular do Departamento de Reprodução Animal da Faculdade de Medicina Veterinária e Zootecnia da Universidade de São Paulo em Pirassununga. O coeficiente de variação inter-ensaio esteve entre $0,7 \%$ e 5,3\% e os coeficientes intraensaio entre $0,6 \%$ e $3,9 \%$ e entre $7,1 \%$ e $12,9 \%$, respectivamente para referências contendo baixa e média concentração de progesterona.

\subsubsection{Delineamento experimental e análise estatística}

O delineamento experimental empregado foi o inteiramente casualizado. Os resultados foram analisados de acordo com a natureza específica de cada variável utilizando-se o programa SAS System for Windows (STATISTICAL ANALYSIS SYSTEM, 1993). Nos casos em que os dados não atenderam as premissas de normalidade dos resíduos e de homogeneidade das variâncias, procedeu-se a sua transformação pelas funções logarítmica ou de raiz quadrada. Os dados transformados foram submetidos às análises apropriadas pelo SAS.

A concentração plasmática de progesterona foi analisada por ANOVA com medidas repetidas no tempo pelos procedimentos GLM e MIXED do SAS. As variáveis de natureza discreta foram submetidas a ANOVA pelo procedimento GLM do SAS, a exceção daquelas tomadas como "taxas", "freqüências" ou "ocorrências", 
as quais foram expressas como proporções e analisadas aplicando-se o teste exato de Fischer (GOMES, 1987).

Os resultados foram apresentados na forma não-transformada como média pelo quadrados mínimos \pm erro padrão da média. Os efeitos das fontes de variação foram considerados significativos para a probabilidade de até $5 \% \quad(P<0,05)$. Conceituou-se como tendência, quando as probabilidades estiveram entre 5 e 10\% $(0,05<P<0,10)$.

A seguir estão listadas e descritas as variáveis.

- Variável contínua:

- Concentração plasmática de progesterona diária.

- Variável discreta:

- Duração do ciclo estral: intervalo em dias entre o estro induzido e o subseqüente (identificado pelos rufiões).

- Variáveis discretas derivadas das dosagens de progesterona:

- duração da fase luteínica: intervalo em dias entre a ovulação induzida e até a data em que a concentração de progesterona $\left(\left[\mathrm{P}_{4}\right]\right)$ foi $\geq 1 \mathrm{ng} / \mathrm{mL}$;

- maior $\left[\mathrm{P}_{4}\right]$;

- dia do ciclo estral em que ocorreu a maior $\left[\mathrm{P}_{4}\right]$;

- $\left[P_{4}\right]$ média: eqüivale a soma das $\left[P_{4}\right]$ de $D_{15}$ até o último dia da fase luteínica dividida pelo número de dias entre $\mathrm{D}_{15}$ e a último dia da fase luteínica;

- dia da luteólise - dia do ciclo estral em que a $\left[\mathrm{P}_{4}\right]<1 \mathrm{ng} / \mathrm{mL}$;

- intervalo em dias entre a luteólise e o estro. 
CT - controle

\begin{tabular}{|c|c|c|c|}
\hline $\begin{array}{l}\text { Norgestomet } \\
+ \\
\mathrm{E}_{2} \text { (Valerato) } \\
\downarrow\end{array}$ & $\begin{array}{l}\text { Remoção } \\
\text { do implante } \\
+ \\
\text { eCG } \\
\downarrow\end{array}$ & $\begin{array}{l}\text { Ultra-som } \\
\text { (ovulação) }\end{array}$ & $\begin{array}{l}\text { estro } \\
\text { ou } D_{30} \\
\downarrow\end{array}$ \\
\hline 9 dias & 2 dias & $\mathrm{D}_{1+30 \text { Hora }}$ & $\begin{array}{l}\text { Coleta de sangue + rufião } \\
D_{15}\end{array}$ \\
\hline
\end{tabular}

RF - remoção farmacológica

\begin{tabular}{|c|c|c|c|c|c|}
\hline $\begin{array}{l}\text { Norgestomet } \\
+ \\
\mathrm{E}_{2} \text { (Valerato) } \\
\downarrow\end{array}$ & $\begin{array}{l}\text { Remoção } \\
\text { do implante } \\
+ \\
\text { eCG } \\
\quad \downarrow\end{array}$ & $\begin{array}{l}\text { Ultra-som } \\
\text { (ovulação) } \\
\downarrow\end{array}$ & $\begin{array}{l}\text { GnRH } \\
\downarrow\end{array}$ & $\begin{array}{l}\text { hCG } \\
\downarrow\end{array}$ & $\begin{array}{l}\text { estro } \\
\text { ou } D_{30}\end{array}$ \\
\hline 9 dias & 2 dias & & & & Coleta de sangue + rufião \\
\hline
\end{tabular}

RM - remoção mecânica

\begin{tabular}{|c|c|c|c|c|}
\hline $\begin{array}{l}\text { Norgestomet } \\
+ \\
E_{2} \text { (Valerato) } \\
\downarrow\end{array}$ & $\begin{array}{l}\text { Remoção } \\
\text { do implante } \\
+ \\
\text { eCG }\end{array}$ & $\begin{array}{l}\text { Ultra-som } \\
\text { (ovulação) } \\
\downarrow\end{array}$ & $\downarrow_{\downarrow}^{\text {Punções }} \downarrow$ & $\begin{array}{l}\text { estro } \\
\text { ou } D_{30} \\
\end{array}$ \\
\hline 9 dias & 2 dias & & & \\
\hline
\end{tabular}

Figura 3.1 - Protocolos de administração dos tratamentos no experimento 3, Mococa, 2004 


\subsection{RESULTADOS}

A descrição dos resultados segue por variável ou grupo de variáveis.

\subsubsection{Formação dos grupos}

Houve 13 vacas que não foram aproveitadas pois: uma fêmea desenvolveu formação cística ovariana, três vacas não possuíam folículo dominante (diâmetro $\geq 7 \mathrm{~mm}$ ) à ultra-sonografia realizada 48 horas após a remoção do implante e outras nove não ovularam o folículo dominante até 80 horas desde a retirada do implante (assincronía). A formação definitiva dos grupos mostrou-se homogênea, pois não houve efeito $(P>0,05)$ de grupo para os seguintes fatores: idade da vaca $(46,3 \pm 0,4$ meses; $n=14)$, peso vivo $(500,3 \pm 30,5 \mathrm{~kg} ; n=17)$, ECC $(5,0 \pm 0,3 ; n=17)$, dias pós-parto $(150,5 \pm 12,6 ; n=17)$ e ordem de parto ao início do experimento $(1,5$ parto/vaca; $n=17)$. O peso vivo e o ECC ao final do experimento foram de, respectivamente: $505,2 \pm 22,9 \mathrm{~kg}$ e $5,0 \pm 0,3$. 


\subsubsection{Concentração plasmática de progesterona diária}

A análise de progesterona permitiu retirar mais três vacas, pois uma delas desenvolveu formação cística num dos ovários e as outras duas apresentaram apenas traços de progesterona entre $D_{15}$ e $D_{30}$. Deste modo, para as variáveis derivadas da concentração de progesterona, os grupos controle, remoção farmacológica e remoção mecânica ficaram compostos por, respectivamente: cinco ( $\left.n G_{C T}=5\right)$, quatro $\left(n G_{R F}=5\right)$ e quatro $\left(n G_{R M}=4\right)$ vacas.

A análise de variância para a variável concentração da progesterona plasmática foi realizada sobre a variável transformada pela função logarítmica para que se atingisse a homogeneidade das variâncias. A figura 3.2 contém a representação gráfica das concentrações de progesterona plasmática em função do dia do ciclo estral. Verificou-se que os valores para $G_{R F}$ foram maiores $(P<0,05)$ que os demais grupos entre $D_{17}$ e $D_{20}$. Além disso, houve a extensão da fase luteínica nesse mesmo grupo.

\subsubsection{Duração do ciclo estral}

Após 30 dias de observação do estro verificou-se que duas vacas do $G_{R F} e$ três do $G_{R M}$ não apresentaram estro, enquanto todas do $G_{C T}(5 / 5=100 \%)$ mostraram. A duração do ciclo estral foi de $20,0 \pm 1,2$ dias para $G_{C T}(n=5), 29,0 \pm 1,1$ dias para $G_{R F}(n=4)$ e $22,7 \pm 4,0$ dias para $G_{R M}(n=3)$. Não houve diferenças entre os grupos 
quando comparados ao controle, seja em comparação individual (Tabela 3.1) ou pela combinação dos grupos $\left(P=0,13 ; G_{R F}+G_{R M}\right)$.

5.3.4 Imagens ultra-sonográficas dos ovários nas ocasiões de punção

No $G_{\mathrm{RF}}$, constatou-se a formação de corpo lúteo acessório induzido pelo GnRH em duas vacas. Outras duas vacas mostraram corpo lúteo acessório induzido pela hCG. No $G_{C T}$ e no $G_{R M}$ nenhum animal teve corpo lúteo acessório.

Houve vacas com folículos $>8 \mathrm{~mm}$ em todos os grupos, em todas ocasiões de punção. As médias (quadrados mínimos \pm erro padrão da média) para o diâmetro do maior folículo foram de: $11,2 \pm 1,2 \mathrm{~mm}(n=5)$ em $D_{14} ; 13,2 \pm 1,0 \mathrm{~mm}(n=5)$ em $D_{17} ; \mathrm{e}$ $11,4 \pm 1,9 \mathrm{~mm}(\mathrm{n}=5)$ em $\mathrm{D}_{20}$ para $\circ \mathrm{G}_{\mathrm{CT}}$. No caso do $\mathrm{G}_{\mathrm{RF}}$, essas médias foram: de $11,6 \pm 2,4 \mathrm{~mm}(n=5)$ em $D_{14} ; 12,7 \pm 1,7 \mathrm{~mm}(n=3)$ em $D_{17} ; \mathrm{e} 15,4 \pm 3,2 \mathrm{~mm}(n=5)$ em $D_{20}$ e para o $G_{R M}$ observaram-se: $10,8 \pm 1,3 \mathrm{~mm}(n=4)$ em $D_{14} ; 11,0 \pm 1,0 \mathrm{~mm}(n=2)$ em $D_{17}$; e $10,2 \pm 1,0 \mathrm{~mm}(n=4)$ em $D_{20}$. Na tabela 1 do Apêndice $B$ constam os dados completos dos folículos maiores que $8 \mathrm{~mm}$ em $D_{14}, D_{17}$ e $D_{20}$.

\subsubsection{Variáveis derivadas das dosagens de progesterona}

$\mathrm{Na}$ tabela 3.2 constam a análise de variância e as médias dos quadrados mínimos e erros padrão da média para todas as variáveis discretas derivadas das 
dosagens de progesterona. Cumpre lembrar, que as análises de variância para a duração da fase luteínica, o dia da luteólise e o intervalo entre a luteólise e a manifestação do estro foram feitas sobre as variáveis transformadas pela função logarítmica para normalizar a distribuição dos seus resíduos. No entanto, suas médias e erros foram estimadas sobre as variáveis não-transformadas.

A fase luteínica do $G_{R F}(22,60 \pm 1,05$ dias $)$ foi mais longa $(P<0,01)$ que a do $\mathrm{G}_{\mathrm{CT}}\left(17,20 \pm 1,05\right.$ dias) ou do $\mathrm{G}_{\mathrm{RM}}(17,75 \pm 1,17$ dias), pois a luteólise (dia seguinte) se deu tardiamente em $G_{R F}(P<0,01)$. Do mesmo modo que as concentrações máxima e média da progesterona também foram maiores (respectivamente $P<0,05$ e $P<0,01$ ) para $G_{R F}$ (respectivamente de $13,52 \pm 1,74$ e de $7,95 \pm 0,90 \mathrm{ng} / \mathrm{mL}$ ) do que para $G_{C T}$ (respectivamente de $6,37 \pm 1,74$ e de $4,54 \pm 1,94 \mathrm{ng} / \mathrm{mL}$ ) ou para $\mathrm{G}_{\mathrm{RM}}$ (respectivamente de $4,54 \pm 1,94$ e de $3,06 \pm 1,01 \mathrm{ng} / \mathrm{mL}$ ). Por sua vez, o intervalo entre a luteólise e a ocorrência do estro tendeu ser mais curto $(P<0,10)$ para $\circ G_{C T}$ $(1,80 \pm 0,72$ dias $)$ que os demais grupos $(4,00 \pm 0,81$ e $4,50 \pm 1,15$ dias, respectivamente para $\mathrm{G}_{\mathrm{RF}}$ e $\mathrm{G}_{\mathrm{RM}}$ ).

A variável dia do ciclo estral da concentração máxima de progesterona não atendeu as premissa de normalidade dos resíduos, mesmo após transformações pelas funções logarítmicas e de raiz quadrada. Suas médias dos quadrados mínimos e erros padrão da média foram de: $15,0 \pm 0,0 ; 17,0 \pm 1,2$ e 16,0 $\pm 1,1$, respectivamente para $\mathrm{G}_{\mathrm{TC}} ; \mathrm{G}_{\mathrm{RF}} ; \mathrm{G}_{\mathrm{RM}}$.

Em adição, foi elaborada a tabela $3.3 \mathrm{com}$ dados individuais das vacas que fizeram parte do grupo $G_{R F}$. Na figura 3.3 há as concentrações de progesterona ao final da fase luteínica para todas as vacas de todos os grupos. 


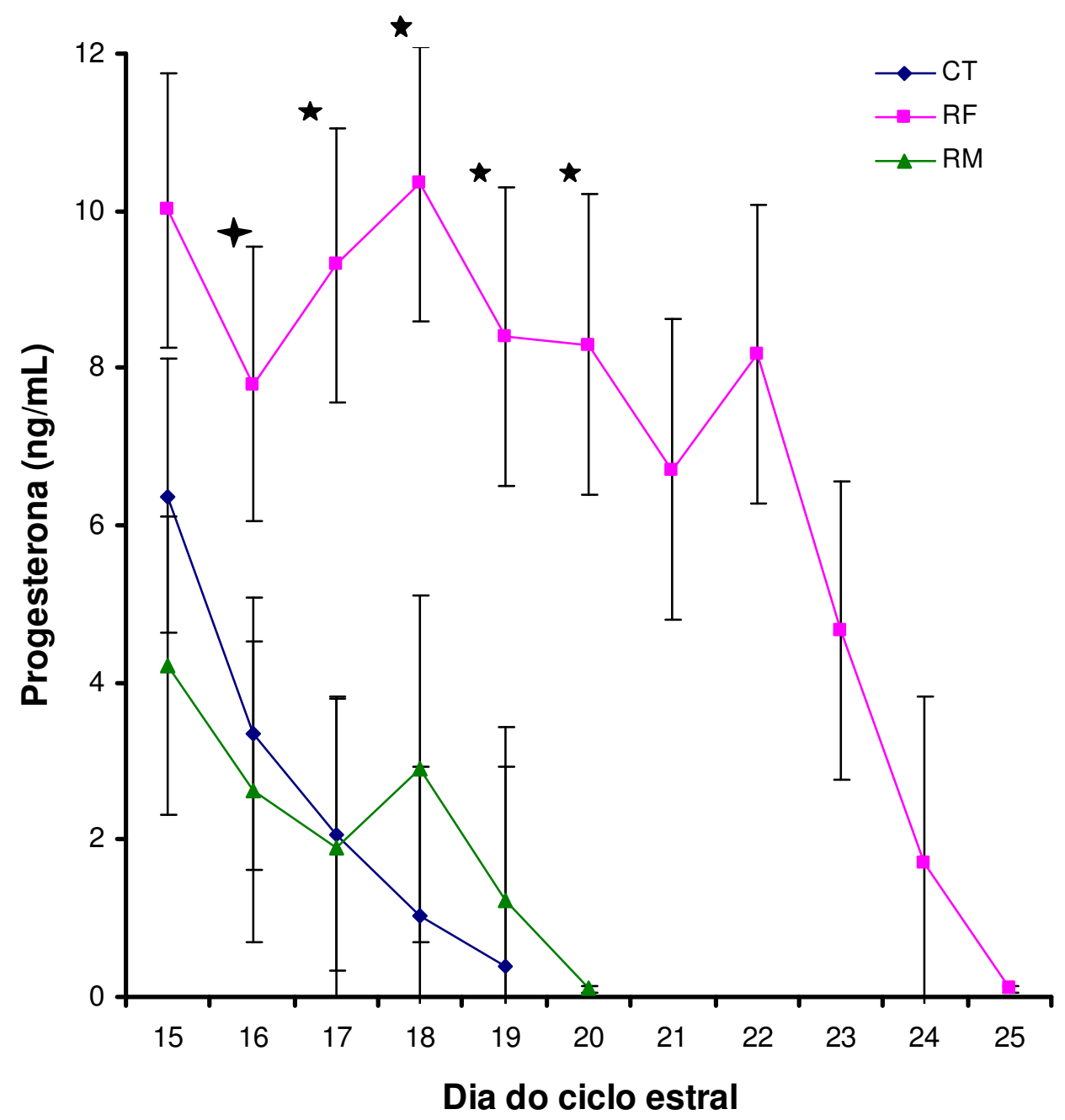

Figura 3.2 - Médias dos quadrados mínimos e erros-padrão da média para concentração plasmática de progesterona $(\mathrm{ng} / \mathrm{mL})$ ao final da fase luteínica do ciclo estral para os grupos: controle(CT), remoção farmacológica $(R F)$ e remoção mecânica (RM). Médias em mesmo dia diferem estatisticamente se: $+(0,10<P<0,05)$ e $\star(P<0,01)$. Mococa, 2004 
Tabela 3.1- Níveis de probabilidade pelo teste exato de Fischer, para as comparações das taxas de manifestação do estro até 30 dias depois da ovulação induzida. (Graus de Liberdade=1). Mococa, 2004

\begin{tabular}{lcc} 
& \multicolumn{2}{c}{ Grupo } \\
\cline { 2 - 3 } Grupo & $\begin{array}{c}\text { Remoção } \\
\text { Mecânica }\end{array}$ & Remoção \\
& $0,12^{\text {ns }}$ & $0,27^{\text {ns }}$ \\
Controle & - & $0,38^{\text {ns }}$ \\
Remoção Mecânica & & \\
\hline
\end{tabular}


Tabela 3.2 - Médias dos quadrados mínimos (erros-padrão da média) para variáveis discretas relativas à função luteínica e à luteólise. São Carlos, 2004

\begin{tabular}{|c|c|c|c|c|c|}
\hline \multirow{3}{*}{$\begin{array}{l}\text { Variável } \\
\text { Dependente }\end{array}$} & \multicolumn{3}{|c|}{ Médias \pm erros-padrão da média } & \multirow{3}{*}{$\operatorname{Pr}>\mathrm{F}$} & \multirow{3}{*}{$\mathrm{R}^{2}$} \\
\hline & \multirow[t]{2}{*}{ Controle } & \multirow{2}{*}{$\begin{array}{c}\text { Remoção } \\
\text { Farmacológica }\end{array}$} & \multirow{2}{*}{$\begin{array}{l}\text { Remoção } \\
\text { Mecânica }\end{array}$} & & \\
\hline & & & & & \\
\hline FASELUT (dias) $^{a}$ & $17,20 \pm 1,05$ & $22,60 \pm 1,05$ & $17,75 \pm 1,17$ & 0,01 & 0,59 \\
\hline P4MAX $(\mathrm{ng} / \mathrm{mL})^{\mathrm{b}}$ & $6,37 \pm 1,74$ & $13,52 \pm 1,74$ & $4,54 \pm 1,94$ & 0,05 & 0,56 \\
\hline$\underset{c}{\mathrm{P} 4 M E D}(\mathrm{ng} / \mathrm{mL} / \mathrm{dia})$ & $4,07 \pm 0,90$ & $7,95 \pm 0,90$ & $3,06 \pm 1,01$ & 0,01 & 0,58 \\
\hline Dia da luteólise ${ }^{d}$ & $18,20 \pm 1,05$ & $23,60 \pm 1,05$ & $18,75 \pm 1,17$ & 0,01 & 0,59 \\
\hline Inter Lise-cio (dias) ${ }^{\mathrm{e}}$ & $1,80 \pm 0,72$ & $4,00 \pm 0,81$ & $4,50 \pm 1,15$ & 0,10 & 0,44 \\
\hline
\end{tabular}


Tabela 3.3 - Resposta individual das vacas do grupo remoção farmacológica ${ }^{1}$ em relação à formação de corpo lúteo $(\mathrm{CL})$ acessório, produção de progesterona e manifestação do estro. Mococa, 2004

CL acessório $^{2}$

Vaca $\left[\mathrm{P}_{4}\right]$ máxima $^{3} \quad$ Fase luteínica $^{4} \quad$ Dia do estro $(\mathrm{ng} / \mathrm{mL}) \quad$ (dias)

GnRH $\quad H C G$

73

0

1

7,16

22

28

104

1

0

9,33

17

186

0

1

15,35

27

30

300

0

0

15,08

23

28

313 1

0

20,71

24

30

1. Este grupo recebeu $200 \mu \mathrm{g}$ de gonadorrelina no $\mathrm{D}_{5}$ e $3000 \mathrm{UI}$ da hCG no $\mathrm{D}_{12}$;

2. Identificado nas ultra-sonografias de $D_{14}, D_{17}$ e $D_{20}$;

3. Maior Concentração de progesterona plasmática $\left(\left[P_{4}\right]\right)$ entre $D_{15}$ e a luteólise;

4. Último dia do ciclo em que $a\left[P_{4}\right]$ foi $\geq 1,0 \mathrm{ng} / \mathrm{mL}$. 


\section{Controle}
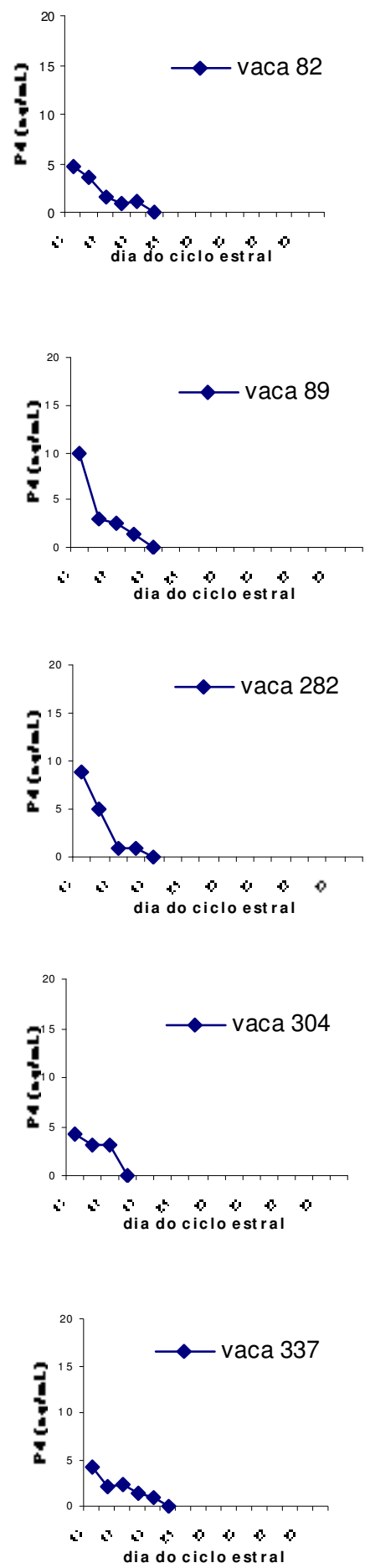

Remoção Farmacológica
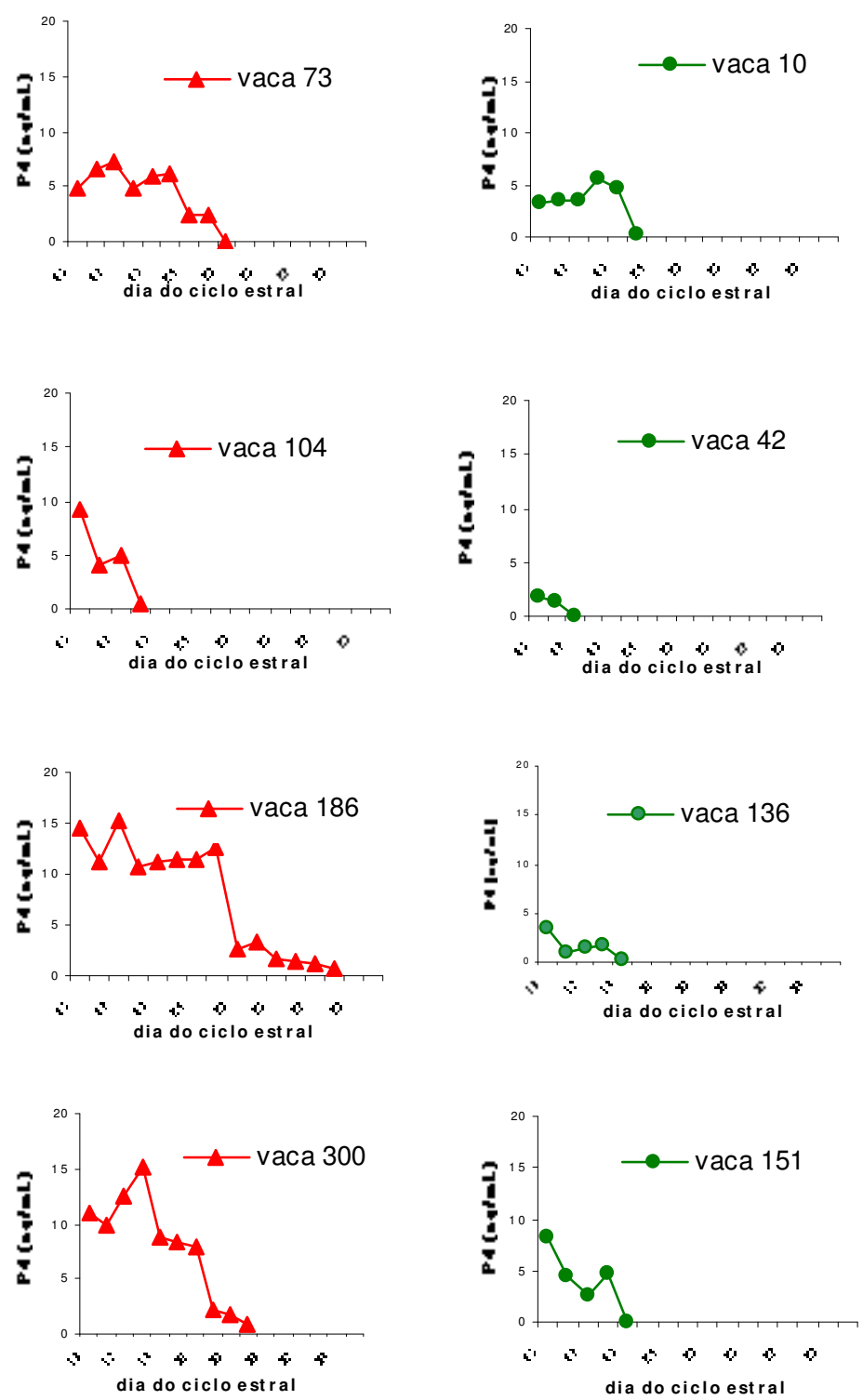

Figura 3.3 -

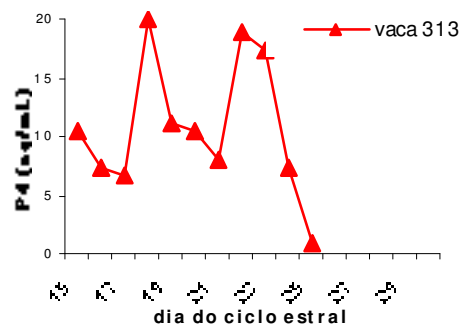




\subsection{DISCUSSÃO}

A taxa líquida de aproveitamento após a indução do ciclo estral foi de 56,7\% (17/30 vacas). Essa resposta deveu-se, principalmente, ao baixo percentual de ovulações síncronas após o uso do protocolo para sincronização inicial do ciclo estral. Baruselli et al. (2004b) e Bergamaschi (2005) lograram taxas de ovulação síncrona, respectivamente de $73,1 \%$ e $70 \%$ após a adição da eCG ao protocolo Crestar $^{\circledR}$ aplicado em vacas Nelore. No entanto, o presente experimento teve como objeto vacas de raça européia, com bezerro ao pé e foi realizado em pleno verão com extremos de chuva, temperatura ambiente e umidade relativa do ar. Em adição, a dose empregada da eCG foi de $300 \mathrm{UI}$, enquanto que relatos mais bem sucedidos empregaram doses maiores de gonadotrofina.

Com relação às estratégias propostas, o $\mathrm{G}_{\mathrm{RF}}$ foi capaz de prolongar $(\mathrm{P}<0,05)$ a fase luteínica, ou seja retardar a luteólise, bem como aumentar $(P<0,01)$ as concentrações circulantes de progesterona entre os dias 17 e 20 do ciclo estral (Tabela 3.2 e Figura 3.2). Por outro lado, ambas estratégias testadas $\left(G_{R F}\right.$ e $\left.G_{R M}\right)$ não foram totalmente eficientes na remoção do folículo dominante durante o período crítico (Tabela 1 do Anexo B).

O resultado esperado para o $G_{R F}$ seria que o $G n R H$ causasse a ovulação do folículo dominante da $1^{\sharp}$ onda de crescimento folicular e o recrutamento sincronizado de uma $2^{\mathrm{a}}$ onda. A hCG causaria então a ovulação do dominante dessa $2^{\mathrm{a}}$ onda e a emergência de uma $3^{a}$ onda no $D_{15}$, de modo que não antecipava-se a presença de folículos maiores que $8 \mathrm{~mm}$ pelo menos até $\mathrm{D}_{19}$, limite superior do período crítico de 
reconhecimento da prenhez. Assim, seria assegurado a indisponibilidade de concentrações de estrógeno com magnitude suficiente para deflagrar a luteólise.

No presente experimento, apenas duas vacas responderam com ovulação ao desafio com o GnRH (Tabela 3.3). Achados similares aos de Kastelic e Mapletoft (1998) em que nem sempre o uso de GnRH foi seguido por ovulação. Cavalieri (2004) enfatizou que a eficiência do $\mathrm{GnRH}$ para causar ovulação depende da formulação empregada. Apesar dessa baixa eficiência do $\mathrm{GnRH}$ para causar ovulação, houve bloqueio da luteólise e extensão da fase luteínica (Tabela 3.2). Peters (1996) reportou um efeito anti-luteolítico do $G n R H$, se aplicado entre $D_{11}$ e $D_{13}$ após a inseminação e especulou sobre o mecanismo desse efeito. Para o autor, o GnRH suprimiu a secreção folicular do $17_{\beta}$-estradiol e uterina da $\mathrm{PGF}_{2 \alpha}$. No presente experimento, usou-se a hCG em $D_{13}$ ao invés do $G n R H$ no $D_{11}$ ou 12. A hCG induziu a ovulação do folículo existente em $D_{13}$ em duas vacas e causou o prolongamento da fase luteínica e o retardamento da luteólise em quatro animais (Tabela 3.3 e Figura 3.3).

No $G_{R M}$ previa-se a remoção física dos folículos $\geq 5 \mathrm{~mm}$ por aspiração transvaginal em $D_{14}, D_{17}$ e $D_{20}$, o que resultaria na inexistência de folículos $\geq 8 \mathrm{~mm}$ entre $D_{14}$ e $D_{24}$, retardando assim o estímulo estrogênico para a luteólise. Porém, o $G_{R M}$ não foi totalmente eficiente na remoção folicular e provavelmente, não provocou a emergência de uma nova 1,5 dia depois como relatado por Bó et al. (1995). Assim, não houve o esperado bloqueio da luteólise e o dia da sua ocorrência não diferiu $(P>0,05)$ do $G_{C T}$.

As prováveis causas desse malogro estiveram vinculadas às particularidades da técnica adotada. Poderiam ser conjeturadas: $1^{2}$ ) o intervalo entre punções foi prolongado demais; $2^{\mathrm{a}}$ ) o limite do tamanho dos folículos destinados à punção foi 
exagerado e $3^{\mathrm{a}}$ ) a acurácia na remoção de folículos com diâmetros menores é baixa quando da técnica com a sonda de Hill. A $1^{3}$ causa provável pode ser descartada pois, Bodensteiner et al. (1996) estabeleceram critérios de punção que asseguram a ruptura do folículo dominante daquela onda e recomendaram intervalos de três dias entre punções, desde que fossem aspirados os três maiores folículos. Para Martinez et al. (2004) a seleção dos folículos ocorre aparentemente 3 dias após a emergência da onda. Portanto tomaria lugar 4,5 dias após a aspiração. Neste caso, o intervalo de três dias entre aspirações seria suficiente para prevenir a influência de um folículo dominante no período crítico, desde que as aspirações fossem bem sucedidas. Portanto, o intervalo adotado foi adequado (BODENSTEINER et al., 1996; MARTINEZ et al., 2004)

No entanto, o tamanho dos folículos puncionados certamente contribuiu para os resultados inconsistentes ora obtidos. Ocorre que, a aplicação da técnica não foi bem-sucedida ao tentar puncionar folículos de diâmetros próximos aos $5 \mathrm{~mm}$, pois no momento da perfuração o operador não tinha a visão ultra-sonográfica do ovário e teve que localizar o folículo por meio de palpação retal. Deste modo, devido à limitação da técnica, adotou-se como critério factível puncionar aqueles com diâmetro $\geq 7 \mathrm{~mm}$. Essa medida $(7 \mathrm{~mm})$ adotada foi inadequada. De fato, um folículo com $6 \mathrm{~mm}$ no $D_{14}$ não seria puncionado, poderia assumir a dominância (KASTELIC, 2004) e mantendo uma taxa de crescimento entre $1,5 \mathrm{~mm} /$ dia (BERGAMASCHI, 2005) e 1,8mm/dia (GINTHER et al., 1989a) atingiria aproximadamente $11 \mathrm{~mm}$ de diâmetro em $D_{17}$, com plena atividade esteroidogênica.

A técnica em si não teve a acurácia requerida para remover folículos entre $5 \mathrm{~mm}$ e $7 \mathrm{~mm}$ de diâmetro. Bodensteiner et al. (1996) recomendaram que para intervalo de três dias entre punções, devem ser aspirados os três maiores folículos. 
Ainda, independentemente do intervalo entre aspirações, se forem aspirados os três maiores e o diâmetro deles for superior aos $7 \mathrm{~mm}$ fica assegurada a ruptura do dominante daquela onda. Baracaldo et al. (2000) sugeriram a remoção dos dois folículos maiores para ocorrer a emergência de uma nova onda.

No presente experimento, a análise da imagem ultra-sonográfica em $D_{17}$ (Tabela 1 do Apêndice $B$ ) aliada às dimensões observadas nos folículos puncionados em $D_{14}$ e depois em $D_{20}$ permitem inferir que não houve a ruptura de todos os maiores folículos e nem a conseqüente abolição daquela onda de crescimento. De fato, conjectura-se que em apenas duas das quatro vacas do $G_{R M}$ houve a emergência de uma nova onda de crescimento após a punção de $D_{14}$. Esse evento explicaria o insucesso em retardar a luteólise no $G_{R M}$ pois Martinez et al. (2004) afirmaram que para ocorrer um pico de FSH e emergência de nova onda, todos os folículos $\geq 5 \mathrm{~mm}$ devem ser removidos. Tal recomendação é coerente com o fato de que a concentração de estradiol no fluído folicular do dominante é maior que a de todos os subordinados da mesma onda (FORTUNE et al., 2004), embora a concentração nos $1^{\circ}$ e $2^{\circ}$ maiores folículos é similar durante a fase comum de crescimento, momento em que todos folículos têm potencial para futura dominância (KASTELIC, 2004).

Assim, as imperfeições na remoção folicular com a sonda de Hill permitiram o desenvolvimento de folículos com potencial esteroidogênico, capazes de assumir a dominância antes da próxima punção. Na verdade, posturas conservadoras como as Boni et al. (1997) lograram obter efetiva abolição do ciclo estral quando todos os folículos terciários $(\geq 2 \mathrm{~mm}$ ) foram aspirados numa freqüência de duas vezes por semana com o uso de um aparato para "ovum pick up" (OPU) guiado por ultra-som. Foi enfatizado que para tornar a aspiração folicular bem sucedida em nível de 
campo, são requeridas instalações e equipamento apropriados (MARTINEZ et al., 2004).

Portanto, o uso da metodologia de punção folicular com a sonda de Hill, embora eficaz na terapia de cistos foliculares (RODRIGUES; GARCIA, 1997) não sincronizou a onda de crescimento folicular e permitiu o crescimento de folículos dominantes no intervalo de três dias. Deste modo, para o controle físico do crescimento folicular a ablação dos folículos deve ser feita com aparato de ultra-som acoplado a sonda específica, similar à empregada para OPU (BÓ et al., 2002). Além disso, para assegurar a emergência de uma nova onda de crescimento é requerida que as aspirações sejam feitas também em folículos com menor diâmetro.

No $G_{R F}$, apesar da presença de um folículo dominante em três vacas no $D_{17} \mathrm{e}$ em todas vacas no $D_{20}$ (Tabela 1 do apêndice $B$ ) aparentemente sua influência mediada por estrógenos foi deprimida já que a luteólise foi retardada e só ocorreu entre $D_{22}$ e $D_{23}$ (Figura 3.3). Além disso, a competência esteroidogênica do folículo dominante correspondente esteve aparentemente deprimida pois o intervalo entre a luteólise e o estro foi maior que no $\mathrm{G}_{\mathrm{CT}}$. No presente experimento, a presença de folículos com diâmetros $\geq 12 \mathrm{~mm}$ ainda em $\mathrm{D}_{20}$ pode ter contribuído para retardar a manifestação do estro em relação à luteólise.

No caso do $G_{R M}$ a remoção física do fluído folicular dos maiores folículos possivelmente depletou os estrógenos que ganhariam a circulação, o que provavelmente retardou a manifestação do cio em relação ao grupo controle.

A luteólise e o comportamento do estro estão relacionados aos estrógenos circulantes. No entanto, esta bem documentada a ocorrência de luteólise dissociada da manifestação do cio (BERGAMASCHI, 2005). No presente experimento, houve três vacas, sendo duas delas do $\mathrm{G}_{\mathrm{RM}}$, que não mostraram estro após a luteólise 
(Tabela 3.1). Resta determinar quais são as condições particulares que favorecem a ocorrência da luteólise dissociada do estro, mesmo em vacas pré-sensibilizadas por tratamento progestogênico $\left(\right.$ Crestar $\left.^{\circledR}\right)$ prévio.

No grupo da remoção farmacológica não houve apenas o retardamento da luteólise, mas também o estímulo à produção da progesterona (Tabela 3.2; Figuras 3.2 e 3.3$)$.

A associação $\mathrm{GnRH} / \mathrm{hCG}$ teve um efeito luteotrófico prolongado e possivelmente continuado (Figura 3.3), o que permitiu ao $G_{R F}$ a obtenção de concentrações de progesterona maiores que $8 \mathrm{ng} / \mathrm{mL}$ no $D_{19}$ (Figura 3.2), considerado como o limite temporal superior do período crítico para o reconhecimento da prenhez. No mesmo dia, nem o grupo controle nem o $G_{R M}$ suportavam concentrações tipicamente luteínicas $(\geq 1 \mathrm{ng} / \mathrm{mL})$ de progesterona circulante. Com efeito, a concentração média de progesterona do $\mathrm{G}_{\mathrm{RF}}$ ao final da fase luteínica ( $D_{15}$ até a luteólise) foi aproximadamente o dobro das concentrações do $G_{C T}$ ou do $G_{R M}$.

Importante notar que a maior concentração de progesterona para $G_{R F}$ $(13,52 \mathrm{ng} / \mathrm{mL})$ também foi aproximadamente o dobro daquela para o $\mathrm{G}_{\mathrm{CT}}$ e três vezes maior que a do $\mathrm{G}_{\mathrm{RM}}$ (Tabela 3.2). Além disso, foi superior aos $8,4 \mathrm{ng} / \mathrm{mL}$ relatados por Marques (2002) entre $D_{13}$ e $D_{17}$ para receptoras de embrião suplementadas com $1500 \mathrm{UI}$ de hCG à inovulação $\left(D_{7}\right)$ ou aos $10,0 \mathrm{ng} / \mathrm{mL}$ verificados para vacas Nelore suplementadas com $3000 \mathrm{UI}$ de hCG no $\mathrm{D}_{5}$, conforme relatado no experimento 1 ou aos $8,1 \mathrm{ng} / \mathrm{mL}$ relatados por Bergamaschi (2005) para vacas Nelore que receberam eCG no protocolo de sincronização do ciclo estral baseado no Crestar ${ }^{\circledR}$. Analogamente, os valores observados no presente experimento para concentração média da progesterona entre $D_{13}$ e $D_{17}$, dia da luteólise e duração da fase luteínica 
(Tabela 3.2) foram maiores que os relatados por Marques (2002), por Bergamaschi (2005) ou no experimento 1. Coletivamente, estas comparações pressupõe que o protocolo imposto ao $\mathrm{G}_{\mathrm{RF}}$ foi a opção mais efetiva tanto para o bloqueio da luteólise como para a estimulação luteotrófica.

O mecanismo de ação para que a remoção farmacológica represente um estímulo luteotrófico potente relacionou-se possivelmente aos efeitos combinados das ações do $\mathrm{GnRH}$ e da $\mathrm{hCG}$ sobre a função luteínica. No $\mathrm{G}_{\mathrm{RF}}$ houve duas vacas com corpo lúteo acessório em resposta à ovulação induzida pelo $G n R H$ no $D_{5}$ (KASTELIC; MAPLETOFT, 1998). Por sua vez, a hCG aplicada em $D_{13}$ também induziu a formação de corpo lúteo acessório em outras duas vacas (Tabela 3.3). Price e Webb (1989) induziram a formação de corpo lúteo acessório em 66\% de novilhas da raça holandesa com o uso de $1500 \mathrm{UI}$ de hCG entre $\circ D_{14}$ e $\circ D_{16}$. Portanto, o efeito luteotrófico da hCG ocorreu então por vias diferentes e sinérgicas. Atuou na extensão da sobrevida dos corpos lúteos preexistentes (original + acessório induzido pelo $\mathrm{GnRH}$ ), bem como pela indução de ovulação e neoformação de corpo lúteo acessório. Para tanto, contribuíram os atributos bioquímicas da hCG, os quais conferem a ela uma meia-vida prolongada e também uma lenta degradação do complexo hCG-receptores do LH. Estes fatores podem explicar o diferenciado padrão secretório de progesterona entre o corpo lúteo acessório induzido por $\mathrm{GnRH}$ daquele induzido por hCG, o qual possui maior tamanho e mais células luteínicas (SCHMITT et al., 1996b). Como resultante, a luteólise foi retardada e as concentrações circulantes da progesterona ao final da fase luteínica foram otimizadas para o $\mathrm{G}_{\mathrm{RF}}$.

Quatro das cinco vacas do $G_{R F}$ prolongaram a fase luteínica (Tabela 3.3). Aparentemente esta ocorrência não esteve relacionada à formação de um corpo 
lúteo acessório e nem à máxima concentração de progesterona alcançada ao final da fase luteínica. De fato, ficou demonstrado, que a sensibilidade aos estímulos luteolíticos não difere entre o corpo lúteo acessório e o original (SCHMITT et al., 1996 a). Com efeito, Binelli et al. (2004a) verificaram que o estradiol estimulou a liberação da $\mathrm{PGF}_{2 \alpha}$ independentemente da ação da progesterona no dia 17 do ciclo estral. Em adição, a presença de um corpo lúteo acessório induzido por LH aumentou apenas modestamente a liberação de prostaglandina em resposta ao estrógenos no $D_{17}$ (GOISSIS et al., 2004).

Assim, independentemente da formação de um corpo lúteo acessório em resposta ao $\mathrm{GnRH}$ e/ou à hCG, o efeito luteotrófico se instalou. Tal achado representa um forte indício da ação luteotrófica direta daqueles agentes sobre os corpos lúteos preexistentes. Inferência similar foi encontrada por Fricke et al. (1993). Portanto, o efeito luteotrófico exercido pela associação $\mathrm{GnRH/hCG}$ aumentou as concentrações circulantes da progesterona ao longo de todo o período crítico e pode representar uma estratégia eficaz na redução da mortalidade embrionária em bovinos. De fato, Marques (2002) reportou que as taxas mais altas de concepção ocorreram para as receptoras suplementadas com $\mathrm{GnRH}$ ou $\mathrm{hCG}$ à inovulação $\left(\mathrm{D}_{7}\right)$ atingindo respectivamente, $53,5 \%$ e $51,0 \%$ superiores $(P<0,05)$ aos $28,6 \%$ das não suplementadas. Porém, em outros estudos, o uso de agentes luteotróficos não assegurou a redução na mortalidade embrionária. Com efeito, Araújo et al. (1998) e Galambert et al. (1998) aplicaram 10 $\mu \mathrm{g}$ de buserelina, respectivamente à inovulação $\left(D_{7}\right)$ e cinco dias depois $\left(D_{12}\right)$ e não houve maior retenção de prenhez nas receptoras tratadas em comparação às do controle. 


\subsection{CONCLUSÕES}

A estratégia de remoção farmacológica por meio da combinação GnRH/hCG retardou a luteólise, ampliou a fase luteínica e aumentou a produção de progesterona no período critico e representa uma alternativa a ser testada à campo para reduzir a mortalidade embrionária em bovinos. Por outro lado, a metodologia de punção folicular adotada não removeu os folículos potencialmente esteroidogênicos no período crítico de reconhecimento da prenhez e em conseqüência a luteólise e a função luteínica seguiram sua programação fisiológica. O uso de outra técnica, aparato e critérios de ablação folicular podem viabilizar a remoção mecânica do folículo dominante como estratégia anti-luteolítica. 
DISCUSSÃO GERAL 


\section{DISCUSSÃo GERAL}

A literatura mundial sobre a ocorrência (KUNZ et al., 2002; VANROOSE et al., 2000) e sobre os impactos da mortalidade embrionária nas taxas reprodutivas dos bovinos (HUMBLOT, 2001) é abundante. Entretanto, ainda não há números genuinamente brasileiros, obtidos de experimentação feita com rebanhos típicos dos sistemas de produção mais adotados no Brasil. Assim, estudos sobre a mortalidade embrionária em rebanhos zebuínos de corte criados sob regimes extensivos ou semi-intensivos de manejo ainda estão por serem feitos. Não obstante, a despeito da carência desses dados é razoável concluir que as perdas de prenhez também imputam grandes prejuízos às explorações pecuárias brasileiras. De fato, índices reprodutivos como a taxa de parição permanecem aquém do potencial (ANUALPEC, 2004). A maioria dos estudos com inseminação artificial tanto em bovinos leiteiros (VASCONCELOS et al., 2004) como nos de corte teve resultados apenas marginais, em que as taxas de parição não superam a casa dos 80\% (BARUSELLI et al., 2004a; FERNANDES et al., 2001; VILELA et al., 2004).

Além disso, é fato notório na indústria de transferência de embriões do Brasil que as taxas de retenção de prenhez das receptoras é insuficiente para que a técnica se viabilize em escala ainda maior e a custos mais competitivos. Há relato com taxas tão baixas quanto $28,6 \%$ (MARQUES, 2002), o que pressupõe o forte impacto das perdas embrionárias no processo. Coletivamente, sugere-se a partir desses valores que existem oportunidades para incrementos substanciais nos 
índices reprodutivos. Em adição, é mister desenvolver protocolos de redução das perdas de prenhez que sejam factíveis de se implantar à campo.

Há abundante documentação sobre a importância da mortalidade embrionária precoce $\left(\right.$ até $\left.D_{16}\right)$. A maioria dos relatos a coloca como a principal fonte dentre todas perdas reprodutivas dos bovinos (DISKIN; SREENAN, 1980; DUNNE et al., 2000; STARBUCK et al., 2004). O mecanismo da mortalidade embrionária precoce envolve os distúrbios do reconhecimento materno da prenhez, pois caso a comunicação bioquímica entre concepto e unidade materna seja sub-ótima, mantém-se a programação para ocorrência da luteólise (MANN et al., 1996; MANN et al., 1998).

Portanto, estratégias para a redução da mortalidade embrionária precoce devem focar a otimização da comunicação entre o concepto e a unidade materna e o bloqueio da luteólise.

Neste contexto, os conceptos com melhor desenvolvimento têm mais êxito ao sinalizarem sua presença à unidade materna pois produzem mais interferon- $\tau$ (GEISERT et al., 1988). Para assegurar condições mais favoráveis ao desenvolvimento otimizado do concepto, o útero gestante deve estar devidamente preparado pela progesterona (KERBLER et al., 1997). Portanto, a amplificação e/ou a extensão do aporte progesterônico ao útero no período crítico do reconhecimento da prenhez deve ser perseguida.

Por sua vez, para retardar ou bloquear a luteólise, a síntese da prostaglandina $F_{2 \alpha}$ deve ser protelada ou prevenida, pois a prostaglandina $F_{2 \alpha}$ é o agente endógeno efetor da regressão do corpo lúteo (GALINA; ARTUR, 1990). Neste contexto, tanto os estrógenos exógenos (THATCHER et al., 1986; WILTBANK et al., 1961) como os estrógenos produzidos intra-folicularmente (SALFEN et al., 1999) foram implicados no mecanismo que deflagra a luteólise. Portanto, pode-se 
relacionar o papel do folículo dominante nos eventos que levam à luteólise, uma vez que a concentração de estrógenos no fluído folicular do dominante é muito maior que a dos demais foliculos (FORTUNE et. al., 2004).

Em síntese, o bloqueio da luteólise pode ser conseguido pela remoção dos efeitos esteroidogênicos protagonizados pelo folículo dominante (BINELLI et al., 2001) e o aumento na produção de progesterona pode ser alcançado pela administração de agentes luteotróficos, como o GnRH (MARQUES, 2002) ou a hCG (DIAZ et al., 1998).

Objetivou-se com os estudos desta tese testar protocolos de remoção dos efeitos causados pelo folículo dominante. Para tanto, foram delineados três experimentos. Nos dois primeiros, realizados com vacas Nelore, a abordagem de remoção foi farmacológica e baseou-se na aplicação de $17_{\beta}$-estradiol no $D_{12}$ do ciclo estral. O resultado esperado era a abolição da onda de crescimento folicular pelo mecanismo de retroalimentação entre o estradiol e a hipófise para em seguida ocorrer o recrutamento de uma nova onda, aproximadamente 4 dias depois (BÓ et al., 1995) assegurando a inexistência de um folículo dominante com capacidade esteroidogênica ao longo do período crítico para o reconhecimento da prenhez $\left(D_{13}\right.$ ao $D_{19}$ ). Como resultante a luteólise seria retardada e a fase luteínica prolongada. Uma estratégia de otimização da função luteínica por meio da aplicação da hCG no $D_{5}$ também foi avaliada nesses experimentos.

Num terceiro experimento, realizado com vacas Red Angus testaram-se duas abordagens de remoção do folículo, uma farmacológica e outra mecânica. Esta última, baseada na punção dos folículos para abolir a onda de crescimento e sincronizar 1,5 dia depois (MARTINEZ et al., 2004) a emergência de uma nova onda de crescimento folicular. O intervalo entre as aspirações e os dias do ciclo estral 
escolhidos para as punções assegurariam a inexistência de folículos $>8 \mathrm{~mm}$ durante o período crítico. A abordagem farmacológica associou o $\mathrm{GnRH}$ à hCG de modo a sincronizar a emergência de nova onda de crescimento por duas ocasiões num mesmo ciclo estral, prevenindo a ocorrência de folículos $>8 \mathrm{~mm}$ durante o período crítico.

A estratégia de remoção mecânica malogrou. A técnica adotada para punção não permitiu, como antecipado, a ablação de folículos com diâmetros entre $5 \mathrm{~mm}$ e 7mm. Assim, aparentemente a onda de crescimento não foi abolida (Tabela 1 do apêndice B), o que seria um indício de que o folículo dominante não foi puncionado. Não obstante, Kastelic (2004) afirmou que um folículo subordinado permanece viável até pelo menos um dia depois do desvio e pode assumir a dominância da onda, caso o foliculo dominante existente seja removido. No caso do experimento 3 , a técnica empregada nem sempre possibilitou a retirada dos três maiores folículos, caso algum deles tivesse diâmetro menor a $7 \mathrm{~mm}$. Assim, algum subordinado (nãopuncionado e $<7 \mathrm{~mm}$ ) pode ter assumido a dominância (KASTELIC, 2004), ou o próprio dominante não tenha sido puncionado (BODENSTEINER et al., 1996). Portanto, essas ocorrência explicariam as imagens ultra-sonográficas de $D_{17}$ e de $D_{20}$ de algumas vacas que tinham folículos maiores que $9 \mathrm{~mm}$ e $11 \mathrm{~mm}$, respectivamente (Tabela 1 do apêndice B). Como resultado, um folículo $\geq 8 \mathrm{~mm}$ esteve presente em $D_{14}, D_{17}$ e $D_{20}$ (período crítico) e a fase luteínica não foi prolongada no $\mathrm{G}_{\mathrm{RM}}$. Embora a premissa experimental não tenha sido comprovada, ela tampouco pode ser negada, pois com a presença desses folículos no período crítico, a luteólise seguiu seu curso e ocorreu em prazo análogo $(P>0,05)$ ao do grupo controle. 
As estratégias farmacológicas foram melhor sucedidas. Cumpre destacar que a remoção proporcionada pela associação $\mathrm{GnRH} / \mathrm{hCG}$ foi de natureza funcional, já que em algumas vacas foi observada a presença de folículos com diâmetro $\geq 7 \mathrm{~mm}$ (Tabela 1 do apêndice $B$ ) em $D_{14}, D_{17}$ e $D_{20}$ (período crítico), embora a luteólise tenha ocorrido, em média, entre $D_{22}$ e $D_{23}$ (Tabela 3.2 e Figuras 3.2 e 3.3).

O $17_{\beta}$-estradiol atuou como previsto na dinâmica folicular. De fato o intervalo entre a sua aplicação e a emergência de uma nova onda de crescimento foi de $4,00 \pm 0,69$ dias e a presença de um folículo dominante durante o período crítico $\left(D_{13}\right.$ ao $\left.D_{19}\right)$ foi praticamente abolida, uma vez que, esteve presente em média, por apenas $0,60 \pm 0,87$ dias, diferindo $(P<0,05)$ das vacas que não receberam 0 estrógeno (Tabela 1.1). Entretanto, o $17_{\beta}$-estradiol desencadeou a luteólise, a qual ocorreu, em média no dia 17,00 $\pm 0,57$ do ciclo estral (Tabela 1.5). De fato, a comprovação da luteólise resultou na redução $(P<0,05)$ das taxas de prenhez das vacas no experimento 2 (Tabela 2.1). Neste caso, a indução da luteólise incorreu diretamente na indução da morte embrionária precoce, ao invés de preveni-la por mecanismo indireto, como antecipado ao se elaborar o protocolo. Assim, o impacto $(P<0,05)$ da aplicação do $17_{\beta}$-estradiol 12 dias depois da inseminação sobre as taxa de prenhez à essa IA $A_{T F}(11,8 \%)$ não foi revertido nos 64 dias da estação reprodutiva e proporcionou uma taxa de prenhez acumulada (Tabela 2.2) também menor $(66,4 \% ; P<0,05)$. Permaneceu intrigante o fato de que o uso da $h C G$ diminuiu o efeito negativo do $17_{\beta}$-estradiol sobre a taxa de prenhez à IA $A_{T F}$ (Tabela 2.1 e Figura 2.2), embora não tenha prevenido a ocorrência da luteólise (Figuras 1.2 e 1.3) nas vacas do experimento 1. Em alguns relatos verificou-se que a resposta luteolítica ao desafio com $17_{\beta}$-estradiol pode ser amplificado em ambiente progestogênico (BINELLI et al., 2004 a; GOISSIS et al., 2004). 
Bergamaschi (2005) ao testar protocolo similar também verificou a ocorrência da luteólise e o aumento do tônus uterino após a aplicação do $17_{\beta}$-estradiol.

Bó et al. (1994) verificaram que a ação dos estrógenos sobre a dinâmica folicular não esteve associada à luteólise quando estes foram aplicados nos dias $D_{1}$, $D_{3}, D_{6}$ ou $D_{9}$ do ciclo estral. No presente estudo ficou patente a inadequação do $D_{12}$ como data escolhida. Talvez nesta data as condições dos tecidos uterino e lúteo sejam mais propícias para a síntese e ação da prostaglandina $F_{2 \alpha \text {. Essa assertiva }}$ ganha suporte no fato que as atividades bio-síntéticas e catabólicas nos tecidos uterino e luteínico dependem do estado da vascularização bem como da presença de substâncias vasoativas naquele tecido (ACOSTA; MIYAMOTO, 2004), atributos que variam ao longo do ciclo estral. Além disso, a presença, concentração e afinidade dos receptores (BINELLI; THATCHER, 1999) participantes da cascata de eventos bioquímicos deflagrados pelo $17_{\beta}$-estradiol também variam ao longo do ciclo estral e esta variação pode ser determinante para a ocorrência ou não da luteólise após desafio pelos estrógenos. De fato, o efeito desencadeado pelo $17_{\beta}$-estradiol no $D_{12}$ sobre a função luteínica teve sincronia muito íntima entre as vacas tratadas, ilustrado pela redução linear e abrupta na concentração circulante da progesterona $(1,83 \mathrm{ng} / \mathrm{mL} / \mathrm{dia})$, reforçando o potencial luteolítico do $17_{\beta}$-estradiol administrado nas condições experimentais impostas.

Marques et al. (2004) relataram que as concentrações de progesterona e as taxas de concepção de receptoras de embrião estão direta e positivamente correlacionadas com a área de tecido lúteo existente à inovulação. Portanto, a antecipação da luteólise pelo uso do $17_{\beta}$-estradiol no $\mathrm{G}_{\text {E2 }}$ e $\mathrm{G}_{\mathrm{nCG} / \mathrm{E} 2}$ (Figuras $1.2 \mathrm{e}$ 1.3) teve outra conseqüência indesejável, pois favoreceu a ovulação de folículos com diâmetros menores (Tabela 1.1), os quais potencialmente podem dar origem 
aos corpos lúteos de menor dimensão (BINELLI et al., 2001). Entretanto, no experimento 2 esse efeito do $17_{\beta}$-estradiol sobre a função luteínica do ciclo subsequente aparentemente não ocorreu. De fato, as taxas de concepção e de prenhez (Tabela 2.1) à $1^{\mathrm{a}} \mathrm{IA}$ de repasse não diferiram entre vacas tratadas $\left(\mathrm{G}_{\mathrm{E} 2} \mathrm{e}\right.$ $G_{n C G / E 2}$ ) e não tratadas com o $17_{\beta}$-estradiol ( $G_{C}$ e $G_{h C G}$ ) após uma IA $A_{T F}$ inicial.

Em conclusão, o efeito do $17_{\beta}$-estradiol aplicado no $D_{12}$ do ciclo estral foi muito consistente em sincronizar não só a emergência de uma nova onda de crescimento folicular, mas também a luteólise. Portanto, essa classe de esteróide é adequada para a manipulação das funções folicular e luteínica, embora deva ser usada com cautela por ser potencialmente luteolítica.

Com relação à abordagem farmacológica de remoção do folículo dominante (experimento 3) verificou-se que estímulo luteotrófico pela associação $\mathrm{GnRH/hCG}$ aumentou $(P<0,05)$ a concentração da progesterona circulante ao final da fase luteínica (Tabela 3.2 e Figuras 3.2 e 3.3). Além disso, é possível especular que esse protocolo exerceu algum efeito limitante sobre a função esteroidogênica dos folículos presentes no período crítico, uma vez que a luteólise foi retardada (Tabela 3.2).

Fica a suspeita de que a modulação da atividade esteroidogênica dos folículos em crescimento foi alterada pelo $\mathrm{GnRH} / \mathrm{hCG}$ até o fim do período crítico. A progesterona é precursora do estradiol na via metabólica da biosíntese de esteróides e a redução na atividade das enzimas $17_{\alpha}$-hidroxilase e/ou aromatase teria como conseqüências o acúmulo de progesterona e a redução na síntese de $17_{\beta}$-estradiol. Com efeito, as concentrações circulantes da progesterona foram significativa $(P<0,01)$ e substancialmente (Tabela 3.2; Figuras 3.2 e 3.3$)$ maiores para o grupo tratado com $\mathrm{GnRH} / \mathrm{hCG}$. Em adição, embora não tenham sido dosadas as concentrações de $17_{\beta}$-estradiol, a expressão das variáveis "estrógeno- 
dependentes" foi reduzida. De fato, no $\left.G_{R F}: 1^{\circ}\right)$ houve duas vacas que não mostraram estro, mesmo após a confirmação da luteólise; $2^{\circ}$ ) a luteólise foi retardada $(P<0,01)$ e $\left.3^{\circ}\right) \circ$ intervalo entre a luteólise e a manifestação do estro tendeu $(P<0,10)$ a se prolongar.

Entretanto, Portela et al. (2004) concluíram que a indução da luteólise mediada pelo benzoato de estradiol não envolveu incrementos na expressão da enzima ciclo-oxigenase, limitante da biosíntese da prostaglandina $F_{2 \alpha}$. Se tal inferência se aplica ao $17_{\beta}$-estradiol de origem intra-folicular, outras hipóteses devem ser formuladas para explicar o mecanismo pelo qual a associação $\mathrm{GnRH} / \mathrm{hCG}$ retardou a luteólise, pois não haveria relação entre modulações na esteroidogênese e luteólise. Na verdade, é possível que o bloqueio tenha ocorrido por mais de um mecanismo de ação.

A participação de outros fatores, mediados por progesterona e pela razão entre as concentrações de progesterona e estrógeno não deve ser descartada. Apesar que a ação estimulante dos estrógenos sobre a liberação de prostaglandina $F_{2 \alpha}$ é potencializada em ambientes progesterônicos (GOISSIS et al., 2004), a elevação da progesterona para concentrações muito altas pode ter tido algum papel no bloqueio da luteólise.

Outra conjectura relaciona-se à atividade gonadotrófica especifica da hCG. Lindsell et al. (1984) verificaram existir diferenças "entre-partidas" na razão FSH:LH, bem como na bioatividade predominante (FSH ou $\mathrm{LH}$ ) de uma gonadotrofina comercialmente disponível. Por sua vez, a hCG possui alguma atividade FSH (CARRUTHERS, 1986; HAFEZ et al., 1988), embora tenha afinidade muito maior pelos receptores do LH (CARRUTHERS, 1986). Em adição, a atividade LH é responsável pelo estimulo à síntese de andrógenos precursores do $17_{\beta}$-estradiol 
(KASTELIC, 2004). Especula-se que a ação da associação $G n R H / h C G$ possa ter num primeiro momento, acelerado o crescimento folicular continuado a partir de $D_{13}$, explicando a presença de folículos $>7 \mathrm{~mm}$ em $D_{14}$ e $D_{17}$ para em seguida e graças sua meia-vida prolongada serem encontrados folículos $>12 \mathrm{~mm}$ em $D_{20}$.

Além disso, sua atividade LH prolongada, estimulando continuamente o eixo hipotalâmico-hipofisário-gonadal pode ter alterado o padrão de liberação das gonadotrofinas endógenas e de indução da síntese de receptores, com conseqüências sobre o aporte gonadotrófico ao folículo. (CARRUTHERS, 1986) e sobre o seu potencial esteroidogênico. Neste contexto, variações nas concentrações e na afinidade de receptores para FSH ou LH poderiam explicar a cronologia alterada de síntese da progesterona que foi observada (Figura 3.2 e 3.3) nas vacas tratadas com $\mathrm{GnRH} / \mathrm{hCG}$ do experimento 3. A ocorrência de estímulos deficitários para a produção antral de estrógenos e/ou dos seus precursores (andrógenos) teria como conseqüência o atraso na luteólise e na manifestação do estro e da ovulação relativos àquele ciclo estral. Eventos observados nas vacas do $\mathrm{G}_{\mathrm{RF}}$ do experimento 3 Além de retardar a luteólise, a associação $\mathrm{GnRH} / \mathrm{hCG}$ foi eficaz como agente luteotrófico o que indica os efeitos sinérgicos desses fármacos sobre a função luteínica. A hCG não só induziu a formação de corpo lúteo acessório (Tabela 3.3) mas também foi estimulante aos corpos lúteos preexistentes (Tabela 3.2).

Em conclusão, a remoção dos efeitos de um folículo dominante ("funcional") durante o período crítico para o reconhecimento da prenhez foi obtida com a associação $\mathrm{GnRH} / \mathrm{hCG}$. Assim, esse protocolo é uma das poucas metodologias disponíveis que efetivamente conseguiu ampliar a fase luteínica em vacas (VILLAGODOY et al., 1985; SALFEN et al., 1999) e talvez seja a única aplicável em condições de campo com objetivos relacionados diretamente com a produção 
animal. Conjeturou-se que o mecanismo de ação desse efeito esteve relacionado às altas concentrações de progesterona elicitadas pelo tratamento ou a modificações na modulação das relações de retroalimentação hormonal do eixo hipófise-gônadas. Tais alterações, induzidas pela hCG resultariam em menor competência esteroidogênica dos folículos antrais ao final da fase luteínica culminando com o retardamento da luteólise induzida por estrógenos.

A partir desses resultados criam-se possibilidades de estudo e de aplicação do protocolo. De fato, podem ser pesquisados: as relações dose-efeito, outros análogos do $\mathrm{GnRH}$, outras doses da onerosa hCG e principalmente o efeito da aplicação do protocolo sobre as taxas de prenhez em vacas inseminadas à campo e em receptoras inovuladas. 


\section{REFERÊNCIAS}

ACOSTA, T. J.; MYIAMOTO, A . Vascular control of ovarian function: ovulation, corpus luteum formation and regression. Animal Reproduction Science, v. 82-83, p. 127-140. 2004.

ADAMS, G. P.; MATTERI, R. L.; GINTHER, O. J. Effect of progesterone on ovarian follicles, emergence of follicular waves and circulating follicle-stimulating hormone in heifers. Journal of Reproduction and Fertility, v. 95, p. 627-640, 1992.

AHMAD, N.; TOWNSEND, E. C.; DAILEY, R. A.; INSKEEP, E. K. Relationships of hormonal patterns and fertility to occurrence of two or three waves of waves of ovarian follicles, before and after breeding in beef cows. Animal Reproduction Science, v. 49, p. 13-28. 1997.

ALONSO, A.; MAPLETOFT, R. J.; BO, G. A.; TRIBULO, H. E.; CARCEDO, J.; TRIBULO, R.; MENAJOVSKY, J. R. Niveles de hormona luteinizante y de estrógeno em hembras bos indicus tratadas com prostaglandina F2 $\alpha$. Revista Argentina de Producción Animal, v. 15, p. 961-963, 1995.

AMBROSE, J. D.; PIRES, M. F. A.; MOREIRA, F.; BINELLI, M.; THATCHER, W.W. Influence os Deslorelin (GnRH-agonist) implant on plasma progesterone, first wave dominant follicle and pregnancy in dairy cattle. Theriogenology, v. 50, p. 11571170, 1998.

ANUALPEC. Anuário da Pecuária Brasileira, 1994-2004. São Paulo: FNP Consultoria e Comércio. 2004. p. 42-75.

ARAÚJO, M. C. C.; FREITAS, C.; COSTA, E. P. ; GALIMBERT, A. M.; SÁ, W. F. GUIMARÃES, J. D.; COSTA, D. S. GnRH analogous (buserelin) in bovine embryo recipients. Arquivos da Faculdade de Veterinária da UFRGS, v. 26, n. 1, p. 219, 1998. Suplemento 26.

AYALON, N. A review of embryonic mortality in cattle. Journal of Reproduction and Fertility, v. 54, p. 483-93, 1978.

BANU, S. K.; AROSH, J. A.; CHAPDELAINE, P. ; FORTIER, M. Expression and regulation of prostaglandin transporter in corpus luteum and utero-ovarian plexus during the bovine estrous cycle and pregnancy. Biology of Reproduction, v. 68, p. 175-176, 2003. Supplement 1.

$\mathrm{BAO}_{2}$ B.; GARVERICK, H. A. Expression of steroidogenic enzyme and gonadotropin receptor genes in bovine follicles during ovarian follicular waves: a review. Journal of Animal Science, v. 76, p. 1903-1921, 1998.

BARACALDO, M. I.; MARTINEZ, M. F.; ADAMS, G. P. ; MAPLETOFT, R. J. Superovulatory response following transvaginal device ablation in cattle. Theriogenology, v. 53, p. 1239-1250, 2000. 
BARROS, C. M.; FIGUEIREDO, R. A.; PINHEIRO, O. L. Estro, ovulação e dinâmica folicular em zebuínos. Revista Brasileira de Reprodução Animal, v. 19, n. 1-2, p. 9-22.1995.

BARROS, C. M.; MOREIRA, M. B. P.; FERNANDES, P. Pharmacological manipulation of estrous cycle to improve artificial insemination or embryo transfer programs. Arquivos da Faculdade de Veterinária da UFRGS, v. 26, n. 1, p. 179198. 1998. Suplemento 26.

BARUSELLI, P. S.; BÓ, G. A.; REIS, E. L.; MARQUES, M. O. Inseminação artificial em tempo fixo em bovinos de corte. In: SIMPÓSIO INTERNATIONAL DE REPRODUÇÃO ANIMAL APLICADA, 1., 2004, Londrina. Anais... , São Paulo:

Faculdade de Medicina Veterinária e Zootecnia, Universidade de São Paulo, 2004a. p. $155-165$.

BARUSELLI, P. S.; MARQUES, M. O.; CARVALHO, N. A. T.; VALENTIM, R.; BERBER, R. C. A.; CARVALHO FILHO, A. F.; MADUREIRA, E. H.; COSTA NETO, W. P. Aumento da taxa de prenhez em receptoras de embrião bovino pela utilização do protocolo "OvSynch" com inovulação em tempo fixo. Arquivos da Faculdade de Veterinária da UFRGS, v. 28, n. 1, p. 216, 2000. Suplemento 28.

BARUSELLI, P. S.; MARQUES, M. O.; MADUREIRA, E. H.; COSTA NETO, W. P.; GRANDINETTI, R. R.; BO, G. A. Increased pregnancy rates in embryo recipients treated with CIDR-b devices and eCG. Theriogenology, v. 55, p. 157, 2001. (Series Abstract).

BARUSELLI, P. S.; REIS, E. L.; CARVALHO, N. A. T.; CARVALHO, J. B. P. eCG increase ovulation rate and plasmatic progesterone concentration in nelore (bos indicus) heifers treated with progesterone releasing device. In: INTERNATIONAL CONGRESS ON ANIMAL REPRODUCTION, 15., 2004, Porto Seguro. Abstracts..., Belo Horizonte: Colégio Brasileiro de Reprodução Animal, 2004b. p. 117.

BARUSELLI, P. S.; REIS, E. L.; MARQUES, M. O.; NASSER, L. F.; BÓ, G. A. The use of hormonal treatments to improve reproductive performance of anestrous beef cattle in tropical climates. Animal Reproduction Science, v. 82-83, p. 479-86, 2004c.

BENNETT, W. A.; GONZALEZ, L. V.; STUART, M. J.; FUQUAY, J. W. Effects of human Corionic Gonadotrophin pretreatment on endocrine, cytological and Prostaglandin $\mathrm{F}_{2 \alpha}$ receptor patterns of the bovine corpus luteum. Animal Reproduction Science, v. 19, p. 179-189,1989.

BENNETT, W. A.; GONZALEZ, L. V.; STUART, M. J.; FUQUAY, J. W. Effects of human Corionic Gonadotrophin (hCG) pretreatment on endocrine and behavioural responses of dairy cattle to exogenous Prostaglandin $\mathrm{F}_{2 \alpha}$. Animal Reproduction Science, v. 25, n. 1, p. 97-107.1991. 
BERGAMASCHI, M.A.C.M. Estratégias hormonais para otimizar a função luteínica da vacas da raça Nelore após a sincronização do estro. 2005. $111 \mathrm{f}$. Tese (Doutorado) - Faculdade de Ciências Agrárias e Veterinárias, Universidade Estadual Paulista, Jaboticabal, 2005.

BINELLI, M.; LOUREIRO, J. G. P.; CUNHA, P. M. da; LIMA. W.; NOGUEIRA, G. P.; CIRILO, P. D.; BERTAN, C. M. Blocking progesterone receptors does not alter estradiol $17_{\beta}$-estimulated prostaglandin $F_{2 \alpha}$ production in cows. In: INTERNATIONAL CONGRESS ON ANIMAL REPRODUCTION, 15., 2004, Porto Seguro. Abstracts..., Belo Horizonte: Colégio Brasileiro de Reprodução Animal, 2004a. p. 338.

BINELLI, M.; MACHADO, R.; BERGAMASCHI, M. A. C. M.; BARUSELLI, P. S. Atualizações sobre estratégias antiluteolíticas para o aumento da fertilidade em bovinos. In: SIMPÓSIO INTERNATIONAL DE REPRODUÇÃO ANIMAL APLICADA, 1., 2004, Londrina. Anais... , São Paulo: Faculdade de Medicina Veterinária e Zootecnia, Universidade de São Paulo, 2004b. p. 91-198.

BINELLI, M.; THATCHER, W. W. Conceptus stimulated signal transduction pathway in the endometrium to maintain pregnancy. Annual Review of Biomedical

Sciences, v. 1, n. 1, p. 59-85, 1999.

BINELLI, M.; THATCHER, W. W.; MATTOS, R.; BARUSELLI, P. S. Antiluteolytic strategies to improve fertility in cattle. Theriogenology, v. 56, n. 9, p. 1451-1463, 2001.

BÓ, G. A.; ADAMS, G. P.; PIERSON, R. A.; MAPLETOFT, R. J. Exogenous control of follicular wave emergency in cattle. Theriogenology, v. 43, n. 1, p. 31-40, 1995.

BÓ, G. A.; ADAMS, G. P.; PIERSON, R. A.; TRIBULO, H. E.; CACCIA, M.; MAPLETOFT, R. J. Follicular wave dynamics after estradiol-17 $\beta$ treatment of heifers with or without progestogen implant. Theriogenology, v. 41, p. 1555-1569, 1994.

BÓ, G. A.; BARUSELLI, P. S.; MARTINEZ, M. F. Pattern and manipulation of follicular development in bos indicus cattle. Animal Reproduction Science, v. 78, p. 307-326, 2003.

BÓ, G. A.; BARUSELLI, P. S.; MORENO, D.; CUTAIA, L.; CACCIA, M.; TRÍBULO, R.; TRÍBULO, H.; MAPLETOFT, R. J. The control of follicular wave development for self-appointed embryo transfer programs in cattle. Theriogenology, v. 57, n.1, p. 53-72, 2002.

BODENSTEINER, K. J.; KOT, K.; WILTBANK, M. C.; GINTHER, O. J. Synchronization of emergence of follicular waves in cattle. Theriogenology, v. 45, p. 1115-1128, 1996.

BONI, R.; ROELOFSEN, M. W. M.; PIETERSE, M. C.; KOGUT, J.; KRUIP, T. A. M. Theriogenology, v. 48, p. 227-289, 1997. 
BREUEL, K. F.; LEWIS, P. E.; INSKEEP, E. K.; BUTCHER, R. L. Endocrine profiles and follicular development in early-weaned postpartum beef cows. Journal of Reproduction and Fertility, v. 97, p. 205-212, 1993.

BREUEL, K. F.; SPITZER, J. C.; HENRICKS, D. M. Systemic progesterone concentration following hcg administration at various times during the estrous cycle in beef heifers. Journal of Animal Science, v. 67, n. 6, p. $1564-1572,1989$.

BROADBENT, P. J.; STEART, M.; DOLMAN, D. F. Recipient management and embryo transfer. Theriogenology, v. 35, p. 25-139, 1991.

CARRUTHERS, T.D. Principles of hormone therapy in Theriogenology. In:

MORROW, D. A . Current Therapy in Theriogenology. 2.ed., Philadelphia: W.B. Sauders Company, 1986. p. 3-13.

CARTMILL, J. A.; EL-ZARKOUNY, S. Z.; HENSLEY, B. A.; ROZELL, T. G.; SMITH, J. F.; STEVENSON, J. S. An alternative AI breeding protocol for dairy cows exposed to elevated ambient temperatures before or after calving or both. Journal of Dairy Science, v. 84, p. 799-806, 2001.

CASTILHO, C.; DAYAN, A .; BARROS, C. M. Responsiveness of nelore cows corpus luteum tro PGF2a administered intramuscularly or via submucosa vulvar. Arquivos da Faculdade de Veterinária da UFRGS, v. 25, n. 1, p. 205, 1997. Suplemento 25.

CAVALIERI, J. Induction of ovulation Bos indicus and Bos taurus cattle following synchronization of oestrous cycles witn emphasis on Australian studies. In:

SIMPÓSIO INTERNATIONAL DE REPRODUÇÃO ANIMAL APLICADA, 1., 2004, Londrina. Anais... , São Paulo: Faculdade de Medicina Veterinária e Zootecnia, Universidade de São Paulo, 2004. p. 82-104.

CHRISTIANSON, W. T. Stillbirths, mummies, abortions and early embryonic death. The Veterinary Clinics of North America, Food Animal Practice, v. 8, p. 623-639, 1992.

COLAZO, M. G.; KASTELIC, J. P.; SMALL, J. A.; MAPLETOFT, R. J. Follicle dynamics, estrus and ovulation in CIDR-treated cows given ECP, GnRH, or progesterone during diestrus. In: INTERNATIONAL CONGRESS ON ANIMAL REPRODUCTION, 15., 2004, Porto Seguro. Abstracts..., Belo Horizonte: Colégio Brasileiro de Reprodução Animal, 2004. p. 330.

CORDOBA, M. C.; FRICKE, P. M. Initiation of the breeding season in a grazingbased dairy by synchronization of ovulation. Journal of Dairy Sciences, v. 85, n. 1752-1763, 2002.

DEMMERS, K. J.; DERECKA, K.; FLINT, A. Trophoblast interferon and pregnancy. Reproduction, v. 121, p. 41-49, 2001. 
DIAZ, T.; SCHMITT, E. J. P.; DE LA SOTA, R. L.; THATCHER, M. J.; THATCHER, W. W. HCG-induced alterations in ovarian folicular dynamics during the estrous cycle of heifers. Journal of Animal Science, v. 76, n. 7, p. 1929-1936, 1998.

DISKIN, M. G.; AUSTIN, E. J.; ROCHE, J. F. Exogenous hormonal manipulation of ovarian activity in cattle. Domestic Animal Endocrinology, v. 23, p. 211-228. 2002.

DISKIN, M. G.; SREENAN, J. M. Fertilization and embryonic mortality rates in beef heifers after artificial insemination. Journal of Reproduction and Fertility, v. 59, p. 463-468, 1980.

DOBSON, H.; FITZPATRICK, R. J. The effect of hCG or endogenous gonadotrophin on normal bovine follicular activity. Journal of Reproduction and Fertility, v. 43, p. 337-340, 1975.

DOBSON, H.; SMITH, R. F. Stress and subfertility. Reproduction in Domestic Animals, v. 33, p. 107-111, 1998.

DUNNE, L. D.; DISKIN, M. G.; SREENAN, J. M. Embryo and foetal loss in beef heifers between day 14 of gestation and full term. Animal Reproduction Science, v. 58 , n. 1, p. 39-44. 2000.

EDVQST, L.E.; SETTERGREN, I.; ASTROM, A. Pheripheral plasma levels of progesterone and fertility after prostaglandin F2-alpha induced oestrus in heifers. Cornell Veterinary, v. 65, p. 120-131, 1975.

FERNANDES, P.; GAMBINI, A. L. G.; MOREIRA, M. B. P.; BARROS, C. M. Timed artificial insemination in Nelore cows. Arquivos da Faculdade de Veterinária da UFRGS, v. 25, n. 1, p. 223. 1997. Suplemento 25.

FERNANDES, P.; TEIXEIRA, A. B.; CROCCI, A. J.; BARROS, C. M. Timed artificial insemination in beef cattle using gnrh agonist, pgf2 $\alpha$ and estradiol benzoate. Theriogenology, v. 55, p. 1521-32, 2001.

FIGUEIREDO, R. A.; BARROS, C. M.; PINHEIRO, O. L.; SOLER, J. M. P. Ovarian follicular dynamics in nelore breed (bos indicus) cattle. Theriogenology, v. 47, p. 1489-1505, 1997.

FLINT, A .P. F.; HEARN, J.P.; MICHAEL, A .E. The maternal recognition of pregnancy in mammals. Journal Zoology, v. 221, p. 327-341, 1990.

FORTUNE, J. E. Ovarian follicular growth and development in mammals. Biology of Reproduction, v. 50, p. 225-232, 1994.

FORTUNE, J. E.; RIVERA, G. M.; YANG, M. Y. Follicular development: the role of the follicular microenvironment in selection of the dominant follicle. Animal Reproduction Science, v. 82-83, p. 109-126, 2004. 
FRICKE, P. M.; REYNOLDS, L. P.; REDMER, D. A. Effect of human Corionic Gonadotrophin administered early in the estrous cycle on ovulation and subsequent luteum function in cows. Journal of Animal Science, v. 71, p. 1242-1246, 1993.

FUENTES, S.; DE LA FUENTES, J. Different synchronization treatment for direct embryo transfer to recipients heifers. In: ANNUAL MEETING AETE, 13., 1997, Lyon. Proceedings... Lyon: AETE, 1997. p. 148.

GABOR, G.; TOTH, F.; SZASZ, F. Influence of synchronized ovulation and presynchronization on pregnancy rates used timed Al in lactating dairy cows. In: INTERNATIONAL CONGRESS ON ANIMAL REPRODUCTION, 15., 2004, Porto Seguro. Abstracts..., Belo Horizonte: Colégio Brasileiro de Reprodução Animal, 2004. p. 338.

GALIMBERT, A. M.; FREITAS, C.; FONSECA, F. A.; FERREIRA, A. M.; ARAÚJO, M. C. C.; GUIMARÃES, J. D.; COSTA, D. S. One buserelin injection onday $5^{\text {th }}$ after inovulation on pregnancy rate of bovine embryo recipients. Arquivos da Faculdade de Veterinária da UFRGS, v. 26, n. 1, p. 277. 1998. Suplemento 26.

GALINA, C. S.; ARTHUR, G. H. Review on cattle reproduction in the tropics. Oestrus cycles. Animal Breeding Abstracts, v. 58, p. 697-707, 1990.

GALINA, C. S.; ORIHUELA, A.; RUBIO, I. Behavioural trends affecting oestrus detection in zebu cattle. Animal Reproduction Science, v. 42, p. 465-70, 1996.

GEISERT, R. D.; ZAVY, M. T.; BIGGERS, B. G.; GARRET, J. E.; WETTEMANN, R. $P$. Characterization of the uterine environment during early conceptus expansion in the bovine. Animal Reproduction Science, v. 16, n. 1, p. 11-25, 1988.

GINTHER, O. J.; BERGFELT, D. R.; BEG, M. A.; KOT, K. Follicle selection in cattle: role of luteinizing hormone. Biology of Reproduction, v. 64, p. 197-205, 2001.

GINTHER, O. J.; KASTELIC, J. P. ; KNOPF, L. Composition and characteristics of follicular waves during the bovine estrus cycle. Animal Reproduction Science, v. 20 , p. 187-200, 1989a.

GINTHER, O. J.; KNOPF, L.; KASTELIC, J. P. Temporal associations among ovarian events in cattle during oestrus cycle with two and three follicular waves. Journal of Reproduction and Fertility, v. 87, p. 223-30, 1989b.

GINTHER, O. J.; WILTBANK, M. C.; FRICKE, P. M.; GIBBONS, J. R.; KOT, K. Selection of the dominant follicle in cattle. Biology of Reproduction, v. 55, p. 11871194, 1996.

GOISSIS, M. D.; BRESSAN, F. F.; ALMEIDA, A. B.; BERTAN, C. M.; BINELLI, M. Influence of an accessory corpus luteum on estradiol-17 $7_{\beta}$-induced prostaglandin $\mathrm{F}_{2 \alpha}$ release in cattle. In: INTERNATIONAL CONGRESS ON ANIMAL REPRODUCTION, 15., 2004, Porto Seguro. Abstracts..., Belo Horizonte: Colégio Brasileiro de Reprodução Animal, 2004. p. 125. 
GOMES, F. P. Análise de grupos de experimentos. In: Curso de

Estatística Experimental. 12.ed. São Paulo: Livraria Nobel, 1987. p. 126-150.

GRAZZINI, E.; GUILLON, G.; MOUILLAC, B.; ZINGG, H. H. Inhibition of oxytocin receptor function by direct binding of progesterone. Nature, v. 392, p. 509-12, 1998.

HAFEZ, E. S. E.; LEVASSEUR, M. C.; TRIBAULT, C. Foliculogênese, maturação ovular e ovulação. In: HAFEZ, E. S. E. Reprodução Animal. 4.ed. São Paulo: Manole, 1988. p. 168-186.

HAMILTON, S. A.; XU, Z. Z.; KIEBORZ, K. R.; YOUNGQUIST, R. S.; GARVERICK, $\mathrm{H}$. A. Relationship between ovarian follicular dynamics and follicle-stimulating hormone levels during the bovine estrous cycle. Journal of Animal Science, v. 70, p. 261, 1992. Supplement 1.

HARIADI, M.; BROOMFIELD, D.; WRIGHT, P. J. The synchrony of prostaglandin induces estrus in cows was reduced by pre-treatment with hCG. Theriogenology, $v$. 49, n. 5, p. 967-74, 1998.

HASLER, J. F.; BOWEN, R. A.; NELSON, L. D.; SEIDEL Jr., G. E.; Serum progesterone concentrations in cows receiving embryo transfer. Journal of Reproduction and Fertility, v. 58, p. 72-77, 1980.

HUGHES, T. L.; VILLA-GODOY, A.; KESNER, J. S.; FOGWELL, R. L. Destruction of bovine ovarian follicles: effects on pulsatile release of $\mathrm{LH}$ and prostaglandin F2ainduced luteal regression. Biology of Reproduction, v. 36, p. 523-529, 1987.

HUMBLOT, P. Use of pregnancy specific proteins and progesterone assays to monitor pregnancy and determine the time, frequaencies and sources of embryonic mortality in ruminants. Theriogenology, v. 56, p. 1417-1433, 2001.

HUNTER, R.H.F. Mating, fertilisation and maintenance of pregnancy . In: WHITTMORE, C. T.; THOMAS, R. J.; PRESCOTT, J. H. D. Reproduction of Farm Animals. London: Longman Inc., 1982. p. 42-72.

INSKEEP, E. K. Factors that affect embryo survival in the cow: application of technology to improve calf crop. In: FIELDS, M. J.; SAND, R. S.; YELICH, J. V. (Ed.). Factors affecting calf crop: Biotechnology of Reproduction. Boca Raton: CRC Press, 2002. p. 255-279.

IRELAND, J. L.; GOOD, T. E.; KNIGHT, P. G.; IRELAND, J. J. Alterations in amounts of different forms of inhibin during follicular atresia. Biology of Reproduction, v. 50, p. 1265-1276, 1994.

KASTELIC, J. P. Folliculogenesis in cattle. In: SIMPÓSIO INTERNATIONAL DE REPRODUÇÃO ANIMAL APLICADA, 1., 2004, Londrina. Anais... , São Paulo: Faculdade de Medicina Veterinária e Zootecnia, Universidade de São Paulo, 2004. p. 191-198. 
KASTELIC, J. P.; MAPLETOFT, R. J. Follicular responses in dairy cows treated with GnRH and cloprostenol. Canadian Veterinary Research, v. 39, p. 107-109, 1998.

KERBLER, T. L.; BUHR, M. M.; JORDAN, L. T.; LESLIE, K. E.; WALTON, J. S. Relationship between maternal plasma progesterone concentration and interferontau synthesis by the conceptus in cattle. Theriogenology, v. 47, p. 703-714, 1997.

KOJIMA, F. N. The estrous cycle in Cattle, Physiology, endocrinology and folicular waves. The Professional Animal Scientist, v. 19, n. 1, p. 83-95, 2003.

KNICKERBOCKER, J. J.; THATCHER, W. W.; BAZER, F. W.; DROST, M.; BARNUM, D. H.; FINCHER, K. B.; ROBERTS, R. M. Proteins secreted by day 16 1018 conceptuses extended corpus luteum function in cows. Journal of Reproduction and Fertility, v. 37, p. 381-391, 1986a.

KNICKERBOCKER, J. J.; THATCHER, W. W.; FOSTER, D. B.; WOLFENSON, D.; BARTOL, F. F.; CATON, D. Uterine prostaglandin and blood flow responses to estradiol $17 \beta$ in cyclic cattle. Prostaglandins, v. 31, n. 14, p. 757-776. 1986b.

KUNZ, T. L.; GAMBARINI, M. L.; OLIVEIRA FILHO, B. D.; GALINDO, A. D. S. Mortalidade embrionária em bovinos: inter-relações embrião-patógenos. Revista CFMV, v. 8, n. 26, p. 27-36, 2002.

LAMMING, G. E.; DARWASH, A. O.; BACK, H. L. Corpus luteum function in dairy cows and embryo mortality. Journal of Reproduction and Fertility, v. 37, p. 245252, 1989. Supplement.

LINDSELL, C. E.; RAJKUMAR, K.; MANNING, A. W.; EMERY, S. K.; MAPLETOFT, R. J.; MURPHY, B. D. Variability in the FSH:LH ratios among batches of commercially available gonadotrophins. Theriogenology, v. 25, p. 167, 1984.

LÓPEZ-GATIUS, F.; SANTOLARIA, P. ; YÁNIZ, J.; RUTLLANT, J. LÓPEZBÉJAR, M. Factors affecting pregnancy loss from gestation day 38 to 90 in lactating dairy cows from a single herd. Animal Reproduction Science, v. 57, p. 1251-1261, 2002.

LUCY, M. C. Reproductive loss in high-producing dairy cattle: where will it end? Journal of Dairy Science, v. 84, p. 1277-1293, 2001.

LUCY, M. C.; SAVIO, J. D.; BADINGA, R. L.; DE LA SOTA, R. L.; THATCHER, W. $W$. Factors that affect ovarian follicular dynamics in cattle. Journal of Animal Science, v. 70, p. 3615-3626, 1992.

LUKASZEWSKA, J.; HANSEL, W. Corpus luteum maintenance during early pregnancy in the cow. Journal of Reproduction and Fertility, v. 59, p. 485-493, 1980. 
MACHADO, R. Effects of prostaglandin $F_{2 \alpha}$ and norgestomet on estrus synchronization and fertility in postpartum beef cows. 1994. 123f. Dissertação (Mestrado) - Department of Animal Sciences - University of Illinois, Urbana Champaign, 1994.

MACMILLAN, K. L.; SEGWAGWE, B. V. E.; PINO, C. S. Associations between the manipulation of patterns of follicular development and fertility in cattle. Animal Reproduction Science, v. 78, p. 327-344, 2003.

MADUREIRA, E. H.; PIMENTEL, J. R. V.; ALMEIDA, A. B.; ROSSA, L. A. F. Sincronização com progestágenos. In: SIMPÓSIO INTERNATIONAL DE REPRODUÇÃO ANIMAL APLICADA, 1., 2004, Londrina. Anais... , São Paulo:

Faculdade de Medicina Veterinária e Zootecnia, Universidade de São Paulo, 2004. p. 117-128.

MANN, G. E. Corpus luteum function and early embryonic death in the bovine. THE WORLD BUIATRICS CONFERENCE, Proceedings, p. 300-306, 2002.

MANN, G. E. Pregnancy rates during experimentation in dairy cows. The Veterinary Journal, v. 161, p. 301-305, 2001.

MANN, G. E.; LAMMING, G. E. Progesterone inhibition of development of the luteolytic signal in cows. Journal of Reproduction and Fertility, v. 104, p. 1-5, 1995.

MANN, G. E.; LAMMING, G. E. Relationship between maternal endocrine environment early embryo development and inhibition of the luteolytic mechanism in cows. Reproduction, v. 121, p. 175-80, 2001.

MANN, G. E.; LAMMING, G. E. The influence of progesterone during early pregnancy in cattle. Reproduction of Domestic Animals, v. 34, p. 269-74, 1999.

MANN, G. E.; LAMMING, G. E.; FISCHER, P. A. Progesterone control of interferon-t production during early pregnancy in the cow. Journal of Reproduction and Fertility, v. 21, p. 37, 1998. (Series abstracts).

MANN, G. E.; LAMMING, G. E.; FRAY, M. D. Plasma oestradiol and progesterone during early pregnancy in the cow and the effects of treatment with buserelin.

Animal Reproduction Science, v. 37, p. 121-131, 1995.

MANN, G. E.; LAMMING, G. E.; ROBINSON, R. S.; WHATES, D. C. The regulation of interferon- $\tau$ production and uterine receptors during early pregnancy. Journal of Reproduction and Fertility, v. 54, p. 317-328. 1999. Supplement.

MANN, G. E.; MANN, S. J.; LAMMING, G. E. The inter relationship between the maternal hormone environment and the embryo during the early stages of pregnancy. Journal of Reproduction and Fertility, v. 17, p. 55, 1996. (Series Abstracts). 
MARQUES, M. O. Ultra-sonografia ovariana, concentração plasmática de progesterona e taxa de concepção em novilhas receptoras de embriões submetidas a diferentes tratamentos no dia 7 do ciclo estral. 2002. $78 f$. Dissertação (Mestrado) - Faculdade de Medicina Veterinária e Zootecnia, Universidade de São Paulo, São Paulo, 2002.

MARQUES, M. O.; NASSER, L. F.; SILVA, R. C. P. ; BO, G. A.; BARUSELLI, P. S. Increased pregnancy rates in bos taurus $x$ bos indicus embryo recipients with treatments to increase plasma progesterone concentration. Theriogenology, v. 59, p. 369, 2003. (Series Abstract).

MARQUES, M. O., REIS, E. L., BARUSELLI, P. S. Sincronização de receptoras para inovulação em tempo fixo. In: SIMPÓSIO INTERNATIONAL DE REPRODUÇÃO ANIMAL APLICADA, 1., 2004, Londrina. Anais... , São Paulo: Faculdade de Medicina Veterinária e Zootecnia, Universidade de São Paulo, 2004. p. $199-211$.

MARTÍNEZ, M. F.; BÓ, G.; MAPLETOFT, R. J. Synchronization of follicular wave emergence and ovulation for reproductive biotechnology. In: SIMPÓSIO INTERNATIONAL DE REPRODUÇÃO ANIMAL APLICADA, 1., 2004, Londrina. Anais... , São Paulo: Faculdade de Medicina Veterinária e Zootecnia, Universidade de São Paulo, 2004. p. 26-55.

MIHM, M; CURRAN, N.; HYTTEL, P; BOLAND, M. P.; ROCHE, J. F. Effect of dominant follicle persistence on follicular fluid oestradiol and inhibin and on oocyte maturation in heifers. Journal of Reproduction and Fertility, v. 116, p. 293-304, 1999.

MILVAE, R. A.; HINCKLEY, S. T.; CARLSON, J. E. Luteotropic and luteolytic mechanisms in the bovine corpus luteum. Theriogenology, v. 45, p. 1327-43, 1996.

MIZUTA, K. Estudo comparativo dos aspectos comportamentais do estro e dos teores plasmáticos de Lh, FSH, progesterona e estradiol que precedem a ovulação em fêmeas bovinas nelore (bos taurus indicus) e nelore $\mathrm{x}$ angus (bos taurus indicus $\boldsymbol{x}$ bos taurus taurus). 2003. 98f. Tese (Doutorado) - Faculdade de Medicina Veterinária e Zootecnia, Universidade de São Paulo, São Paulo, 2003.

MORENO, I.; GALINA, C. S.; ESCOBAR, F. J.; RAMIREZ, B.; NAVARRO-FIERRO, $R$. Evaluation of the lytic response of PGF2 $\alpha$ in zebu cattle based on serum progesterone. Theriogenology, v. 25, p. 413-421, 1986.

MOSER, M. T.; GARVERICK, H. A.; SMITH, M. F.; YOUNGQUIST, R. S. Follicular growth and endocrine patterns of prepubertal heifers administered bovine follicular fluid and (or) FSH. Animal Reproduction Science, v. 18, p. 227-242. 1989.

NEUMANN, A. L.; LUSBY, K. S. The commercial cow-calf program . In: Beef

Cattle. 8. ed. New York: John Wiley e Sons, 1986. p. 1-14. 
NIASARI-NASLAJI, A.;JILLELLA, D.; FENWICK, D; KINDER, J. E.; D'OCCHIO, M. J. Estrus synchronization and fertility after the control of formation and regression of the corpus luteum, and emergence of the ovarian dominant follicle in cattle.

Theriogenology, v. 46, n. 8, p. 1451-1465, 1996.

NIEMANN, H.; SACHER, B.; ELSAESER, F. Pregnancy rates relative to recipient plasma progesterone levels on the day of nonsurgical transfer of frozen/thawed bovine embryos. Theriogenology, v. 23, p. 631-39, 1985.

NOGUEIRA, L. A .G.; COUTINHO, G. T. R. M.; VIANA, J. H. M.; PALHÃO, M. P.; SÁ, W.F. Follicle dynamics and divergence in Guzera Breed (Bos indicus) cows. In: INTERNATIONAL CONGRESS ON ANIMAL REPRODUCTION, 15., 2004, Porto Seguro. Abstracts..., Belo Horizonte: Colégio Brasileiro de Reprodução Animal, 2004. p. 44.

NOGUEIRA, M. F. G.; MELO, D. S.; CARVALHO, L. M.; FUCK, E. J.; BARROS, C. $M$. High levels of progesterone, induced by eCG, decreased conception rates in heifers, after frozen embryo transfer. Theriogenology, v. 57, p. 556, 2002. (Series Abstract).

PAYAS, A. J.; BROADBENT, P. J.; DOLMAN, D. F.; CHRISTIE, W. B. Factors affecting pregnancy rate in embryo transfer recipients with reference to plasma progesterone. Theriogenology, v. 31, p. 238, 1989.

PETERS, A. R. Embryo mortality in the cow. Animal Breeding Abstracts, v. 64, p. 587-598, 1996.

PETERS, A. R.; DREW, S. B.; MANN, G. E; LAMMING, G. E.; BECK, N. F. Experimental and practical approaches to the stablishment and maintainance of pregnancy. Journal Physiology and Pharmacology, v. 43, n. 4, p. 143-152. 1992. Supplement 1.

PIERSON, R. A.; GINTHER, O. J. Ultrasonic imaging of the ovaries and uterus in cattle. Theriogenology, v. 49, p. 21-37, 1988.

PINHEIRO, O. L.; BARROS, C. M.; FIGUEREDO, R. A.; VALLE, E. R.; ENCARNAÇÃO, R. O.; PADOVANI, C. R. Estrous behaviour and the estrus-toovulation interval in nelore cattle (bos indicus) with natural estrus or estrus induced with prostaglandin F2 $\alpha$ or norgestomet and estradiol valerate. Theriogenology, v. 49, p. 667-681, 1998.

PORTELA, V. V. M.; FARIAS, A. M.; SILVEIRA, R. S.; LOF, H. K.; CECCIM, M. S.; GONÇALVES, P. B. D.; OLIVEIRA, J. F. C. Transcription of ciclooxygenase (COX-2) and progesterone receptors genes in uterus after injecting oestradiol benzoate. In: INTERNATIONAL CONGRESS ON ANIMAL REPRODUCTION, 15., 2004, Porto Seguro. Abstracts..., Belo Horizonte: Colégio Brasileiro de Reprodução Animal, 2004. p. 115.

PRICE, C. A .; WEBB, R. Ovarian response to hcg treatment during the estrous cycle in heifers. Journal of Reproduction and Fertility, v. 86, n. 1, p. 303-8, 1989. 
PRITCHARD, J. Y.; SHRICK, F. N. ; INSKEEP, E. K. Relationship of pregnancy rate to peripheral concentrations of progesterone and estradiol in beef cows.

Theriogenology, v. 42, p. 247-259. 1994.

PURSLEY, J. R.; MEE, M. O . WILTBANK, M. C. Synchronization of ovulation in dairy cows using PG F2 $\alpha$ and GnRH. Theriogenology, v. 44, p. 915-923, 1995.

RAJAMAHENDRAN, R.; AALI, M.; GIRITHARAN, G.; RAMAKRISHMAPPA, N. Corpus luteum function and pregnancy rates following OvSynch and CIDR ovulation synchronization and timed artificial insemination in postpartum dairy cows. In: INTERNATIONAL CONGRESS ON ANIMAL REPRODUCTION, 15., 2004, Porto Seguro. Abstracts..., Belo Horizonte: Colégio Brasileiro de Reprodução Animal, 2004. p. 335.

RAJAMAHENDRAN, R.; MANIKKAM, M. Effects of exogenous steroid hormones on the dominant follicle maintained by a norgestomet implant in heifers. Canadian Journal of Animal Science, v. 74, p. 457-64, 1994.

RAJAMAHENDRAN, R.; SIANANGAMA, P. C. Effect human Corionic Gonadotrophin on dominant follicles in cows. Formation of accessory corpora lutea, progesterone production and pregnancy rates. Journal of Reproduction and Fertility, v. 95, n. 2, p. 577-584, 1992.

RAMAKRISHMAPPA, N. ; RAJAMAHENDRAN, R.; AALI, M.; GIRITHARAN, G. Influence of postbreeding $\mathrm{GnRH}$ or hCG administration on corpus luteum function and pregnancy in dairy cattle. In: INTERNATIONAL CONGRESS ON ANIMAL REPRODUCTION, 15., 2004, Porto Seguro. Abstracts..., Belo Horizonte: Colégio Brasileiro de Reprodução Animal, 2004. p. 129.

RANDEL, R. D. Seasonal effects on female reproductive functions in the bovine (indian breeds). Theriogenology, v. 21, p. 170-185, 1984.

REMSEN, L. G.; ROUSSEL, J. D. Pregnancy rates relating to plasma progesterone levels in recipient heifers at day of transfer. Theriogenology, v. 18, p. 365-372, 1982.

RHODES, F. M.; DE'ATH, G.; ENTWISTLE, K. W. Animal and temporal effects on ovarian follicular dynamics in brahman heifers. Animal Reproduction Science, v. 38, p. 265-277, 1995.

RHODES, F. M.; ENTWISTLE, K. W. KINDER, J.E. Changes in ovarian function and gonadotrophin secretion preceding the onset of nutritially induced anoestrus in Bos indicus heifers. Biology of Reproduction, v. 55, p. 1437-1443,1996.

ROCHA, J. L. Sincronização hormonal da onda folicular e do estro em novilhas de corte mestiças monitoradas por radiotelemetria. 2000. 125f. Tese (Doutorado) - Faculdade de Medicina Veterinária e Zootecnia, Universidade de São Paulo, São Paulo, 2000. 
RODRIGUES, C. F. M.; GARCIA, J. M. The application of ultrasound guided follicular aspiration in cattle. Arquivos da Faculdade de Veterinária da UFRGS, v. 25, n. 1, p, 156-159, 1997. Suplemento 25.

SÁ FILHO, M. F.; REIS, E. L.; VIEL Jr., J. O.; NICHI, M.; MADUREIRA, E. H.; BARUSELLI, P. S. Dinâmica folicular de vacas nelore lactentes em anestro tratadas com progestágenos, ecg, e gnrh. Acta Scientiae Veterinariae, v. 32, p. 235, 2005. Suplemento.

SALFEN, B. E.; CRESSWELL, J. R.; XU, Z. Z.; BAO, B.; GARVERICK, H. A. Effects of the presence of a dominant follicle and exogenous estradiol on the duration of the luteal phase of the bovine estrous cycle. Journal of Reproduction and Fertility, v. 115, n. 1, p. 15-21, 1999.

SANGSRITAVONG, S.; COMBS, D. K.; SARTORI, R; AMENTANO, L. E.; WILTBANK, M. C. High feed intake increases liver blood flow and metabolismo $f$ progesterone and estradiol-17 $\beta$ in dairy cattle. Journal of Dairy Scince, v. 85, p. 2831-2842, 2002.

SANTOS, J. C.; FERREIRA, A. M.; SÁ, W. F.; NOGUEIRA, L. A .G.; FREITAS, C.; CAMARGO, L. S. Ultrassonographis evaluation of follicular dynamics in cows (Gyr breed). Arquivos da Faculdade de Veterinária da UFRGS, v. 26, n. 1, p. 367, 1998. Suplemento 26.

SANTOS, J. E. P.; CERRI, R. L. A.; BALLOU, M. A.; HIGGINBOTHAM, G. E.; KIRK, $\mathrm{J}$. H. Effect of timing of first clinical mastitis occurrence on lactational and reproductive performance of holstein dairy cows. Animal Reproduction Science, v. 80 , p. $31-45,2004 a$.

SANTOS, J. E. P.; THATCHER, W. W.; CHEBEL, R. C.; CERRI, R. L. A.; GALVÃO, K. N. The effect of embryonic death rates in cattle on the efficacy of estrus synchronization programs. Animal Reproduction Science, v. 82-83, p. 513-535, 2004b.

SANTOS, J. E. P.; THATCHER, W. W.; POLL, L.; OVERTON, M. W. Effects of hCG on luteal function and reproductive performance of high producing lactating Holstein dairy cows. Journal of Animal Science, v. 79, p. 2881-2894, 2001.

SANTOS, J. E. P.; THATCHER, W. W.; POLL, L.; OVERTON, M. W.; REYNOLDS, J. $P$. Human chorionic gonadotropin influences numbers of corpora lutea, plasma progesterone and conception rates of dairy cows. In: INTERNATIONAL CONGRESS ON ANIMAL REPRODUCTION, 14., 2000, Stockholm. Proceedings..., Stockolm: STS, 2000. v. 1, p. 144.

SAS INSTITUTE, SAS/STAT: user's guide, Version 6. 4. ed. Cary: SAS INSTITUTE, 1993. v. 2, p. 891-1686. 
SCHMITT, E. J. P.; BARROS, C. M.; FIELDS, P. A.; FIELDS, M. J.; DIAZ, T.; KLUGE, J. M.; THATCHER, W. W. A celular and endocrine characterization of the original and induced corpus luteum after administration of a $\mathrm{GnRH}$-agonist or hCG on day five of the estrous cycle. Journal of Animal Science, v. 74, n. 8, p. 1915-1929, 1996a.

SCHMITT, E. J. P.; DIAZ, T.; BARROS, C. M.; DE LA SOTA, R. L.; DROST, M. FREDERICKSSON, E. W.; STAPLES, C. R.; THORNER, R.; THATCHER, W. W. Diferential response of the luteal phase and fertility in cattle following ovulation of the first wave follicle with $\mathrm{hCG}$ or an agionist of GnRH. Journal of Animal Science, v. 74, n. 5, p. 1074-1083, 1996b.

SHAHAM-ALBALANCY, A.; FOLMAN, Y.; KAIM, M.; ROSENBERG, M.; WOLFENSON, D. Delayed effect of low progesterone concentrations on bovine uterine $\mathrm{PGF}_{2 \alpha}$ secretion in the subsequent oestrous cycle. Reproduction, v. 122, p. 643-648, 2001.

SHEPHARD, R. Investigation of a whole-heerd controlled breeding program using $\mathrm{GnRH}$ and prostaglandin in commercial seasonally-calving dairy herds. Australian Cattle Veterinary, v. 23, p. 24-28, 2002.

SHIRASUNA, K.; WIJAYAGUNAWARDANE, M. P. B.; MATSUI, M.; KANEKO, E.; OHTANI, M.; MIYAMOTO, A. A. Blood flow in the corpus luteum acutely increases ar early stage of regression and decreases afterward during spontaneous luteolysis in the cow. In: INTERNATIONAL CONGRESS ON ANIMAL REPRODUCTION, 15., 2004, Porto Seguro. Abstracts..., Belo Horizonte: Colégio Brasileiro de Reprodução Animal, 2004. p. 62.

SIANANGAMA, P. C.; RAJAMAHENDRAN, R. Characteristics of corpus luteum formed from the first wave dominant folicle following hCG in cattle. Theriogenology, v. 45 , n. 5 , p. $977-990,1996$.

SILKE, V.; DISKIN, M. G.; KENNY, D. A.; BOLAND, M. P.; DILLON, P.; MEE, J. F.; SREENAN, J. M. Extent, pattern and factors associated with late embryonic losses in dairy cows. Animal Reproduction Science, v. 71, n. 1, p. 1-12, 2002.

SIROIS, J.; FORTUNE, J. E. Ovarian follicular dynamics during the estrous cycle in heifers monitored by real-time ultrasonography. Biology of Reproduction, v. 39, p. 308-317, 1988.

SPELL, A. R.; BEAL, W. E.; CORAH, L. R.; LAMB, G. C. Evaluating recipient and embryo factors that affect pregnancy rates of embryo transfer in beef cattle. Theriogenology, v. 56, p. 287-297, 2001.

SPITZER, J. C. Influences of nutrition on reproduction in beef cattle. In: MORROW, D. A. (Ed.). Current therapy in theriogenology. Philadelphia: W. B. Saunders, 1986. p. 320. 
STARBUCK, M. J.; DAILEY, R. A.; INSKEEP, E. K. Factors affecting retention of early pregnancy in dairy cattle. Animal Reproduction Science, v. 84, n. 1, p. 27-39, 2004.

STUBBINGS, R. B.; WALTON, J. S. Relationship between plasma progesterone concentrations and pregnancy rates in cattle receiving either fresh or previously frozen embryos. Theriogenology, v. 26, p. 145-155, 1986.

THATCHER, W. W.; DRIANCOURT, M. A.; TERQUI, M.; BADINGA, L.; Dynamics of folicular development in cattle following histerectomy and during early pregnancy.

Domestic Animal Endocrinology, v. 8, p. 223-234, 1991.

THATCHER, W. W.; GUZELOGLU, A.; MATTOS, R.; BINELLI, M.; HANSEN, T. R.; $\mathrm{PRU}, \mathrm{J}$. K. Uterine-conceptus interactions and reproductive failure in cattle.

Theriogenology, v. 56, p. 1435-1450, 2001.

THATCHER, W. W.; HANSEN, P. J. Systems to alter embryo survival. In: VAN HORN, H. H.; WILCOX, C. J. (Ed.). Large dairy herd management. Champaign: American Dairy Sciences Association, 1992. p. 16-30.

THATCHER, W. W.; TERQUI, M.; THIMONIER, J.; MAULEON, P. Effect of estradiol $17 \beta$ on peripheral plasma concentration of 15 -keto-13,14 dihydro $\mathrm{PGF}_{2 \alpha}$ and luteolysis in cyclic cattle. Prostaglandins, v. 31, p. 745-756, 1986.

THUN, R.; KAUFMANN, C.; JANETT, F. The influence of restraint stress on reproductive hormones in the cow. Reproduction in Domestic Animals, v. 33, p. 255-260, 1998.

TOWSON, D. H.; TSANG, P. C. W.; BUTLER, W. R.; FRAJBLAT, M.; GRIEL, L. C.; JOHNSON, C. J.; MILVAE, C. J.; MILVAE, R. A.; NICSIK, G. M.; PATE, J. L. Relationship of fertility to ovarian follicular waves before breeding in dairy cows. Journal of Animal Science, v. 80, p. 1053-1058. 2002.

TRIBULO, R.; NIGRO, M.; BURRY, E.; CACCIA, M.; TRIBULO, H.; BO, G. A. Pregnancy rates in recipients receiving CIDR-b devices immediately following embryo transfer. Theriogenology, v. 47, p. 372, 1997. (Series Abstract).

TURZILLO, A.M.; FORTUNE, J. Suppression of the secondary FSH surge with bovine follicular fluid is associated with delayed ovarian follicular development in heifers. Journal of Reproduction and Fertility, v. 89, p. 643-653, 1990.

VASCONCELOS, J. L. M.; SANTOS, R.M.; PEREZ, G.C. Controle do estro e da ovulação visando a inseminação artificial em tempo fixo em bovinos de leite a pasto ou confinados. In: SIMPÓSIO INTERNATIONAL DE REPRODUÇÃO ANIMAL APLICADA, 1., 2004, Londrina. Anais... , São Paulo: Faculdade de Medicina Veterinária e Zootecnia, Universidade de São Paulo, 2004. p. 129-146.

VIANA, J. H. M.; FERRREIRA, A. M.; SÁ, W. F.; CAMARGO, L. S. A . Follicular dynamics in zebu cattle. Pesquisa Agropecuária Brasileira, v. 35, n. 12, p. 25012509, 2000. 
VIANA; J. H. M. FERREIRA, A. M.; SÁ, W. F.; CAMARGO, L. S. A .; FREITAS, C.; SANTOS, J. C. Follicular dynamics in Gyr cattle. Arquivos da Faculdade de Veterinária da UFRGS, v. 26, n. 1, p. 379. 1998. Suplemento 26.

VILELA, E. R.; VASCONCELOS, J. L. M.; SANTOS, R. M.; SÁ FILHO, O. G.; MARQUEZINI, G. H. L.; WECHLER, F. S.; Effect of progesterone device on conception at timed $\mathrm{Al}$ protocol and pregnancy rate during breeding season in sucled Nelore cows. In: INTERNATIONAL CONGRESS ON ANIMAL REPRODUCTION, 15., 2004, Porto Seguro. Abstracts..., Belo Horizonte: Colégio Brasileiro de Reprodução Animal, 2004. p. 368.

VILLA-GODOY, A.; IRELAND, J. J.; WORTMAN, J. A.; AMES, N. K.; HUGHES, T. L.; FOGWEL R. L.; Effect of ovarian follicles on luteal regression in heifers. Journal of Animal Sciences, v. 60, p. 519-527, 1985.

VANROOSE, G.; deKRUIF, A.; VanSOOM, A. Embryonic mortality and embryopathogen interactions. Animal Reproduction Science, v. 60-61, p. 131-143, 2000.

VOH, A. A.; OYEDIPE, E. O.; PATHIRAJA, N.; BUVANENDRAN, V.; KUMI-DIAKA, J. Peripheral plasma levels of progesterone in Nigerian zebu cows after synchronization of oestrus with prostaglandin F2alpha analogue (dinoprost tromethamine). British Veterinary Journal, v. 143, p. 254-263, 1987.

VOSS, A. K.; FORTUNE, J. E. Levels of messenger ribonuclic acid for cytocrome p450 and 17ß-hydroxylase and p450 aromatase in bovine preovulatory follicles after the Ih surge. Endocrinology, v. 132, p. 888-894, 1993.

ZAVY, M. T. Embryonic mortality in cattle. In: ZAVY, M. T.; GEISERT, R. D. (Ed.). Embryonic mortality in domestic species. Boca Raton: CRC Press, 1994. p. 99140.

ZEITOUN, M. M.; RODRIGUEZ H. F.; RANDEL, R. D. Effect of season on ovarian follicular dynamics in brahman cows. Theriogenology, v. 45, p. 1577-1581, 1996.

ZERON, Y.; OCHERETNY, A.; KEDAR, O.; BOROCHOV, A.; SKLAN, D.; ARAV, A. Seasonal changes in bovine fertility: relation to developmental competence of oocytes, membrane properties and fatty acid composition of follicles. Reproduction, v. 121 , p. $447-454,2001$.

XU, Z.; GARVERICK, H. A.; SMITH, G. W.; SMITH, M. F.; HAMILTON, S. A.; YOUNGQUIST, R. S. Expression on follicle-stimulating hormone and luteinizing hormone receptor messenger ribonucleic acid in bovine follicles during the first follicle wave. Biology of Reproduction, v. 53, p. 951-957, 1995.

YOUNGS, C.R.; POWERS-MEYER, A .M.; WONDERLICH, M.G.; MOREIRA, M.B. The effect of cloprostenol, administered at two different sites on the expression of estrus in postpartum dairy cattle. In: INTERNATIONAL CONGRESS ON ANIMAL REPRODUCTION, 15., 2004, Porto Seguro. Abstracts..., Belo Horizonte: Colégio Brasileiro de Reprodução Animal, 2004. p. 60. 
WALTON, J. S.; HALBERT, G. W.; ROBINSON, N. A.; LESLIE, K. E. Effects of progesterone and human corionic gonadotrophin administration five days postinsemination on plasma and milk concentrations of progesterone and pregnancy rates of normal and repeat breeder dairy cows. Canadian Journal of Veterinary Research, v. 54, p. 305-308, 1990.

WATHES, D. C.; ROBINSON, R. S.; MANN, G. E.; LAMMING, G. E. The establishment of early pregnancy in cows. Reproduction of Domestic Animals, v. 33, p. 279-284, 1998.

WATHES, D. C.; TAYLOR, V. J.; CHENG, Z.; MANN, G. E. Follicle growth, corpus luteum function and their effect on embryo development in postpartum dairy cows. Reproduction, v. 61, p. 219-237, 2003. Supplement.

WILTBANK, J. N. ; INGALLS, J. E.; ROWDEN, W. W. Effects of various forms and levels of estrogens alone or in combination with gonadotrophins on the estrous cycle of beef heifers. Journal of Animal Science, v. 20, p. 341-346, 1961.

WOLFENSON, D.; ROTH, Z.; MEIDAN, R. Impaird reproduction in het-stressedcattle: basic and applied aspects. Animal Reproduction Sciences, v. 60, p. 535-547, 2000.

WRATHALL, A. E.; SUTMÖLLER, P. Potential of embryo transfer to control transmission of disease. In; STRINGFELLOW, D. A.; SEIDEL, S. M. (Ed.). Manual of the international embryo transfer society. Champaign: IETS, 1998. p. 17-44. 
APÊNDICE 


\section{APÊNDICE A}
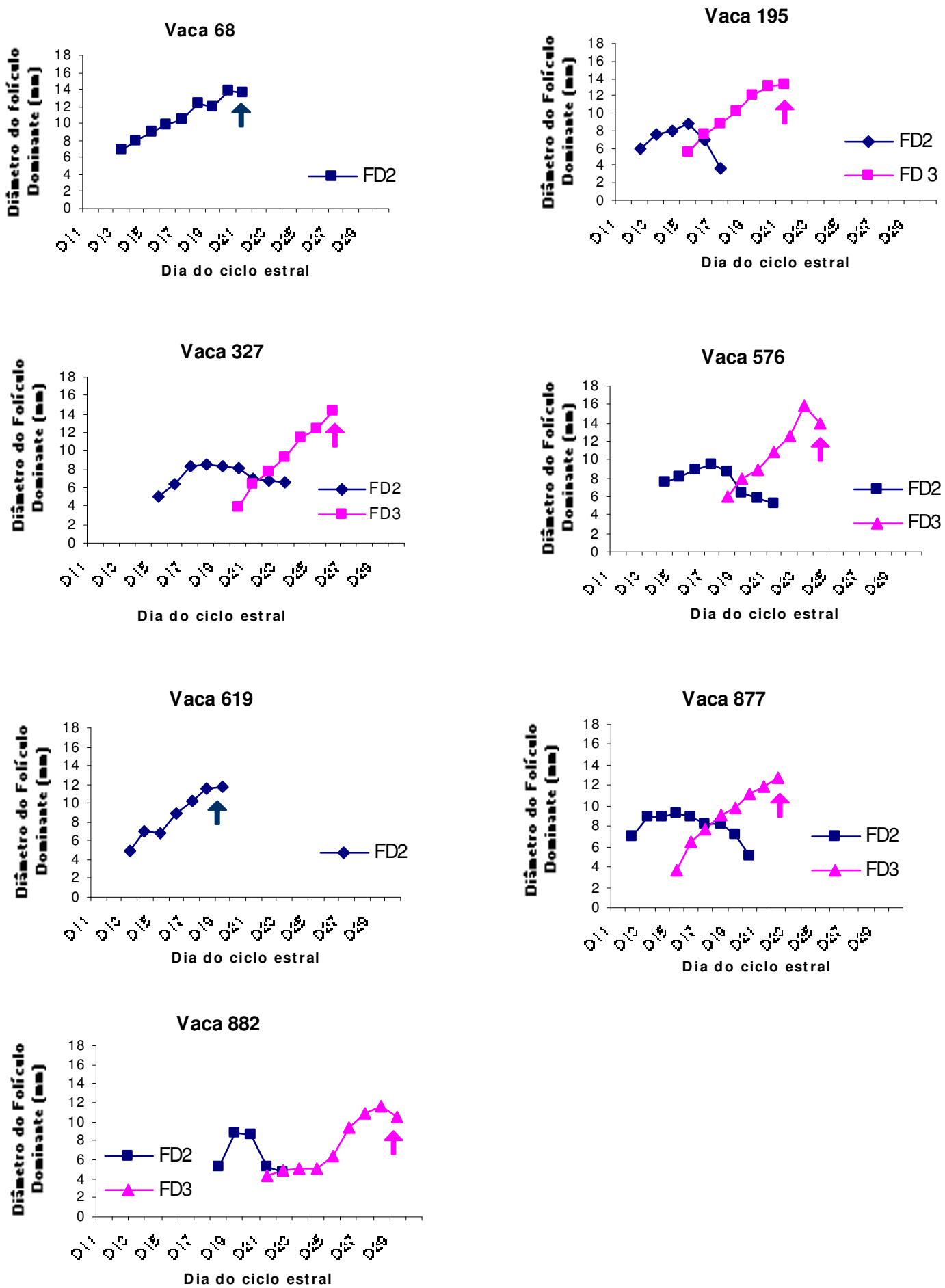

Figura 1 - Gráficos da dinâmica folicular individual para o diâmetro do folículo dominante (FD) em cada onda de crescimento em função do dia do ciclo estral e da ovulação ( $\boldsymbol{\uparrow}$ - grupo Controle. São Carlos, 2004 


\section{APÊNDICE A}
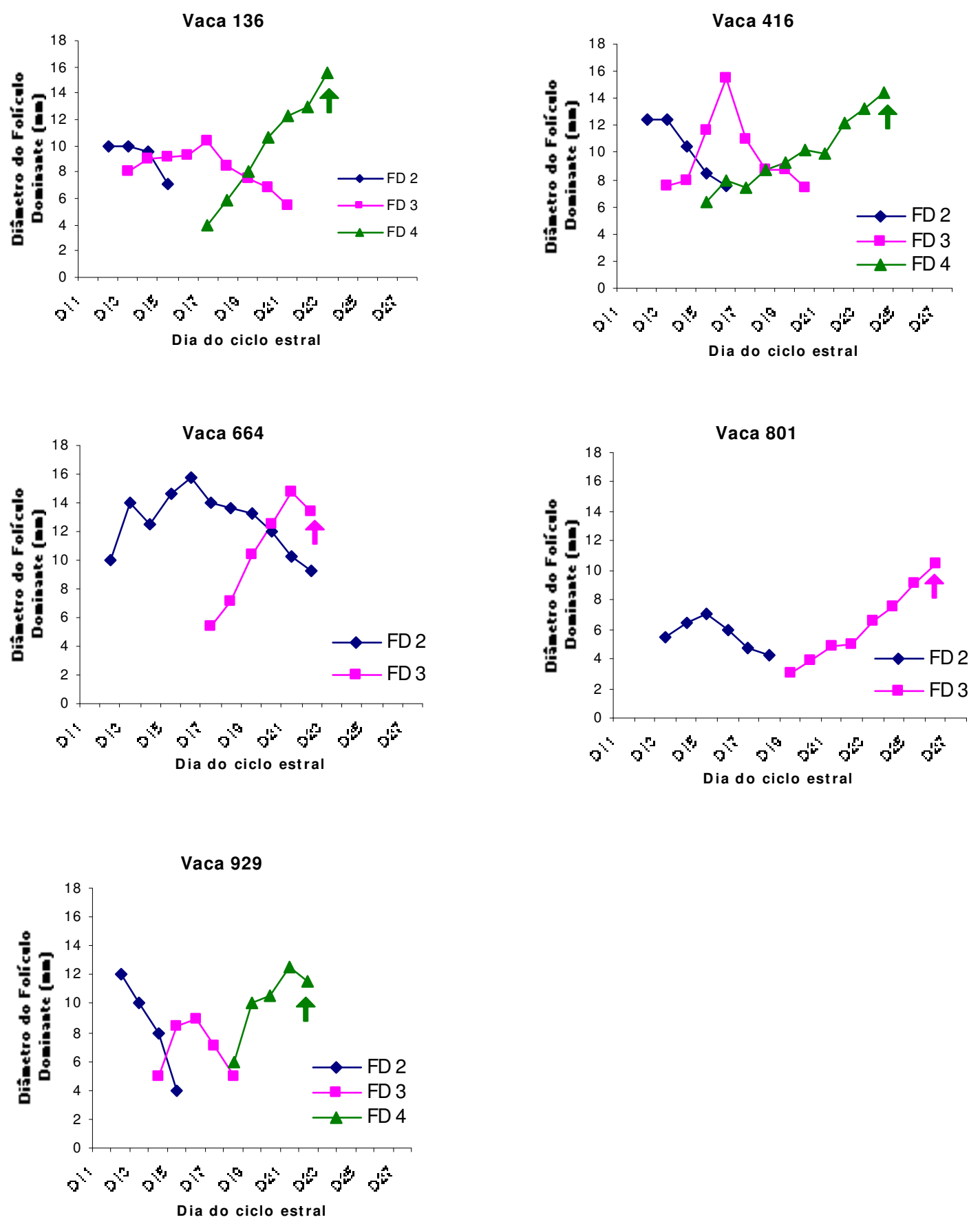

Figura 2 - Gráficos da dinâmica folicular individual para o diâmetro do folículo dominante (FD) à cada onda de crescimento em função do dia do ciclo estral e da ovulação ( $\uparrow$ )- grupo hCG. São Carlos, 2004 


\section{APÊNDICE A}

Vaca 255
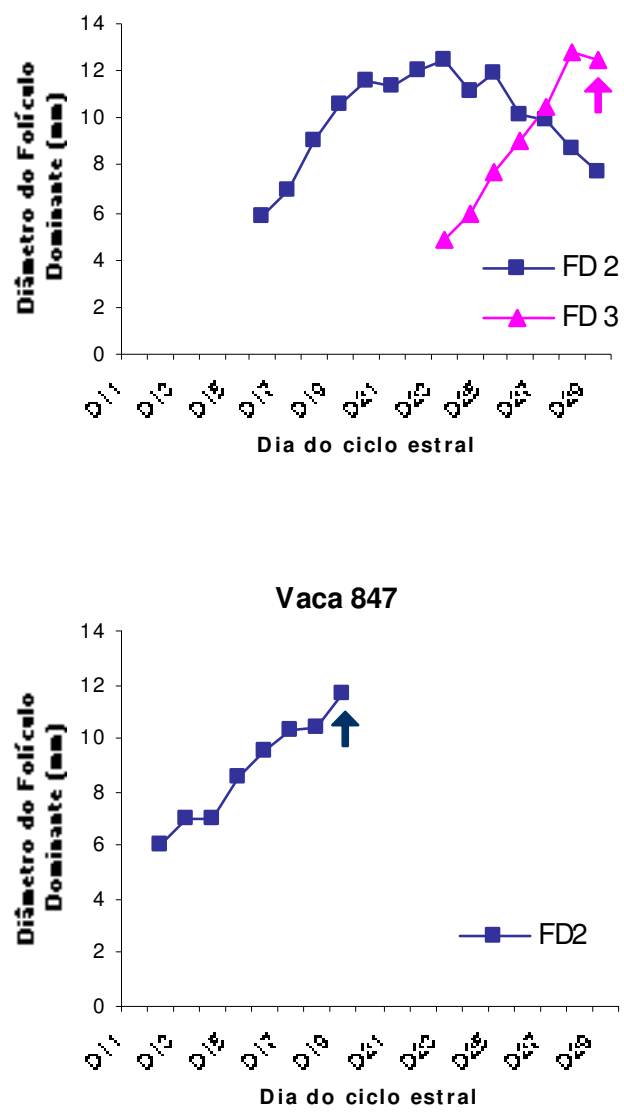

Vaca 5535

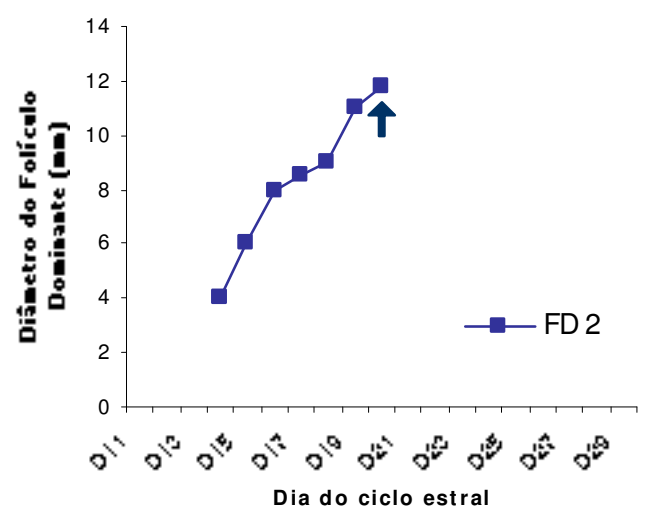

VACA 630

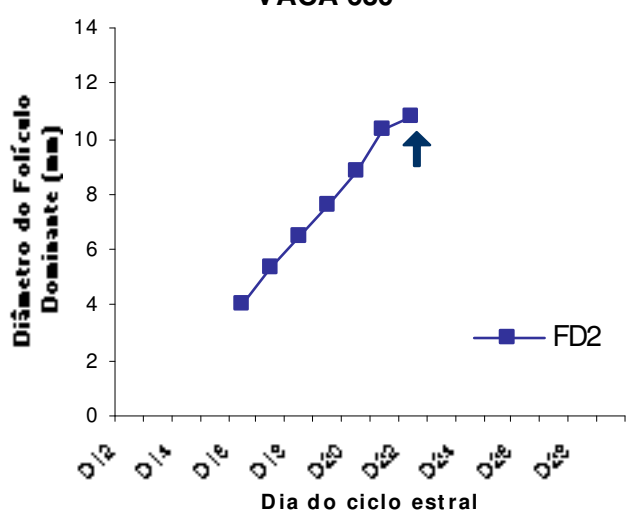

VACA 963

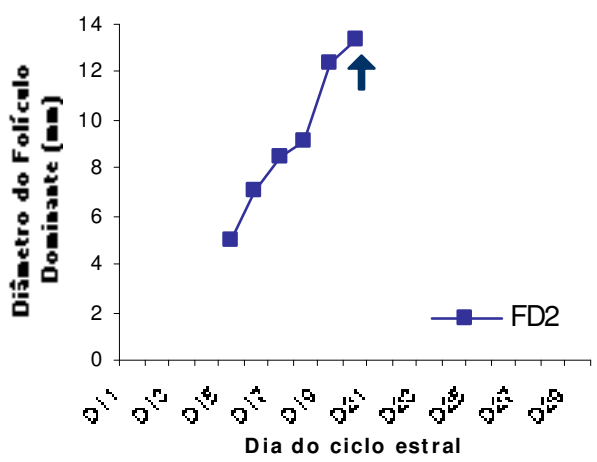

VACA 8687

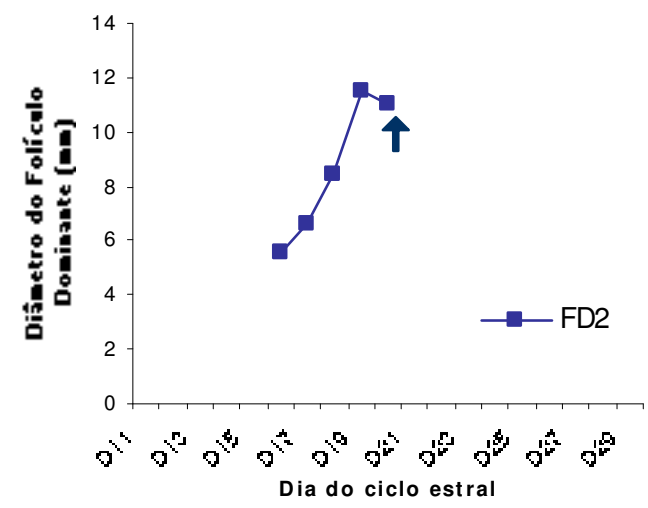

Figura 3 - Gráficos da dinâmica folicular individual para o diâmetro do folículo dominante (FD) à cada onda de crescimento em função do dia do ciclo estral e da ovulação $(\boldsymbol{\uparrow})$ - grupo $\mathrm{E}_{2}$-São Carlos, 2004 


\section{APÊNDICE A}
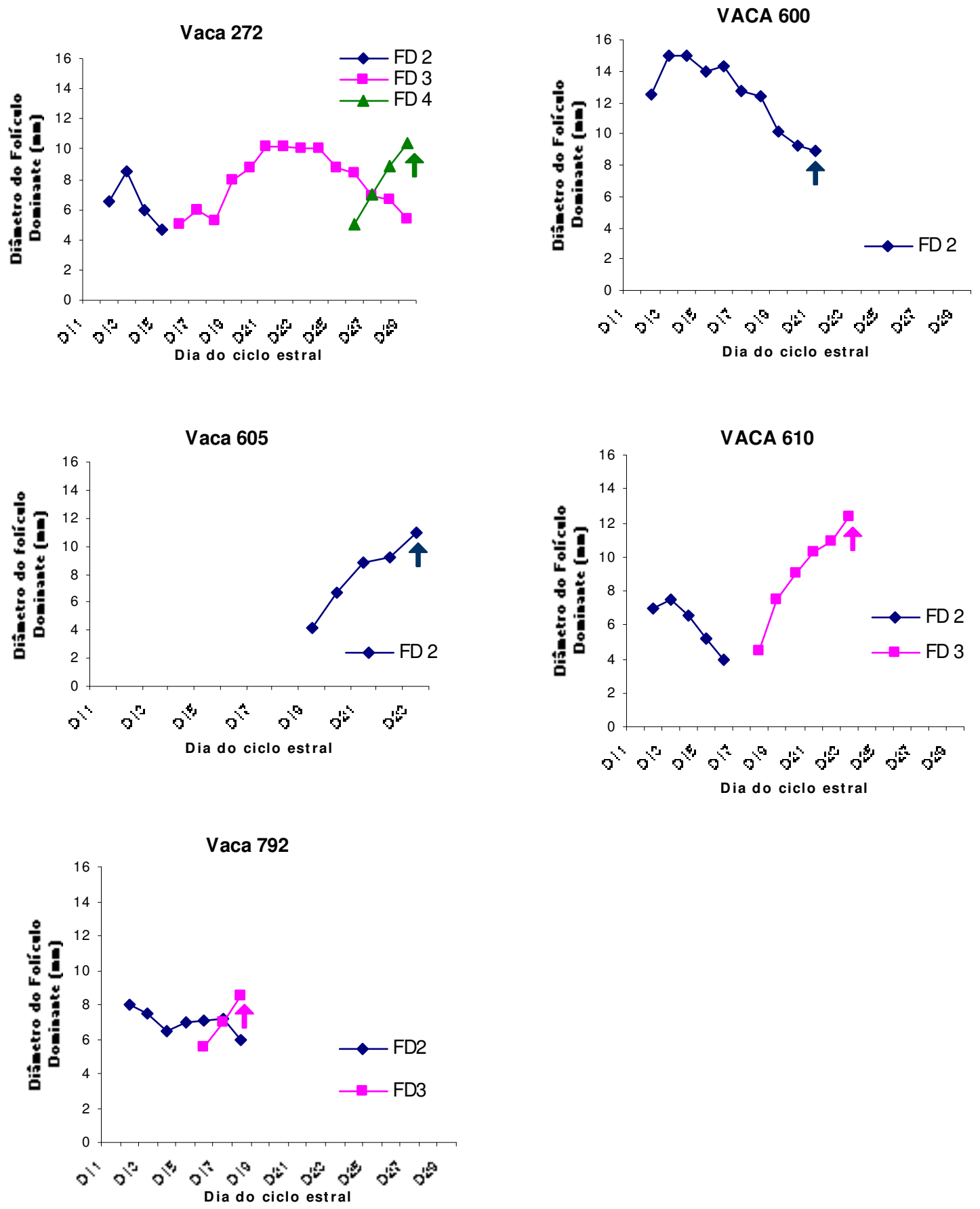

Figura 4 - Gráficos da dinâmica folicular individual para o diâmetro do folículo dominante (FD) à cada onda de crescimento, em função do dia do ciclo estral e da ovulação $(\boldsymbol{\uparrow})$ - grupo $h C G / E_{2}$. São Carlos, 2004 


\section{APÊNDICE A}
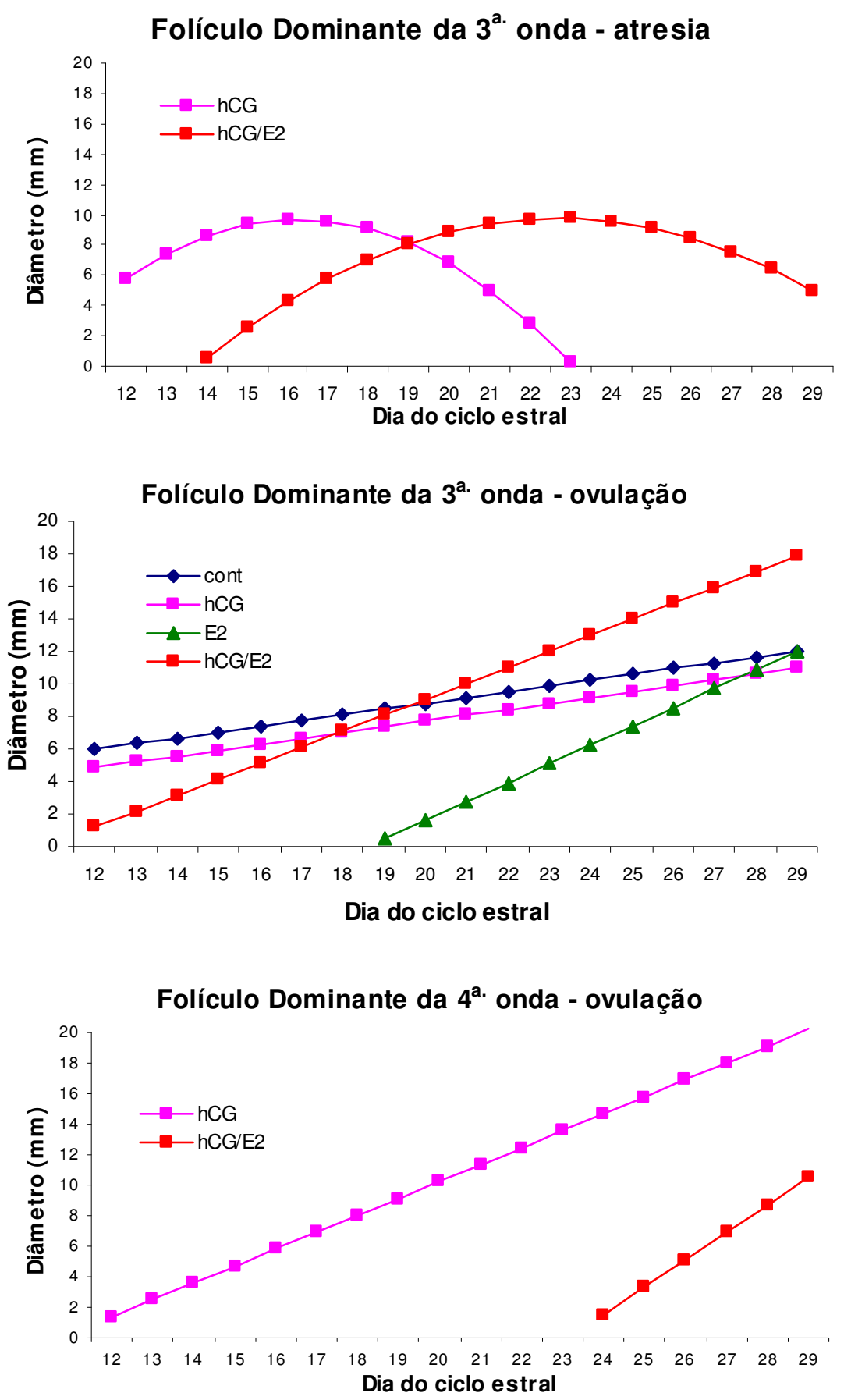

Figura 5 -

Gráficos das curvas obtidas das análises de regressão para o diâmetro do folículo dominante das $3^{\mathrm{a}}$ e $4^{\mathrm{a}}$ ondas de crescimento ao longo do ciclo estral. São Carlos, 2004 
APÊNDICE A
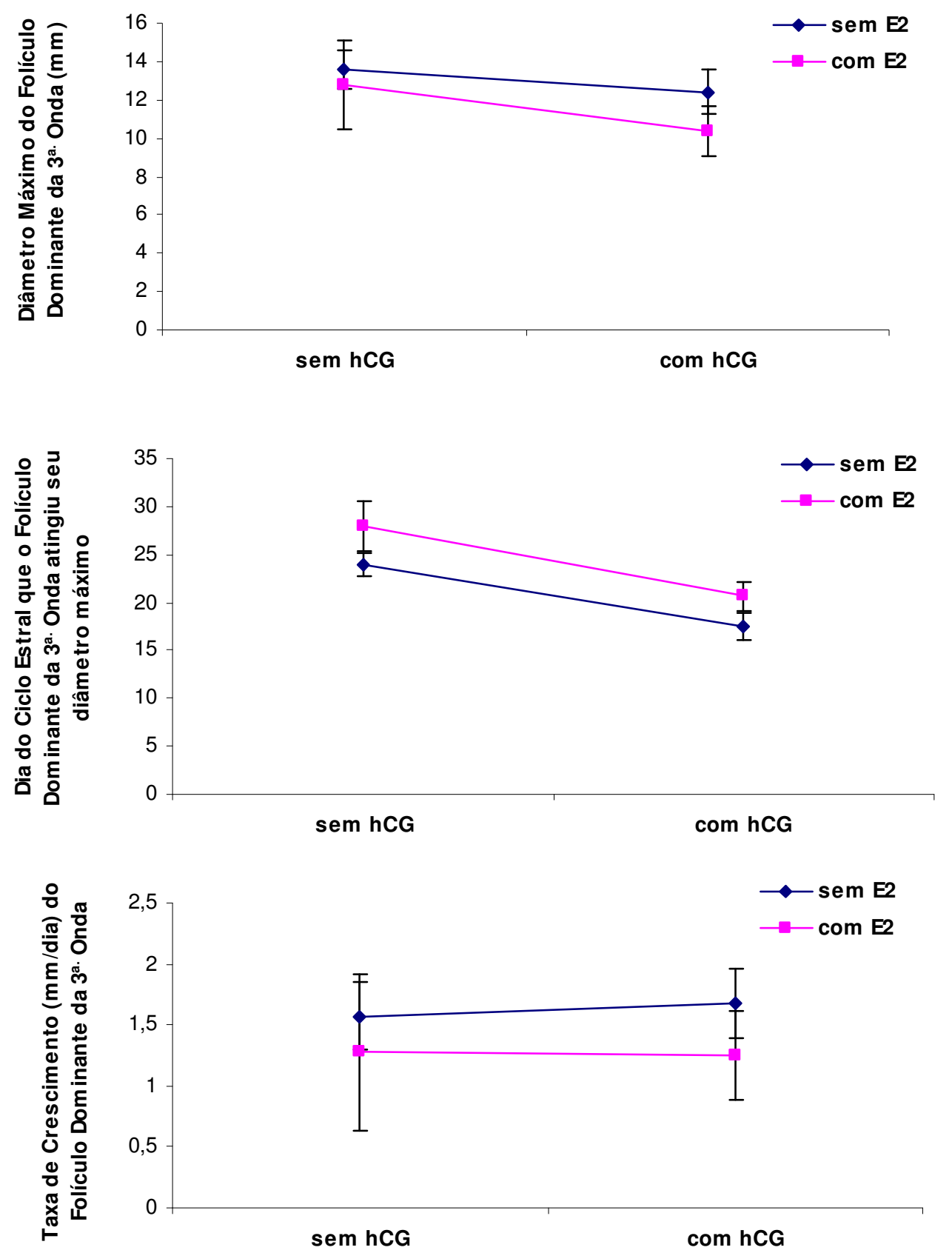

Figura 6 - Gráficos das médias e erros-padrão das médias dos fatores "hCG" e " $\mathrm{E}_{2}$ " para as variáveis diâmetro máximo do folículo dominante da $3^{\mathrm{a}}$ onda de crescimento folicular $(\mathrm{mm})$, dia em que esse folículo atingiu seu diâmetro máximo e sua taxa de crescimento (mm/dia). São Carlos, 2004 
APÊNDICE A

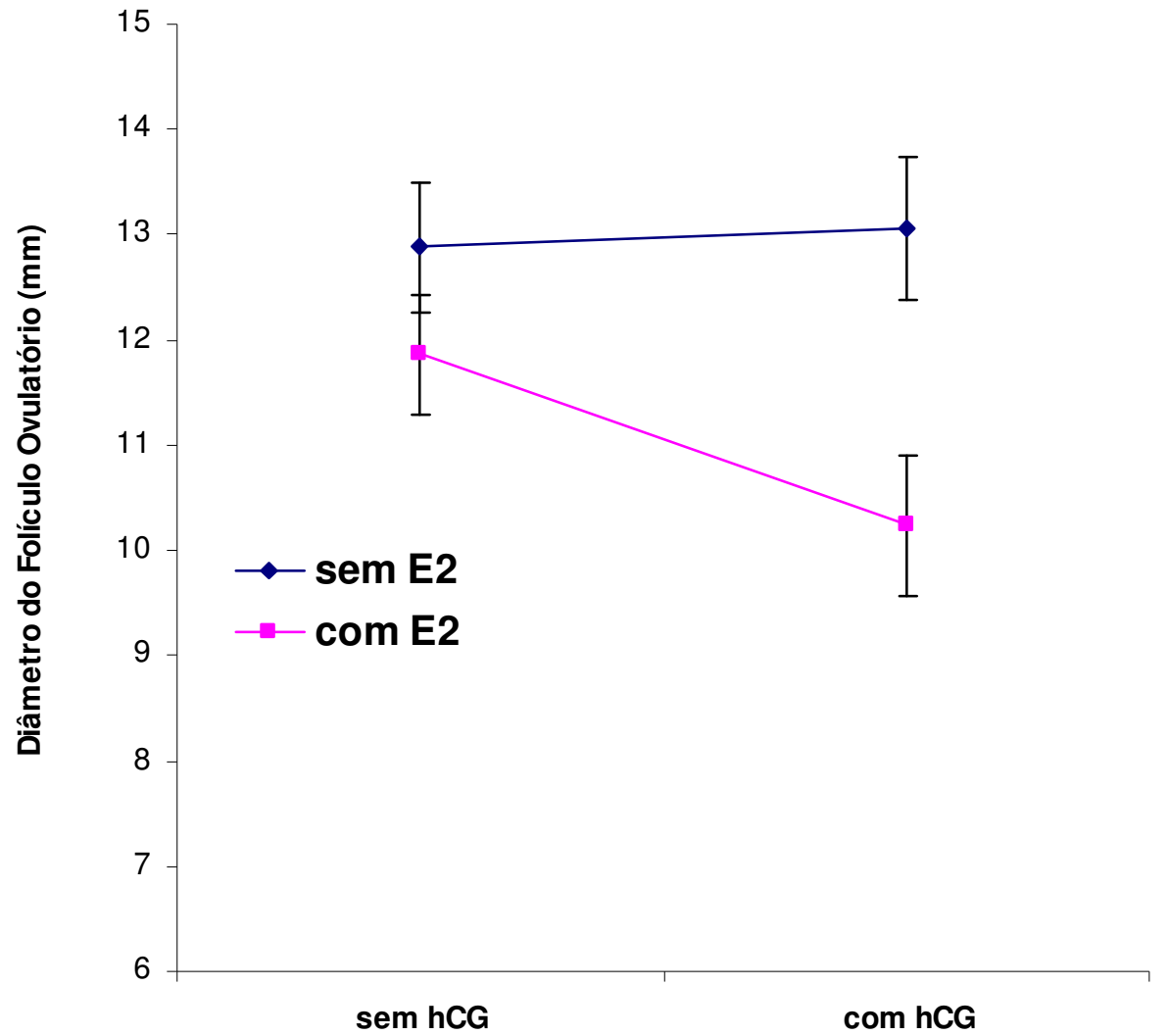

Figura 7 - Gráfico da interação entre os fatores "hCG" e "E" para o diâmetro do folículo pré-ovulatório (mm). São Carlos, 2004 


\section{APÊNDICE A}

Vaca 68

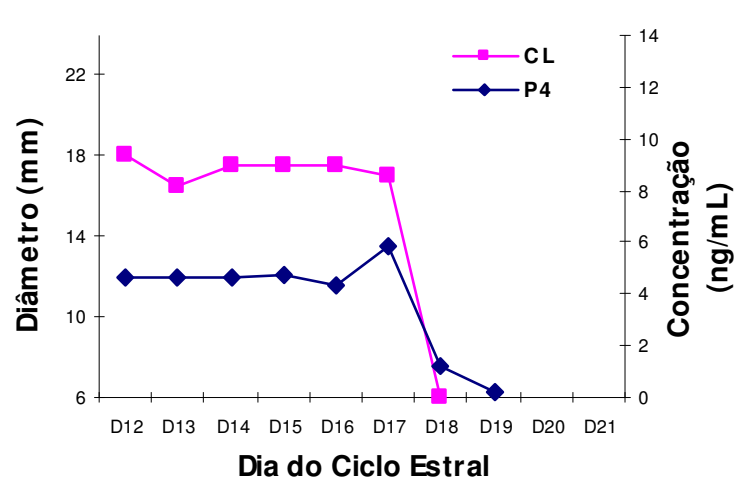

Vaca 576

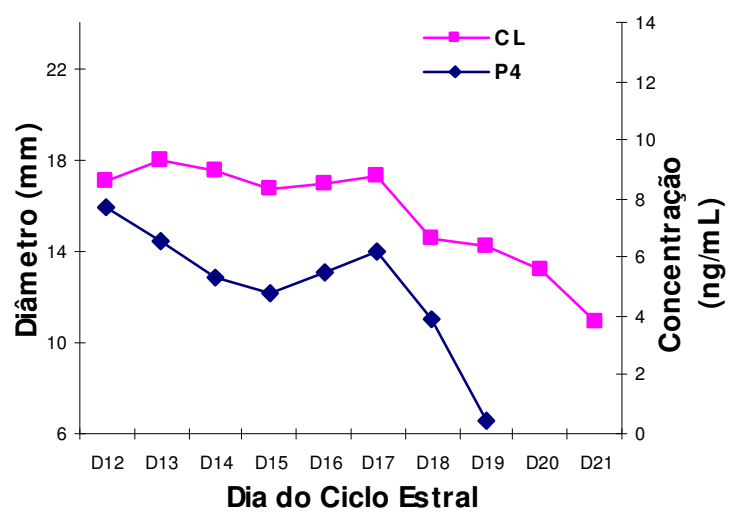

Vaca 877

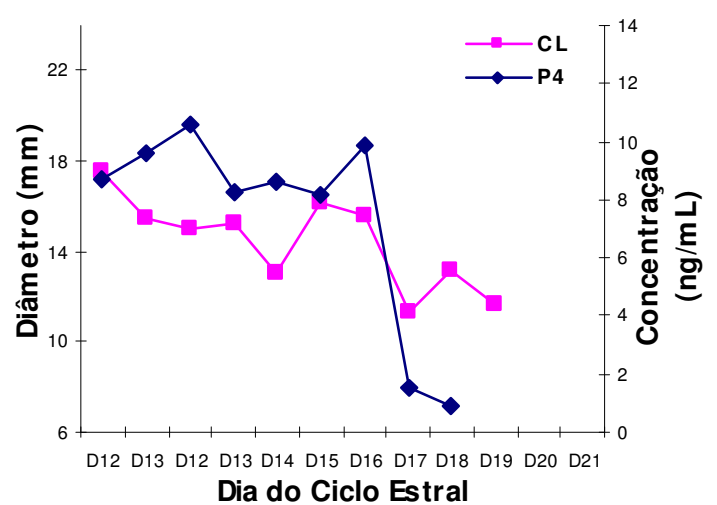

Vaca 195

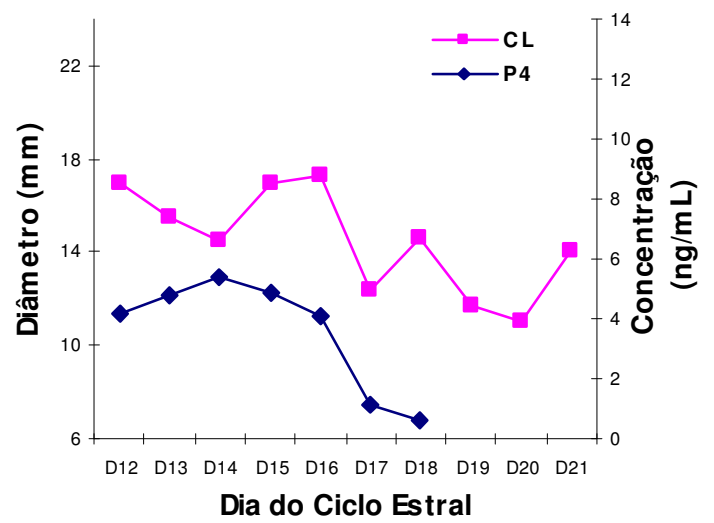

Vaca 619

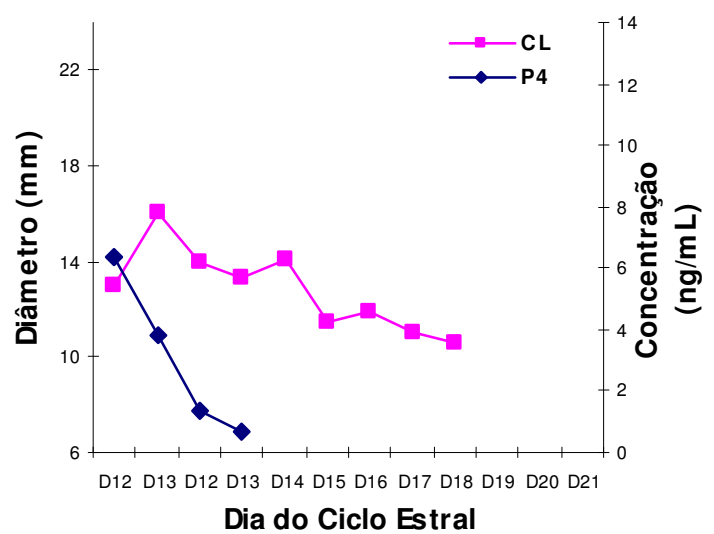

Figura 8 -

Gráficos da dinâmica luteínica das vacas do grupo controle representando o diâmetro do corpo lúteo $(\mathrm{CL})$ e a concentração plasmática da progesterona (P4), em função do dia do ciclo estral. São Carlos, 2004 


\section{APÊNDICE A}
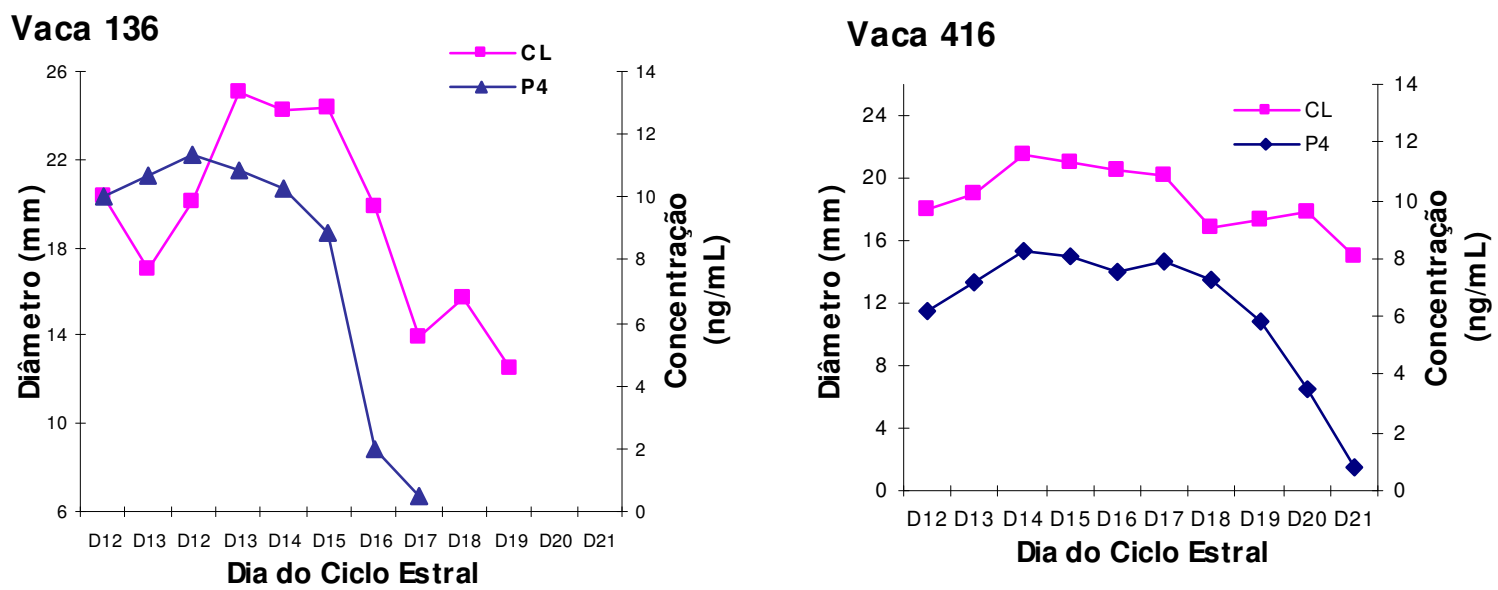

\section{Vaca 664}

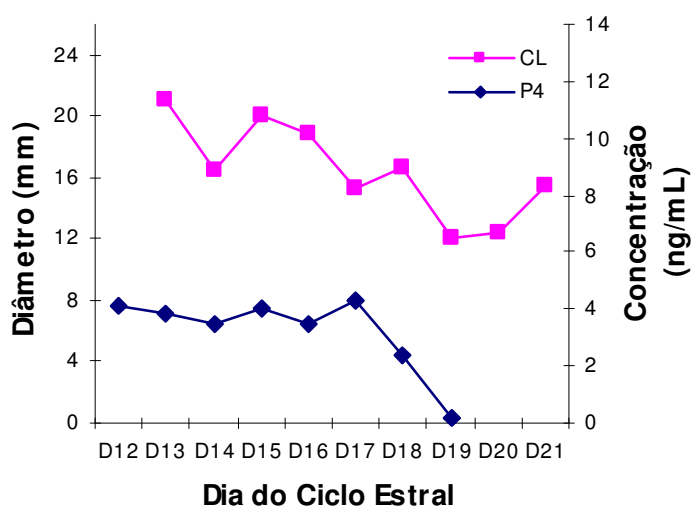

Vaca 801

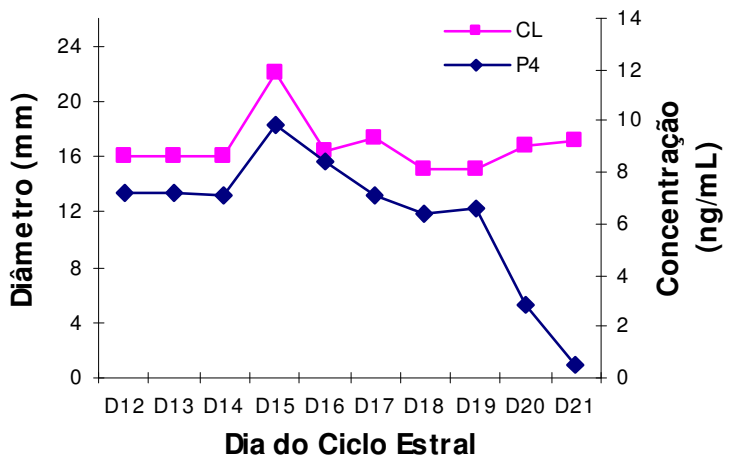

Vaca 929

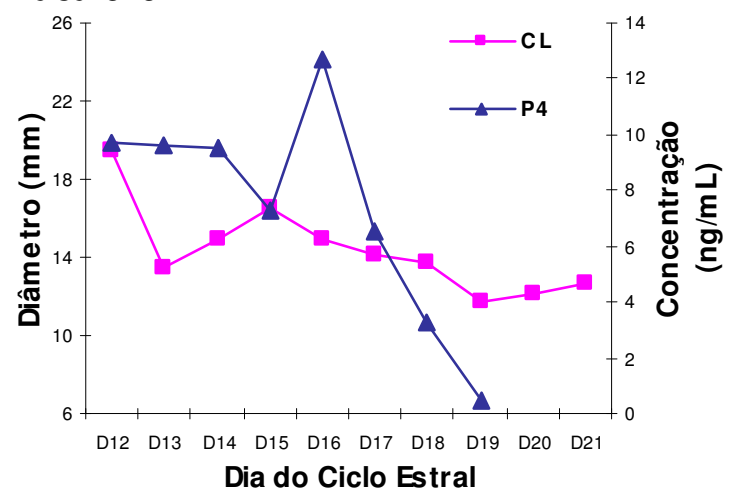

Figura 9 - Gráficos da dinâmica luteínica das vacas do grupo hCG representando o diâmetro do corpo lúteo $(\mathrm{CL})$ e a concentração plasmática da progesterona (P4), em função do dia do ciclo estral. São Carlos, 2004 


\section{APÊNDICE A}
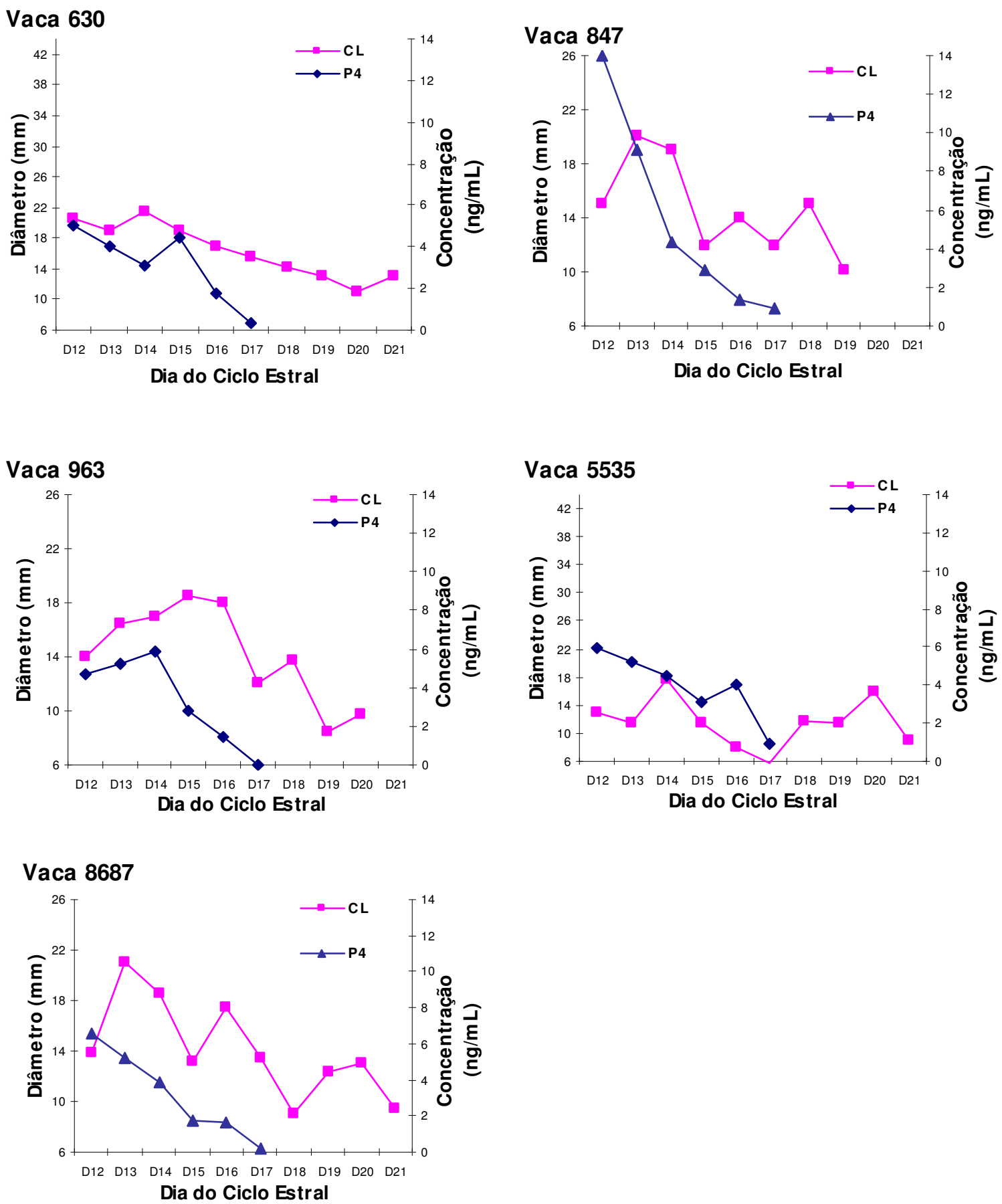

Figura 10 - Gráficos da dinâmica luteínica das vacas do grupo $E_{2}$ representando o diâmetro do Corpo Lúteo $(\mathrm{CL})$ e a concentração plasmática da progesterona (P4), em função do dia do ciclo estral. São Carlos, 2004 


\section{APÊNDICE A}
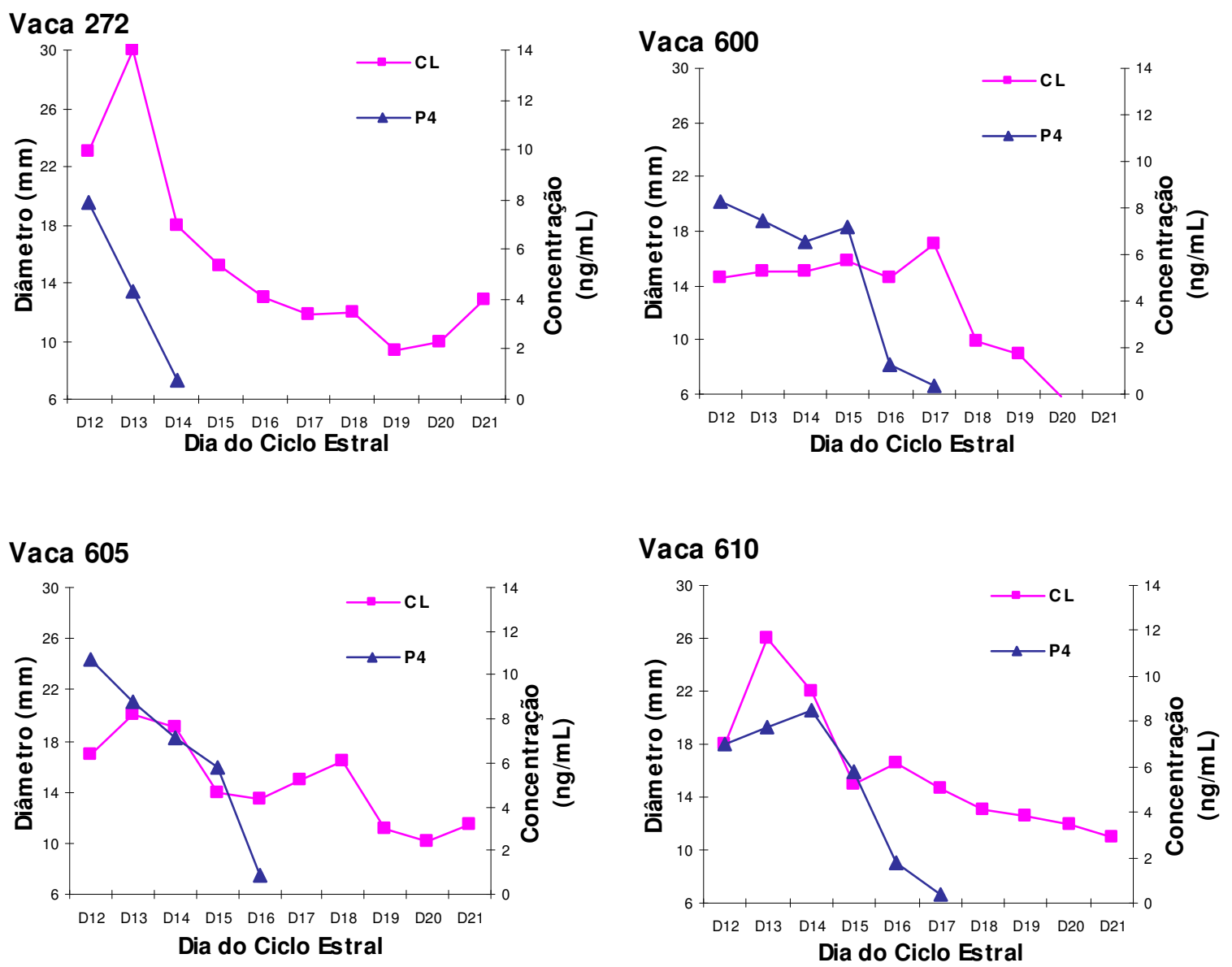

Vaca 792

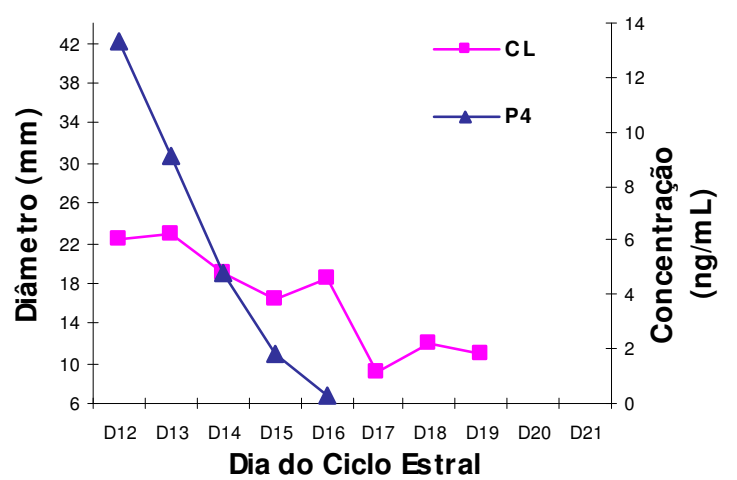

Figura 11 - Gráficos da dinâmica luteínica das vacas do grupo $h C G / \mathrm{E}_{2}$ representando o diâmetro do Corpo Lúteo $(\mathrm{CL})$ e a concentração plasmática da progesterona (P4), em função do dia do ciclo estral. São Carlos, 2004 


\section{APÊNDICE A}

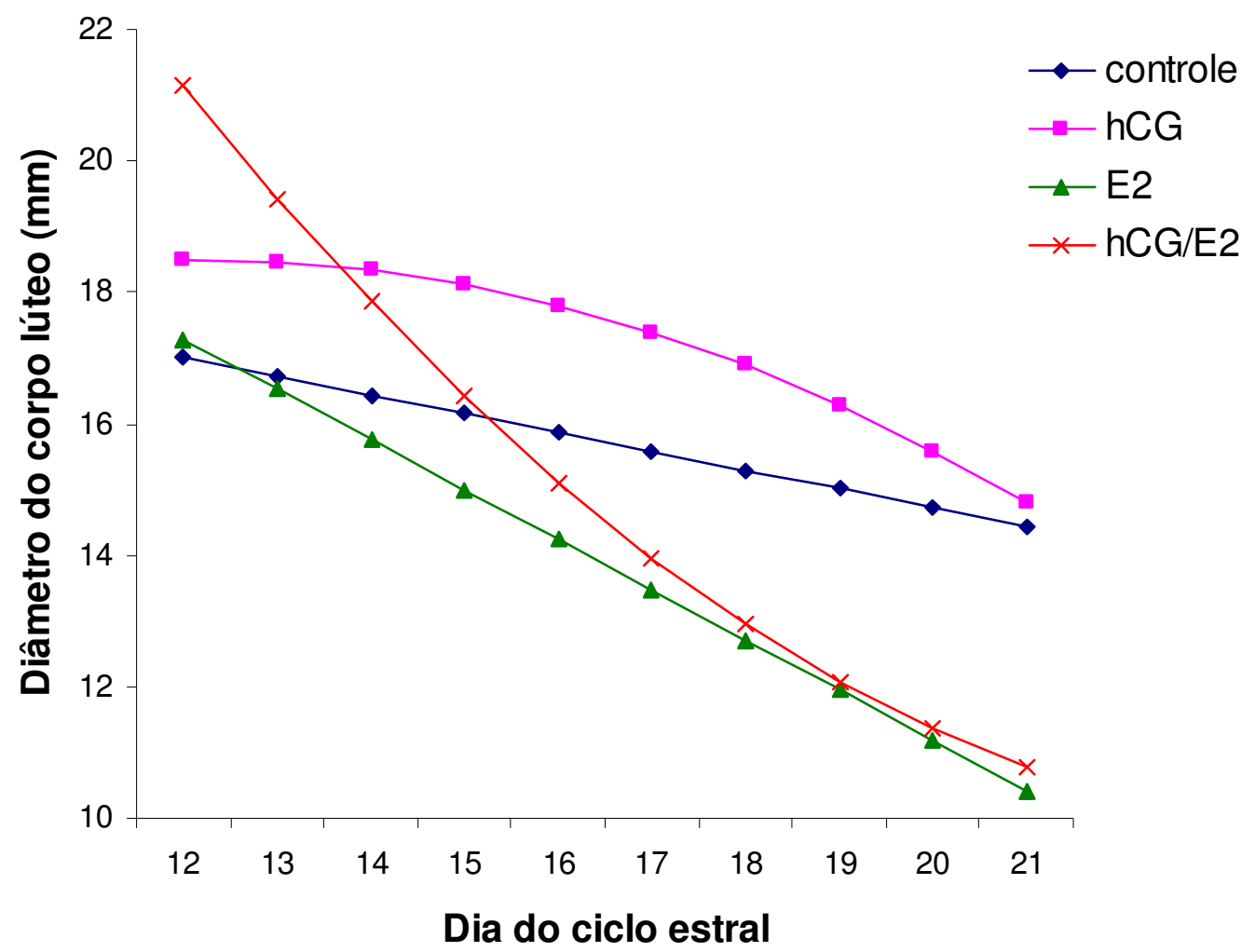

$$
\begin{array}{lll}
\varnothing C L_{\text {controle }}=20,41-0,284 D & R^{2}=0,17 \\
\varnothing C L_{\text {hCG }}=11,31+1,174+0,048 D^{2} & R^{2}=0,43 \\
\varnothing C L_{\text {E2 }}=26,44-0,763 D & R^{2}=0,37 \\
\varnothing C L_{\text {hCG/E2 }}=52,97-3,507 D+0,071 D^{2} & R^{2}=0,58
\end{array}
$$

Figura 12 -

Gráfico e equações das curvas obtidas a partir das análises de regressão para o diâmetro do corpo lúteo $(\varnothing \mathrm{CL})$ em função do dia do ciclo estral (D) para os diferentes grupos experimentais. São Carlos, 2004 


\section{APÊNDICE A}

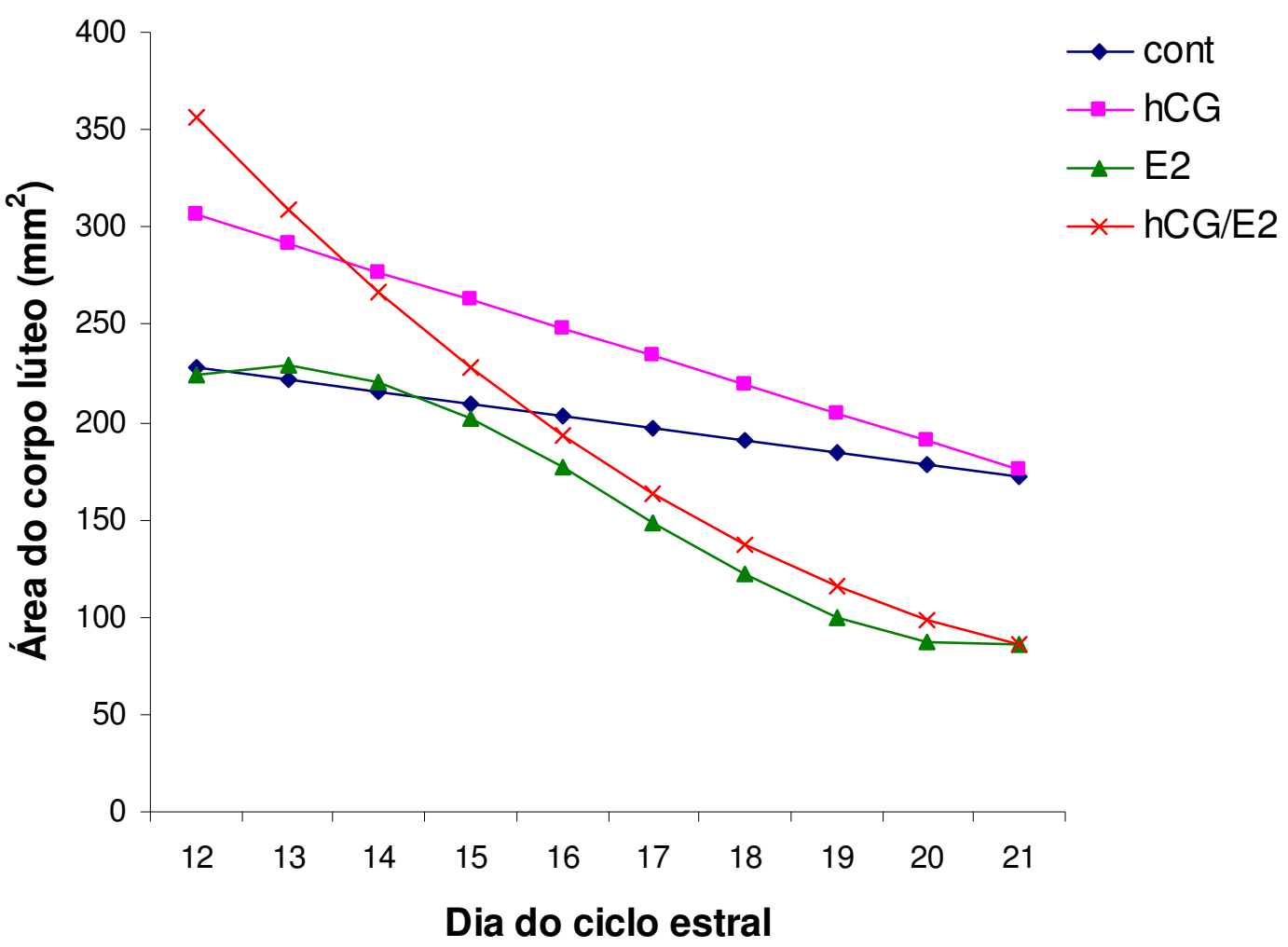

Figura 13 - $\quad$ Gráfico e equações das curvas obtidas a partir das análises de regressão para a área do corpo lúteo $\left(\mathrm{S}_{\mathrm{CL}}\right)$ em função do dia do ciclo estral (D) para os diferentes grupos experimentais. São Carlos, 2004

$\begin{array}{ll}S_{C L \text { controle }}=302,3-6,224 D & R^{2}=0,15 \\ S_{C L \text { hCG }}=479,6-14,46 D & R^{2}=0,34 \\ S_{C L \text { E2 }}=-2315+500,5 D-31,66 D^{2}+0,632 D^{3} & R^{2}=0,40 \\ S_{C L \text { hCG/E2 }}=1258-100,9 D+2,147 D^{2} & R^{2}=0,52\end{array}$

$\begin{array}{ll}S_{C L \text { controle }}=302,3-6,224 D & R^{2}=0,15 \\ S_{C L \text { hCG }}=479,6-14,46 D & R^{2}=0,34 \\ S_{C L \text { E2 }}=-2315+500,5 D-31,66 D^{2}+0,632 D^{3} & R^{2}=0,40 \\ S_{C L \text { hCG/E2 }}=1258-100,9 D+2,147 D^{2} & R^{2}=0,52\end{array}$

$\begin{array}{ll}S_{C L \text { controle }}=302,3-6,224 D & R^{2}=0,15 \\ S_{C L \text { hCG }}=479,6-14,46 D & R^{2}=0,34 \\ S_{C L \text { E2 }}=-2315+500,5 D-31,66 D^{2}+0,632 D^{3} & R^{2}=0,40 \\ S_{C L \text { hCG/E2 }}=1258-100,9 D+2,147 D^{2} & R^{2}=0,52\end{array}$

$\begin{array}{ll}S_{C L \text { controle }}=302,3-6,224 D & R^{2}=0,15 \\ S_{C L \text { hCG }}=479,6-14,46 D & R^{2}=0,34 \\ S_{C L \text { E2 }}=-2315+500,5 D-31,66 D^{2}+0,632 D^{3} & R^{2}=0,40 \\ S_{C L \text { hCG/E2 }}=1258-100,9 D+2,147 D^{2} & R^{2}=0,52\end{array}$

$\begin{array}{ll}S_{C L \text { controle }}=302,3-6,224 D & R^{2}=0,15 \\ S_{C L \text { hCG }}=479,6-14,46 D & R^{2}=0,34 \\ S_{C L \text { E2 }}=-2315+500,5 D-31,66 D^{2}+0,632 D^{3} & R^{2}=0,40 \\ S_{C L \text { hCG/E2 }}=1258-100,9 D+2,147 D^{2} & R^{2}=0,52\end{array}$ 


\section{APÊNDICE A}

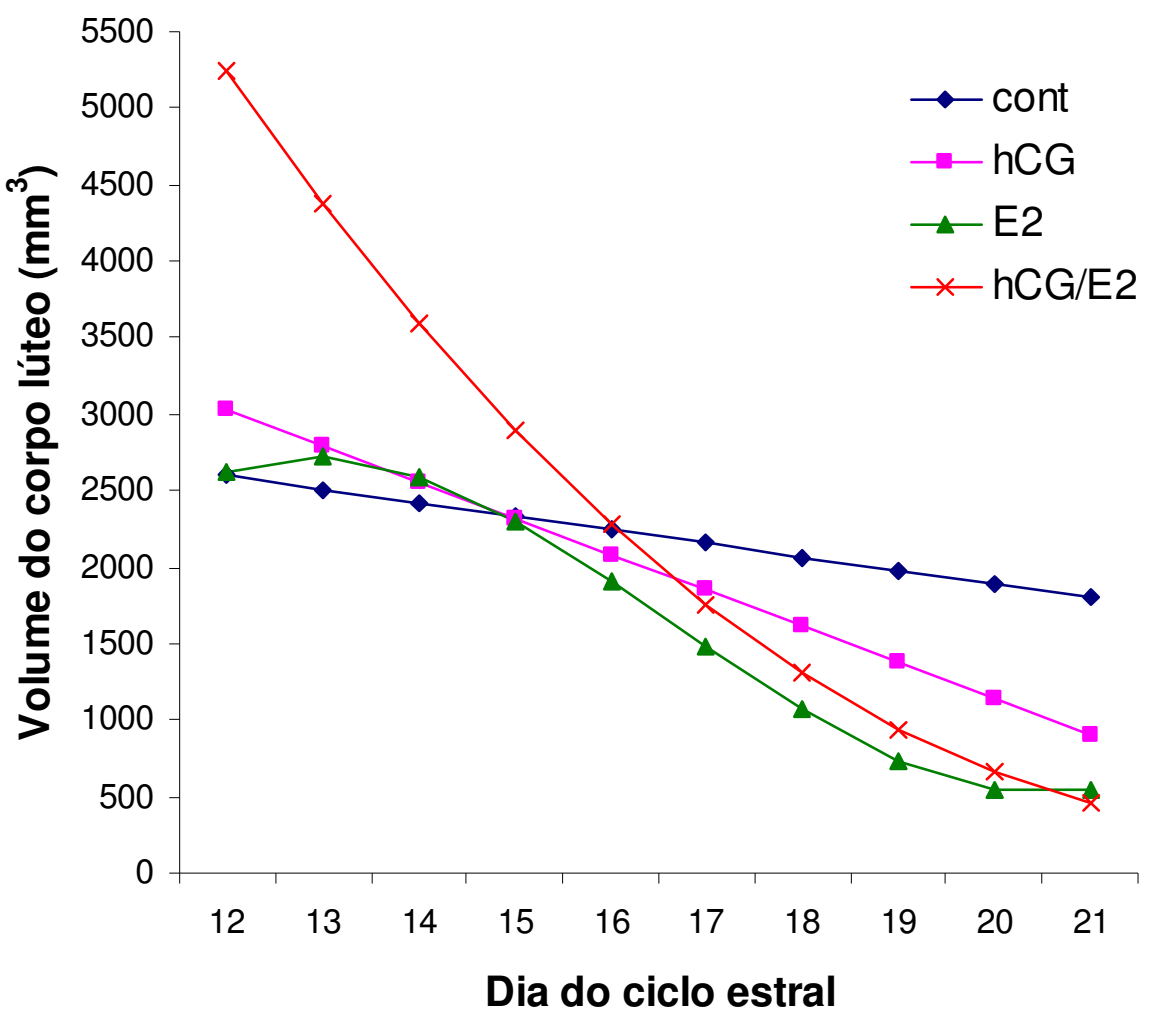

$$
\begin{array}{ll}
V_{C L \text { controle }}=3669-89,06 \mathrm{D} & R^{2}=0,13 \\
V_{C L \text { hCG }}=5856-235,7 \mathrm{D} & R^{2}=0,28 \\
V_{\mathrm{CL} \text { E2 }}=-3790+7978 \mathrm{D}-504,4 D^{2}+10,08 \mathrm{D}^{3} & R^{2}=0,39 \\
V_{\mathrm{CL} \text { hCG/E2 }}=22133-1980 \mathrm{D}+41,77 \mathrm{D}^{2} & \mathrm{R}^{2}=0,42
\end{array}
$$

Figura 14 - Gráfico e equações das curvas obtidas a partir das análises de regressão para o volume do corpo lúteo $\left(\mathrm{V}_{\mathrm{CL}}\right)$ em função do dia do ciclo estral (D) para os diferentes grupos experimentais. São Carlos, 2004 
APÊNDICE A

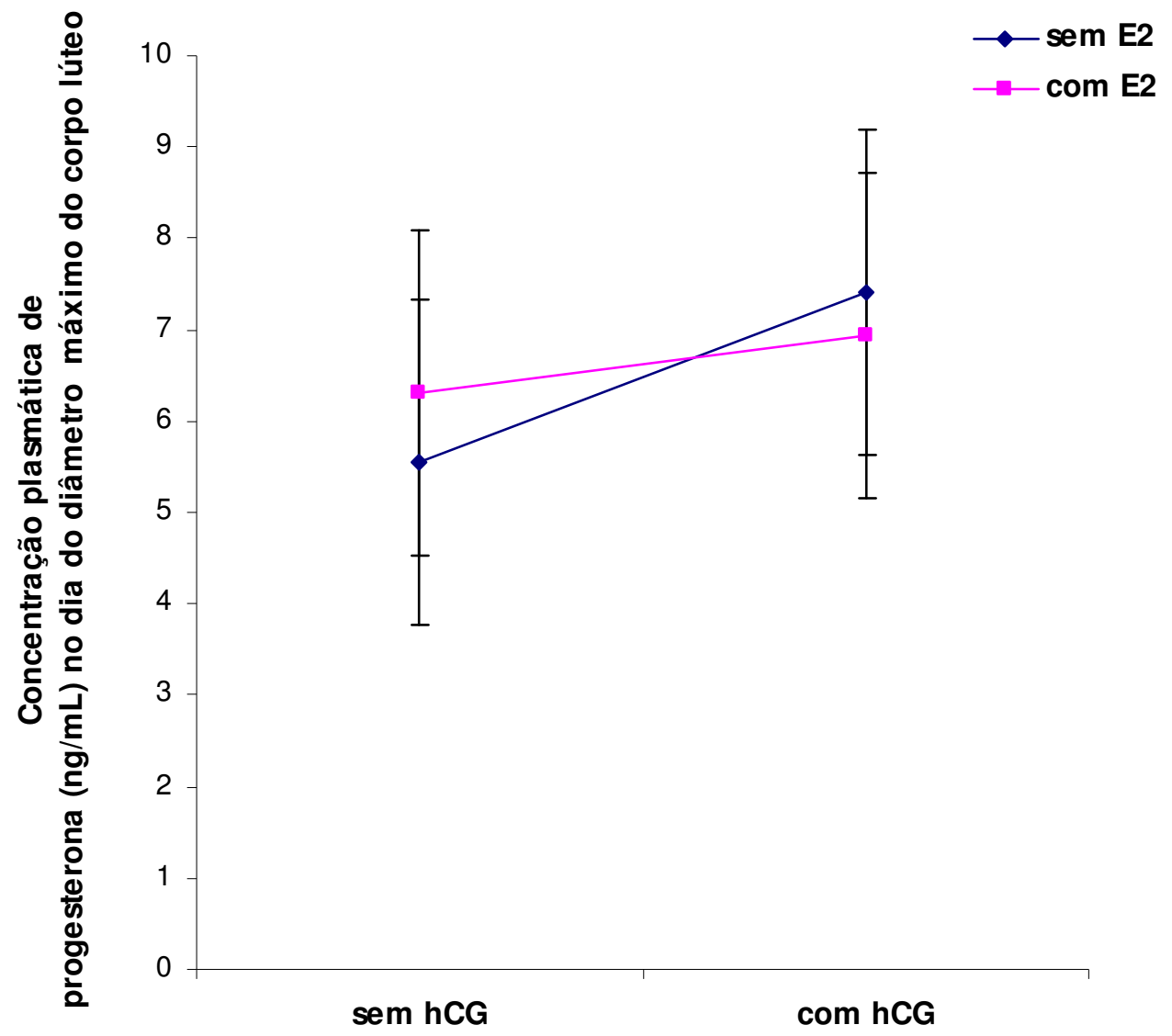

Figura 15 - G Gáfico da interação entre os fatores "hCG" e "E2" para a concentração de progesterona plasmática no dia em que o corpo lúteo atingiu seu diâmetro máximo. São Carlos, 2004 
APÊNDICE A
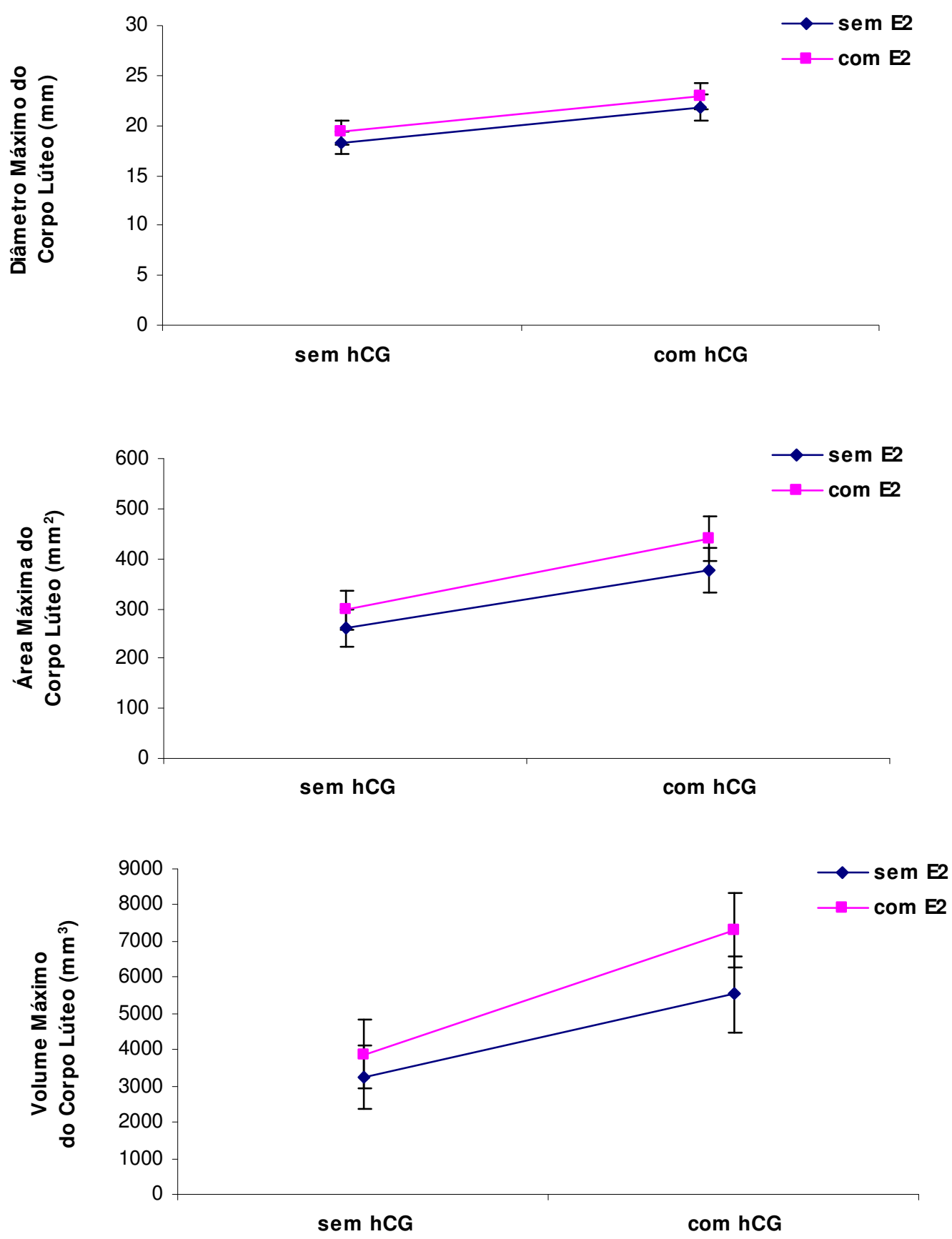

Figura 16 - G Gáficos das interações entre os fatores "hCG" e " $E_{2}$ " para as variáveis Diâmetro Máximo do Corpo Lúteo $(\mathrm{mm})$, Área Máxima do Corpo Lúteo $\left(\mathrm{mm}^{2}\right)$ e Volume Máximo do Corpo Lúteo $\left(\mathrm{mm}^{3}\right)$. São Carlos, 2004 
APÊNDICE A

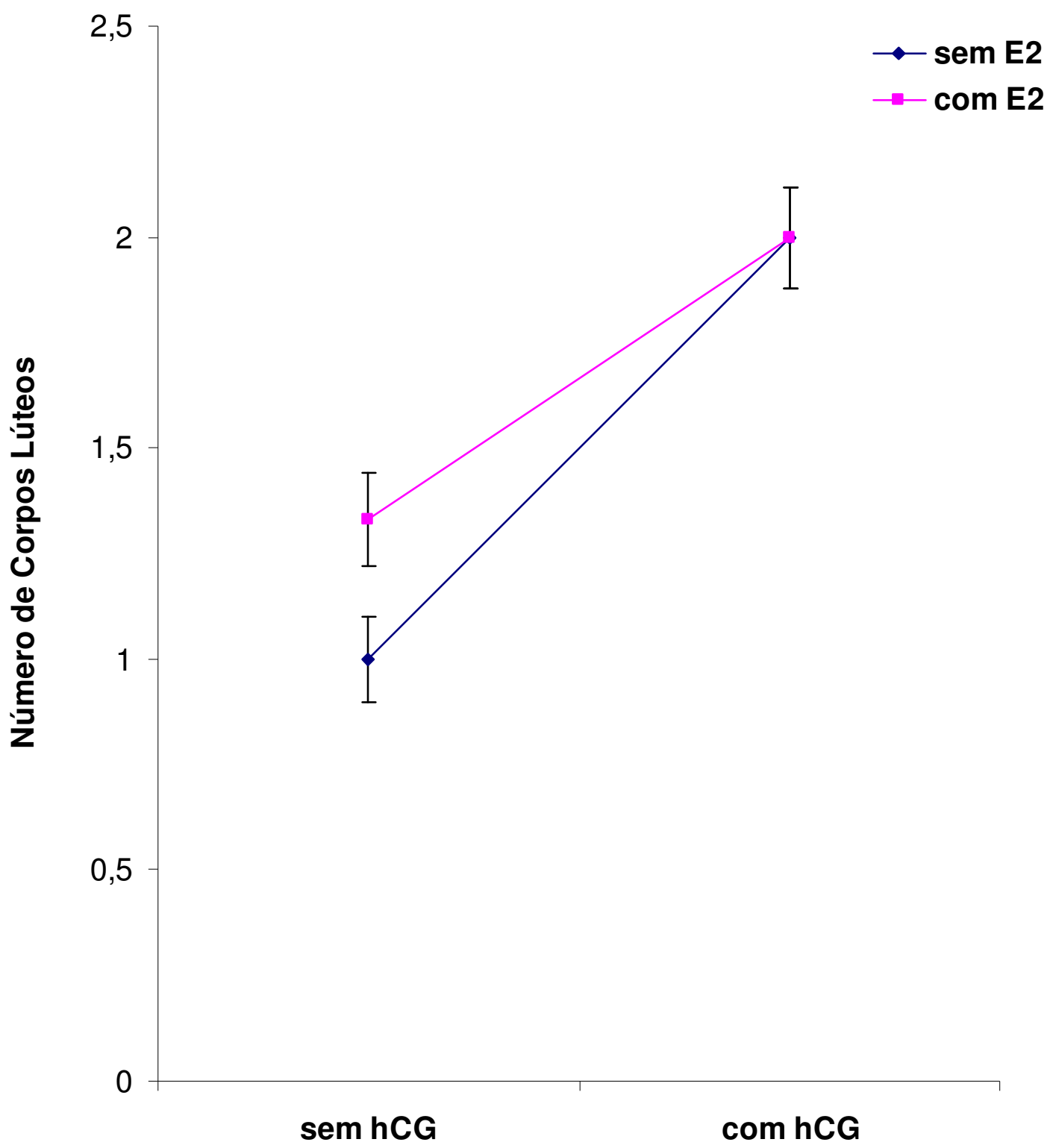

Figura 17 - G Gráfico da interação entre os fatores "hCG" e "E $E_{2}$ para o número de corpos lúteos. São Carlos, 2004 


\section{APÊNDICE A}

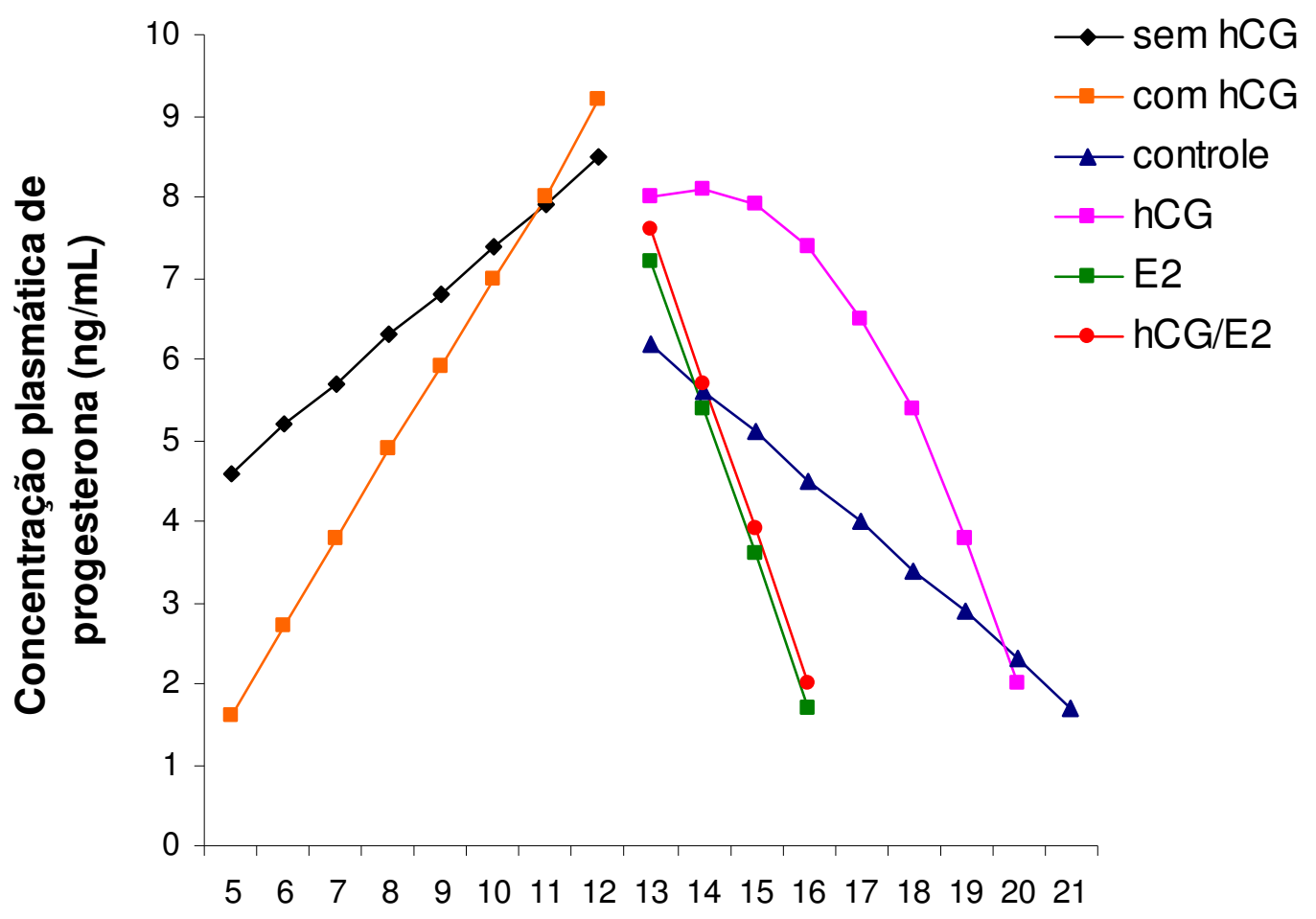

Dia do ciclo estral

$$
\begin{aligned}
& {\left[\mathrm{P}_{4}\right]_{\text {SEM hCG }}=1,83+0,554 \mathrm{D}} \\
& {\left[\mathrm{P}_{4}\right]_{\text {com hCG }}=-3,76+1,078 \mathrm{D}} \\
& {\left[\mathrm{P}_{4}\right]_{\text {controle }}=13,46-0,058 \mathrm{D}} \\
& {\left[\mathrm{P}_{4}\right]_{\text {hCG }}=-23,80+4,59 \mathrm{D}-0,165 \mathrm{D}^{2}} \\
& {\left[\mathrm{P}_{4}\right]_{\text {E2 }}=30,97-1,826 \mathrm{D}} \\
& {\left[\mathrm{P}_{4}\right]_{\text {hCG/E2 }}=31,91-1,870 \mathrm{D}+2,147 \mathrm{D}^{2}}
\end{aligned}
$$
regressão para a concentração plasmática de progesterona $\left(\left[\mathrm{P}_{4}\right]\right)$ em função do dia do ciclo estral (D) para os diferentes grupos experimentais. São Carlos, 2004 
APÊNDICE A

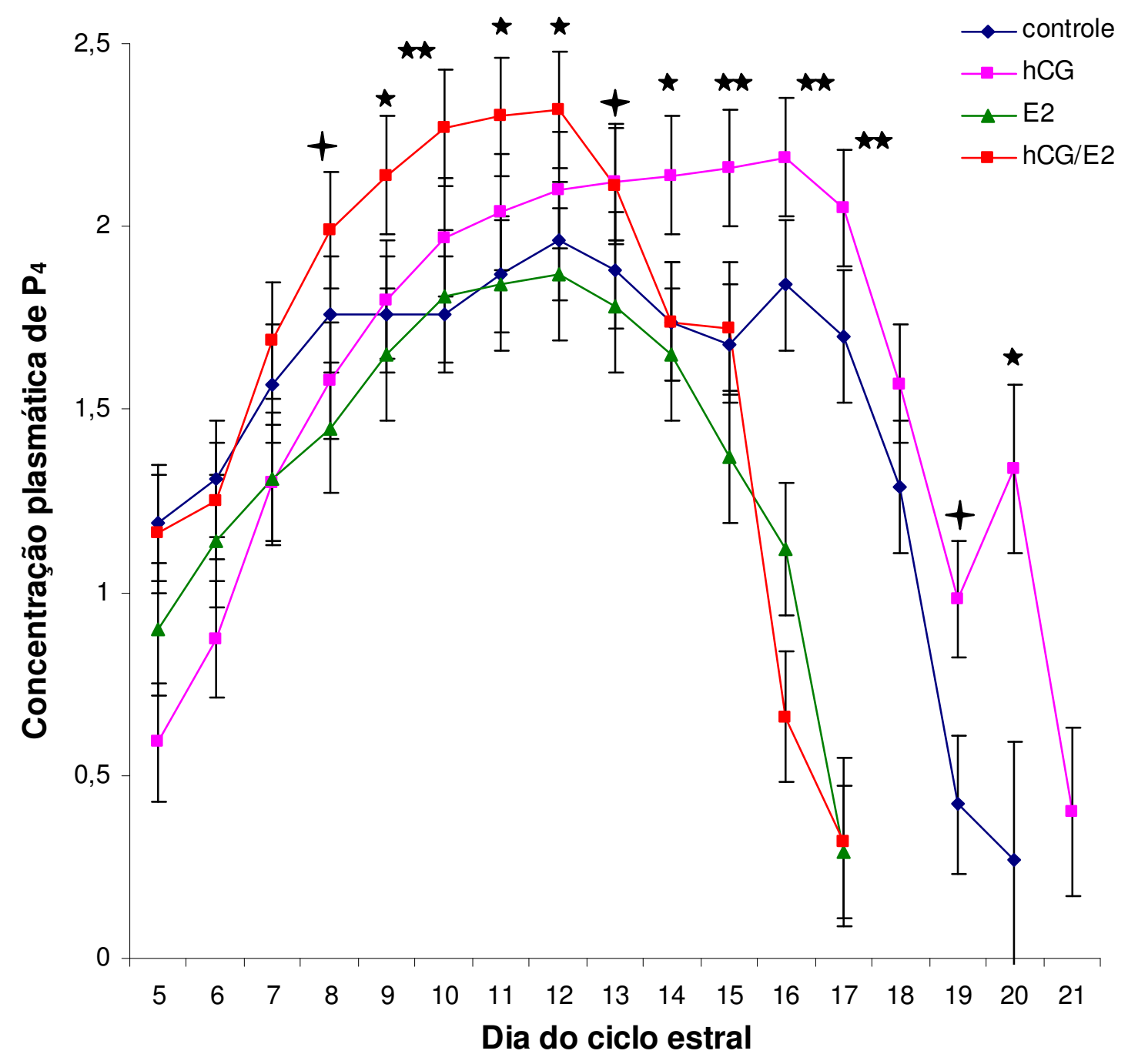

$\begin{aligned} \star & 0,10<P<0,05 \\ \star \quad & P<0,05 \\ \star \quad & P<0,01\end{aligned}$

Figura 19 - $\quad$ Médias pelos quadrados mínimos e erros-padrão da média para concentração plasmática de progesterona $\left(\mathrm{P}_{4} \mathrm{em} \mathrm{ng} / \mathrm{mL}\right)$ ao longo do ciclo estral para os diferentes grupos experimentais. São Carlos, 2004 
APÊNDICE A

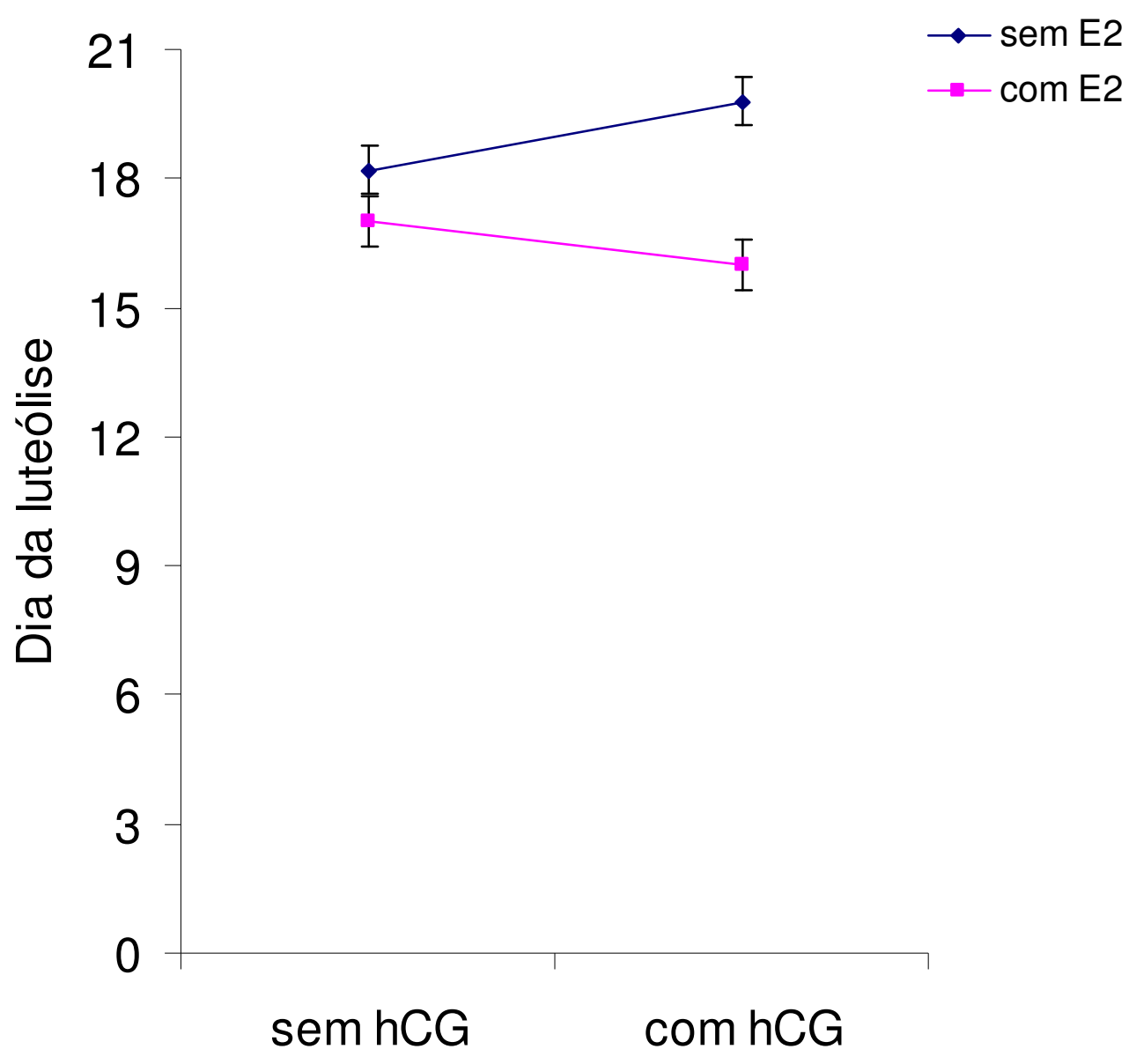

Figura 20 - G Gáfico da interação entre os fatores "hCG" e "E $\quad$ " para o dia no ciclo estral em que ocorreu a luteólise. São Carlos, 2004 


\section{APÊNDICE A}

Tabela 1 - Equações polinomiais relacionando o diâmetro $(\mathrm{mm})$ do folículo dominante ( $\$ F D)$ de cada onda de crescimento folicular ${ }^{1,2}$ e o dia do ciclo estral (D) para cada grupo experimental. São Carlos, 2004

Grupo

\begin{tabular}{|c|c|c|c|c|c|}
\hline Controle & ФFD3ov $=1,69$ & $+0,356$ & $D$ & & ${ }^{*} 0,13$ \\
\hline hCG & $\Phi F D 30 v=0,53$ & $+0,539$ & $D$ & & 0,01 \\
\hline$E_{2}$ & $\Phi F D 3_{O V}=-21,5$ & $+1,155$ & $\mathrm{D}$ & & ${ }^{* *} 0,96$ \\
\hline $\mathrm{hCG} / \mathrm{E}_{2}$ & $\Phi F D 3_{O V}=-10,6$ & $+0,982$ & $\mathrm{D}$ & & ${ }^{* *} 0,78$ \\
\hline hCG & $\Phi F D 3_{N O}=-46,0$ & $+6,842$ & $\mathrm{D}$ & - $0,210 \quad D^{2}$ & ${ }^{*} 0,20$ \\
\hline $\mathrm{hCG} / \mathrm{E}_{2}$ & $\phi F D 3_{N O}=-52,8$ & $+5,502$ & $\mathrm{D}$ & - $0,121 \quad D^{2}$ & ${ }^{* *} 0,87$ \\
\hline hCG & $\Phi F D 4_{O v}=-11,9$ & $+1,110$ & $\mathrm{D}$ & & ${ }^{* *} 0,79$ \\
\hline $\mathrm{hCG} / \mathrm{E}_{2}$ & $\Phi F D 4_{O v}=-41,9$ & $+1,810$ & $\mathrm{D}$ & & ${ }^{* *} 0,99$ \\
\hline
\end{tabular}

1. Designadas como 3 e 4 respectivamente para $3^{2}$ e $4^{\underline{2}}$ onda de crescimento folicular;

2. $\mathrm{OV}=$ consideradas apenas as que ovularam nessa onda de crescimento; $\mathrm{NO}=$ consideradas apenas aquelas que não ovularam nesta onda;

3. A Figura $A-1.5$ do Anexo I apresenta os gráficos das equações;

4. ${ }^{*}=$ modelo significativo $(P<0,05) ;{ }^{* *}=$ modelo altamente significativo $(P<0,01$.$) .$ 


\section{APÊNDICE A}

Tabela 2 -

Médias dos quadrados mínimos e erros-padrão da média para o diâmetro do corpo lúteo $(\mathrm{mm})$ conforme o dia do ciclo estral. São Carlos, 2004

\begin{tabular}{|c|c|c|c|c|c|}
\hline Dia & Controle & hCG & $E_{2}$ & $\mathrm{hCG} / \mathrm{E}_{2}$ & $\mathrm{Pr}>\mathrm{F}$ \\
\hline 12 & $17,0 \pm 1,0$ & $18,3 \pm 1,4$ & $15,6 \pm 1,1$ & $19,0 \pm 1,2$ & n.s. \\
\hline 13 & $16,5 \pm 1,0$ & $17,3 \pm 1,2$ & $17,6 \pm 1,1$ & $22,8 \pm 1,2$ & 0,01 \\
\hline 14 & $16,5 \pm 1,1$ & $17,8 \pm 1,2$ & $18,5 \pm 1,1$ & $18,6 \pm 1,2$ & n.s. \\
\hline 15 & $16,0 \pm 1,0$ & $20,9 \pm 1,2$ & $14,6 \pm 1,1$ & $15,3 \pm 1,2$ & 0,01 \\
\hline 16 & $16,5 \pm 1,0$ & $18,9 \pm 1,2$ & $14,2 \pm 1,1$ & $15,2 \pm 1,2$ & 0,03 \\
\hline 17 & $15,6 \pm 1,0$ & $18,2 \pm 1,2$ & $11,5 \pm 1,1$ & $13, \pm 1,2$ & 0,01 \\
\hline 18 & $15,8 \pm 1,1$ & $16,4 \pm 1,2$ & $12,7 \pm 1,1$ & $12,6 \pm 1,2$ & 0,04 \\
\hline 19 & $14,0 \pm 1,1$ & $14,0 \pm 1,2$ & $10,8 \pm 1,1$ & $10,6 \pm 1,2$ & 0,06 \\
\hline 20 & $14,4 \pm 1,1$ & $15,0 \pm 1,2$ & $11,7 \pm 1,2$ & $9,6 \pm 1,4$ & 0,01 \\
\hline 21 & $14,1 \pm 1,2$ & $14,5 \pm 1,2$ & $10,3 \pm 1,3$ & $11,2 \pm 1,5$ & 0,05 \\
\hline 22 & $13,4 \pm 1,2$ & $14,7 \pm 1,2$ & $10,3 \pm 1,8$ & $12,2 \pm 1,5$ & n.s \\
\hline 23 & $14,7 \pm 1,3$ & $14,4 \pm 1,2$ & $10,3 \pm 2,4$ & $11,6 \pm 1,5$ & n.s \\
\hline 24 & $13,3 \pm 1,7$ & $10,6 \pm 1,8$ & - & $8,6 \pm 1,5$ & n.s \\
\hline 25 & $12,2 \pm 1,7$ & $12,6 \pm 1,8$ & - & $10,3 \pm 2,4$ & n.s. \\
\hline 26 & $12,6 \pm 1,7$ & $7,50 \pm 2,4$ & - & $10,3 \pm 2,4$ & n.s. \\
\hline 27 & $8,55 \pm 1,7$ & $7,10 \pm 2,4$ & - & $10,1 \pm 2,4$ & n.s. \\
\hline 28 & $6,51 \pm 2,4$ & - & - & $5,3 \pm 2,4$ & n.s. \\
\hline 29 & $6,41 \pm 2,4$ & - & - & - & - \\
\hline
\end{tabular}




\section{APÊNDICE A}

Tabela 3 - $\quad$ Médias dos quadrados mínimos e erros-padrão da média para a área do corpo lúteo $\left(\mathrm{mm}^{2}\right)$ conforme o dia do ciclo estral. São Carlos, 2004

\begin{tabular}{|c|c|c|c|c|c|}
\hline Dia & Controle & hCG & $E_{2}$ & $\mathrm{hCG} / \mathrm{E}_{2}$ & $\mathrm{Pr}>\mathrm{F}$ \\
\hline 12 & $231 \pm 27$ & $266 \pm 32$ & $197 \pm 29$ & $292 \pm 32$ & n.s. \\
\hline 13 & $217 \pm 27$ & $240 \pm 32$ & $250 \pm 29$ & $428 \pm 32$ & 0,05 \\
\hline 14 & $215 \pm 27$ & $254 \pm 32$ & $271 \pm 29$ & $275 \pm 32$ & n.s. \\
\hline 15 & $203 \pm 27$ & $349 \pm 32$ & $174 \pm 29$ & $184 \pm 32$ & 0,01 \\
\hline 16 & $217 \pm 27$ & $291 \pm 32$ & $169 \pm 29$ & $185 \pm 32$ & 0,06 \\
\hline 17 & $195 \pm 27$ & $271 \pm 32$ & $111 \pm 29$ & $150 \pm 32$ & 0,01 \\
\hline 18 & $202 \pm 28$ & $215 \pm 32$ & $129 \pm 29$ & $129 \pm 32$ & 0,03 \\
\hline 19 & $163 \pm 28$ & $156 \pm 32$ & $94 \pm 29$ & $89 \pm 32$ & 0,02 \\
\hline 20 & $174 \pm 28$ & $180 \pm 32$ & $113 \pm 31$ & $77 \pm 35$ & 0,01 \\
\hline 21 & $164 \pm 31$ & $168 \pm 32$ & $85 \pm 34$ & $96 \pm 39$ & 0,02 \\
\hline 22 & $150 \pm 31$ & $172 \pm 32$ & $103 \pm 46$ & $116 \pm 39$ & n.s. \\
\hline 23 & $176 \pm 33$ & $167 \pm 32$ & $89 \pm 63$ & $104 \pm 32$ & n.s. \\
\hline 24 & $139 \pm 46$ & $87 \pm 46$ & - & $58 \pm 46$ & 0,04 \\
\hline 25 & $115 \pm 46$ & $133 \pm 46$ & - & $73 \pm 63$ & n.s. \\
\hline 26 & $119 \pm 46$ & $49 \pm 64$ & - & $71 \pm 64$ & 0,03 \\
\hline 27 & $39 \pm 32$ & $45 \pm 63$ & - & $68 \pm 63$ & n.s. \\
\hline
\end{tabular}




\section{APÊNDICE A}

Tabela 4 - $\quad$ Médias dos quadrados mínimos e erros-padrão da média para o volume do corpo lúteo $\left(\mathrm{mm}^{3}\right)$ conforme o dia do ciclo estral. São Carlos, 2004

\begin{tabular}{|c|c|c|c|c|c|}
\hline Dia & Controle & hCG & $E_{2}$ & $\mathrm{hCG} / \mathrm{E}_{2}$ & $\operatorname{Pr}>\mathrm{F}$ \\
\hline 12 & $2684 \pm 489$ & $3306 \pm 529$ & $2173 \pm 529$ & $3909 \pm 579$ & n.s. \\
\hline 13 & $2441 \pm 489$ & $2887 \pm 529$ & $3102 \pm 529$ & $7129 \pm 579$ & 0,05 \\
\hline 14 & $2430 \pm 489$ & $3142 \pm 529$ & $3397 \pm 529$ & $3513 \pm 579$ & n.s. \\
\hline 15 & $2213 \pm 489$ & $5039 \pm 529$ & $1837 \pm 529$ & $1891 \pm 579$ & 0,01 \\
\hline 16 & $2480 \pm 489$ & $3899 \pm 529$ & $1795 \pm 529$ & $1946 \pm 579$ & 0,06 \\
\hline 17 & $2122 \pm 489$ & $3562 \pm 529$ & $957 \pm 529$ & $1455 \pm 579$ & 0,01 \\
\hline 18 & $2237 \pm 522$ & $2438 \pm 529$ & $1143 \pm 529$ & $1154 \pm 579$ & 0,03 \\
\hline 19 & $1692 \pm 522$ & $1524 \pm 529$ & $714 \pm 529$ & $650 \pm 579$ & 0,02 \\
\hline 20 & $1877 \pm 522$ & $1886 \pm 579$ & $969 \pm 570$ & $565 \pm 635$ & 0,01 \\
\hline 21 & $1705 \pm 564$ & $1685 \pm 579$ & $605 \pm 627$ & $642 \pm 719$ & 0,02 \\
\hline 22 & $1518 \pm 564$ & $1726 \pm 579$ & $802 \pm 854$ & $914 \pm 719$ & n.s. \\
\hline 23 & $1901 \pm 620$ & $1662 \pm 634$ & $705 \pm 1183$ & $746 \pm 719$ & n.s. \\
\hline 24 & $1241 \pm 848$ & $599 \pm 858$ & - & $272 \pm 860$ & 0,04 \\
\hline 25 & $849 \pm 848$ & $1278 \pm 858$ & - & $176 \pm 1185$ & n.s. \\
\hline 26 & $898 \pm 848$ & $378 \pm 1183$ & - & $156 \pm 1185$ & 0,03 \\
\hline 27 & - & $346 \pm 1183$ & - & $118 \pm 1185$ & n.s. \\
\hline
\end{tabular}




\section{APÊNDICE A}

Tabela 5 -

Médias dos quadrados mínimos e erros-padrão da média para a concentração plasmática de progesterona ${ }^{1}(\mathrm{ng} / \mathrm{mL})$ conforme o dia do ciclo estral. São Carlos, 2004

\begin{tabular}{|c|c|c|c|c|c|}
\hline Dia & Controle & hCG & $E_{2}$ & $\mathrm{hCG} / \mathrm{E}_{2}$ & $\mathrm{Pr}>\mathrm{F}$ \\
\hline 5 & $1,19 \pm 0,16$ & $0,59 \pm 0,16$ & $0,90 \pm 0,18$ & $1,16 \pm 0,16$ & n.s. \\
\hline 6 & $1,32 \pm 0,16$ & $0,87 \pm 0,16$ & $1,14 \pm 0,18$ & $1,25 \pm 0,16$ & n.s. \\
\hline 7 & $1,57 \pm 0,16$ & $1,30 \pm 0,16$ & $1,31 \pm 0,18$ & $1,69 \pm 0,16$ & n.s. \\
\hline 8 & $1,76 \pm 0,16$ & $1,58 \pm 0,16$ & $1,45 \pm 0,18$ & $1,99 \pm 0,16$ & 0,10 \\
\hline 9 & $1,76 \pm 0,16$ & $1,80 \pm 0,16$ & $1,65 \pm 0,18$ & $2,14 \pm 0,16$ & 0,05 \\
\hline 10 & $1,76 \pm 0,16$ & $1,97 \pm 0,16$ & $1,81 \pm 0,18$ & $2,27 \pm 0,16$ & 0,01 \\
\hline 11 & $1,87 \pm 0,16$ & $2,04 \pm 0,16$ & $1,84 \pm 0,18$ & $2,30 \pm 0,16$ & 0,05 \\
\hline 12 & $1,96 \pm 0,16$ & $2,10 \pm 0,16$ & $1,87 \pm 0,18$ & $2,32 \pm 0,16$ & 0,05 \\
\hline 13 & $1,88 \pm 0,16$ & $2,12 \pm 0,16$ & $1,78 \pm 0,18$ & $2,11 \pm 0,16$ & 0,10 \\
\hline 14 & $1,74 \pm 0,16$ & $2,14 \pm 0,16$ & $1,65 \pm 0,18$ & $1,74 \pm 0,16$ & 0,05 \\
\hline 15 & $1,68 \pm 0,16$ & $2,16 \pm 0,16$ & $1,37 \pm 0,18$ & $1,72 \pm 0,18$ & 0,01 \\
\hline 16 & $1,84 \pm 0,18$ & $2,19 \pm 0,16$ & $1,12 \pm 0,18$ & $0,66 \pm 0,18$ & 0,01 \\
\hline 17 & $1,70 \pm 0,18$ & $2,05 \pm 0,16$ & $0,29 \pm 0,18$ & $0,32 \pm 0,23$ & 0,01 \\
\hline 18 & $1,29 \pm 0,18$ & $1,57 \pm 0,16$ & - & - & n.s. \\
\hline 19 & $0,42 \pm 0,19$ & $0,98 \pm 0,16$ & - & - & 0,10 \\
\hline 20 & $0,27 \pm 0,32$ & $1,34 \pm 0,23$ & - & - & 0,05 \\
\hline 21 & - & $0,40 \pm 0,23$ & - & - & - \\
\hline
\end{tabular}

1. Até o $D_{12}$ os grupos controle e $E_{2}$ tiveram o mesmo tratamento, bem como os grupos hCG e hCG/E $E_{2}$ pois o $17 \beta$-Estradiol foi administrado apenas em $D_{12}$. 


\section{APÊNDICE A}

Tabela 6 - $\quad$ Médias dos quadrados mínimos e erros-padrão da média para a concentração plasmática de progesterona ${ }^{1}(\mathrm{ng} / \mathrm{mL})$ conforme o dia do ciclo estral, considerando-se a administração da hCG. São Carlos, 2004

\begin{tabular}{ccc} 
& & \\
& & \\
Dia do ciclo estral & & \\
& & \\
& Sem hCG & \\
& & Com hCG \\
\cline { 2 - 3 } 05 & & \\
06 & $1,43 \pm 0,16$ & $1,28 \pm 0,16$ \\
07 & $1,61 \pm 0,16$ & $1,44 \pm 0,16$ \\
08 & $1,85 \pm 0,16$ & $1,91 \pm 0,16$ \\
10 & $2,06 \pm 0,16$ & $2,30 \pm 0,16$ \\
11 & $2,15 \pm 0,16$ & $2,54 \pm 0,18$ \\
12 & $2,24 \pm 0,16$ & $2,76 \pm 0,18$ \\
& $2,34 \pm 0,16$ & $2,83 \pm 0,18$ \\
$2,44 \pm 0,18$ & $2,91 \pm 0,18$ \\
\hline
\end{tabular}

1. Sem hCG = vacas Nelore sincronizadas pelo método "ovsynch"; Com hCG = vacas Nelore sincronizadas pelo método "ovsynch", recebendo $3000 \mathrm{UI}$ da hCG no $\mathrm{D}_{5}$. 


\section{APÊNDICE B}

Tabela 1 - $\quad$ Presença de folículos ovarianos com diâmetro $\geq 7 \mathrm{~mm}$ no período crítico do reconhecimento materno da prenhez em vacas Red Angus (Bos taurus taurus). Mococa, 2004

\begin{tabular}{|c|c|c|c|c|c|c|c|}
\hline \multirow{3}{*}{$\begin{array}{c}\text { Grupo }^{1} \\
\text { E } \\
\text { Vaca }\end{array}$} & \multicolumn{7}{|c|}{ Diâmetro folicular (mm) ${ }^{2,3,4}$} \\
\hline & \multicolumn{2}{|c|}{$D_{14}$} & \multicolumn{2}{|c|}{$D_{17}$} & \multicolumn{2}{|c|}{$D_{20}$} & \multirow[b]{2}{*}{$\begin{array}{l}\text { Dia } \\
\text { do } \\
\text { Estro }\end{array}$} \\
\hline & $1^{\circ}$ maior & $2^{\circ}$ maior & $1^{\circ}$ maior & $2^{\circ}$ maior & $1^{\circ}$ maior & $2^{\circ}$ maior & \\
\hline \multicolumn{8}{|l|}{$\overline{G_{c}}$} \\
\hline 082 & 12 (D) & 8 & $12(\mathrm{D})$ & 10 & 12 & - & 20 \\
\hline 089 & 10 & - & 13 & - & 8 & 8 & 22 \\
\hline 282 & 11 (D) & - & $13(\mathrm{D})$ & - & $14(\mathrm{D})$ & - & 19 \\
\hline 304 & 10 (D) & 10 (D) & 13 & 8 (D) & 11 (D) & - & 19 \\
\hline 337 & 13 & - & 15 & - & 12 & - & 20 \\
\hline \multicolumn{8}{|l|}{$\mathrm{G}_{\mathrm{RM}}$} \\
\hline 010 & 9 & - & 12 & - & 9 & - & 27 \\
\hline 042 & 11 (D) & 9 (D) & - & - & $11(\mathrm{D})$ & 10 (D) & 19 \\
\hline 135 & 11 (D) & - & - & - & 11 (D) & 10 (D) & - \\
\hline 151 & 10 (D) & 9 (D) & 10 (D) & - & 9 (D) & - & - \\
\hline $252^{5}$ & 13 (D) & 8 & - & - & $11(\mathrm{D})$ & - & 22 \\
\hline $348^{5}$ & 10 & 6 & 11 & 7 (D) & 15 & - & - \\
\hline \multicolumn{8}{|l|}{$\mathrm{G}_{\mathrm{RF}}$} \\
\hline 073 & 12 (D) & 11 & $11(\mathrm{D})$ & - & $18(\mathrm{D})$ & 13 & 28 \\
\hline 104 & 13 (D) & - & 12 (D) & - & 12 (D) & - & - \\
\hline 186 & 15 & 12 (D) & 15 & 8 (D) & 12 & 7 (D) & 30 \\
\hline 300 & 10 (D) & 10 (D) & - & - & 15 & - & 28 \\
\hline 313 & $8(\mathrm{D})^{\prime}$ & - & - & - & $20(D)$ & - & 30 \\
\hline $349^{5}$ & 12 & - & - & - & 15 & 15 & - \\
\hline $\begin{array}{l}\text { 1. } G_{C}=g r l \\
\text { 2. Avaliaçã } \\
\text { 3. Avaliaça } \\
\text { 4. Não det } \\
\text { 5. Dados }\end{array}$ & $\begin{array}{l}\text { ole, } G_{R 1} \\
\text { ra-sono } \\
\text { os } D_{14}, \\
\text { se qual } \\
\text { dessa }\end{array}$ & $\begin{array}{l}\text { grupo rel } \\
\text { a para G } \\
D_{20} \text { apó } \\
\text { o domina } \\
\text { não fora }\end{array}$ & $\begin{array}{l}\text { ção me } \\
\text { e } G_{R M} \\
\text { stro sin } \\
\text { pois a } \\
\text { conside }\end{array}$ & $\begin{array}{l}\text { e } G_{R F} \\
\text { mativa } p \\
\text { ado. (D } \\
\text { nica nãc }\end{array}$ & $\begin{array}{l}\text { upo rem } \\
\text { palpaçãc } \\
\text { Folículos } \\
\text { i acompa }\end{array}$ & $\begin{array}{l}\text { o farmac } \\
\text { al para G } \\
\text { ovário di } \\
\text { ada diaria }\end{array}$ & $\begin{array}{l}\text { ógica; } \\
; \\
\text { ito. } \\
\text { ente;. }\end{array}$ \\
\hline
\end{tabular}

